ORRL/TM- 12.184

DE92 041230

\title{
CONCEPTUAL DESIGN SUMMARY
}

Advanced Neutron Source Project Staff

Principal Author: F. J. Peretz

September 1992

Prepared by the

Oak Ridge National Laboratory

Oak Ridge, Tennessee 37831

managed by

MARTIN MARIETTA ENERGY SYSTEMS, INC.

for the

U.S. DEPARTMENT OF ENERGY under contract ACO5-840R21400 


\section{CONTENTS}

Page

LIST OF FGURES $\ldots \ldots \ldots \ldots \ldots \ldots \ldots \ldots \ldots \ldots \ldots \ldots \ldots \ldots \ldots$

LIST OF TABLES $\ldots \ldots \ldots \ldots \ldots \ldots \ldots \ldots \ldots \ldots \ldots \ldots \ldots \ldots \ldots \ldots$

ACRONYMS $\ldots \ldots \ldots \ldots \ldots \ldots \ldots \ldots \ldots \ldots \ldots \ldots \ldots \ldots \ldots \ldots \ldots \ldots$

EXECUTTVE SUMMARY $\ldots \ldots \ldots \ldots \ldots \ldots \ldots \ldots \ldots \ldots \ldots \ldots \ldots \ldots \ldots$

1. INTRODUCTION $\ldots \ldots \ldots \ldots \ldots \ldots \ldots \ldots \ldots \ldots \ldots \ldots \ldots \ldots \ldots \ldots \ldots \ldots \ldots$

1.1 PROJECT PURPOSE AND SCOPE $\ldots \ldots \ldots \ldots \ldots \ldots \ldots \ldots \ldots \ldots \ldots \ldots$

1.2 PROJECT GOALS AND REQUIREMENTS $\ldots \ldots \ldots \ldots \ldots \ldots \ldots \ldots \ldots \ldots . \ldots \ldots$

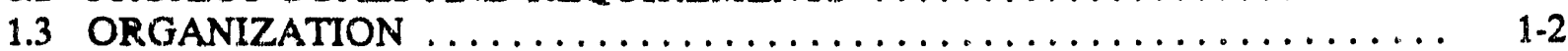

2. GENERAL PROJECT DESCRIPTION $\ldots \ldots \ldots \ldots \ldots \ldots \ldots \ldots \ldots \ldots \ldots \ldots$

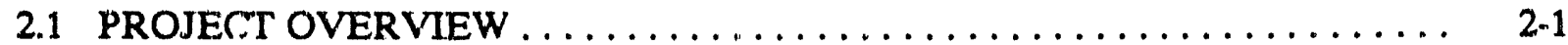

2.1.1 Overview of the ANS Complex ................... $2-1$

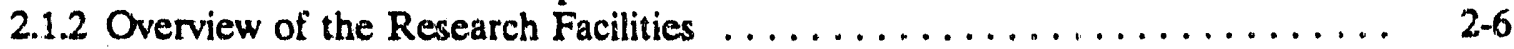

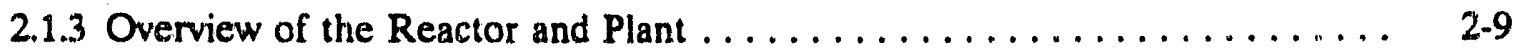

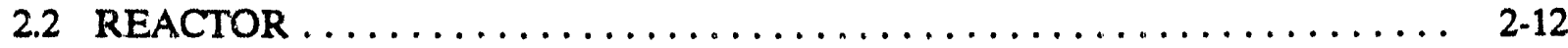

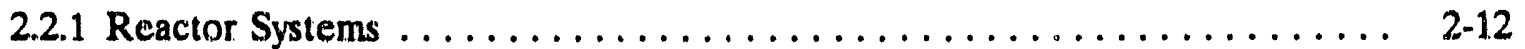

2.2.2 Reactor Control .............................. 2-26

2.2.3 Refueling and Maintenance ..................... 2-27

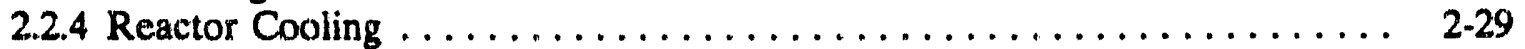

2.2 .5 Reactor Containment ........................... 2.31

2.2 .6 Reactor Mockup and Simulator $\ldots \ldots \ldots \ldots \ldots \ldots \ldots \ldots \ldots \ldots \ldots$

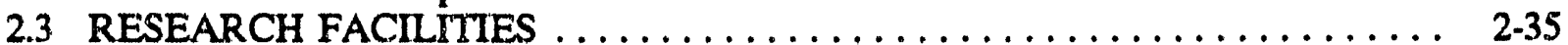

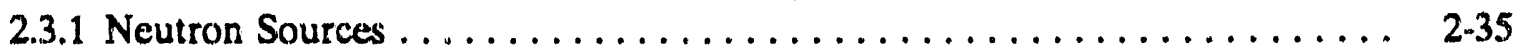

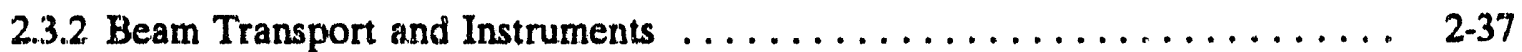

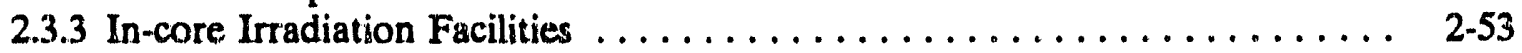

2.3.4 Reflector and Pool Irradiation Facilities .................. 2-57

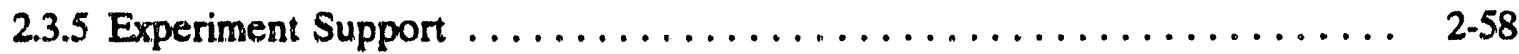

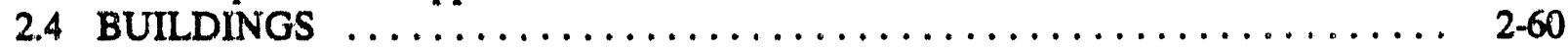

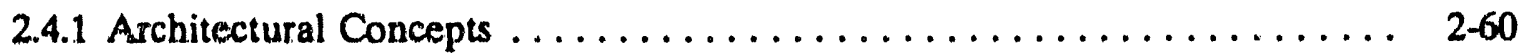

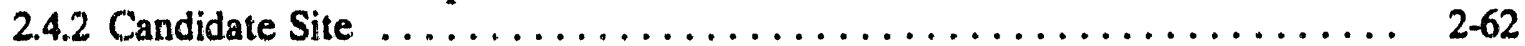

2.4 .3 Reactor Complex ............................ 2-62

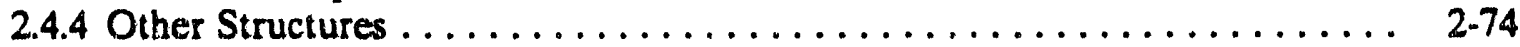

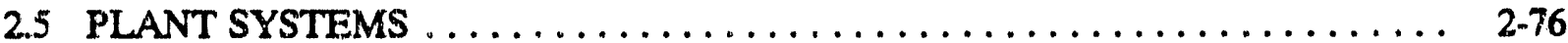

2.5 .1 Heavy Water Systems ........................ 2.76

25.2 Electrical Power and Communications ................. 2.79

2.5 .3 Environmental Control Systems ...................... 2-79

25.4 Water and Service Systems . . . . . . . . . . . . . . . . . . 2-83

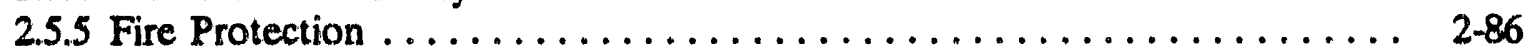

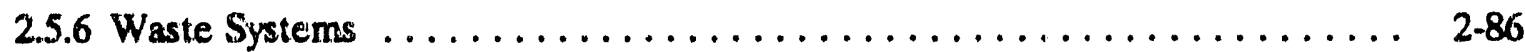


2.5.7 Heavy Water Detritiation and Upgrade ................. 2-88

2.5.8 Plant Instrumentation, Control, and Data Systems $\ldots \ldots \ldots \ldots \ldots \ldots$. $\ldots \ldots$

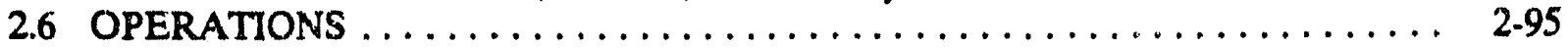

2.6.1 Facility Operations ............................. 2.95

2.6.2 Research Program Operations . . . . . . . . . . . . . . . . 2-98

2.6.3 Transition to Operations . . . . . . . . . . . . . . . . . . . . . . . 2.98

2.6.3.1 Definition of Project Completion ... . . . . . . . . . . . . . . 2-98

2.6.3.2 Buildup of Operations Activities ................. 2-99

2.6.3.3 First Year of Operations .................... 2-99

2.7 SUMMARY OF ALTERINATTVES $\ldots \ldots \ldots \ldots \ldots \ldots \ldots \ldots \ldots \ldots \ldots \ldots$

2.7.1 Overall Concept Alternatives ..................... 2-100

2.7 .2 Reactor Concept Alternatives ...................... 2-101

2.7.3 Neutron Source, Transport, and Utilization Alternatives . . . . . . . . 2-102

2.7.4 Plant System Alternatives . . . . . . . . . . . . . . . . . 2-102

3. JUSTIFICATION $\ldots \ldots \ldots \ldots \ldots \ldots \ldots \ldots \ldots \ldots \ldots \ldots \ldots \ldots \ldots \ldots \ldots \ldots$

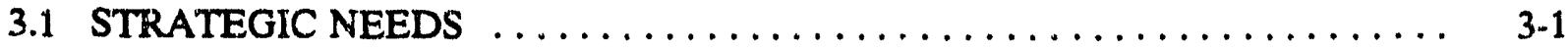

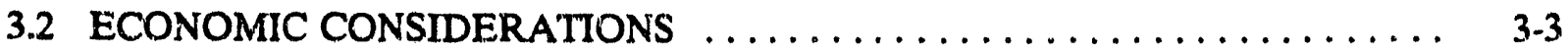

3.3 IMPACT IF NOT FUNDED $\ldots \ldots \ldots \ldots \ldots \ldots \ldots \ldots \ldots \ldots \ldots \ldots \ldots \ldots$

4. SIGNIFICANT FACTORS $\ldots \ldots \ldots \ldots \ldots \ldots \ldots \ldots \ldots \ldots \ldots \ldots \ldots \ldots \ldots$ 4-1

4.1 PROJECT REQUIREMENTS $\ldots \ldots \ldots \ldots \ldots \ldots \ldots \ldots \ldots \ldots \ldots \ldots \ldots$. $\ldots \ldots \ldots$

4.2 TECHNICAL AND OPERATIONAL UNCERTAINTIES $\ldots \ldots \ldots \ldots \ldots \ldots .4 .2$

4.2.1 Issues Addressed by the ANS Research and Development Program . . . . . 4 4-2

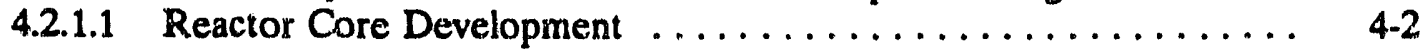

4.2.1.2 Fuel Development $\ldots \ldots \ldots \ldots \ldots \ldots \ldots \ldots \ldots \ldots \ldots \ldots \ldots$ 4-2

4.2.1.3 Corrosion Tests and Analysis $\ldots \ldots \ldots \ldots \ldots \ldots \ldots \ldots \ldots$ 4-2

4.2.1.4 Core Flow Tests ........................ 4-3

4.2.1.5 Control Concepts $\ldots \ldots \ldots \ldots \ldots \ldots \ldots \ldots \ldots \ldots \ldots \ldots \ldots$ 4-3

4.2.1.6 Critical Experiments ...................... $4-3$

4.2.1.7 Materials, Structural Tests, and Analyses .............. 4-3

4.2.1.8 Cold Source Development ................... 4-4

4.2.1.9 Beam Tube, Guide, and Instrument Development .......... 44

4.2.1.10 Hot Source Development ..................... 4-4

4.2.1.11 Neutron and Gamma Transport and Shieiding ........... 4-4

4.2.1.12 Instrumentation and Controls System Development ........ 4.4

4.21.13 Reactor Concepts ......................... 4-5

4.2.1.14 Safety Research and Development ................ 4-5

4.2.2 Uncertainties in the Characteristics of the Candidate Site ... . . . . . . 4-5

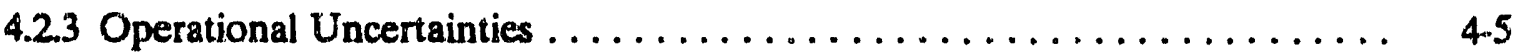

4.3 OPERATIONAL CONSIDERATIONS $\ldots \ldots \ldots \ldots \ldots \ldots \ldots \ldots \ldots \ldots \ldots \ldots$

4.4 SPECIAL REQUIREMENTS $\ldots \ldots \ldots \ldots \ldots \ldots \ldots \ldots \ldots \ldots \ldots \ldots \ldots \ldots$

4.5 CONSTRAINTS $\ldots \ldots \ldots \ldots \ldots \ldots \ldots \ldots \ldots \ldots \ldots \ldots \ldots \ldots \ldots \ldots \ldots \ldots$

4.6 INTERFACES $\ldots \ldots \ldots \ldots \ldots \ldots \ldots \ldots \ldots \ldots \ldots \ldots \ldots \ldots \ldots \ldots$

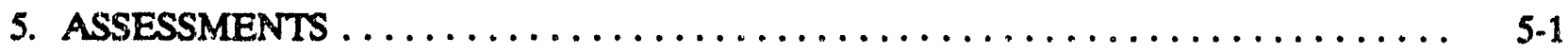

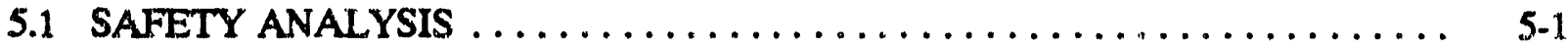

5.2 ENVIRONMENTAL ANALYSIS $\ldots \ldots \ldots \ldots \ldots \ldots \ldots \ldots \ldots \ldots \ldots \ldots \ldots \ldots$ 


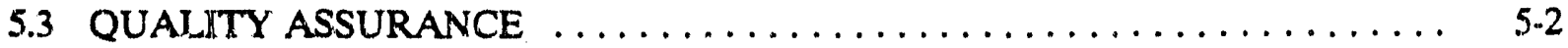

5.4 SELECTION AND CHARACTERIZATION OF THE CANDIDATE SITE $\ldots . . \quad 5-2$

6. METHOD OF ACCOMPLISHMENT, ROLES, AND RESPONSIBILITIES $\ldots \ldots$ 6-1

6.1 DEPARTMENT OF ENERGY $\ldots \ldots \ldots \ldots \ldots \ldots \ldots \ldots \ldots \ldots \ldots \ldots \ldots$

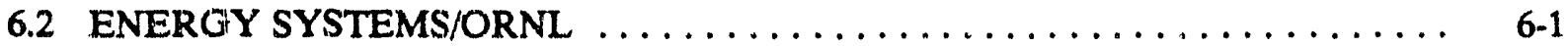

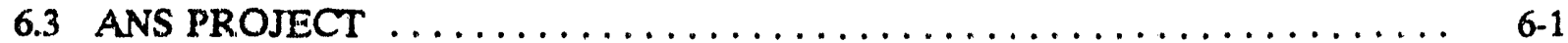

6.3.1 Project Management, Quality Assurance, and Technical Oversight ...... 6-1

6.3.2 Research and Development ......................... 6.5

6.3 .3 Experiment Systems ............................. 6.5

6.3 .4 Safety Analysis and Reports $\ldots \ldots \ldots \ldots \ldots \ldots \ldots \ldots \ldots \ldots \ldots \ldots$

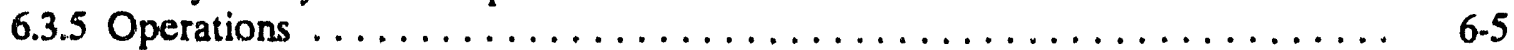

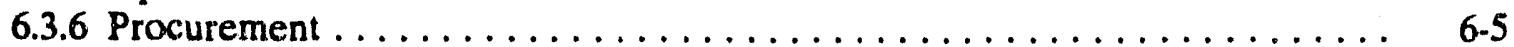

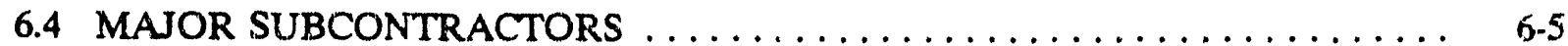

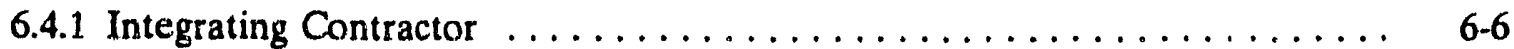

6.4.1.1 Architect-Engineer ...................... 6-6

6.4.1.2 Reactor Manufacturer $\ldots \ldots \ldots \ldots \ldots \ldots \ldots \ldots \ldots \ldots \ldots \ldots$

6.4.1.3 Construction Management Firm $\ldots \ldots \ldots \ldots \ldots \ldots \ldots \ldots .6 .6$

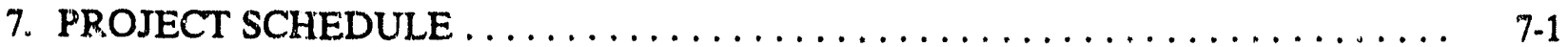

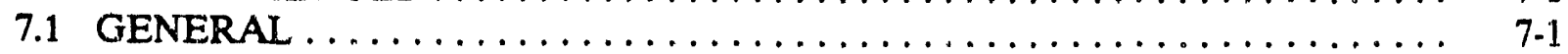

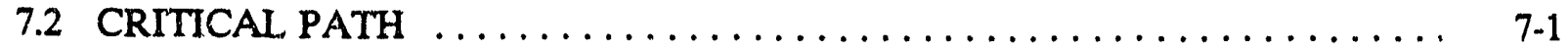

8. SUMMARY OF THE COST ESTIMATE $\ldots \ldots \ldots \ldots \ldots \ldots \ldots \ldots \ldots \ldots \ldots$

8.1 SUMMARY ESTIMATE_TOTAL PROJECT COST $\ldots \ldots \ldots \ldots \ldots \ldots \ldots . . \ldots 8$

8.2 COST $^{4}$ AND FUNDING PLAN $\ldots \ldots \ldots \ldots \ldots \ldots \ldots \ldots \ldots \ldots \ldots \ldots \ldots$

8.3 BASIS FOR THE ESTTMATE $\ldots \ldots \ldots \ldots \ldots \ldots \ldots \ldots \ldots \ldots \ldots \ldots$

8.3.1 Engineering Estimate $\ldots \ldots \ldots \ldots \ldots \ldots \ldots \ldots \ldots \ldots \ldots \ldots \ldots \ldots \ldots$

8.3.2 Construction Estimate $\ldots \ldots \ldots \ldots \ldots \ldots \ldots \ldots \ldots \ldots \ldots \ldots$. 8.4

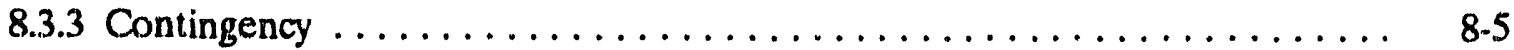

8.3 .4 Escalation $\ldots \ldots \ldots \ldots \ldots \ldots \ldots \ldots \ldots \ldots \ldots \ldots \ldots \ldots \ldots$

9. REFERENCES $\ldots \ldots \ldots \ldots \ldots \ldots \ldots \ldots \ldots \ldots \ldots \ldots \ldots \ldots \ldots \ldots \ldots$ 


\section{ILIST OF FIGURES}

\section{Firure}

Page

1.1 Project summary work breakdown structure $\ldots \ldots \ldots \ldots \ldots \ldots \ldots \ldots \ldots, \quad 1-6$

2.1 Architect's line drawing of the ANS complex $\ldots \ldots \ldots \ldots \ldots \ldots \ldots \ldots, 2-2$

2.2 Location of the ANS candidate site on the Oak Ridge Reservation .......... 2-3

2.3 Site arrangement and landscaping plan for the candidate site $\ldots \ldots \ldots \ldots \ldots, 2-4$

2.4 Ground floor plan of the main building complex $\ldots \ldots \ldots \ldots \ldots \ldots \ldots, 2-5$

2.5 Rendering of the main ANS beam room $\ldots \ldots \ldots \ldots \ldots \ldots \ldots \ldots, 2-7$

2.6 Three-dimensional view of the ANS reactor assembly $\ldots \ldots \ldots \ldots \ldots \ldots \ldots, 2-10$

2.7 General depiction of the ANS fuel element assemblies $\ldots \ldots \ldots \ldots \ldots \ldots \ldots$ 2-11

2.8 Neutron fluxes at core midplane at beginning of cycle, as a function of radius .... 2-14

2.9 Neutron fluxes at a radius of $330 \mathrm{~mm}$ at beginning of cycle, as a function of axial distance from midplane $\ldots \ldots \ldots \ldots \ldots \ldots \ldots \ldots \ldots \ldots, 2-15$

2.10 Plan view of the upper fuel element $\ldots \ldots \ldots \ldots \ldots \ldots \ldots \ldots \ldots, 2-18$

2.11 Plan view of the lower fuel element $\ldots \ldots \ldots \ldots \ldots \ldots \ldots \ldots \ldots \ldots, 2-19$

2.12 Details of an ANS fuel plate $\ldots \ldots \ldots \ldots \ldots \ldots \ldots \ldots \ldots \ldots, 2-20$

2.13 Section through the reactor assembly $\ldots \ldots \ldots \ldots \ldots \ldots \ldots \ldots \ldots \ldots, 2.22$

2.14 Plan view showing penetrations in the reflector vessel upper head $\ldots \ldots \ldots, \ldots, 2-23$

2.15 Plan view showing penetrations at the reflector vessel midplane $\ldots \ldots \ldots \ldots, 2-24$

2.16 Features of the ANS core pressure boundary tube $\ldots \ldots \ldots \ldots \ldots \ldots \ldots, 2-25$

2.17 Section through the refueling stack and tunnel and the refueling cell $\ldots \ldots \ldots \ldots, 2-28$

2.18 Features of the ANS reactor cooling system design $\ldots \ldots \ldots \ldots \ldots \ldots \ldots, 2-30$

2.19 Protective action zones around 'ile ANS $\ldots \ldots \ldots \ldots \ldots \ldots \ldots \ldots \ldots, 2-32$

2.20 Features of the ANS reactor containment system design $\ldots \ldots \ldots \ldots \ldots \ldots, 2-34$

2.21 Elevation of a cold source assembly $\ldots \ldots \ldots \ldots \ldots \ldots \ldots \ldots \ldots \ldots, 2.36$

2.22 Hot source assembly and thimble $\ldots \ldots \ldots \ldots \ldots \ldots \ldots \ldots \ldots \ldots \ldots \ldots \ldots \ldots, 2-38$

2.23 Plan view of the ground floor beam room $\ldots \ldots \ldots \ldots \ldots \ldots \ldots \ldots \ldots$ 2.39

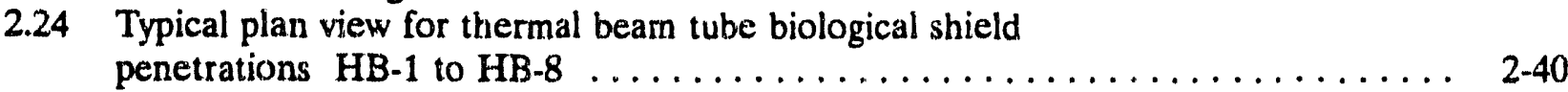

2.25 Plan view of the guide hall $\ldots \ldots \ldots \ldots \ldots \ldots \ldots \ldots \ldots \ldots \ldots \ldots \ldots \ldots \ldots \ldots \ldots, 2-42$

2.26 Plan view of the second floor beam room $\ldots \ldots \ldots \ldots \ldots \ldots \ldots \ldots \ldots, 2-43$

2.27 Elevation view of the ultra cold neutron facility installation $\ldots \ldots \ldots \ldots \ldots \ldots, 2-44$

2.28 Functional diagram of the $\mathrm{T}-1$ and $\mathrm{T}-2$ single crystal diffractometers $\ldots \ldots \ldots \ldots, 2-49$

2.29 Functional diagram and assembly of the $\mathrm{T}-4$ powder diffractometer $\ldots \ldots \ldots \ldots, 2-50$

2.30 Functional diagram of the $\mathrm{T}-11$ triple-axis spectrometer $\ldots \ldots \ldots \ldots \ldots \ldots \ldots, 2-51$

2.31 Functional diagram of the $\mathrm{D}-3$ small angle neutron scattering camera $\ldots \ldots \ldots, \quad 2-52$

2.32 Transuranium production target rod used at HFIR $\ldots \ldots \ldots \ldots \ldots \ldots \ldots, 2.56$

2.33 Schematic diagram of the pneumatic and hydraulic tube systems $\ldots \ldots \ldots \ldots \ldots$ 2-59

2.34 Activity/security zones in the ANS complex $\ldots \ldots \ldots \ldots \ldots \ldots \ldots \ldots \ldots, 2-61$

2.35 Grading plan for the candidate site $\ldots \ldots \ldots \ldots \ldots \ldots \ldots \ldots \ldots \ldots, 2.63$

2.36 Section through the guide hall, reactor building, reactor support building, and compressor building $\ldots \ldots \ldots \ldots \ldots \ldots \ldots \ldots \ldots \ldots, 2-64$

2.37 Ground/second floor plan of the main building complex $\ldots \ldots \ldots \ldots \ldots \ldots$ 2-65

$2.38 \mathrm{Second} /$ third floor plan of the main building complex $\ldots \ldots \ldots \ldots \ldots \ldots \ldots, 2-67$

2.39 Third/fourth floor plan of the main building complex $\ldots \ldots \ldots \ldots \ldots \ldots \ldots, 2-68$

2.40 Fourth/fifth floor plan of the main building complex $\ldots \ldots \ldots \ldots \ldots \ldots \ldots 2-69$ 
2.41 Roof/sixth floor plan of the main building complex $\ldots \ldots \ldots \ldots \ldots \ldots \ldots$

2.42 Section through the reactor building, secondary basin pools, mockup

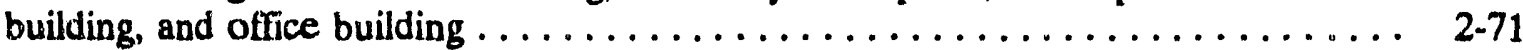

2.43 Foundations of the reactor, reactor support, guide hall, and compressor buildings, section . . . . . . . . . . . . . . . . . . . . 2-72

2.44 Plans and sections of the detritiation building $\ldots \ldots \ldots \ldots \ldots \ldots \ldots \ldots \ldots \ldots$

2.45 Flow diagram of the ANS reactor water systems $\ldots \ldots \ldots \ldots \ldots \ldots \ldots \ldots \ldots . \ldots 27$

2.46 Typical Class $1 \mathrm{E}$ power and signal cable systems $\ldots \ldots \ldots \ldots \ldots \ldots \ldots \ldots \ldots$

2.47 Typical non-Class $1 E$ power and signal cable systems . . . . . . . . . . . . . . . 2-81

2.48 Data communications systems for instrumentation, control, and data

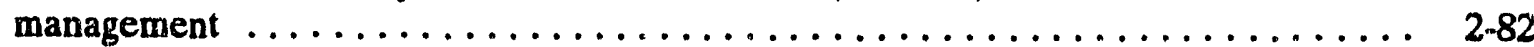

2.49 Overall block diagram of one cold source refrigerator system $\ldots \ldots \ldots \ldots \ldots \ldots . . .25$

2.50 Interface diagram for the heavy water detritiation and upgrade system . . . . . . . 2-89

2.51 Class 1E PCDAS architecture . . . . . . . . . . . . . . . . . . . . . . . 2-91

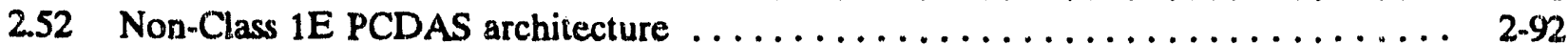

2.53 Layout of the main control complex $\ldots \ldots \ldots \ldots \ldots \ldots \ldots \ldots \ldots \ldots \ldots \ldots$

6.1 ANS Project method of accornplishment and subcontracting organization chart ... 6 6-2

6.2 DOE/ANS Project organization chart $\ldots \ldots \ldots \ldots \ldots \ldots \ldots \ldots \ldots \ldots \ldots \ldots$

6.3 Energy Systems/ORNL ANS Project organization chart . . . . . . . . . . . . $6-4$

7.1 ANS Project schedule at level 2 of the WBS (sheet 1) ...............

7.1 ANS Project schedule at level 2 of the WBS (sheet 2) ............. $7-3$

7.2 ANS critical path schedule (sheet 1$) \ldots \ldots \ldots \ldots \ldots \ldots \ldots \ldots \ldots \ldots \ldots$

7.2 ANS critical path schedule (sheet 2) $\ldots \ldots \ldots \ldots \ldots \ldots \ldots \ldots \ldots \ldots \ldots \ldots$

7.2 ANS critical path schedule (sheet 3$) \ldots \ldots \ldots \ldots \ldots \ldots \ldots \ldots \ldots \ldots \ldots$

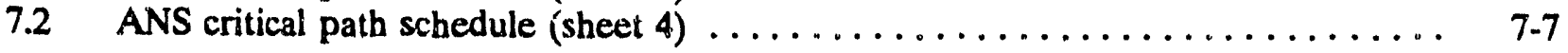




\section{LIST OF TABLES}

Table

Page

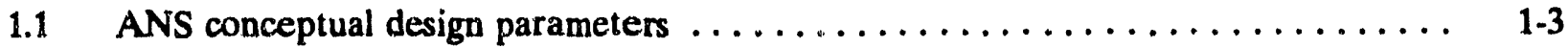

1.2 List of the conceptual design participants $\ldots \ldots \ldots \ldots \ldots \ldots \ldots \ldots \ldots \ldots \ldots$

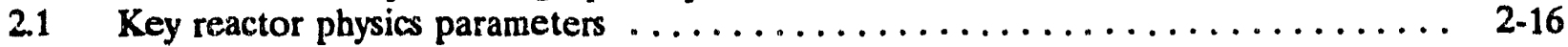

2.2 Primary and secondary coolant parameters $\ldots \ldots \ldots \ldots \ldots \ldots \ldots \ldots \ldots \ldots \ldots \ldots \ldots$

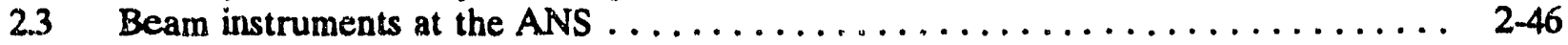

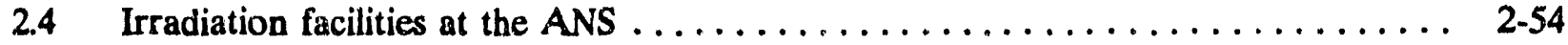

2.5 Manpower and operating cost for steady-state operation $\ldots \ldots \ldots \ldots \ldots \ldots \ldots$

2.6 Summary of operators at the ANS $\ldots \ldots \ldots \ldots \ldots \ldots \ldots \ldots \ldots \ldots \ldots \ldots$

3.1 Annual operating costs for the ANS, the HFIR, and the HFBR . . . . . . . . 3-4

8.1 ANS total project cost in escalated dollars $\ldots \ldots \ldots \ldots \ldots \ldots \ldots \ldots \ldots \ldots .1$

8.2 Line item cost by participant, in escalated dollars $\ldots \ldots \ldots \ldots \ldots \ldots \ldots \ldots . . \ldots$.

8.3 ANS cost and funding plan in escalated dollars $\ldots \ldots \ldots \ldots \ldots \ldots \ldots \ldots \ldots$

8.4 Average contingency for ANS by WBS and fund source $\ldots \ldots \ldots \ldots \ldots \ldots$ 


\section{ACRONYMS}

$\begin{array}{ll}\text { A/E } & \text { architect/engineer } \\ \text { ANS } & \text { Advanced Neutron Source } \\ \text { CECE } & \text { combined electrolysis-catalytic exchange } \\ \text { CM } & \text { construction manager } \\ \text { DOE } & \text { Department of Energy } \\ \text { ER } & \text { Energy Research } \\ \text { HFIR } & \text { High Flux Isotope Reactor } \\ \text { IC } & \text { integrating contractor } \\ \text { ILL } & \text { Institut Laue-Langevin } \\ \text { ISDD } & \text { integrating system design description } \\ \text { ISOL } & \text { isotope separation on-line } \\ \text { LLLW } & \text { liquid low-level waste } \\ \text { NEPA } & \text { National Environmental Policy Act } \\ \text { NSCANS } & \text { National Steering Committee for the Advanced Neutron Source } \\ \text { NRC } & \text { Nuclear Regulatory Commission } \\ \text { NE } & \text { Nuclear Energy } \\ \text { ORNL } & \text { Oak Ridge National Laboratory } \\ \text { PCDAS } & \text { plant control and data acquisition systems } \\ \text { REDC } & \text { Radiochemical Engineering Development Center } \\ \text { RM } & \text { reactor manufacturer } \\ \text { R\&D } & \text { Research and Development } \\ \text { SDD } & \text { systems design description } \\ \text { TVA } & \text { Tennessee Valley Authority } \\ \text { WBS } & \text { work breakdown structure }\end{array}$




\section{EXECUTTVE SUMMARY}

The Advanced Neutron Source (ANS) is a new basic and applied research facility based on a powerful steady-state research reactor that provides beams of neutrons for measurements and experiments in the fields of materials science and engineering, biology, chemistry, materials analysis, and nuclear science. The useful neutron flux for these experiments will be at least five times, and in some cases twenty times, more than is available at the world's best existing facility: the Institut Laue-Langevin (ILL) in Grenoble, France. In addition, ANS will provide irradiation capabilities for the production of radioisotopes for medical applications, research, and industry and facilities for materials irradiation terting; these irradiation facilities will match or exceed the capabilities of the High Flux Isotope Reactor (HFIR) at Oak Ridge, Tennessee.

The need for a new steady-state neutron research facility in the United States was cmphasized hy the 1984 National Academy Report (the Seitz-Eastman report) ${ }^{1}$ and confirmed by the Department of Energy's (DOE's) Energy Research Advisory Board in 1985. These studies defined a minimum thermal neutron flux requirement of $5 \times 10^{19} \mathrm{~m}^{-2} \cdot \mathrm{s}^{-1}$ (the design presented in this report provides $\left.7.5 \times 10^{19} \mathrm{~m}^{-2} \cdot \mathrm{s}^{-1}\right)$. The National Steering Committee for an Advanced Neutron Source, with representation from the major fields of science that will use the facility, was established in 1986 and has continued to define the performance requirements and instrument layouts needed by the user community.

To minimize technical risks and safety issues, the project adopted a policy of not relying upon new inventions to meet the minimum performance criteria, and the design presented in this report is built on technologies already used in other facilities and development programs: for example, the involute aluminum-clad fuel plates common to HFIR and ILL and the uranium silicide fuel developed in DOE's Reduced Enrichment for Research and Test Reactors program and tested in reactors worldwide. At the same time, every state-of-the-art technique has been implemented to optimize neutron beam delivery at the experiments.

The ANS is to be designed, built, and operated under DOE ownership and (under 10 CFR 50) is not subject to the Nuclear Regulatory Commission (NRC) licensing process. However, DOE Orders require its reactors to meet the standards, codes, and guides that are applied to comparable NRC-licensed facilities. Accordingly, the ANS design criteria are chosen to ensure that applicable safety requirements are incorporated into the design. Risk assessment has been an integral part of the ANS design process. The ANS risk limitation goals are based on the NRC policy statement ${ }^{2}$ of August 21, 1984, and on the similar DOE Nuclear Safety Objectives Policy Statement Draft ${ }^{3}$ of February 9,1989 . The basic principle upon which both are based is that risks attributable to nuclear accidents are allowed to cause only an insignificant increase in the preexisting normal risks as published by the U.S. Bureau of Census. As one means of ensuring that the risk is made very low, the design incorporates safety-related cooling features that are inherent or passive to the maximum practicable degree.

The ANS team has followed a proactive policy of building safety into the design. To this end, safety analyses and design advances have been iterated. The safety analyses were concentrated in three areas: probabilistic risk assessments and evaluations, even as early as the preconceptual design stage; transient thermal-hydraulic analyses to support and define the design of the cooling and shutdown systems for the high-power-density core; and the containment response to severe accident conditions.

The final design that arises from these scientific and safety considerations is centered around a 330-MW(f) heavy-water-cooled,-moderated, and -reflected reactor housed in a large, doublewalled containment dome and surrounded by thermal neutron beam experiments. The reactor 
cooling systems are designed with many safety features, including large heat sinks sufficient for decay heat removal; passive inventory control by accumulators, pools, and floodable cells; a layout that maximizes natural circulation capabilities; and fast, redundant shutdown systems. There are two large liquid deuterium cold neutron sources; and most of the cold neutron beams are taken, by low loss guides, to a guide hall that is outside containment and has low background and the necessary space for neutron scattering and other instruments. The entire facility is designed for easy access to scientific users, combined with rigorous separation of experiments from operational and security areas. It is the first research reactor designed to allow easy visitor access without compromising present nuclear security requirements and regulations.

The conceptual design includes all the scientific facilities and appropriate redundant or safety-related systems that have evolved and been accepted as legitimate design requirements through interactions with all the communities involved. These features are documented in the exceptionally complete and detailed conceptual design document package, which is a sound and defensible baseline for the scope documented therein and which can also be used to support evaluation of scope reduction and value engineering trade-off studies that have already begun in order to find the optimum combination of capabilities and cost.

The total estimated construction (line item) cost of the complete full-scope baseline design is $\$ 1.7$ billion, in constant 1992 dollars. There is an associated R\&D program costed at $\$ 114$ million in operating and capital equipment funds. The cost of certain additional instruments that the scientific community proposed not be included in the construction project would be $\$ 34$ million, and preoperational costs (including training or retraining of operators and maintenance staff) is estimated at $\$ 261$ million. These figures are shown in the table below. The costs are based on a plan that would begin a line item for preliminary design work (Title 1) in FY 1994, to be followed with a complementary detailed design and construction line item in 1995. Completion of the project is scheduled for FY 2002, including commissioning of the installed experiments systems.

Casts (BO) (milions of 1992 dollars)

\begin{tabular}{lrrrrrrrrrr}
\hline & 1994 & 1995 & 1996 & 1997 & 1998 & 1999 & 2000 & 2001 & 2002 & Total \\
\hline Line ilem, TEC & 40 & 55 & 96 & 201 & 403 & 541 & 310 & 43 & 11 & 1699.8 \\
Operating expense & & & & & & & & & & \\
$\quad$ R\&D & 13 & 21 & 23 & 22 & 13 & 7 & 4 & 1 & 0 & 104 \\
$\quad$ Capital equipment & 2 & 3 & 2 & 2 & 1 & 0 & 0 & 0 & 0 & 10 \\
Additional instruments & 0 & 0 & 0 & 2 & 22 & 8 & 1 & 1 & 0 & 34 \\
Preoperations & 0 & 1 & 3 & 10 & 17 & 22 & 42 & 68 & 98 & 261 \\
\hline
\end{tabular}




\section{INTRODUCTION}

\subsection{PROJECT PURPOSE AND SCOPE}

The Advanced Neutron Source (ANS) is a world-class center for research using neutrons. It is intended to return the United States to a position of preeminence in scientific research using neutrons, in fields that cut across the full spectrum of scientific endeavors. Research programs at the ANS will cover materials science, biology, chemistry, fundamental and nuclear physics and analytical chemistry, and will generate areas of science not foreseen at the present. Irradiation facilities will be provided for producing key transuranium isotopes, including ${ }^{252} \mathrm{Cf}$ for use as a portable neutron source in applications ranging from cancer therapy to neutron radiography and explosives detection, and including significant quantities of ${ }^{254} \mathrm{Es}$ for fundamental research in superheavy elements. Irradiation facilities also will be provided for examining the behavior of materials in intense radiation fields and for the production of a host of medical and industrial isotopes. The ANS Project consists of a reactor-based, steady-state neutron source and the research facilities and user support facilities needed to create a fully operational research center. The neutron source is a $330 \mathrm{MW}$, reactor cooled, moderated, and reflected with heavy water. The ANS will be a user facility open for research by industrial, university, and national laboratory researchers from throughout the United States and from other facilities throughout the world. At least 1000 users are expected annually. The ANS is a major research center designed for the simultaneous conduct of many small research programs using a single, powerful neutron source. The ANS will be fully staffed with research, operations, maintenance, security, and other support staff to ensure the efficient operation of the reactor in full compliance with all regulations and standards and to ensure effective use of the research facilities.

The ANS Project technical objectives are:

- to design and construct the world's highest-flux research reactor for neutron scattering, which will provide 5 to 10 times the flux of the best existing facilities;

- to provide isotope production facilities that are as good as or better than the High Flux Isotope Reactor (HFIR); and

- to provide materials irradiation facilities that are as good as or better than the HFIR.

The scope of the ANS Project includes all of the site development, buildings, reactor hardware, experiment hardware, and plant systems needed to begin operation of both the reactor and the research facilities. The scope includes all construction at the ANS candidate site, construction of feeders and utilities between the ANS site and existing utility systems, modifications to utility systems to accommodate the ANS feeders, and connections and modifications to roads and other infrastructure around the ANS boundaries. Certain instruments will be supplied by participating research teams and are not costed in this conceptual design. These instruments are defined in the conceptual design documentation. A guest services building may be supplied by the University of Tennessee.

The ANS Project is sponsored by the Department of Energy (DOE) through the Basic Energy Sciences division of Energy Research (ER). Funding and programmatic direction is provided by ER. In accordanre with secretarial directives, the design and construction of the ANS is managed by DOE Nuclear Energy (NE). Project oversight, including the approval of design documentation, is provided by $\mathrm{NE}$. 


\subsection{PROJECT GOALS AND REQUIREMENTS}

The major goal for the project was established by the Major Materials Facilities Committee of the National Research Council, co-chaired by Frederick Seitz and Dean Eastman. The report of this committee, issued in August 1984, called for a steady state neutron source that provides a useable neutron flux that is at least 5 times, and preferably 10 times, the flux currently available. The pieparation of this conceptual design was authorized by the DOE Energy Systems Acquisition Advisory Board at a meeting held on August 23, 1990.

Goals and requirements for the ANS are obtained from the national scientific community that would use the facility. To provide systematic, documented input to the project, a National Steering Committee for the Advanced Neutron Source (NSCANS) was formed in 1986. It meets on a regular basis. NSCANS consists of representatives of universities, industry, and national laboratories both within and outside DOE. The project goals and requirements have been generated with the participation of NSCANS members and are approved at meetings of the full NSCANS membership. The project goals set for the design of the ANS are summarized in Table 1.1.

\subsection{ORGANIZATION}

The elements of the ANS Project are organized in a work breakdown structure (WBS) as depicted in Fig. 1.1. Research and Development (R\&D) covers the set of activities needed to design the reactor core and control system, to validate the correlations and methods used in the ANS design, and to improve upon the use of neutrons produced by the ANS reactor. Project Support covers the administration of the ANS Project and a number of systems engineering, safety, environmental, quality assurance, and training activities. Reactor Systems covers the design, procurement, fabrication, and installation of the reactor assembly. Experiment Systems covers the design, procurement, fabrication, and installation of beam transport systems, beam experiment facilities, irradiation facilities, the cold and hot sources, and experiment support facilities. Site and Buildings covers the design and construction of all structures and land improvements within the scope of the ANS, including construction support facilities. Plant Systems covers the design, procurement, fabrication, and installation of all supporting systems needed for reactor and facility operations, including heavy and light water systems; electrical and communications systems; ventilation systems; services; fire protection systems; waste systems; a heavy water detritiation and upgrade plant; plant instrumentation, control, and data systems; and general purpose equipment. Operations provides the planning and funding for assembling and training the research, operations, maintenance, security, health physics, and other staff needed to begin operations of the ANS; funds services used for reactor operation through completion of the project; and provides initial inventories of heavy water, spent fuel casks, and other operations items. The DOE element provides funding for subcontractor support to the DOE Project Office that oversees the design, construction, and startup of the ANS. 
Table 1.1. ANS conceptual design parameters

\begin{tabular}{|c|c|c|}
\hline Parameter ${ }^{a b}$ & NSCANS goals & $\begin{array}{l}\text { ANS } \\
\text { conceptua! } \\
\text { design }\end{array}$ \\
\hline \multicolumn{3}{|c|}{ Neutron scattering } \\
\hline $\begin{array}{l}\text { Hot neutrons } \\
\text { Thermal tlux at hot source } \\
\text { Number of hot sources } \\
\text { Number of hot reams }\end{array}$ & $\begin{array}{c}21 \\
1 \\
2\end{array}$ & $\begin{array}{l}1 \\
1 \\
2\end{array}$ \\
\hline $\begin{array}{l}\text { Thermal neutrons } \\
\text { Thermal flux in reflector } \\
\text { Thermal:fast ratio } \\
\text { Number of thermal tangential tubes }\end{array}$ & $\begin{array}{c}5-10 \\
280: 1 \\
7\end{array}$ & $\begin{array}{c}\boldsymbol{c}^{c} \\
170: 1 \\
7\end{array}$ \\
\hline $\begin{array}{l}\text { Cold neutrons } \\
\text { Thermal flux at cold scurces } \\
\text { Number of cold sources } \\
\text { Number of horizontal cold guides } \\
\text { Number of slant cold beams for scattering instruments }\end{array}$ & $\begin{array}{c}2-4 \\
7 \\
14 \\
1\end{array}$ & $\begin{array}{c}4 \\
2 \\
14 \\
1\end{array}$ \\
\hline Nuclear and fundame & & \\
\hline $\begin{array}{l}\text { Number of thermal through tubes } \\
\text { Number of slant thermal beams } \\
\text { Number of very cold beams }\end{array}$ & $\begin{array}{l}1 \\
1 \\
2\end{array}$ & $\begin{array}{l}1 \\
1 \\
2\end{array}$ \\
\hline Materials irradi & & \\
\hline $\begin{array}{l}\text { Central irradiation facility } \\
\text { Fast flux } \\
\text { Fast:thermal ratio } \\
\text { Total number of positions } \\
\text { Number of instrumented positions } \\
\text { Damage rate [displacements per atom per year (dpa/y) } \\
\text { in stainless steel] } \\
\text { Nuclear heating rate (W/g in stainless steel) } \\
\text { Axial flux gradient over } 200 \mathrm{~mm} \\
\text { Available diameter (mm) } \\
\text { Avallable length (mm) }\end{array}$ & $\begin{array}{l}z 1.4 \\
\geq 1: 2 \\
10 \\
2 \\
z=30 \\
=54 \\
\leq 30 \% \\
i \geq 17 \\
i \geq 500\end{array}$ & $\begin{array}{l}2.0^{\circ} \\
2.9: 1^{\circ} \\
10 \\
5 \\
T B D \\
570 \\
14 \% \\
48 \\
500\end{array}$ \\
\hline
\end{tabular}


Table 1.1 (continued)

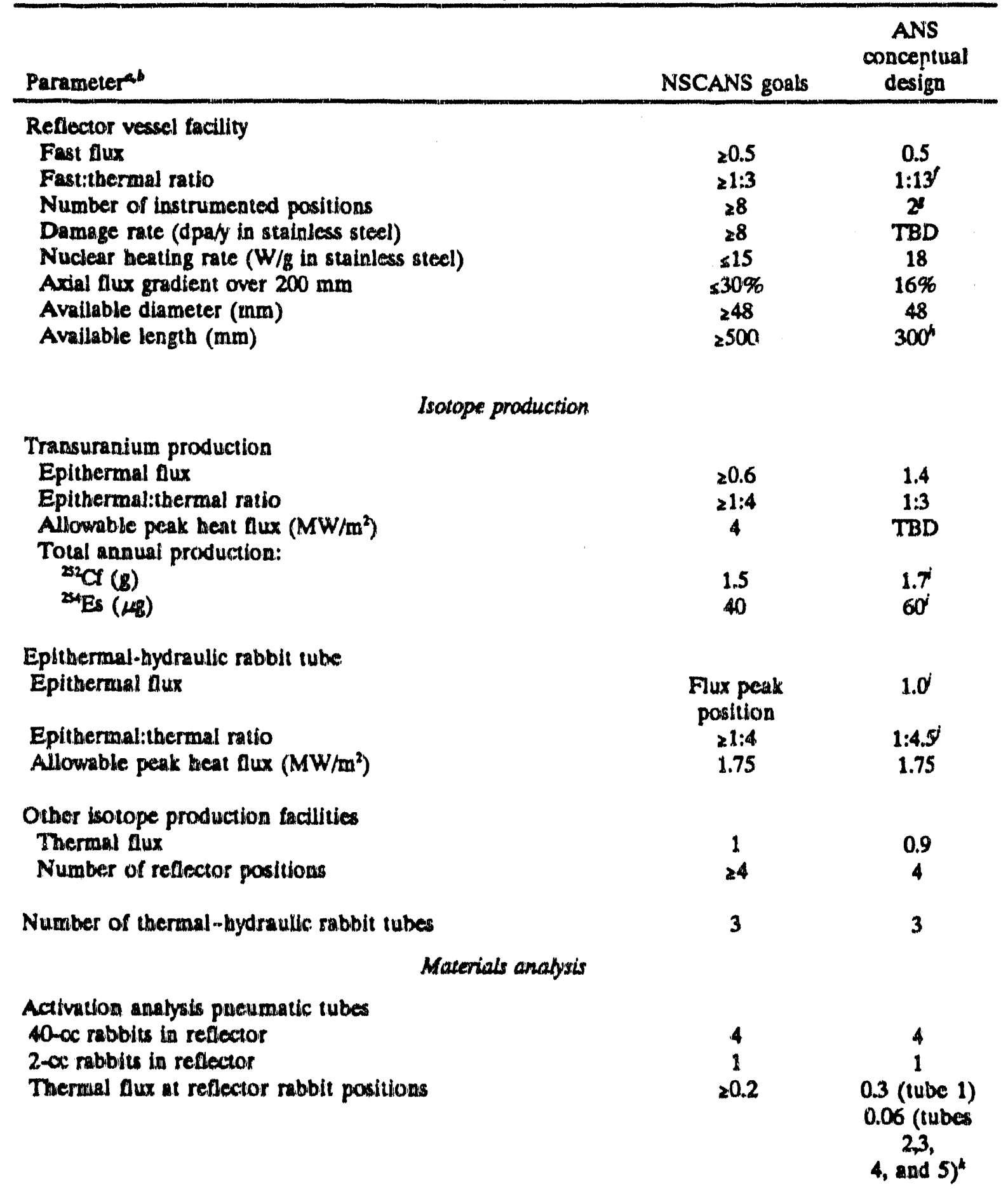


Table 1.1 (continued)

\begin{tabular}{lcc}
\hline Parameter, & NSCANS goals & $\begin{array}{c}\text { ANS } \\
\text { anceptual } \\
\text { design }\end{array}$ \\
\hline $\begin{array}{l}\text { Heating rate } \\
\text { Temperature in a } 40-c c, \text { high-density } \\
\text { polyethylene rabbit }\left({ }^{\circ} \mathrm{C}\right)\end{array}$ & $\leq 120$ & TBD \\
$\begin{array}{l}\text { Rabbit tubes in light water pool } \\
\text { Thermal flux at light water rabbit positions }\end{array}$ & 2 & 2 \\
$\begin{array}{l}\text { Prompt-gamma sctivation analysis cold neutron stations } \\
\text { Low-background (multiple-beam) guide system }\end{array}$ & $\geq 0.04$ & $0.05 ; 0.02$ \\
$\begin{array}{l}\text { Neutron-depth profiling } \\
\text { Number of slant cold beams } \\
\text { Gamma irradiation facility in spent-fuel pool }\end{array}$ & 1 & 1 \\
Positron production position & 1 & 1 \\
\hline
\end{tabular}

${ }^{9}$ All fluxes in units of $10^{19} \mathrm{~m}^{-2} \cdot \mathrm{s}^{-1}$.

'Weutron spectra rerms as used in this table are defined as Thermal $\leq 0.625 \mathrm{eV}$, $0.625 \mathrm{eV} \leq$ epithermal $\leq 100 \mathrm{eV}$, Fast $>0.1 \mathrm{MeV}$.

Sources of neutrons for research are classified as

Ultra-cold $<25 \mu \mathrm{eV}$, $25 \mu \mathrm{eV}<$ very cold $<0.1 \mathrm{meV}$, $0.1 \mathrm{meV}<$ cold $<5 \mathrm{meV}$, $5 \mathrm{meV}<$ thermal $<0.625 \mathrm{eV}$, $0.625 \mathrm{eV}<$ hot $<1 \mathrm{eV}$.

End-of-cycle value.

The materials irradiation facilities are intended to replace irradiation facilities in the HFIR. ANS can not meet all these goals because the simultaneous requirements of high fast:thermal flux ratio, high fast flux, and low heating rate are intrinsically incompatible with the physics of an undermoderated core (optimized for neutron scattering research goals).

Values at $r=160 \mathrm{~mm}$ and beginning.of-cycle. The fast flux increases during the fuel cycle. The fast:thermal ratio decreases to as low as $0.25: 1$ with decreasing radius and burnup.

Best available ratio in reflector vessel.

Access restricted by other facilities in the reflector vessel. Partially offset by providing more instrumented positions than required in the central irradiation facility.

kLength restricted by outer shutdown rods.

The production number quoted is a preliminary value obtained from two-dimensional neutronic analyses. Possible thermal limitations on pellet loadings have not been evaluated.

Value at $250 \mathrm{~mm}$ above midplane at midpoint of cycle.

kOptimized for lowest gamma heating, but will need to be located at a higher neutron flux level. 


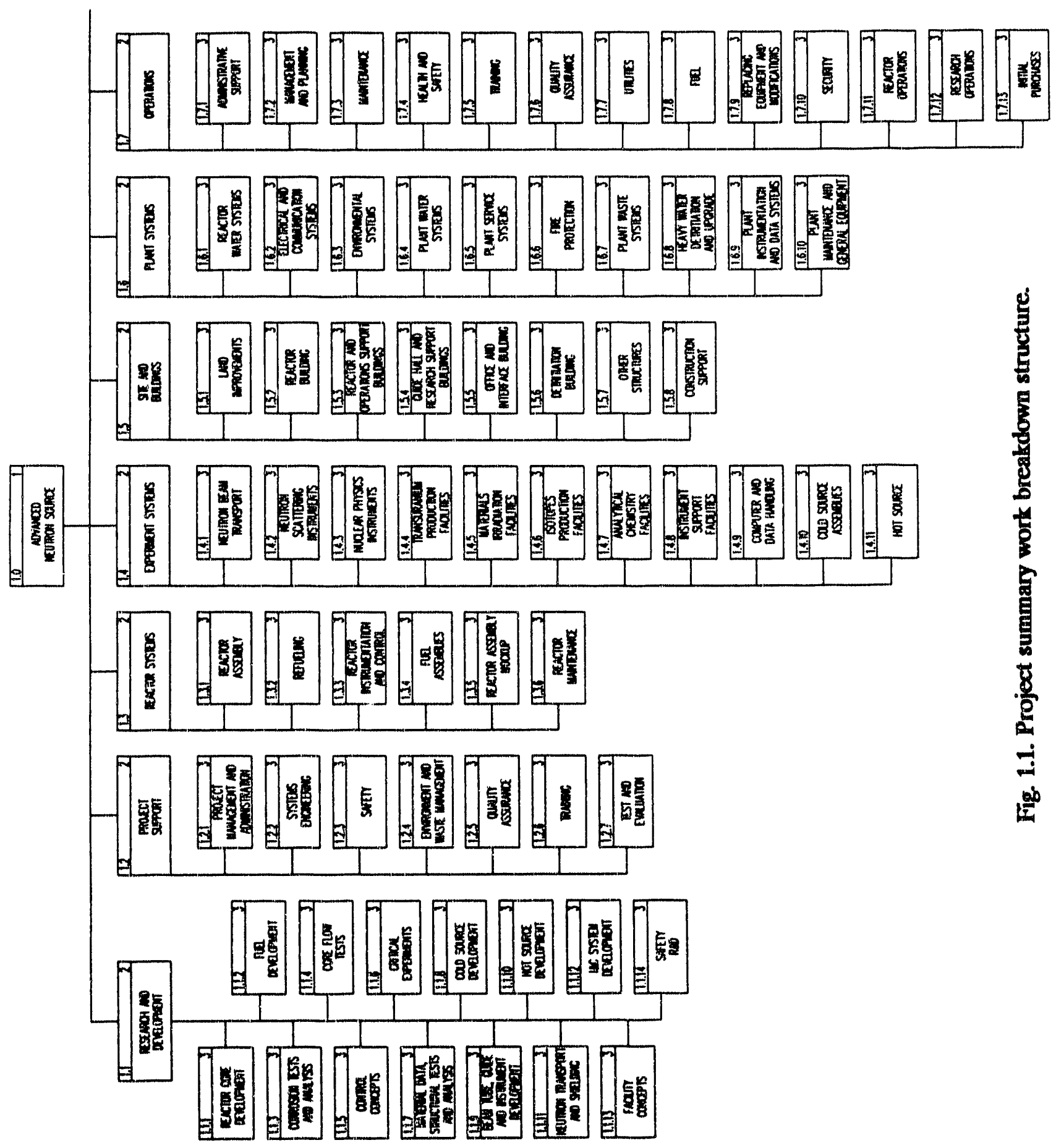


The conceptual design package was assembled by Martin Marietta Energy Systems, Inc. under prime contract to DOE. It was prepared with the assistance of Gilbert/Commonwealth, Inc., an architect/engineer (A/E) under contract to Energy Systems. A complete list of subcontractors who participated in the preparation of the conceptual design report is in Table 1.2.

Table 1.2 List of the conceptual design participants

\begin{tabular}{ll}
\hline AECL Technologies & Marrich, Inc. \\
Air Products and Chemicals, Inc. & $\begin{array}{l}\text { National Institute of Standards and } \\
\text { Technology }\end{array}$ \\
Argonne National Laboratory & Ovonic Synthetic Materials Company \\
Automated Sciences Group, Inc. & Pashek and Associates \\
Babcock \& Wilcox & PLG, Inc. \\
Brookhaven National Laboratory & Rockwell International \\
DRS/Hundley, Kling, Gmitter & Sandia National Laboratory \\
ERC/Edge & Science Applications International \\
Gilbert/Commonwealth, Inc. & Corporation \\
Halliburton NUS Environmental & Tennessee Technological University \\
Corporation & The University of Rhode Island \\
Idaho National Engineering Laboratory & The University of Tennessee \\
\hline
\end{tabular}




\section{GENERAL PROJECT DESCRIYTION}

This chapter provides a general description of the ANS Project and identifies the major alternatives considered in selecting the design concepts. The description is presented in general alignment with the WBS.

\section{PROJECT OVERVIEW}

\subsection{Overview of the ANS Complex}

The ANS Project consists of a $330 \mathrm{MW}$, heavy water-cooled, -moderated, and -reflected reactor; beam transport systems, instruments, and irradiation facilities; a complex of reactor, research, operations, office, and laboratory buildings; and the plant systems needed for reactor and research operations. An architect's rendering of the main ANS complex is shown in Fig. 2.1. The reactor is housed under the central dome. The guide hall is shown to the right and the reactor support buildings to the left. Offices and laboratories are shown in the foreground.

Although no site is selected until the National Environmental Policy Act activities have been completed and a record of decision has been issued, one candidate site has been identified on the Oak Ridge Reservation. The location of that site, shown in Fig. 2.2, is at the intersection of Melton Valley Road and the Health Physics Research Reactor Access Road. That location has not previously been used for construction.

The overall site arrangement is shown in Fig. 2.3. The main reactor buildings are at the center of the candidate site. The site is divided into an accessible research zone to the northwest and an operations zone to the southeast. The main entry to the facility is from the northwest; parking and a guest services building are located near the northwest site boundary. A major feature is the complete separation of research and operations zones, allowing easy access for researchers while providing the levels of security appropriate for a nuclear reactor on the operations side. A double fence is seen in Fig. 2.3, marking the boundary of the security zone. The primary electrical substation is southeast of the main complex, and the secondary electrical substation is just east of the reactor buildings. Cooling towers are located on a rise to the east of the complex, and a stack used in reactor emergencies is located on a rise near the southeast boundary of the site. A heavy water detritiation and upgrade facility is located near the south boundary of the site.

The ground floor plan for the main building complex is seen in Fig. 2.4. The central, cylindrical reactor building houses the reactor and an array of beam instrument stations clustered around the biological shielding. Upper floors of this building hold additional beam stations, the reactor cooling systems, refueling systems, spent fuel pools, and irradiation support facilities. The guide hall, to the west of the reactor building, houses an array of neutron guides and instruments. A laboratory and research operations complex is seen counterclockwise from the guide hall. To the east of the reactor building is the reactor support building. This structure houses most of the plant systems, including secondary coolant systems, demineralizers and filters, electrical power systems, ventilation and filter systems, plant water and service systems, and waste systems. The reactor support building also houses the main control complex, including the main control room and the central control and data acquisition computer and display systems.

The main office building is the northernmost structure in the main complex. This building includes the main entry plaza for the complex and provides office clusters for research groups and 


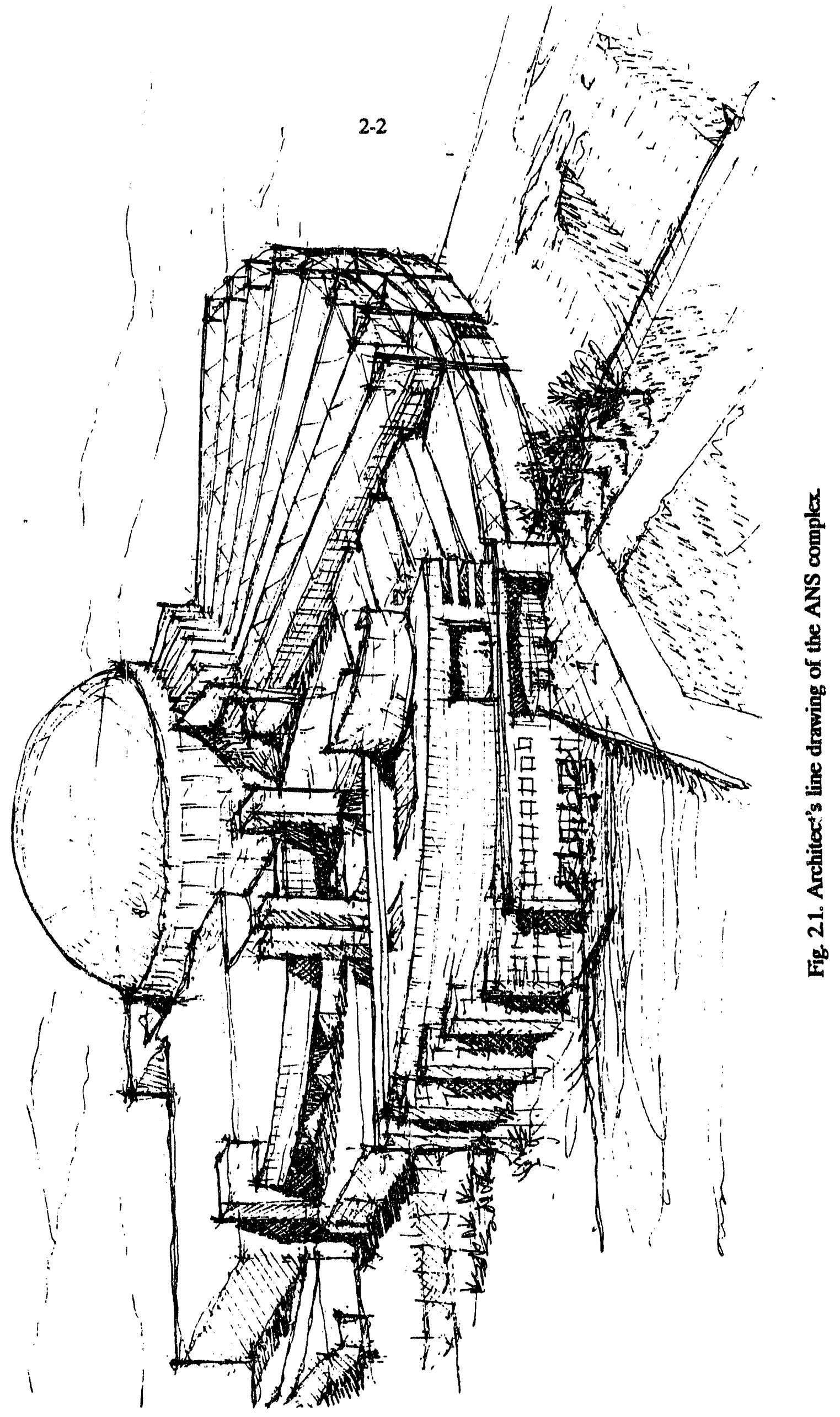


善

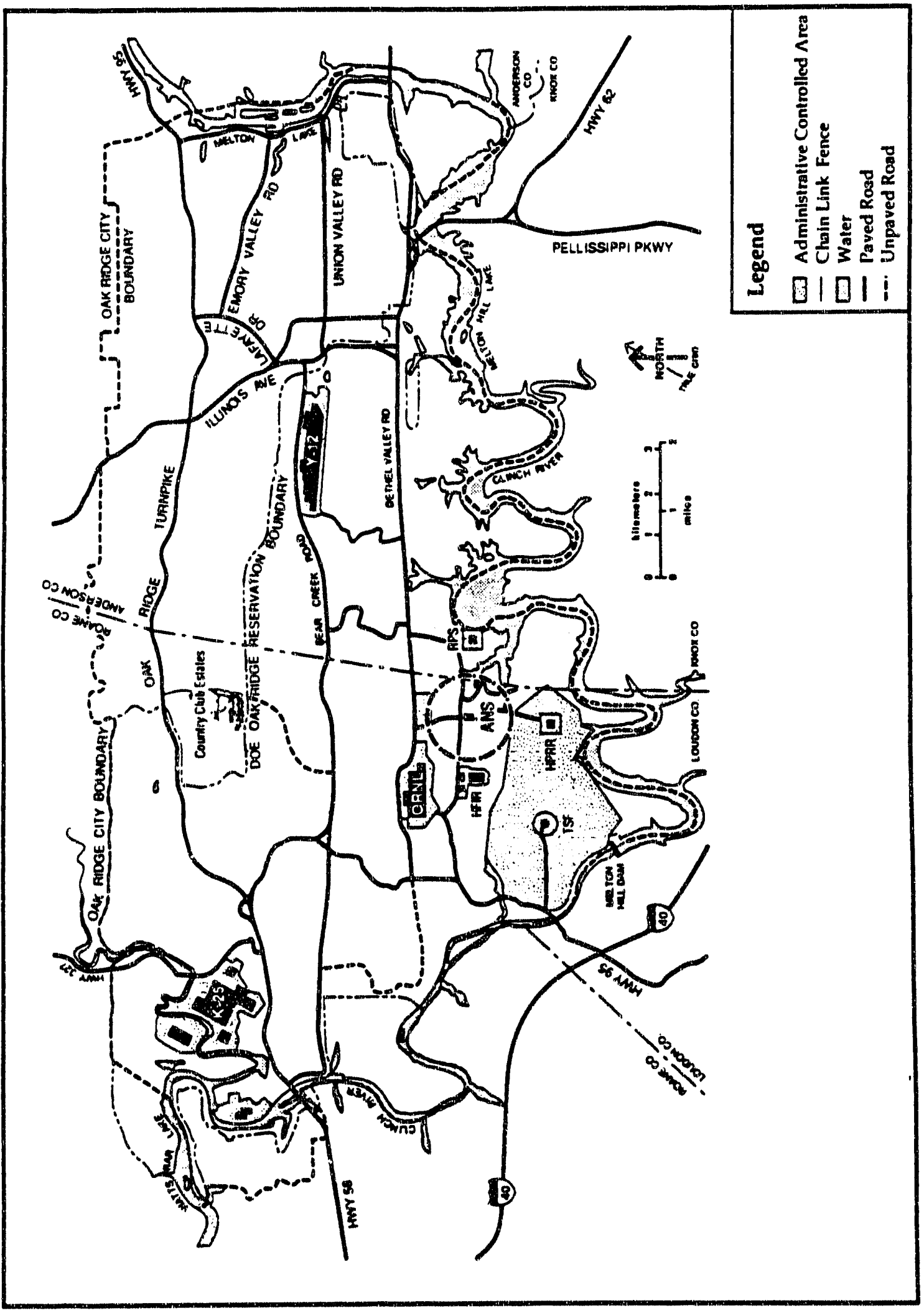

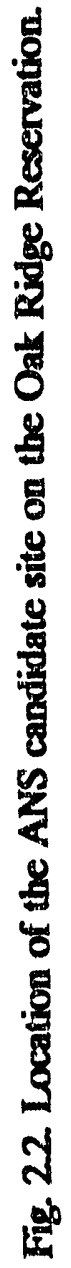




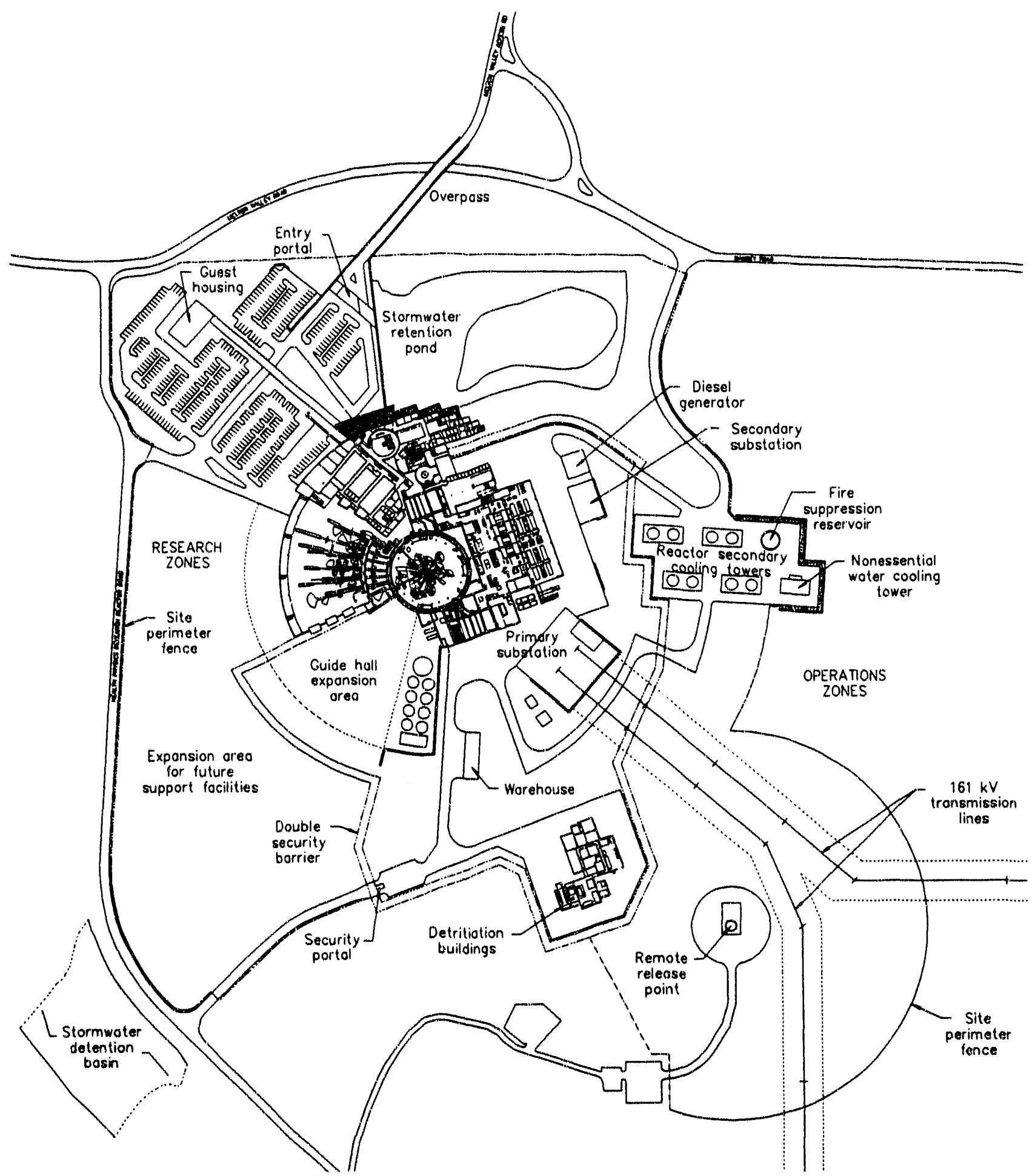

Fig. 23. Site arrangement and landscaping plan for the candidate site. 


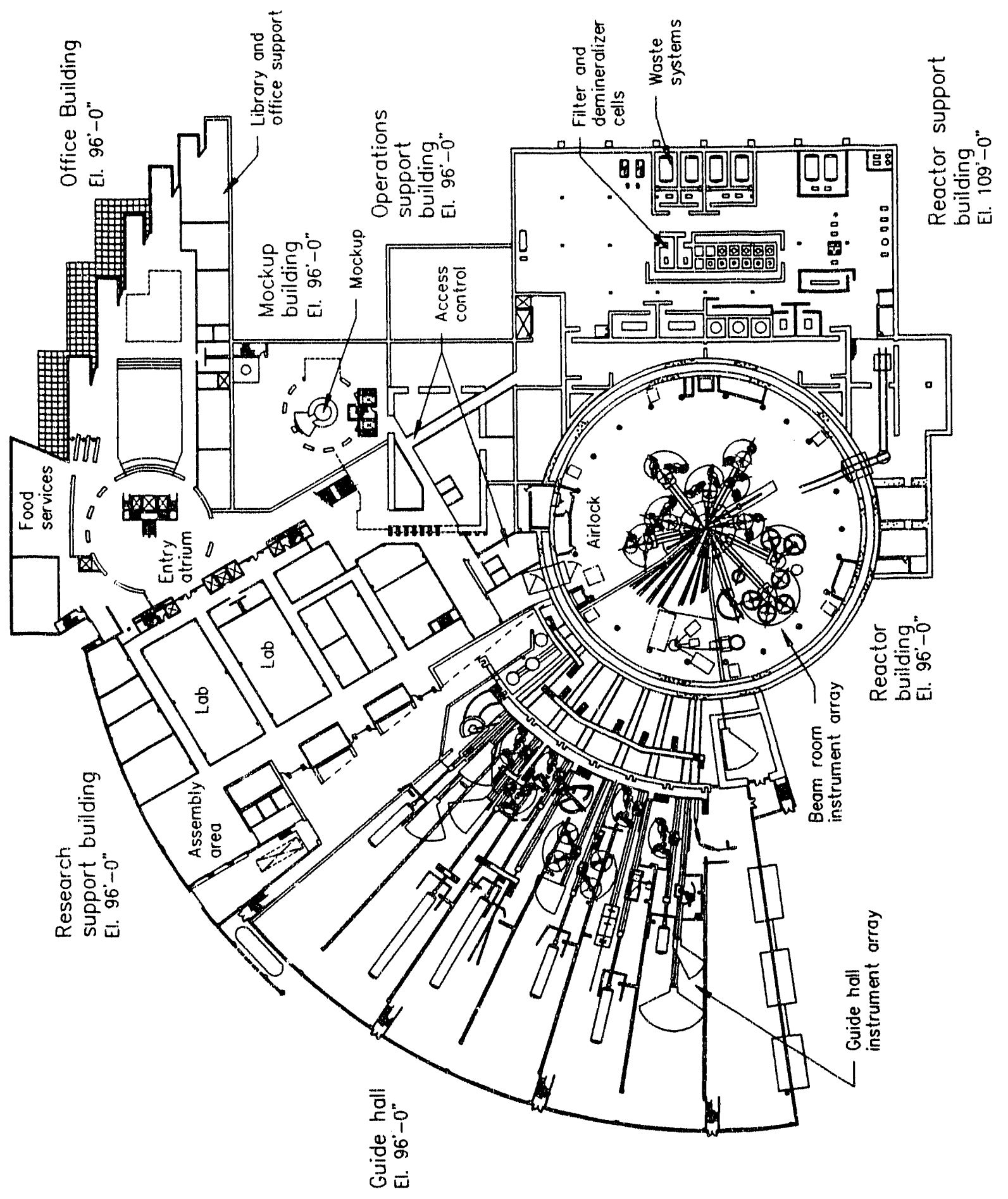

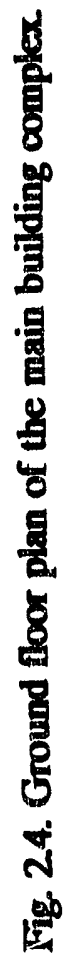


the reactor administration. The office building also includes an auditorium, a library, food services, and other resource areas. An operations support area is on the north side of the reactor support building; this area is structurally integrated into the reactor support building. Between the reactor support building, the office building, and the operations support building is an interface area used as a control point for personnel passing from the entry plaza into the beam room and the operations buildings. A reactor mockup and simulator also are located between the reactor support and office buildings.

\subsection{Overvicw of the Research Facilities}

The central focal point of all the ANS research facilities is the neutron sources. Neutron beam research activities are divided into three classes of thermalized neutrons: thermal, cold, and hot. Thermal neutrons correspond to wavelengths on the order of $0.1 \mathrm{~nm}$ and are useful for the exploration of parameters on an atomic scale. Much of the current scientific interest is in effects that appear over distances of many atoms. Thus neutrons with wavelengths of 1 to $2 \mathrm{~nm}$ (about 10 to 20 times the typical distance between atoms in well-ordered crystals) are desired as a means of investigating phenomena between a purely atomic scale and the larger scales that can be observed with other tools. Since wavelength is an inverse function of energy, which correlates with temperature in a thermalized system, these are referred to as "cold neutrons." Thermalized neutrons with a higher energy, called "hot neutrons," are useful for studies involving inelastic interactions between neutrons and the sample. Typical examples of hot neutron applications are studies of liquids or other disordered systems.

The heavy water reflector in the reactor assembly serves as the thermal neutron source. Thermal neutrons are extracted with evacuated beam tubes that penetrate from the side and top of the reactor assembly. Because of inverse square losses, the instruments using the thermal beams are clustered around the biological shield as close to the reactor as possible. Cold neutrons are produced by placing vessels filled with a liquid deuterium moderator in the reflector region. The high-wavelength, cold neutrons can be reflected off highly polished nickel surfaces and deposited on polished glass or other substrate materials. These surfaces are used to construct neutron guides, which act in a manner analogous to fiber optics to transport neutrons with minimal loss to instruments in a large guide hall. Hot neutrons are produced by placing a graphite block, heated by radiation from the reactor, in the reflector region. Neutrons from the hot source are transported to instruments just outside the shield using standard beam tubes.

An artist's depiction of the main beam room in the reactor building is shown in Fig. 2.5. The biological shield is shown in the center of the figure. Beam tubes transport neutrons to instruments arranged radially in all directions from the reactor. A typical instrument consists of beam collimation and filtering systems, a sample chamber, and some type of analyzer and detector system that measures neutrons scattered off the sample over a range $c^{f}$ angles. In some cases, a new technology for producing supermirror thermal neutron guides is used to stand the instruments away from the shield wall, relieving crowding near the shield. As seen in the figure, neutron instruments are rather large, particularly when space for instrument motion and instrument shielding is taken into account. An overhead bridge crane serves the beam room instrumentation, both for the installation of sample chambers and for instrument modification, repair, or replacement.

The arrays of neutron beams, guides, and instruments are seen in the reactor and guide hall building plans shown in Fig. 2.4. Beam research applications are grouped into neutron scattering, nuclear and fundamental physics, and materials analysis. Neutron scattering covers a wide range of investigations of materials samples carried out by observing the pattern of neutrons scattered from 


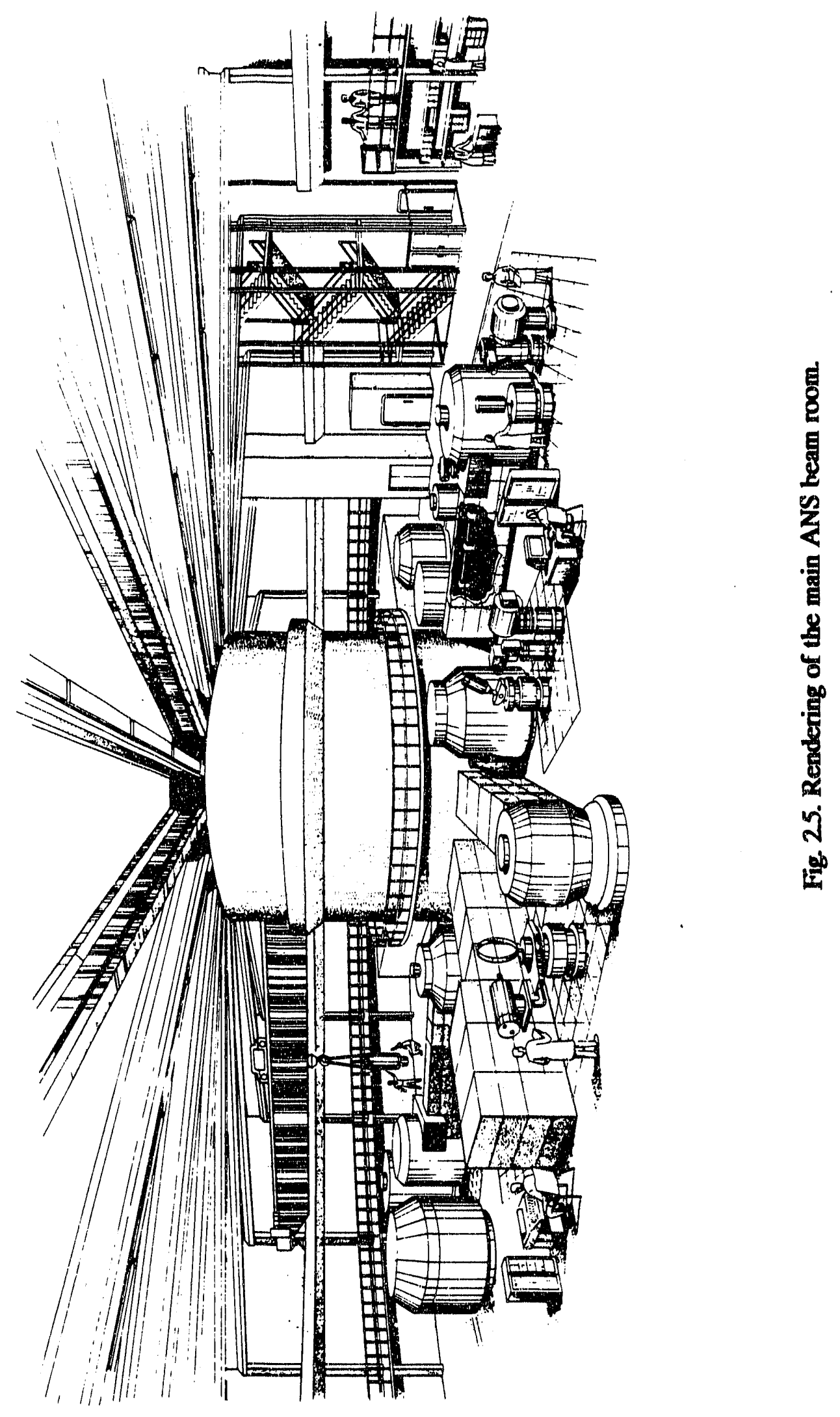


the sample; 38 instrument stations are provided for neutron scattering applications. Many of the scattering instruments are general purpose in nature and can be used by a wide range of scientific disciplines. Nuclear and fundamental physics instruments tend to be more unique in nature; some of these will be supplied by participating research teams from other organizations. Eight nuclear and fundamental physics instruments are envisioned. Two stations are provided for materials analysis: One is a cluster of small irradiation facilities in the guide hall used to analyze the contents of samples by measuring prompt gamma emissions upon bombardment with cold neutrons. The other is a depth profiling station on the second floor of the reactor building.

Irradiation facilities are provided both inside the reactor core regions and in the reflector. Neutron spectra with strong epithermal components are used to irradiate curium feed to produce heavy isotopes, especially ${ }^{252} \mathrm{Cf}$ and ${ }^{254} \mathrm{Es}$, for a variety of applications. Targets are assembled at the nearby Radiochemical Engineering Development Center (REDC) and are irradiated in the ANS. Irradiated targets are shipped back to the REDC, where the desired elements are extracted and the rest of the material is repackaged as feed. The ANS includes the facilities to receive, load, and irradiate the targets and to transfer the irradiated targets to a cask loading station for shipment back to the REDC.

Materials irradiation facilities also are proviced in the hard spectral regions near the core. The neutron spectrum in certain areas allows simulation of the radiation damage that would be encountered in the first wall of the fusion reactor. Material properties coupons are assembled into irradiation capsules (some provided with means to measure and control temperature) and are irradiated in the ANS reactor. The capsules then are moved to a set of hot cells, where the coupons are removed from the capsule and packaged for transport to a testing facility. The remaining capsule scrap is packaged for disposal. Gas circulation and instrument systems are provided for capsule monitoring and control, and a materials irradiation control station is provided in the main control area.

Several types of irradiation facilities are provided to use the thermal flux of the reflector region and, in some cases, to use the harder neutron spectrum close to the core. Two slant facilities are provided for irradiation of instrumented materials irradiation capsules in the reflector, just outside the core. Four hydraulic rabbit tubes are provided in the regions of the reflector that encounter high heating rates; these include epithermal tubes near the core and tubes located near the peak thermal flux in the reflector. A total of seven pneumatic tubes are provided farther out in the reflector, where heating rates are lower, and in the light water pool immediately outside the reflector. Four vertical irradiation positions also are located in the reflector.

The hydraulic rabbit tubes support both the transuranium isotope production program and the general medical and industrial isotopes production program. The vertical irradiation positions are provided for the production of larger quantities of medical and industrial isotopes. Pneumatic tubes are provided for activation analysis. Although specific facilities are provided for given programs, all facilities may be shared for other purposes.

Support for the reflector facilities includes loading and unloading systems for the slant and vertical irradiation facilities, and target storage, handling, and packaging facilities. Loading stations and supporting hydraulic or pneumatic systems are provided for the rabbit tubes. Two counting stations are provided for the activation analysis program: One, located inside the reactor building, is used for counting short-lived isotopes with minimal delay, and a larger facility is located in a low-radiation background area in the basement of the research support building.

Experiment support facilities also include a number of laboratories and shops. These are used for producing crystals for use as monochromators, for sample preparation activities, for the assembly of sample chambers, for the assembly and checkout of new instruments, and for the 
general maintenance of the experiment systems. Personnel support includes office groupings for the various instruments and irradiation programs and meeting rooms, an auditorium, a library, and food services for researchers using the ANS at all hours. A data networking and storage system also is provided. This system allows monitoring of instruments at remote locations in the office building or even at another site, provides communications to other computer networks, and provides for the safe storage of data. A data base has been developed to identify user needs and to serve as a basis for the design of laboratory, office, and other support facilities.

\subsubsection{Overvicw of the Reactor and Plant}

Figure 2.6 is an overall depiction of the reactor assembly. The reactor core at the center of the reactor assembly consists of two annular fuel elements (Fig. 2.7). The fuel is fully enriched $\mathrm{U}_{3} \mathrm{Si}_{2}$ clad with aluminum. Each element consists of hundreds of involute-shaped fuel plates spanning an inner and an outer sideplate. This fuel technology combines the successful designs of the HFIR and the Institut Laue Langevin (ILL) with the high-density fuel developed to operate existing research reactors with reduced enrichment fuels. Pressurized heavy water coolant flows up through the core. Each of the two elements has a different diameter so that each is cooled by a separate stream of heavy water. The coolant is fed through a core pressure boundary tube that encircles the fuel elements; this assembly then is surrounded by a low pressure heivy water reflector vessei. The entire reactor assembly is immersed in a light water pool. Fi'gure 2.6 shows some of the beam tubes and irradiation facilities that penetrate the reflector vessel.

The reactor is controlled by three hafnium control rods that enter the central hole of the fuel elements. The control rods normally are driven as a unit using drive motors beneath the reactor. Each of the three central rods is scrammed independently by the primary reactor protection system; any two are capable of shutting down the reactor for all design basis events. A completely independent set of eight safety rods is located in the reflector vessel. These rods are withdrawn hydraulically and inserted by a signal from the secondary reactor protection system. Any seven of the eight outer rods are capable of safely shutting down the reactor for all design basis events without any contribution from the central rods. The outer rods perform no control or shimming function.

Because the reactor is a heavy water system immersed in a light water pool, and because the spent fuel is stored in light water pools, the reactor must be refueled using a remotely-operated refueling apparatus that maintains separation between the reactor and pool water systems. The operating cycle for the ANS is based on 17 days of steady state operation at full power, followed by 4 days of refueling operations. Thus the reactor is restarted every 3 weeks. The reactor is designed for $80 \%$ availability (excluding infrequent major maintenance activities). Because of the need to schedule a large number of outside users, the predictability of operating cycles is as important as overall availability.

A full-scale mockup of key reactor assemblies is provided for training and component testing and for the development of remote systems recovery operations. A full-scope simulator is provided for operator training and for the simulation of reactor transients.

The reactor cooling systems are arranged to remove decay heat by natural circulation and to provide a number of other passive safety features. The four primary coolant loops (three of which are in use at any time) are elevates with respect to the core and are immersed in water-filled cells that can serve as a heat sink for $72 \mathrm{~h}$ after shutdown even with all secondary coolant lines isolated. The secondary loops also are elevated to allow natural circulation. The secondary tower water inventory is held in pool structures coupled to the reactor support building that are designed to survive the full range of postulated natural phenomena. The water inventory in these 


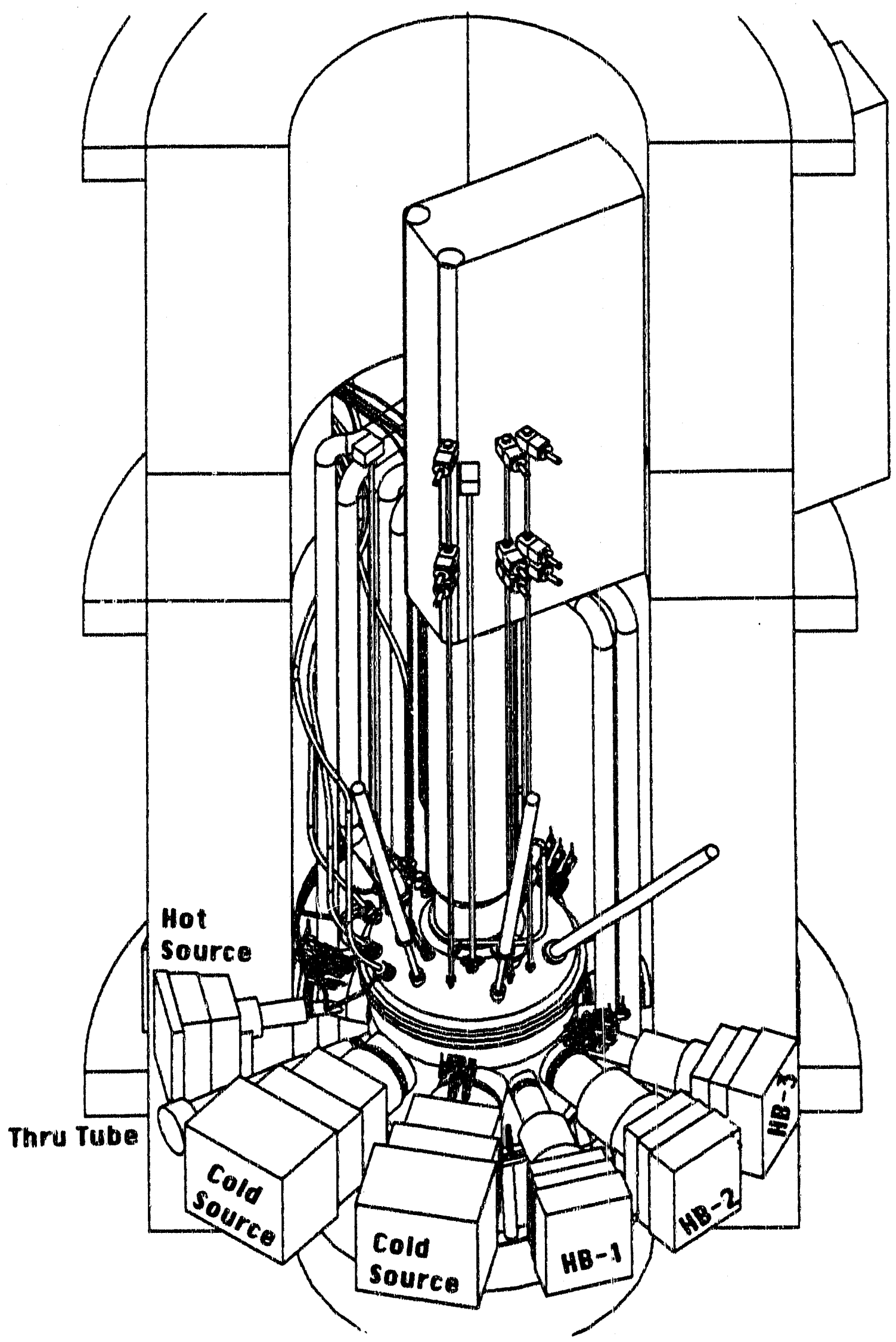

Fig. 26. Three-dimenasional view of the ANS resactor membly. 


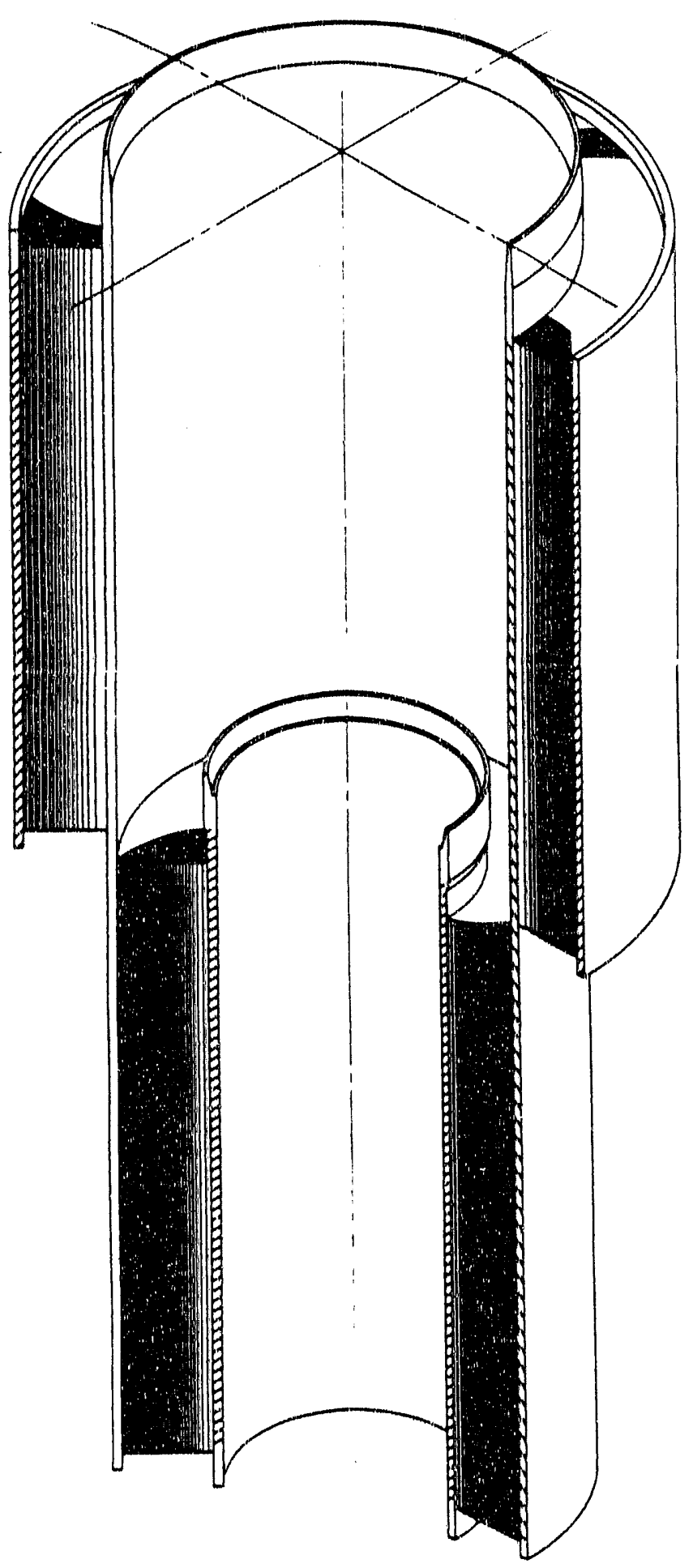

Fig. 27. General depiction of the ANS fuel element assemblies. 
pools is sufficient for storing decay heat through 30 days after reactor shutdown; the cooling towers and the rest of the secondary coolant piping thus are not required for reactor safety. Similar principles are followed in the design of the reflector coolant loops.

The ANS is provided with a dual containment system. Emergency planning zones have been laid out based on preliminary dispersion calculations for postulated severe accident conditions. The postaccident conditions in the ANS containment, which is large in relationship to reactor power and stored energy, are modest by comparison with power reactors. Evacuation zones can be kept entirely within the Oak Ridge Reservation.

Electrical power is brought to the candidate site via a new substation on an existing Tennessee Valley Authority (TVA) $161 \mathrm{kV}$ transmission line. By division of the line, two independent sources of power are provided, each fed from independent generating stations. A third line capable of supplying emergency power requirements is brought over from the Oak Ridge National Laboratory (ORNL) substation. Diesel generator sets also are provided. Divisional separation is maintained throughout the plant.

A heavy water detritiation and upgrading plant is provided to remove tritium from heavy water and to prevent the degradation of neutron flux due to the accumulation of protium. A modification of processes in use in France and Canada is provided, resulting in a tritium-free protium effluent. The recovered tritium is packaged for use in a variety of applications or for storage. Removal of tritium from the reactor heavy water systems reduces the potential for environmental releases of tritium as a result of spills or other occurrences.

Two $35 \mathrm{~kW}$ helium refrigeration plants are provided, one for each of the cold sources. The compressors are located in a building along the east wall of the reactor support building. The cold boxes are in the high bay of the reactor building; cryogenic lines feed gaseous helium at $5 \mathrm{~K}$ to the cold sources on the ground floor of the reactor building.

The ANS is provided with an integrated distributed control system. State-of-the-art signal collection, processing, and networking will be used to couple plant instrumentation with the processurs in the central control complex. The displays and panels of the control room are being designed with the participation of research reactor operators and human factors analysts. Networks from the control system aiso are routed to a secondary control room, a technical operations center, and other emergency centers at ORNL.

Waste systems are designed for tlexibility of operations to accommodate the changing nature of waste management operations on the Oak Ridge Reservation. Other services are supplied from central utility systems when available, or from dedicated systems at the ANS site. The ANS complex is provided with sufficient shops, operator training facilities, and general operator support facilities to enable efficient operation of the facility. Central shops and craft pools at ORNL are used for infrequent activities. An analysis of operations, maintenance, security, bealth physics, and other staff and support requirements has been documented in support of the ANS conceptual design.

\section{REACTOR}

\section{Resctor Syatem:}

Meeting the flux performance goals requires a reactor core producing many neutrons (a high fission rate and thus, for a research reactor, high power) in a small volume (thus compact dimensions). The high thermal flux must be produced in a region that is accessible to the beam tubes and of sufficient volume to accommodate a large number of beam tubes and irradiation 
facilities. The reactor design is to be based on known technology to reduce the technical risk and reduce the amount of $R \& D$ required to verify the design coucept. The core kinetics must be stable, and the reactivity coefficients for power, voiding, and other incidents must be negative. The reactor core design must meet the standards used by comparable licensed facilities, including safety margins for numerous parameters.

For these reasons, the ANS core design is based on the technology used at two existing high flux reactors: the HFIR at ORNL and the ILL at Grenoble, France. The core is a compact arrangement with two annular fuel elements. Because of the small size of the core relative to reactor power, the heat flux across the fuel plates and into the coolant is unusually high. The fuel is highly enriched $\mathrm{U}_{3} \mathrm{Si}_{2}$ mixed with aluminum powder and clad with aluminum. Aluminum has a high thermal conductivity and a relatively low neutron absorption cross section. It is particularly well suited as a material for low remperature reactors designed to produce thermal neutrons. The coolant, moderator, and reflector are all heavy water. Heavy water is an effective moderator, and it has a low absorption rate and a long diffusion length. These qualities result in a thermal flux peak in an accessible region of the reflector a short distance away from the fuel. It also results in a thermal flux profile across the reflector that does not fall off rapidly with distance from the core, and therefore in a large volume of useable flux. Because the fast neutron and gamma fluxes fall off more quickly, the outer volume of the reflector provides a particularly clean thermal neutron flux. Figure 2.8 shows the radial flux profile in the ANS, and Fig. 2.9 shows the axial flux profile at the radius of the peak thermal flux. Some of the key physics parameters of the ANS reactor are summarized in Table 2.1 .

The high power and compact dimensions of the ANS core lead to a high power density and a high heat flux at the surface of the fuel plates. Test loops have been constructed to measure the oxidation of the fuel plate and to verify correlations used for heat transfer and for the critical heat flux. Other research tasks have evaluated correlations for incipient boiling, flow instabilities, and other phenomena. A fuels development program has irradiated highly enriched silicide fuel to burnups that exceed the ANS operating conditions. Fission product retention and swelling characteristics have been shown to be excellent.

Because of the high power density and low operating temperature of the core, a large volume of water must flow between the plates. High coolant velocities also increase heat transfer coefficients. A preliminary test loop has been operated, and others are planned, to validate analytical methods that prove the stability of the thin fuel plates under ANS hydraulic conditions. A summary of the coolant conditions in the ANS is shown in Table 2.2.

The two fuel elements are constructed of 684 involute-shaped fuel plates that span an inner and outer aluminum sideplate. The involute shape provides a constant water gap thickness across the span of the plates. A plan view of the larger, upper fuel element, which has 432 fuel plates, is given in Fig. 2.10. A plan view of the lower fuel element, with 252 plates, is given in Fig. 2.11. The fuel meat is a mixture of crushed $\mathrm{U}_{3} \mathrm{Si}_{2}$ powder and pure aluminum powder, graded in both the radial and axial directions to tailor power profiles in the core. The clad and fuel element structure is made of 'Type 6061 aluminum. The fuel powders are placed in a frame of aluminum, and the clad is welded to both sides. The plates then are hot-rolled to the design thickness and pressed on a die to form the involute shape. This produces a bonded cermet structure (not a melt) in the fuel meat region and ensures a good bond between the fuel and the clad. Extensive measurements are made to ensure the proper fuel distribution, thickness, bonding, and other parameters. A detail of a fuel plate, exaggerated in thickness, is shown in Fig. 2.12. 


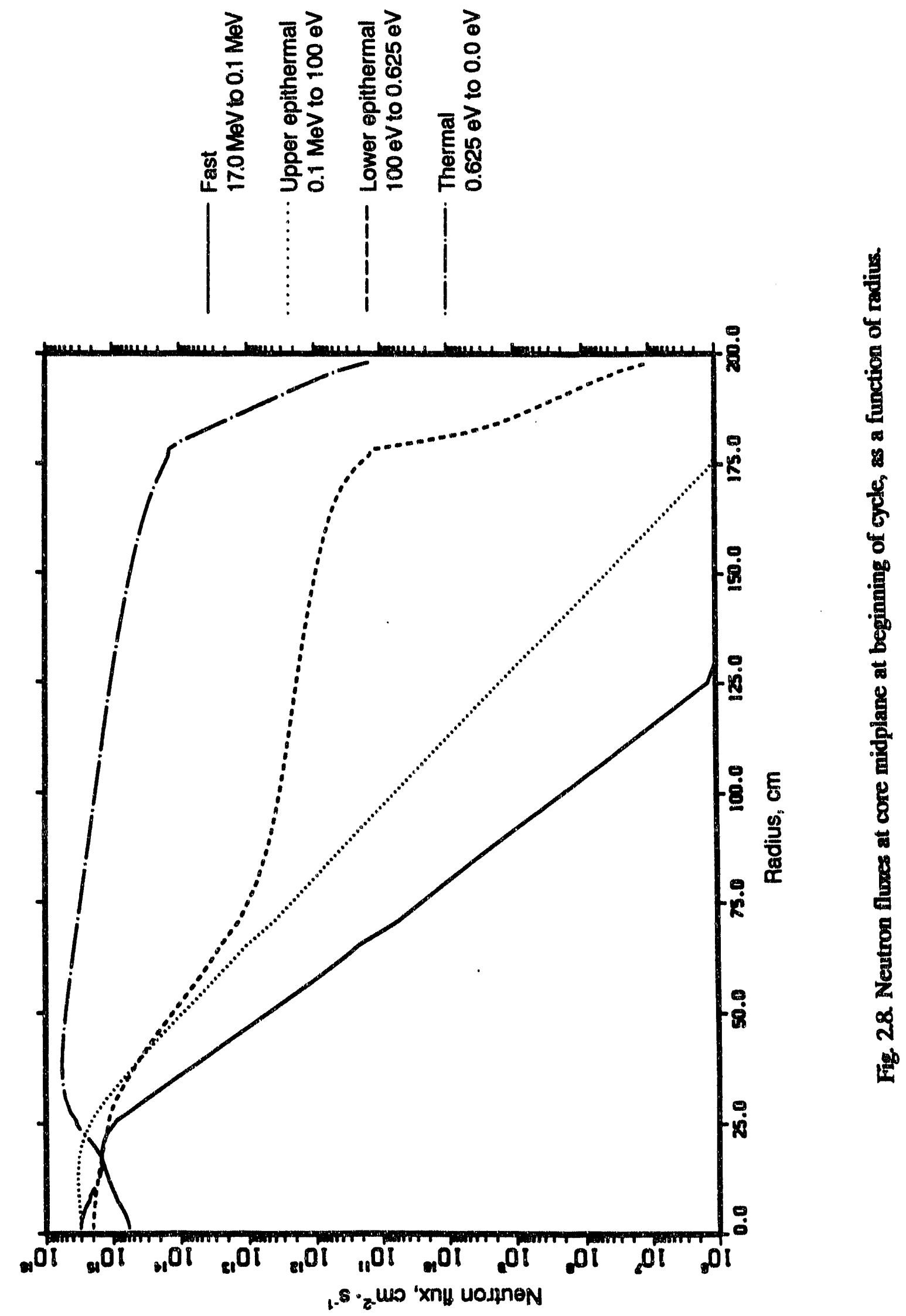



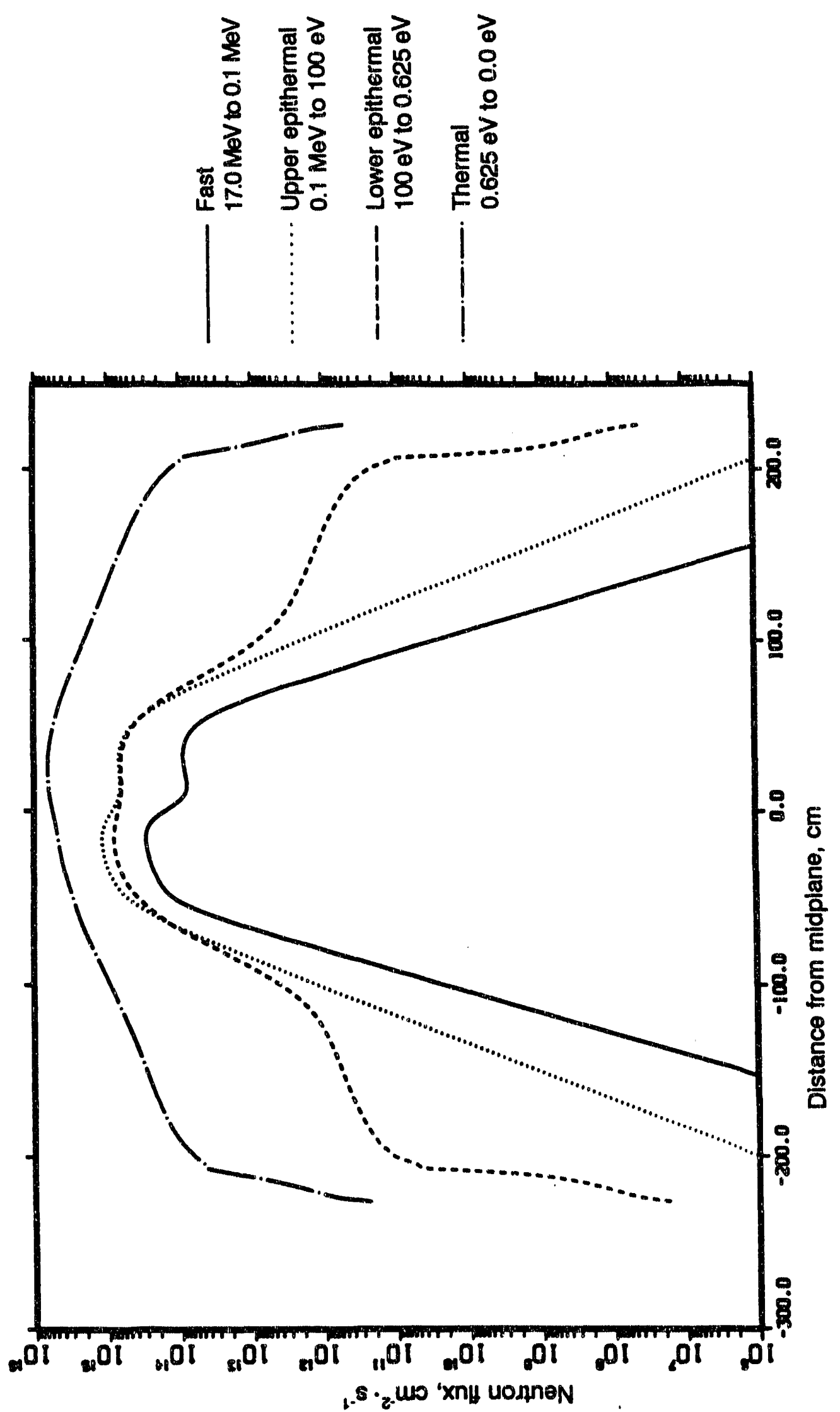

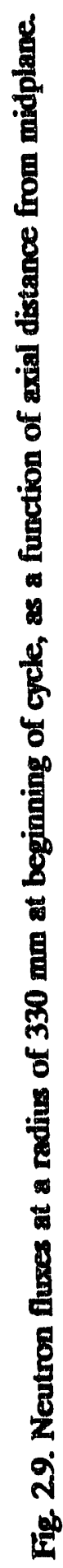


Table 21. Key reactor physics parameters

\begin{tabular}{|c|c|}
\hline Parameter & $\begin{array}{c}\text { Reference } \\
\text { value }\end{array}$ \\
\hline \multicolumn{2}{|l|}{ Reactor power } \\
\hline MW (deposited in fuel plates and fuel structure) & 303 \\
\hline MW (fission) & 330 \\
\hline Core life (full power days) & 17 \\
\hline Core average thermal power density (MW/L) & 4.5 \\
\hline \multicolumn{2}{|l|}{ Core peak-to-average thermal power ratio } \\
\hline Beginning of cycle (BOC) & 2.31 \\
\hline Midcie of cycle (MOC) & 2.12 \\
\hline End of cycle (EOC) & 1.78 \\
\hline Delayed neutron fraction & 0.008 \\
\hline Prompt neutron lifetime (msec) & 0.5 \\
\hline \multicolumn{2}{|l|}{ Peak reflector thermal flux } \\
\hline $\mathrm{BOC}\left(\mathrm{m}^{-2} \mathrm{~s}^{-1}\right)$ & $7.19 \times 10^{19}$ \\
\hline $\operatorname{EOC}\left(\mathbf{m}^{-2} \mathrm{~s}^{-1}\right)$ & $7.40 \times 10^{19}$ \\
\hline Flux efficiency at EOC $\left(\mathrm{m}^{-2} \mathrm{~s}^{-1} \mathrm{MW} \mathrm{f}_{\mathrm{i}}^{-1}\right)$ & $2.24 \times 10^{17}$ \\
\hline Maximum excess reactivity (pcm) ${ }^{\circ}$ & $31,070(26.7 \% \Delta \mathrm{k} / \mathrm{k})$ \\
\hline Core fissile loading at $\mathrm{BOC}\left(\mathrm{Kg}^{25} \mathrm{U}\right)$ & 15.1 \\
\hline Fuel burnup $\left(\mathrm{Kg}_{\mathrm{g}}{ }^{25} \mathrm{U}\right)$ & 7.0 \\
\hline \multicolumn{2}{|l|}{ Core burnable poison loading } \\
\hline $\mathrm{BOC}\left(\mathrm{g}{ }^{10} \mathrm{~B}\right)$ & 13 \\
\hline $\mathrm{EOC}\left(\mathrm{g}^{10 \mathrm{~B}}\right)$ & $<.06$ \\
\hline
\end{tabular}


Table 22. Primary and secondary coolant parameters

\begin{tabular}{lll} 
Parameter & SI units & Alternate units \\
& & \\
\hline Core inlet temperature & $45^{\circ} \mathrm{C}$ & $113^{\circ} \mathrm{F}$ \\
Active core bulk outlet temperature & $85^{\circ} \mathrm{C}$ & $185^{\circ} \mathrm{F}$ \\
Hot leg return temperature & $81^{\circ} \mathrm{C}$ & $178^{\circ} \mathrm{F}$ \\
Primary coolant flow rate: & & \\
Total (through pump) & $2.01 \mathrm{Mg} / \mathrm{s}$ & $29,100 \mathrm{gal} / \mathrm{min}$ \\
Through active core (fuel) & $1.83 \mathrm{Mg} / \mathrm{s}$ & $26,500 \mathrm{gal} / \mathrm{min}$ \\
Vessel gap and island & $0.18 \mathrm{Mg} / \mathrm{s}$ & $2,600 \mathrm{gal} / \mathrm{min}$ \\
Reactor assembly inlet pressure & $3.5 \mathrm{MPa}$ & $508 \mathrm{psia}$ \\
Fuel inlet pressure & $3.2 \mathrm{MPa}$ & $464 \mathrm{psia}$ \\
Reactor assembly outlet pressure & $1.69 \mathrm{MPa}$ & $245 \mathrm{psia}$ \\
Core pressure drop: & $1.51 \mathrm{MPa}$ & $219 \mathrm{psia}$ \\
Core power: & & \\
Fission & $330 \mathrm{MW}$ & $1.13 \times 10^{9} \mathrm{Btu} / \mathrm{h}$ \\
Thermal power in active core & $303 \mathrm{MW}$ & $1.03 \times 10^{9} \mathrm{Btu} / \mathrm{h}$ \\
Heat carried by primary coolant & & \\
Core power to primary coolant & $316 \mathrm{MW}$ & $1.08 \times 10^{9} \mathrm{Btu} / \mathrm{h}$ \\
Pump power to primary coolant & $5.2 \mathrm{MW}$ & $1.77 \times 10^{7} \mathrm{Btu} / \mathrm{h}$ \\
Flow rate & $25 \mathrm{~m} / \mathrm{s}$ & $82 \mathrm{ft} / \mathrm{s}$ \\
Primary loop design temperature & $100^{\circ} \mathrm{C}$ & $212^{\circ} \mathrm{F}$ \\
Primary loop design pressure & $4.0 \mathrm{MPa}$ & $580 \mathrm{psi}$ \\
Primary pD & $4.5-4.9$ & $4.5-4.9$ \\
Maximum primary tritium concentration & $185,000 \mathrm{MBq} / \mathrm{L}$ & $5 \mathrm{Ci} / \mathrm{L}$ \\
Maximum primary protium concentration & $0.2 \mathrm{at} \% \%$ & $0.2 \mathrm{at} \%$ \\
Secondary supply temperature & $29.4^{\circ} \mathrm{C}$ & $85^{\circ} \mathrm{F}$ \\
Secondary return temperature & $46^{\circ} \mathrm{C}$ & $115^{\circ} \mathrm{F}$ \\
Secondary coolant flow rate & $4.96 \mathrm{~m} / \mathrm{s}$ & $78,600 \mathrm{gal} / \mathrm{min}$ \\
Secondary maximum operating pressure & $446 \mathrm{kPa}$ & $64.7 \mathrm{psia}$ \\
\hline
\end{tabular}

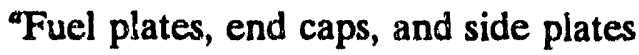




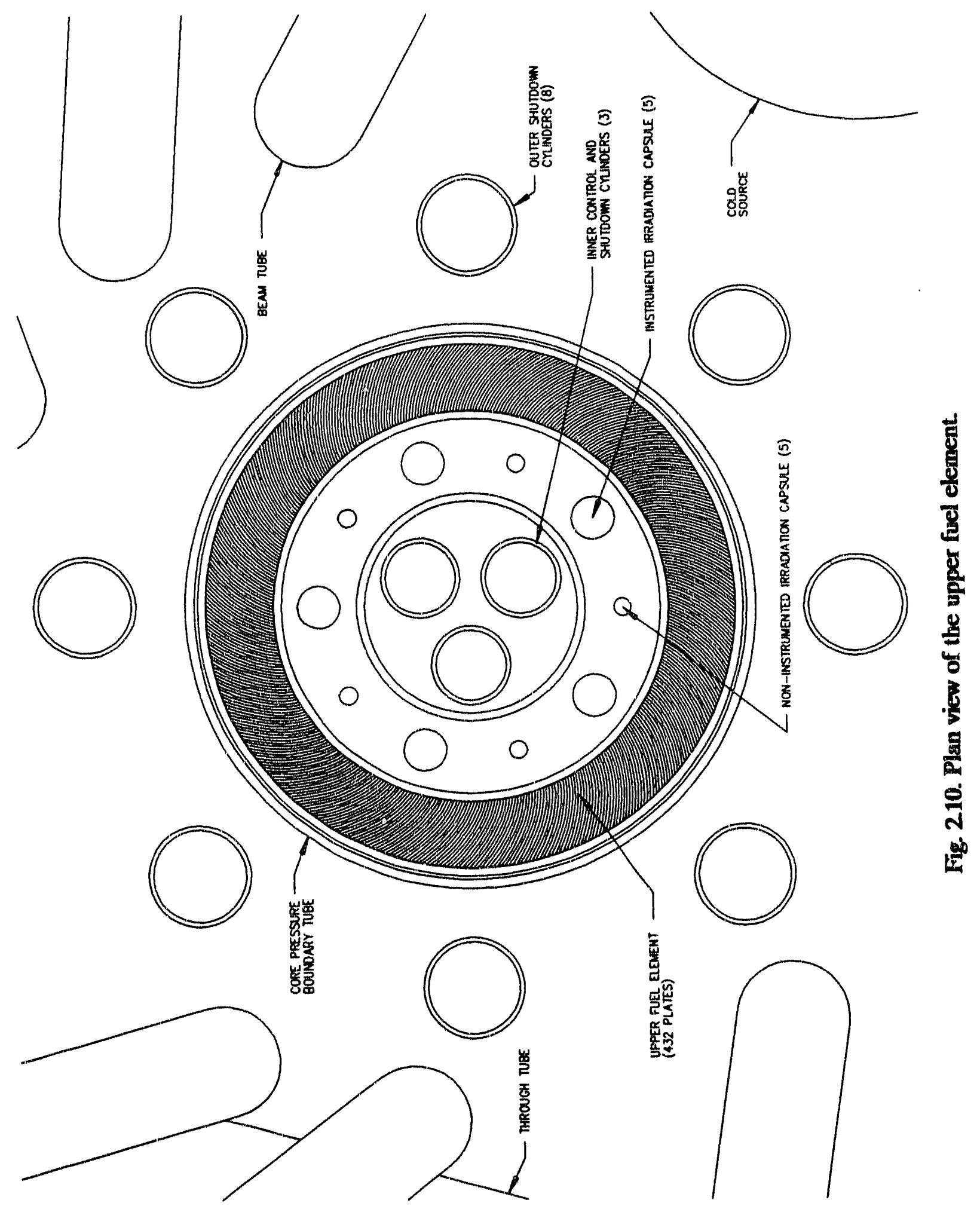




\section{$2 \cdot 19$}

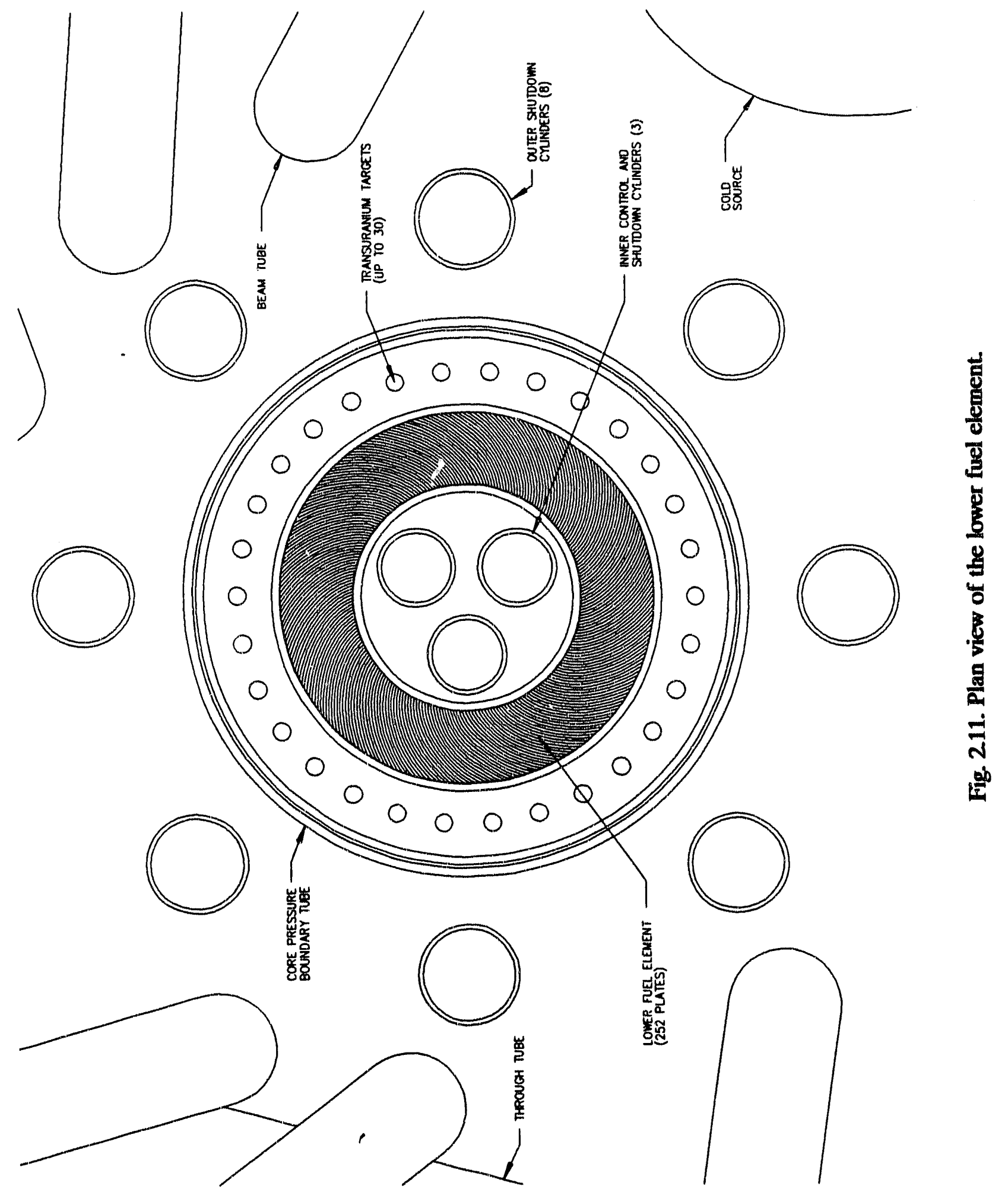




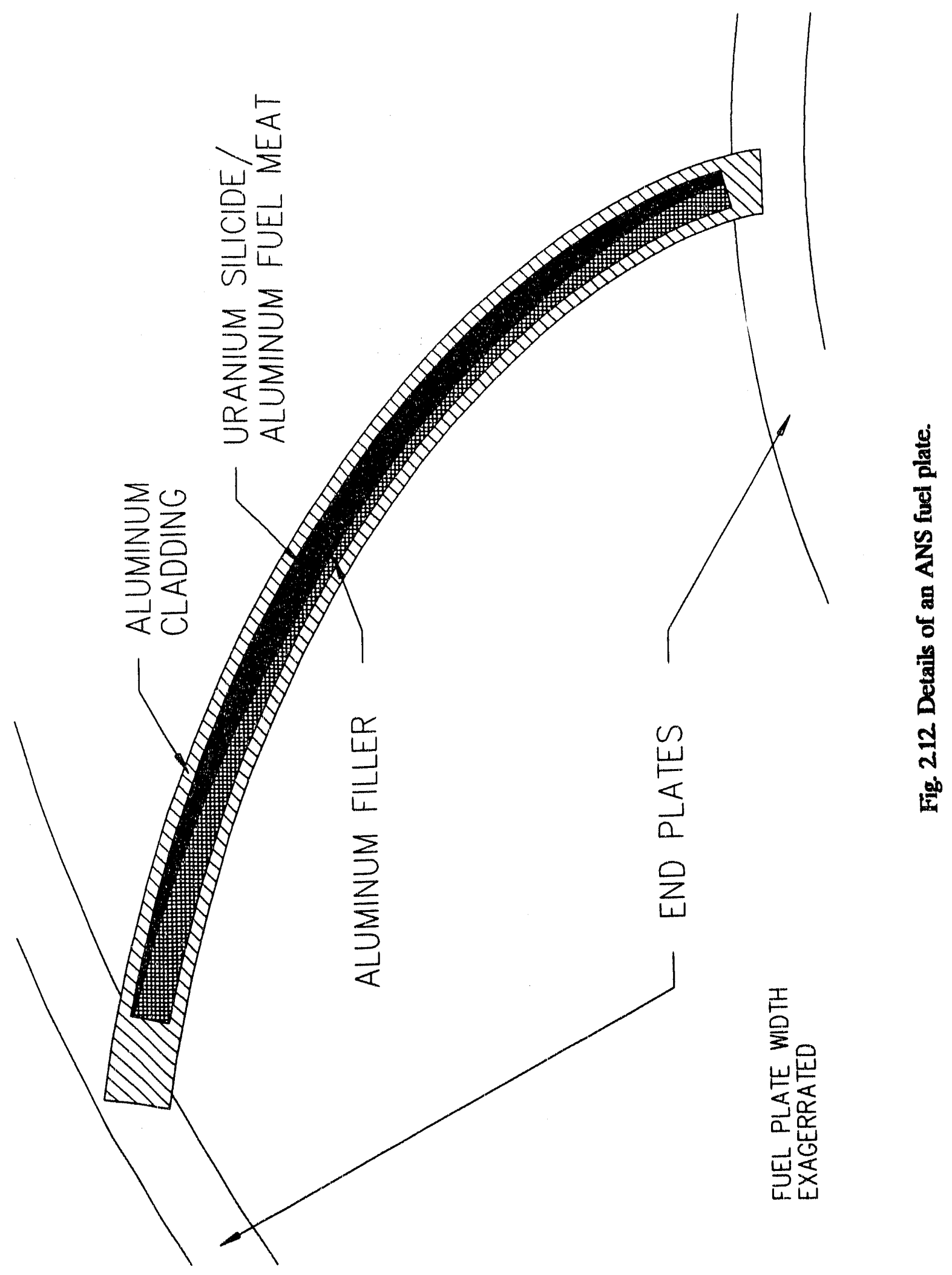


The fuel plates are placed into axial grooves cut into the inside of the outer sideplate and the outside of the inner sideplate. Circumferential grooves are cut on the outer sides of the sideplates, intersecting the axial grooves. A weld is made around the circumferential grooves. This welds the fuel plates into the sideplates at the intervals of the circumferential grooves.

Boron is placed in bands at the top and bottom of the fuel plates in the same manner as the fuel meat. This provides a burnable poison, controlling much of the excess reactivity through the fuel cycle. The location at the ends of the fuel also reduces power peaking from the high thermal flux outside the fuel at these locations.

An elevation view of the reactor assembly is shown in Fig. 2.13. The main features of the reactor assembly include the primary coolant pressure boundary components; the reflector vessel; the central control rods; and the various experiment, refueling, and maintenance penetrations into the reactor assembly. The penetrations in the upper reflector vessel head are shown in Fig. 2.14, and the beam tubes and other facilities at reactor midplane are shown in Fig. 2.15.

The pressurized heavy water coolant flows up through the core. This allows a transition to natural circulation modes of decay heat removal without flow reversal. Four separate cold legs enter the primary coolant supply vessel at the bottom of the reactor assembly. The flow proceeds through a core pressure boundary tube assembly around the fuel elements and then is turned around the refueling access hardware above the reactor and leaves through a single hot leg.

Because the primary coolant pressure boundary components ahead of the core have the greatest importance to reactor safety, they are provided with redundant safety features. The primary coolant supply vessel and the four lines entering the vessel are surrounded by a pressure skirt that spans between the bottom of the reflector vessel and the pool liner and is supported by the reflector vessel supports. This skirt limits the water losses in the event of a mechanical failure in the primary supply vessel hardware. The supply lines are of a reduced diameter and are arranged to restrict the rate of change of flow through the core should a failure occur in the inlet pipes. The core pressure boundary tube is a double-walled structure, as shown in Fig. 2.16. The inner core pressure boundary tube, which also serves as a core support, is normally in slight compression and thus not subject to crack propagation. The outer core pressure boundary tube norrnally carries the pressure load. Orifices allow sufficient coolant to flow between the two structures. The inner core pressure boundary tube is designed to maintain the primary coolant pressure and flow, under emergency load conditions, should the outer tube fail. The orifices between the two are sized so that if the outer tube fails completely, coolant flow and pressure in the inner tube are adequate to cool the core. The core pressure boundary tube components will be replaced on a regular basis because of the accumulation of radiation damage effects at locations close to the core. Two piston ring type seals are used at the attachment of the outer core pressure boundary tube to the primary coolant supply vessel. A traditional face seal is used at the top of the outer core pressure boundary tube. Metallic seals are used throughout the reactor assembly.

The reflector system is maintained at a low pressure, just above the static pressure produced by the pool water. A significant fraction of the reactor heat is deposited in the reflector heavy water and in the metal components inside the reflector. The reflector water is circulated through loops similar to those in the primary coolant system. The flow enters through a distribution network at the bottom of the reflector vessel and exits through the vessel head. Many of the individual components in the reflector vessel, such as the beam tubes, require enhanced cooling provisions. Cooling shrouds are placed around the beam tubes. Reflector water enters each shroud through an opening at the beam tube nose and is collected and returned to the reflector 


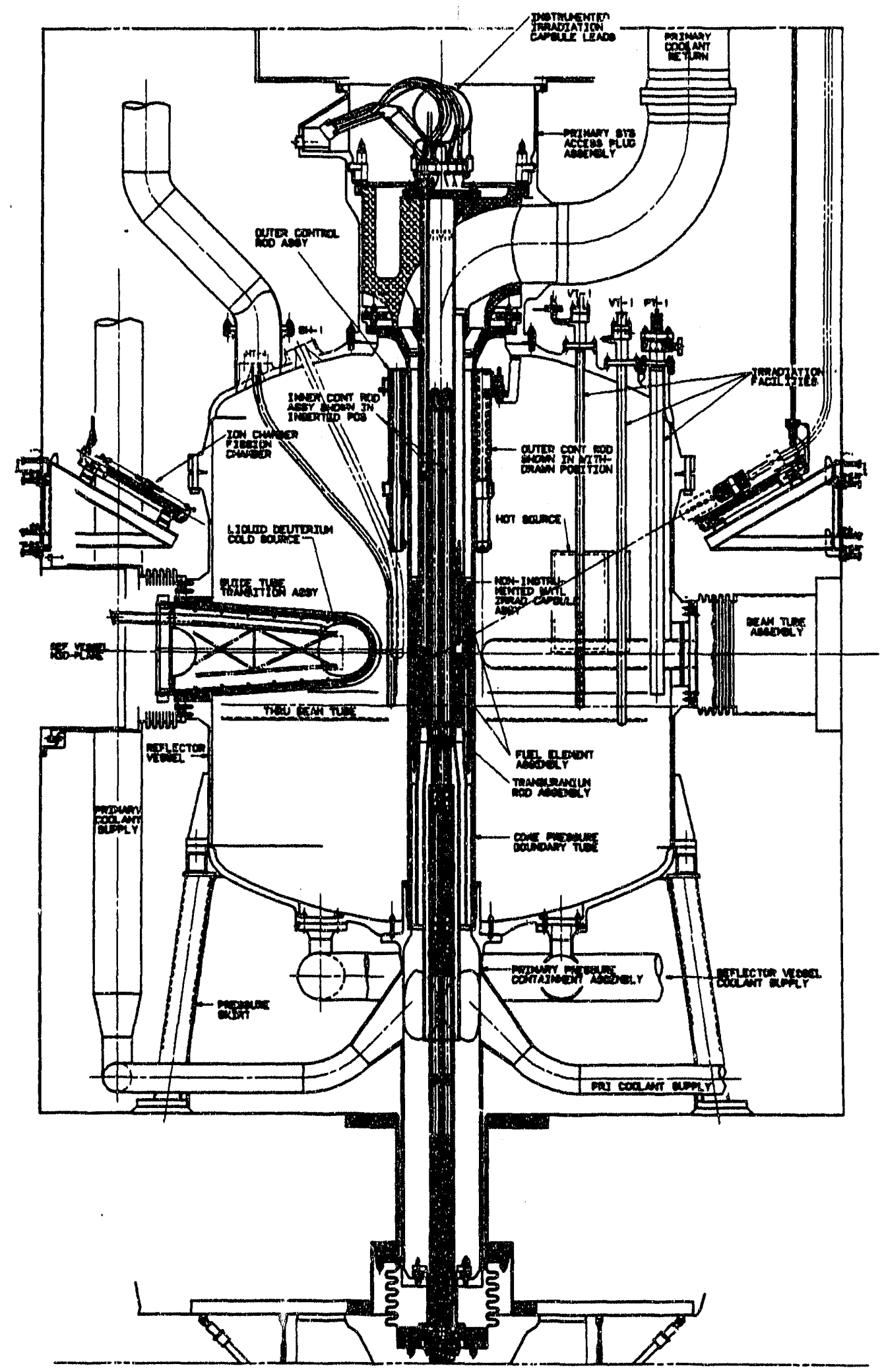

Fig. 213. Section through the resctor assembly. 


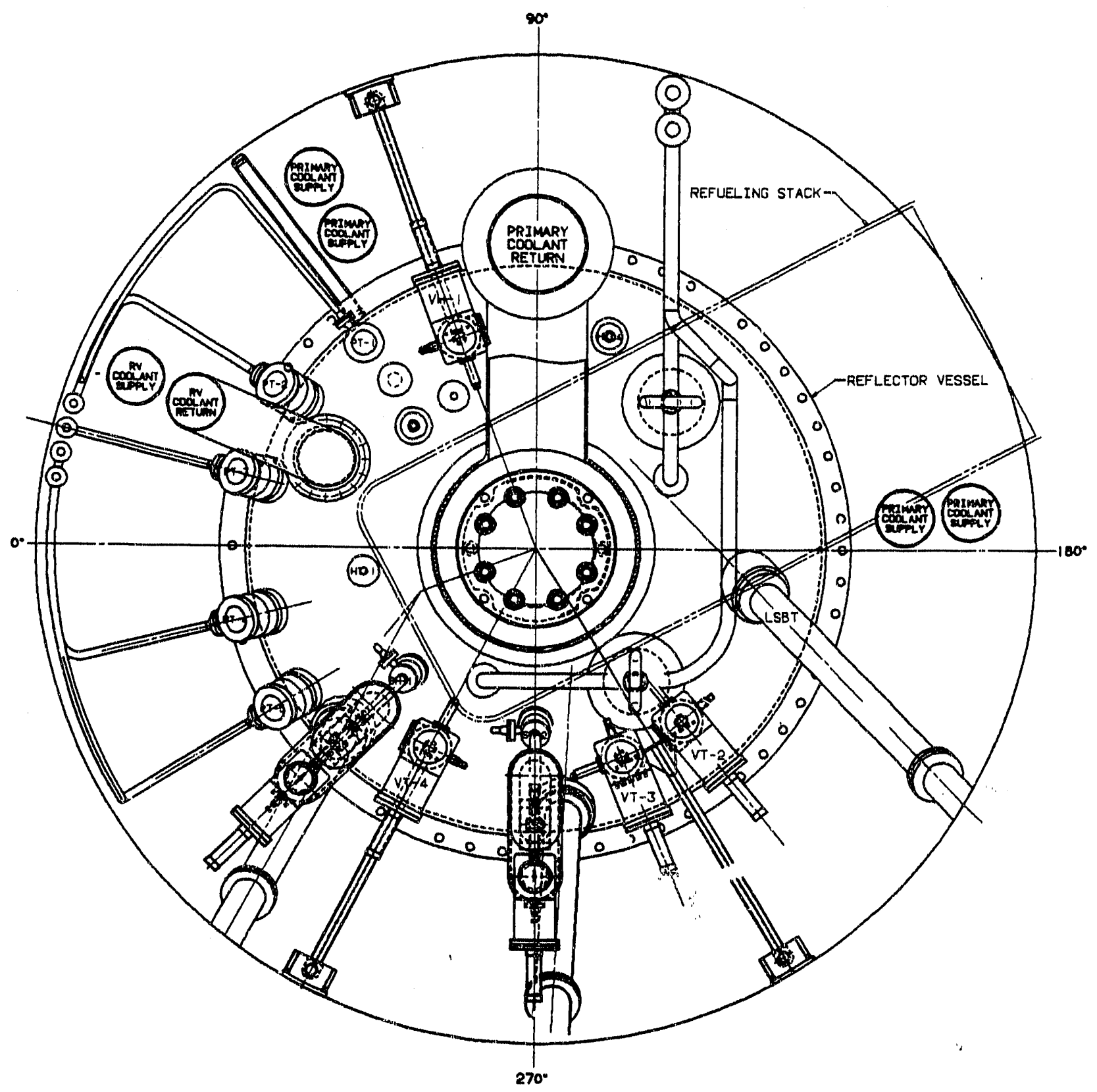

Fig. 214. Plan view showing penetrations in the reflector vessel upper head. 


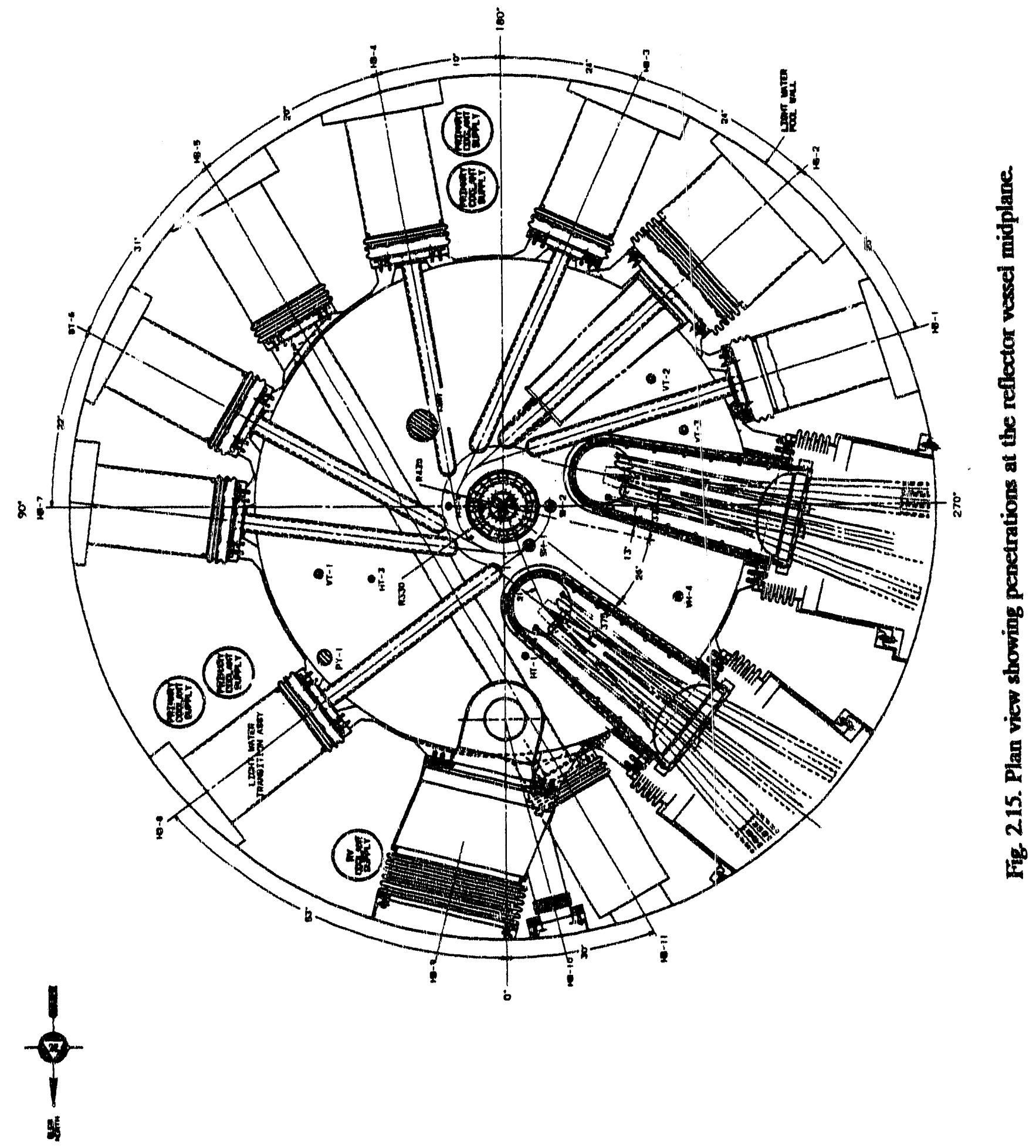




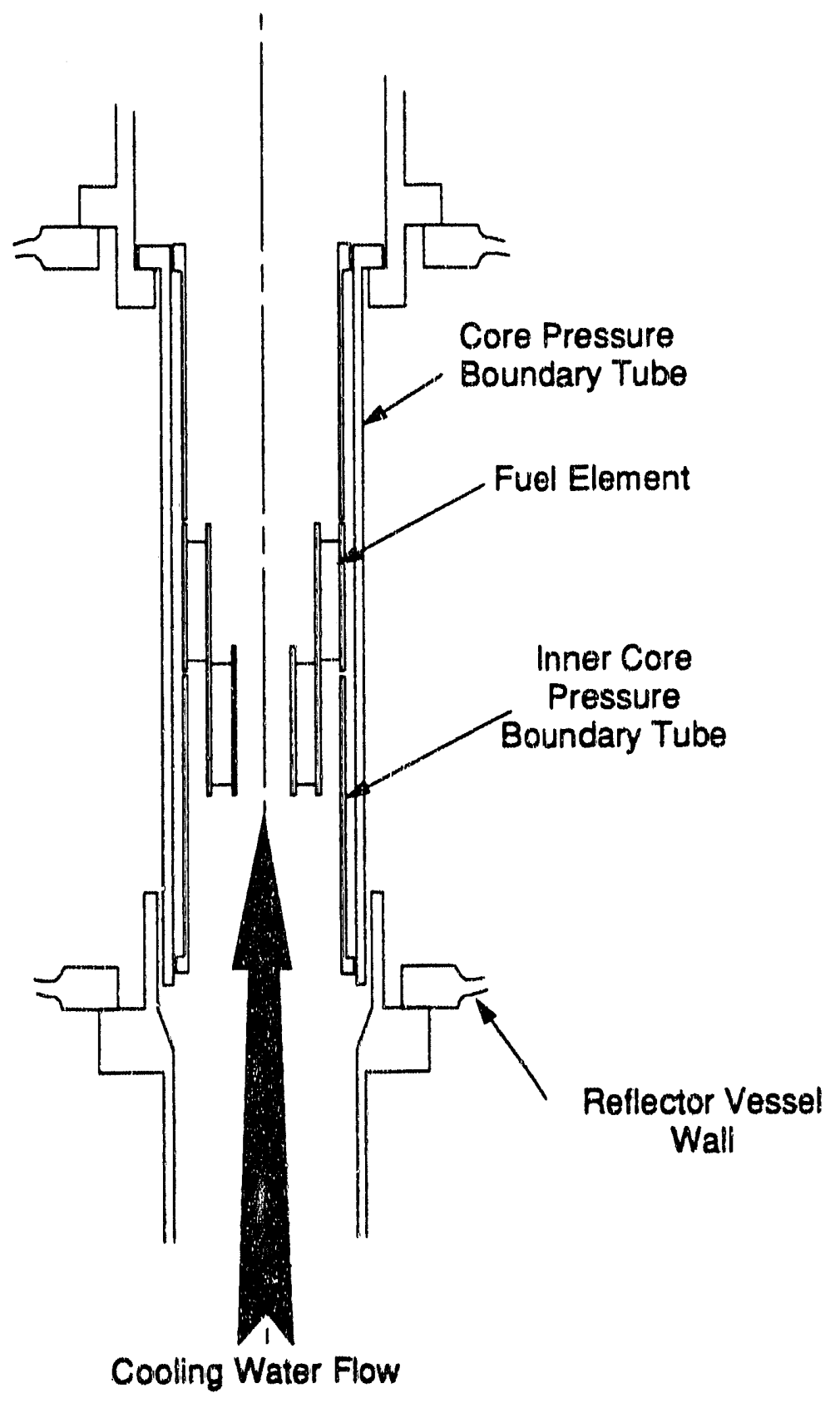

Fis. 216. Features of the ANS core presure boundary tube. 
system through a collection system designed into the outer flange boss. Many of the irradiation systems are provided with internal flow loops to cool the irradiation target or capsule; this flow also cools the irradiation facility structure.

The reflector vessel provides the mechanical integration of the reactor assembly. The entire reactor assembly is supported by the reflector vessel support. Because of the piston ring type seal at the bottom of the core pressure boundary tube, the primary pressure boundary is restrained by the reflector vessel assembly. 'Thus, the reflector vessel carries the loads created by the pressurization of the primary system, and the differential pressure across the core. These functions are considered in the design and safety classification of the reflector vessel.

\section{Reactor Control}

The reactor control system consists of a set of primary control and shutdown rods in the center of the reactor; a set of secondary shutdown rods in the reflector; nuclear instrumentation; primary and secondary shutdown systems; experiment protection systems; and control functions in the plant control and data acquisition systems (PCDAS).

The primary control rods are the mechanical assembly seen in the center of the reactor assembly in Fig. 2.13 and in the plan views of the core given in Figs. 2.10 and 2.11. The control absorbers are cylinders of hafnium supported on aluminum structures. The rods are driven from teneath the reactor assembly by electric motors located in the subpile room. Each of the rods is scrammed independently and is actuated when the primary reactor shutdown system interrupts the current to the magnets. Acceleration springs ensure a rapid initial insertion rate, and deceleration springs and shock absorbers safely stop the rods at the end of their motion. The scram and power level control systems are completely independent of each other.

The control functions are divided into a limited stroke regulating drive function, automatically controlled by a servo, and a shim drive system. The maximum design speed of the regulating motion is $15 \mathrm{~mm} / \mathrm{s}$, corresponding to $0.5 \% \Delta \mathrm{k} / \mathrm{k} \cdot \mathrm{s}$. The total reactivity worth of the regulating stroke is limited to $0.8 \% \Delta \mathrm{k} / \mathrm{k}$, corresponding to a $24 \mathrm{~mm}$ total stroke. The withdrawal rate of the shim drive is $7.5 \mathrm{~mm} / \mathrm{s}$ or slower, corresponding to a reactivity withdrawal rate of $0.25 \% \Delta \mathrm{k} / \mathrm{k} \cdot \mathrm{s}$. The shim system also is provided with a non-reversible air motor for runback.

The secondary rods use boron absorber cylinders; this limits the heat generated in the rods, including decay heat generated after reactor shutdown. The secondary shutdown rods serve as safety and shutdown rods only and perform no power control functions. The eight rods normally are held fully withdrawn by a flow of heavy water through the hydraulic piston system. When the flow is released through a valve by the secondary reactor shutdown system, the absorber cylinders are driven by springs and by gravity to their fully inserted position. The acceleration springs are provided to increase the insertion rate of the secondary rods.

Fission chambers are used for startup range operation and ion chambers for power range operation. Because of the high flux inside the reflector, these instruments are located in the light water pool outside the reactor. Gamma detectors are coupled with the neutron detectors to detect unanticipated changes in neutron attenuation in the pool. Four sets of power range ion chambers are located about $90^{\circ}$ apart just above the horizontal centerline of the reactor assembly. Mechanical drives are provided to adjust the distance between the ion chambers and the reflector vessel, compensating for different power levels by varying the amount of light shielding water between the reactor and the detectors.

The primary reactor shutdown system provides scramming action to the independent magnets that release each of the three absorber cylinders. The primary reactor shutdown system is composed of four redundant, independent instrument channels that are polled in logic circuitry to 
release the scram latches when any two of the four channels indicate that a protection parameter has exceeded its set point. The secondary reactor shutdown system provides scramming action to the eight outer rods by opening valves on the hydraulic system that holds the rods in their withdrawn position. Upon loss of pressure, both the primary and secondary systems send signals to the primary circulation pumps to trip the pumps to pony motor flow levels. Each channel of the protection system consists of independent sensors, cables, logic networks, and actuators. Both systems include provisions for on-line testing of the channels and for bypassing a failed channel.

An experiment protection system reduces reactor power if experiment parameters exceed their set points. This system covers the irradiation facilities, cold sources, and hot source. Protection systems also are provided for reactor secondary coolant isolation, beam tube isolation, and reflector coolant isolation.

Normal control of the reactor is a function of the central PCDAS, which is part of the plant instrumentation, control, and data system. Signals from the reactor protection systems are used by the PCDAS; isolation devices are used to maintain the independence of the protection systems.

\section{Refueling and Maintenance}

Because the ANS reactor is cooled and reflected with heavy water, but is immersed in a light water pool, an automated refueling system is used to maintain the boundary between light and heavy water. The major features of the refueling system are shown in Fig. 2.17.

The major components of the refueling system are a stack that extends from the top of the reactor assembly to the top of the reactor pool, a transfer cell, and a tunnel that reaches horizontally from the refueling stack to an area underneath the transfer cell. The stack and tunnel are filled with heavy water, and the transfer cell is provided with a dry, controlled atmosphere system. A water transfer lock is located at the bottom of the tunnel beneath the refueling cell.

The refueling system is used to disassemble the components at the top of the reactor assembly, to move spent fuel out of the reactor, to place fresh fuel in the reactor, and to reassemble the reactor components. It is also used to replace reactor components, including the core pressure boundary tube and the outer shutdown rod array, that must be replaced periodically because of radiation damage. Portions of the stack act together with other dedicated equipment for the removal of the inner control rod assembly.

During a normal refueling, the materials irradiation target assembly, the closure elbow, and a load stack assembly are removed from the reactor and set aside in a storage area of the tunnel to allow access to the fuel elements. A remote bridge hoist system with a set of custom tool heads is used to remove components from the reactor assembly. Each tool head is designed to mate with a single component only. Once access is gained to the upper fuel element, a neutron absorber is locked onto the element. The element is then raised into a second, outer absorber and moved up the stack and through the tunnel. When physical constraints allow, the dimensions of the heavy water-filled structures are limited so that the elements do not have sufficient moderator for criticality to occur, even without the absorbers. The fuel is moved through a lower, narrower portion of the tunnel; however, the stack must be wide enough for the outer shutdown rod assembly, and thus the absorbers are relied upon for criticality safety in that area. Either fuel element would achieve criticality in infinite heavy water, without absorbers; but both elements are subcritical in any light water configuration. Criticality control features are designed for fresh fuel; this allows for removal of a core at any time due to some unforeseen conditions. Fuel is held for decay of fission products (and thus heat generation rates) in a storage area of the tunnel, under the transfer cell, for two reactor cycles. At the end of the second cycle, the spent fuel is placed in the transfer lock under the tunnel. The lock is closed and purged with light water. The 


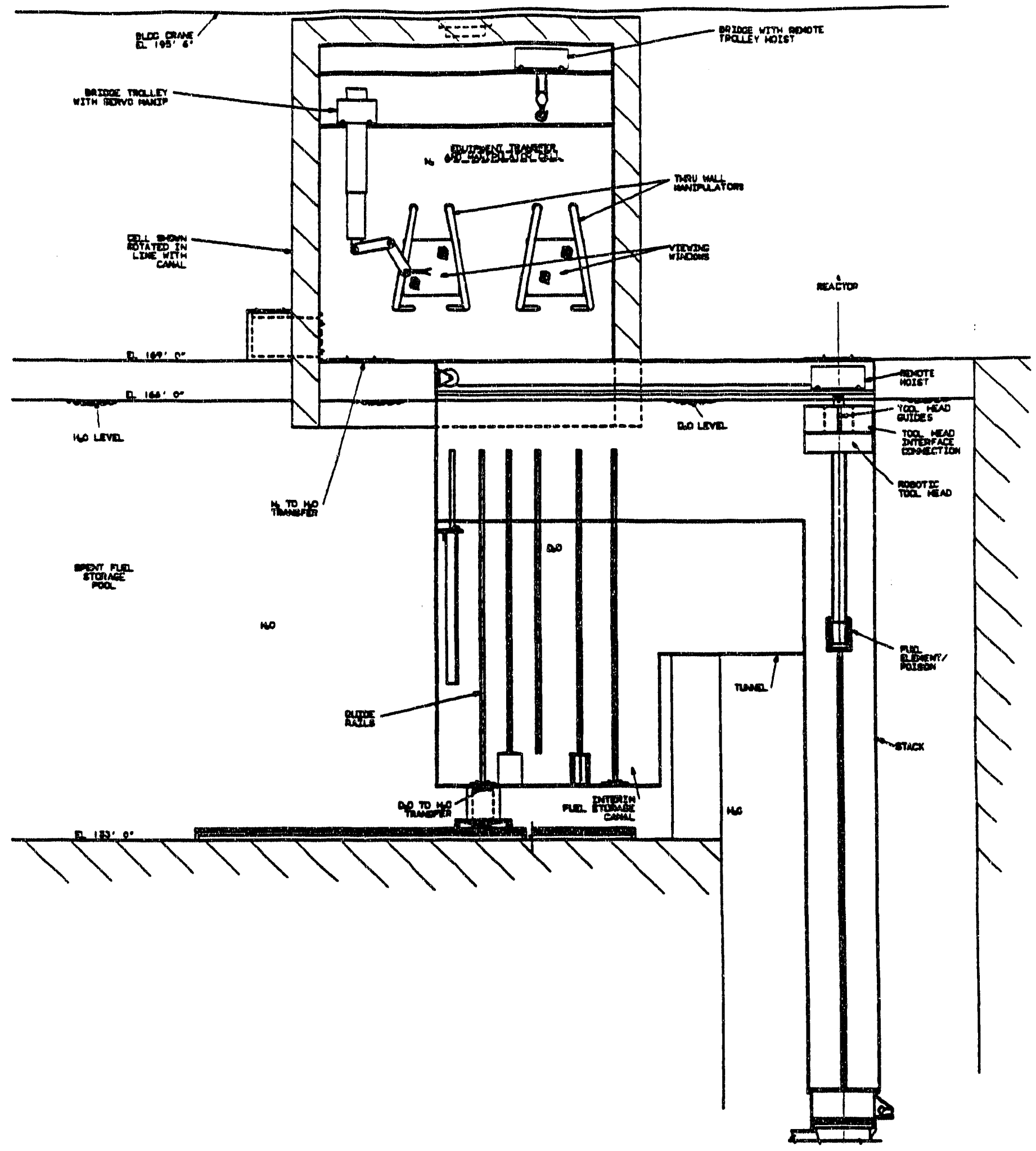

Fig. 217. Section through the refueling stack and tunnel and the refueling cell 
downgraded water is sent to the detritiation and upgrade plant for recovery. Once purged, the lock device is moved to a position in the light water pool, and the fuel is removed into a storage position in the pool. Irradiation targets and reactor components are lifted out of the heavy water into the transfer cell, held to dry, and then lowered through a hatch directly into the light water pool.

Fresh fuel is moved directly from the reactor high bay into the transfer cell. The absorbers are attached, and it is lowered into the tunnel. From here, placement of the fresh fuel and reassembly of the reactor is the inverse of the unloading steps. New seals are placed on the reactor components while the fuel is being handled; in some cases, two components are used so that seals can be placed in advance, reducing the overall time of the refueling operation.

Storage for 2 years of spent fuel inventory is provided inside the reactor building. After 2 years, fuel is transferred through a water lock to a cask loading station in a fuel handling area of the reactor support building. It is assumed that spent fuel later will be shipped to Savannah River, as is fuel from the HFIR. Additional storage capacity is provided in the fuel handling area in case unforeseen circumstances delay the spent fuel shipments.

Tool heads are also provided for handling the core pressure boundary tube components and the outer shutdown rod assemblies. Fuel must be removed prior to disassembly of the core pressure boundary tube, which in turn must be removed prior to removal of the shutdown rod assemblies. The outer core pressure boundary tube is the longest component handled by the refueling system. Tooling for the outer shutdown rods includes devices to disconnect the hydraulic system, as well as tooling to grapple the system hardware.

The inner control rods are removed using a cask that attaches to the top of the refueling stack. Some of the lower components of the inner rod drive assemblies are removed through the subpile room. The reactor must be drained before the lower drive assemblies (but not the control rods themselves) can be removed.

The entire reactor assembly is designed for replacement during infrequent major maintenance outages. All components are designed for access from above, using remote tooling. The reflector and the portion of the primary coolant system in the reactor pool can be drained, dried, and reflooded with light water. This allows major reactor overhauls to take place using standard water pool maintenance techniques. The stack and tunnel inside the reactor pool are designed to be removable so that the entire reflector vessel can be lifted out and replaced. Materials irradiation tests are under way to obtain firm estimates of component lifetime under ANS conditions.

\subsection{Reactor Cooling}

The ANS reactor cooling systems are designed to be highly reliable, and they incorporate a number of passive and inherent safety features. The overall features of the ANS cooling systems are shown in Fig. 2.18. Primary heavy water coolant flows through three of four independent loops; the fourth loop is an isolated spare. Reliability and availability studies have shown that three loops meet reliability goals, and that the capability of holding a loop out of service is necessary to meet availability goals. The primary coolant pump motors are backed up by batterypowered pony motors capable of providing $10 \%$ of the normal flow. Coolant flows up through the core, and the primary coolant loops are arranged in a simple, elevated configuration to allow decay heat removal by natural circulation. The loops are either immersed in light water pools or in limited volume cells; this ensures that a sufficient inventory of water is maintained to cool the core. Heavy water flows through the shell side of the heat exchangers; the tube heads (which extend out of the pools) are thus accessible for maintenance without breaking the heavy water boundary. The main heat exchangers transfer heat to the light water secondary cooling system. 


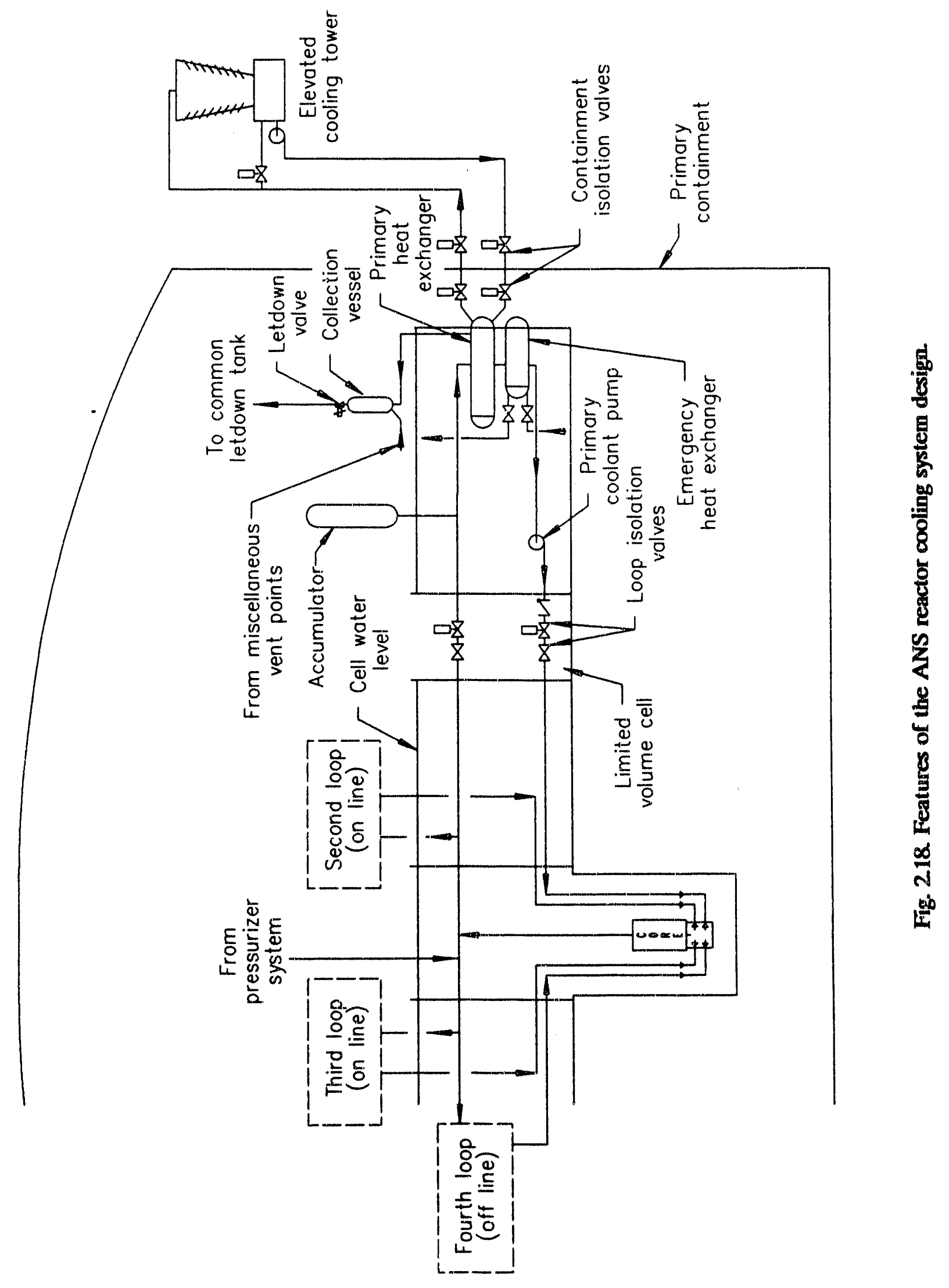


Primary coolant flows from the main heat exchanger into an emergency heat exchanger. The emergency heat exchangers transfer heat to the heat exchanger pool water, which flows by natural circulation. Under normal operating conditions, the primary water is cooled before entering the emergency heat exchangers, and there is little or no driving force for natural convection so that little heat is transferred to the pool water. If the secondary system isolation valves are closed, the emergency heat exchanger warms up, and the flow of pool water through its secondary side begins without any operator action. The heat exchanger pools have sufficient heat capacity for the first $72 \mathrm{~h}$ of decay heat. The secondary isolation valves are actuated independently for each loop based on detection of radioactivity in the secondary loop; simultaneous isolation of all three operating secondary loops is highly unlikely.

The primary cooling system pressure is maintained by a feed-and-bleed let-down and pressurizer pump system. Passive gas-charged accumulators are placed on each loop. The accumulators slow loop depressurization in the event of a line break, allowing the core to survive the initial transient. The accumulators also contain sufficient inventory to flood any limited volume cell. The system is provided with high-point vents, and collection space is provided for non-condensible gas ahead of the let-down valves.

The water inventory of the secondary system is held in pools that are part of the seismically hardened reactor support building structure. The pools are elevated so that sufficient driving force is available for natural circulation to take place. The secondary cooling towers are located on a hill above the elevation of the pools so that they drain into the pools. In the event the cooling towers are lost (such as loss of power to the circulating pumps), a valve automatically opens and establishes a flow path directly through the secondary pool. The pools have sufficient heat capacity for $\mathbf{3 0}$ days of decay heat. This removes the tower, and the coolant piping away from the pools, from the reactor safety case. Each primary loop is coupled to an independent secondary loop so that contamination in the secondary loop can be traced to a given primary (and reflector) heat exchanger.

The reflector cooling system is similar to the primary cooling system. Three of four loops are used during normal operation. The reflector heat exchangers are located in the heat exchanger pools, and all piping is either in the pools or in limited volume cells. The reflector system is pressurized directly by the water head of the elevated let-down tank. Although the primary and reflector systems are kept separate at the reactor, the heavy water of the two systems mixes at the let-down tank. Because forced flow is needed to cool certain components in the reflector vessel, the reflector pumps are backed up with pony motors.

Key parameters of the primary and secondary cooling systems were given earlier in Table 2.2.

\section{Reactor Containment}

The ANS containment meets not only the requirements of 10 CFR 100 but also the lower dose recommendations of the Environmental Protection Agency Protection Action Guides. The design of the containment was an iterative process of determining feasible design concepts, evaluating source terms and releases, and assessing dose rates at control zone boundaries. Containment performance requirements and zone boundaries then were adjusted until the requirements of the regulations and guides were met. For the conceptual eval rations of the ANS containment, the source term used consists of $100 \%$ of the iodine and noble gases and $1 \%$ of other radionuclides. Further R\&D is under way to refine the source term.

The various control zones around the ANS are shown in Fig. 2.19; the lower set of circles is plotted around the remote release point instead of the center of the containment. The first control zone is the candidate site itself. This zone is occupied by the ANS operations and research 


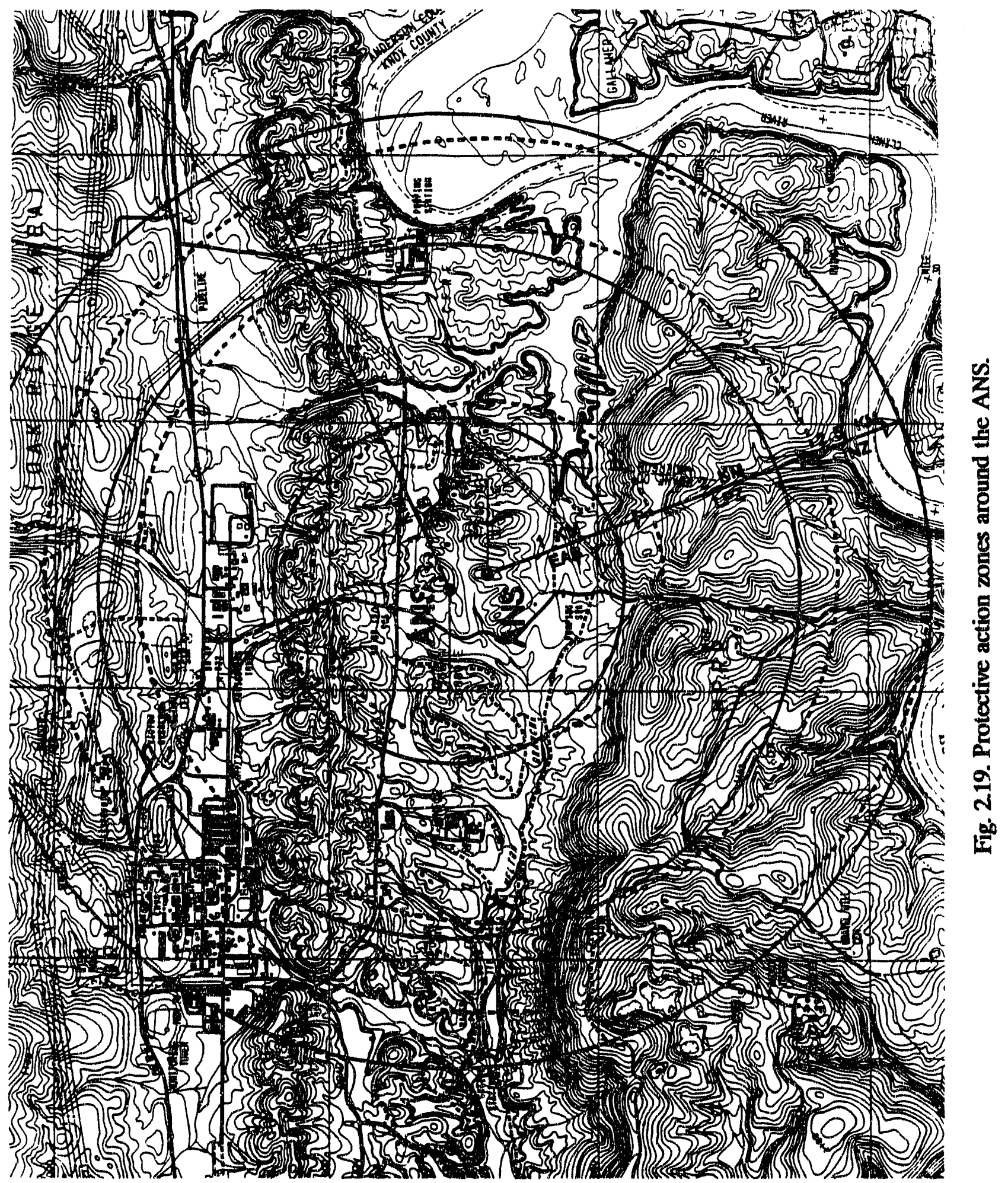


staff; safe evacuation of the site is achieved through training and drills. Any releases during a severe accident would occur at the remote release stack, which is located so that prevailing winds would not carry the plume over evacuation routes.

The exclusion area extends from the candidate site to a distance of $1000 \mathrm{~m}$. The dose at the outer boundary of the exclusion area under the most severe scenario would be $0.05 \mathrm{~Sv}$ ( $5 \mathrm{rem}$ ) whole body and $0.25 \mathrm{~Sv}(25 \mathrm{rem})$ to the thyroid, over $2 \mathrm{~h}$. This zone would be under the direct control of the ANS operations staff and could be evacuated quickly.

The low population zone extends from the outer boundary of the exclusion area to a distance of $2000 \mathrm{~m}$. The dose at the outer boundary of the low population zone under the most severe scenario would be $0.05 \mathrm{~Sv}$ ( $5 \mathrm{rem}$ ) whole body and $0.25 \mathrm{~Sv}$ ( $25 \mathrm{rem}$ ) to the thyroid over the duration of the event. The low population zone includes a number of moderate-sized ORNL facilities. Evacuation times of $2 \mathrm{~h}$ or longer (depending on the distance from the ANS) would avoid exceeding the higher range of the protection action guides.

The immediate notification zone extends from the outer boundary of the low population zone to the Oak Ridge Reservation boundary (not less than $2500 \mathrm{~m}$ ). At the boundary of this zone, the dose would not exceed $0.01 \mathrm{~Sv}$ (1 rem) whole body and 0.05 (5 rem) to the thyroid over $24 \mathrm{~h}$. This zone includes the main ORNL complex but does not include any private residences. No member of the public off the reservation is in a zone that requires immediate notification, even at the lower range of the protection action guides. Emergency planning zones may range from 8 to $16 \mathrm{~km}$ ( 5 to 10 miles) from the ANS candidate site, as agreed to by local government authorities.

The main features of the ANS containment are shown in Fig. 2.20. The containment is a dual structure with an inner steel pressure vessel and an outer concrete shield building. The inner containment is designed for an outleakage not to exceed $0.2 \%$ of containment volume per day (for conservatism, analyses are based on $0.5 \%$ outleakage per day) at a design pressure of $69 \mathrm{kPa}$ (10 psi). The outleakage is collected in the containment annulus, filtered for removal of iodine and particulates, and released at the remote stack. The filter systems are designed for a decontamination factor of 800 (for conservatism, analyses are based on a factor of 400 ).

The operations and research zones within containment are kept separate so that the research zone can be evacuated before the consequences of an incident in the operations zone reach that area. To protect the containment and building structures, relief paths open when the differential pressure between the zones reaches $14 \mathrm{kPa}(2 \mathrm{psi})$.

\subsection{Reactor Mockup and Simulator}

The ANS includes two key systems for training operators and for resolving uncertainties associated with unusual operating circumstances. The first is the mockup. This is a full scale assembly of reactor and refueling components. The mockup is used for general training, to test the fit of experiments and other equipment heing installed in the reactor, and to work through recovery procedures should remote refueling and maintenance equipment fail. The mockup is also used for training for maintenance and replacement of experiment facilities, including beam tubes. The mockup includes many reactor parts identical to the real component; others are simulated to represent the real size and mass; and still others (such as the reflector vessel) are provided with open panels for viewing other components. Since maintenance of the inner control rods is within the scope of the mockup, and since the maintenance systems for control rod removal are quite tall, the mockup building is about as tall as the office and operations support buildings.

The other training device is a full-scope reactor simulator. This facility is laid out to be identical to the main control room. The simulator software is capable of displaying the transient 


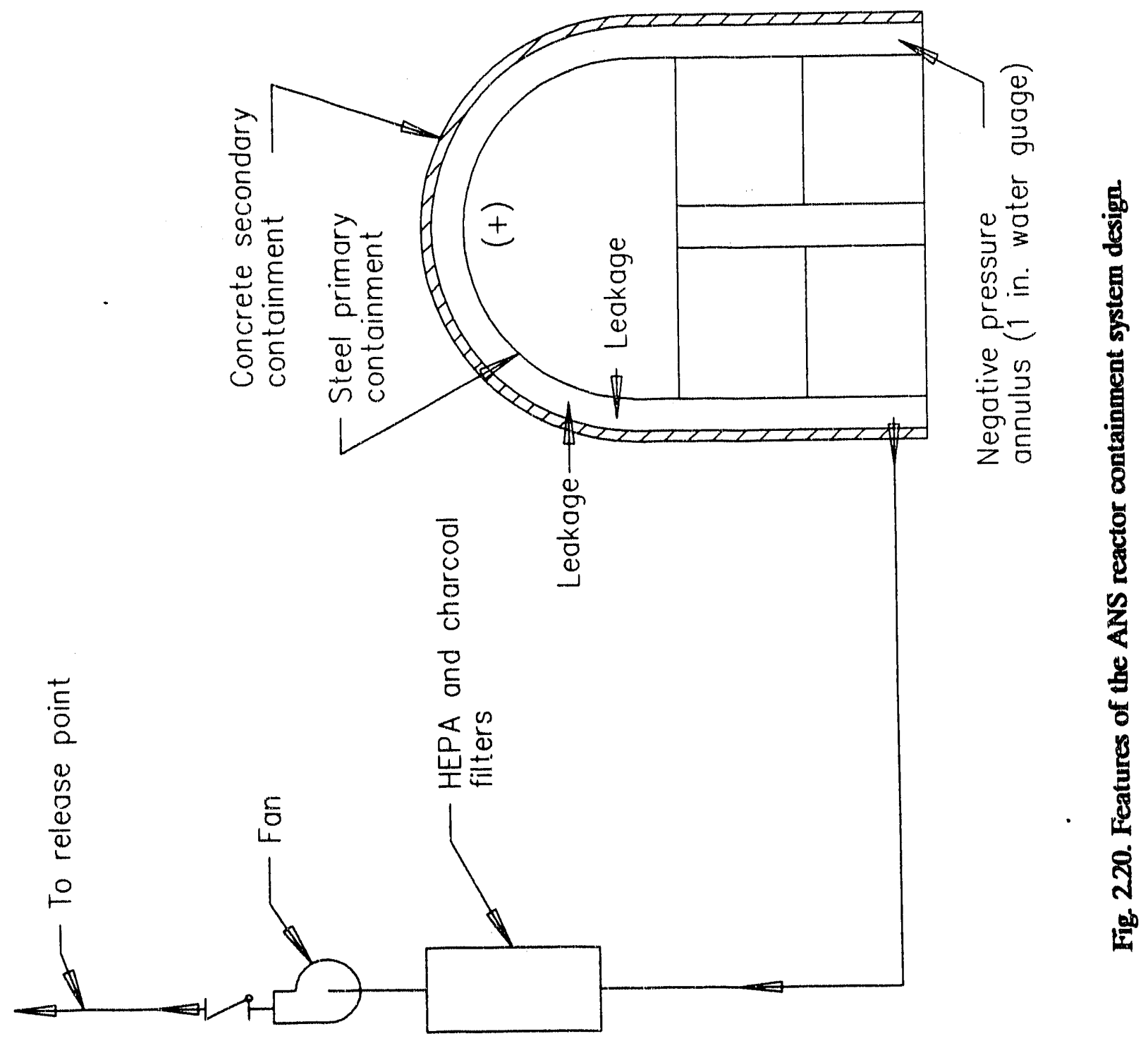


behavior of the reactor over all design basis scenarios. The simulator is located in the operations support building, along with classrooms and other training facilities.

\section{RESEARCH FACUITIES}

\subsection{Neutron Sources}

The heavy water in the reflector serves as the thermal neutron source for beams and irradiation facilities. Axial and radial flux profiles in the reflector were presented earlier in Figs. 2.8 and 2.9. The peak thermal flux in the reflector is at a radius of about $330 \mathrm{~mm}$ at the core axial midplane. The beam tubes are arranged so that the nose of the tube is located near the flux peak, but the beam tube does not directly view the core or the gammas coming off the core pressure boundary tube hardware. The thermal flux falls off slowly with radial and axial distance, but the fast neutron flux and the gamma flux fall off fairly rapidly (although the gamma flux has a local peak near the reflector vessel wall because of neutron capture in aluminum). Thus facilities requiring a strong thermal neutron source but low heating rates (such as the analytical chemistry pneumatic tubes or the general purpose isotope production targets) are located farther out in the reflector. Immediately adjacent to the core pressure boundary tube, the fast and epithermal components of the neutron flux are higher; some materials irradiaticn and transuranic isotope production facilities are located in this region.

The fast and epithermal neutron flux is even higher inside and immediately outside the fuel elements inside the core pressure boundary tube. The main transuranium production and materials irradiation facilities are located in these regions.

The liquid deuterium cold source systems moderate neutrons to an energy spectrum corresponding to an effective moderator temperature below $40 \mathrm{~K}$. With the reactor at full power, the cold flux is about $2.2 \times 10^{18}$ sterad $^{-1} \cdot \mathrm{nm}^{-1} \cdot \mathrm{m}^{-2} \cdot \mathrm{s}^{-1}$ and the cryogenic heat load is $30 \mathrm{~kW}$. The cold sources use centrifugal pumps to circulate liquid deuterium continuously through a cryogenic loop containing a moderator vessel (located in a reflector vessel horizontal thimble) and a cryogenic heat exchanger (located outside the biological shield). Energy is transferred from the liquid deuterium to cold helium gas in the heat exchanger. During normal operation, the lower end of each cold source system (including the heat exchanger, pumps, cryogenic deuterium plumbing, and the moderator vessel) will be flooded with liquid deuterium to a level just above the heat exchanger core. The nominal operating pressure of the cold deuterium system is $0.5 \mathrm{MPa}$, and with the reactor at full power, the temperature of the deuterium entering and leaving the moderator vessel is $20 \mathrm{~K}$ and $24 \mathrm{~K}$, respectively. Each cold source is provided with a large, low pressure receiver $\left(60 \mathrm{~m}^{3}\right.$ at 0.5 to $0.8 \mathrm{MPa}$ ) to hold the deuterium vapor during warmup. This avoids the need to pump or vent the $77 \mathrm{~kg}$ of deuterium in each system under either normal or emergency conditions. The entire deuterium system is surrounded by monitored vacuum and/or helium envelopes to minimize the probability of a deuterium-oxygen reaction.

The major features of the cold source penetration in the reflector vessel are shown in Fig. 2.21. The cold source assembly enters the side of the reflector vessel through a water-cooled, reinforced thimble assembly and vacuum jacket. Thus although the cold source is dimensionally inside the reflector vessel, it is kept physically outside the outer boundary of the reflector. The moderator vessel is at the front of the thimble, supported by a light tubing structure. Thermal neutrons pass through the thimble and vacuum jacket walls, but cold neutrons only need to pass through the thin moderator vessel wall and thin windows at the guide entrances. The horizontal cold neutron guide array extends into the biological shield penetration, almost to the flange 


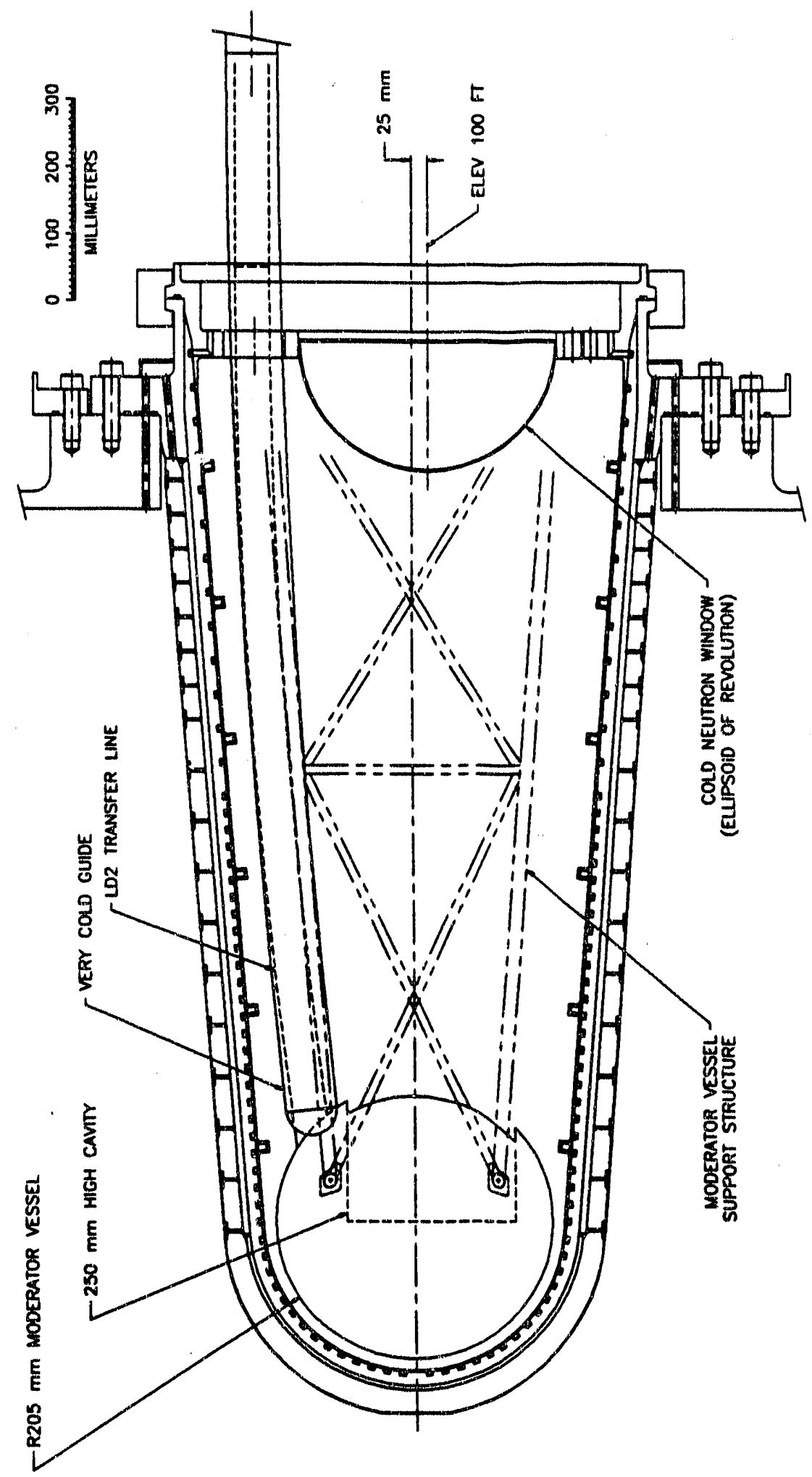

를 
assembly on the outer reflector vessel wall. A very cold neutron guide reaches up to the moderator vessel from above the horizo.tal guides; these guides can be curved to a shorter. radius than the cold guides, allowing some flexibility in their routing. A rotating shutter assembly is located near the rear of the penetration. The deuterium transfer lines also are routed above the cold guides from the moderator vessel to the heat exchanger and circulating pump located in a cold box outside the penetration above the removable roof sections.

An extensive R\&D program supports development of cold source design concepts and includes neutronic performance evaluations and studies of the stability and overall safety of the cold sources.

The hot source, shown in Fig. 2.22, is a cylindrical graphite moderator shrouded within an insulating envelope and enclosed in a water-cooled, double wall containment vessel. The moderator, a monolithic cylinder of high density graphite, is heated to at least $2000 \mathrm{~K}$ by the neutron and gamma flux. Insulation of carbon-bonded carbon fiber graphite and helium surrounds and supports the graphite block inside the containment vessel. The helium environment prevents oxidation of the moderator graphite and is monitored during operation. The structural containment vessel is a double-walled structure made of Zircaloy. The outer wall of the vessel is provided with light water cooling channels, and the gap between the two walls is filled with helium at $0.6 \mathrm{MPa}$. The entire hot source assembly, including cooling water and instrumentation lines, is inserted into a thimble in the reflector vessel. This thimble also is provided with forcedflow cooling. Two beam tubes view the hot source through the hot source penetration and thimble. As with the cold sources, the hot source is located dimensionally inside the reflector vessel but physically outside the reflector outer boundary.

The hot source concept is currently based on existing installations at the ILL and other facilities. An R\&D program to develop the design concepts and analytical tools further will begin soon after the conceptual design. In particular, moderatcrs other than graphite will be evaluated.

\subsubsection{Beam Transport and Instruments}

The array of horizontal beam tubes extending from the reflector vessel to instruments clustered around the biological shield is shown in Fig. 2.23. The beam tubes have an elliptical cross section, $200 \mathrm{~mm}$ tall and $100 \mathrm{~mm}$ wide. Because of the inverse square losses encountered with standard beam tubes, the instruments are located as close to the source as possible. In some cases, however, sections of supermirror guides are used to allow instruments to be moved back from the shield wall.

The peak flux at the front of the beam tubes is on the order of $6.5 \times 10^{19} \mathrm{~m}^{-2} \cdot \mathrm{s}^{-1}$. There are seven horizontal thermal beam tubes, two hot beam tubes, and one through-tube system. In general, the beam tube penetrations consist of five major components. A penetration liner is built into the concrete shield. A typical plan view of a thermal beam tube biological shield penetration is given in Fig. 2.24. A transition casing extends through the pool from a flange on the inside of the penetration liner to the boss on the reflector vessel. The beam tube thimble inside the reflector vessel also attaches to the reflector vessel boss. A beam tube plug extends into the transition casing and provides initial collimation and shielding of the beam. The beam tube plug includes a window that is designed to contain the reflector tank heavy water if the beam tube thimble were to fail. Backing up the window is a sealed valve. A shield plug assembly fills the outer half of the biological shield and includes the rotating shutter and collimator drums. The penetration for one of the beam tubes (HB-2) is enlarged to allow the possibility of a future thermal guide array extending out to a second guide hall. 


\section{$2-38$}

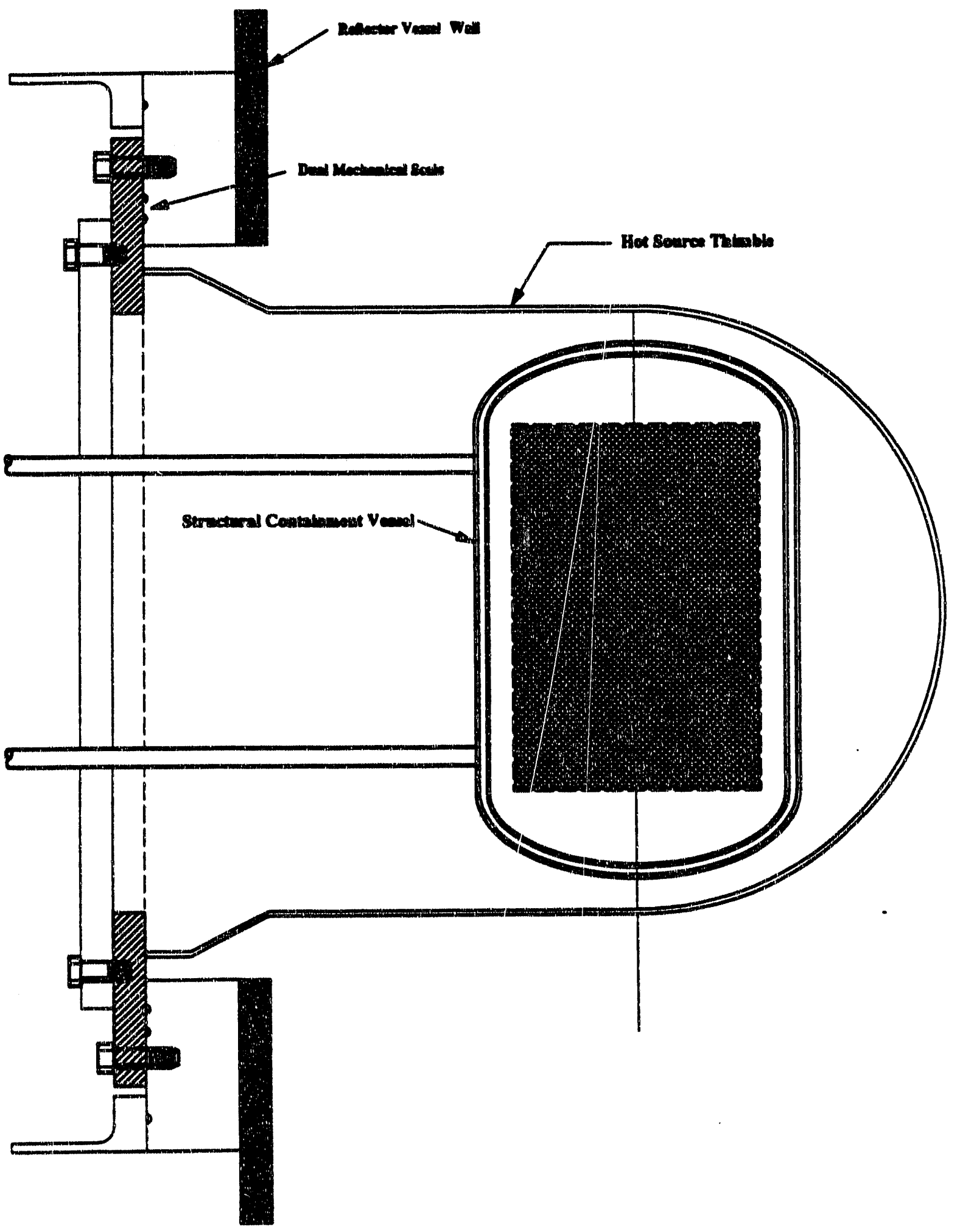

Fig. 222 Hot source asuembly and thimble. 


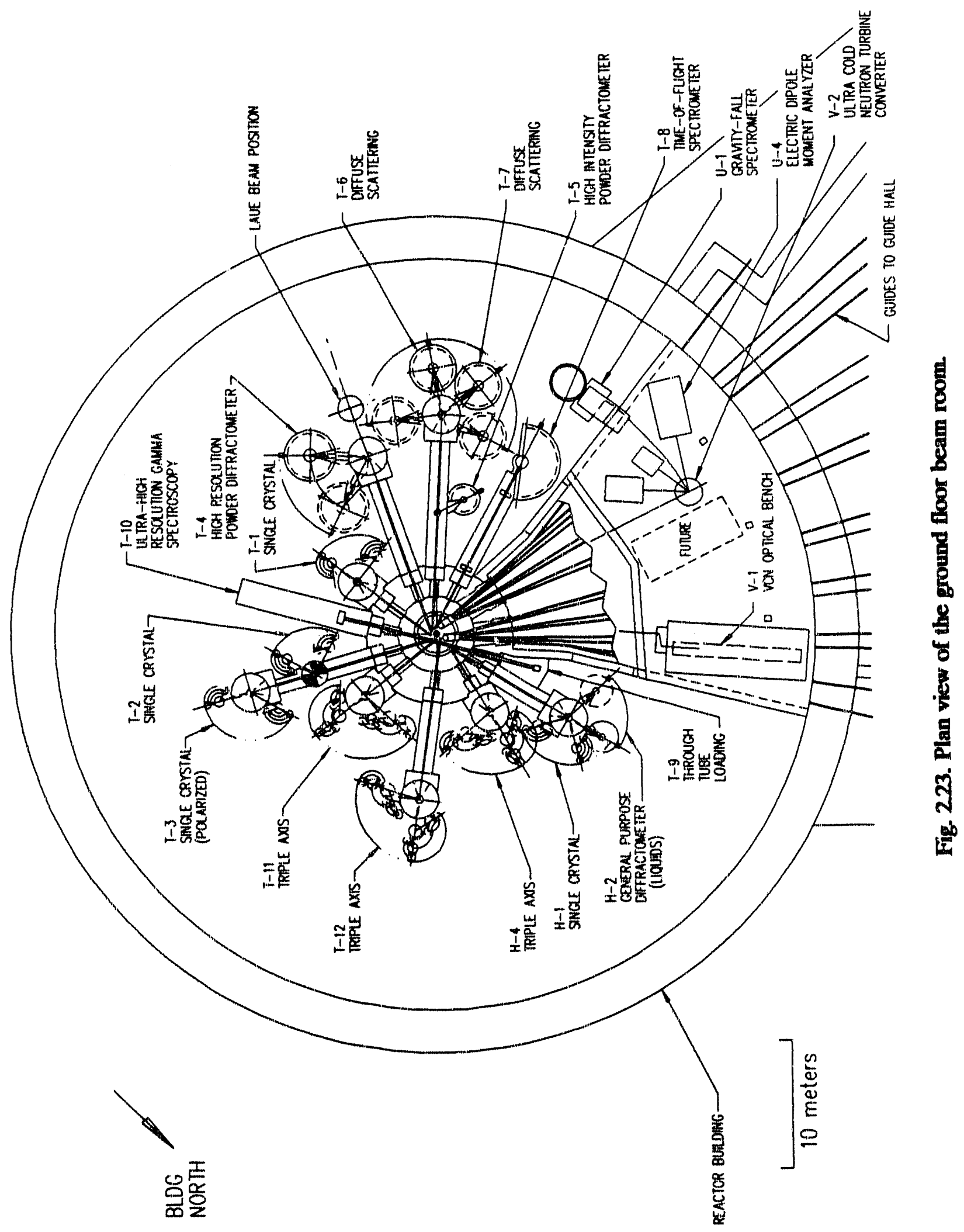




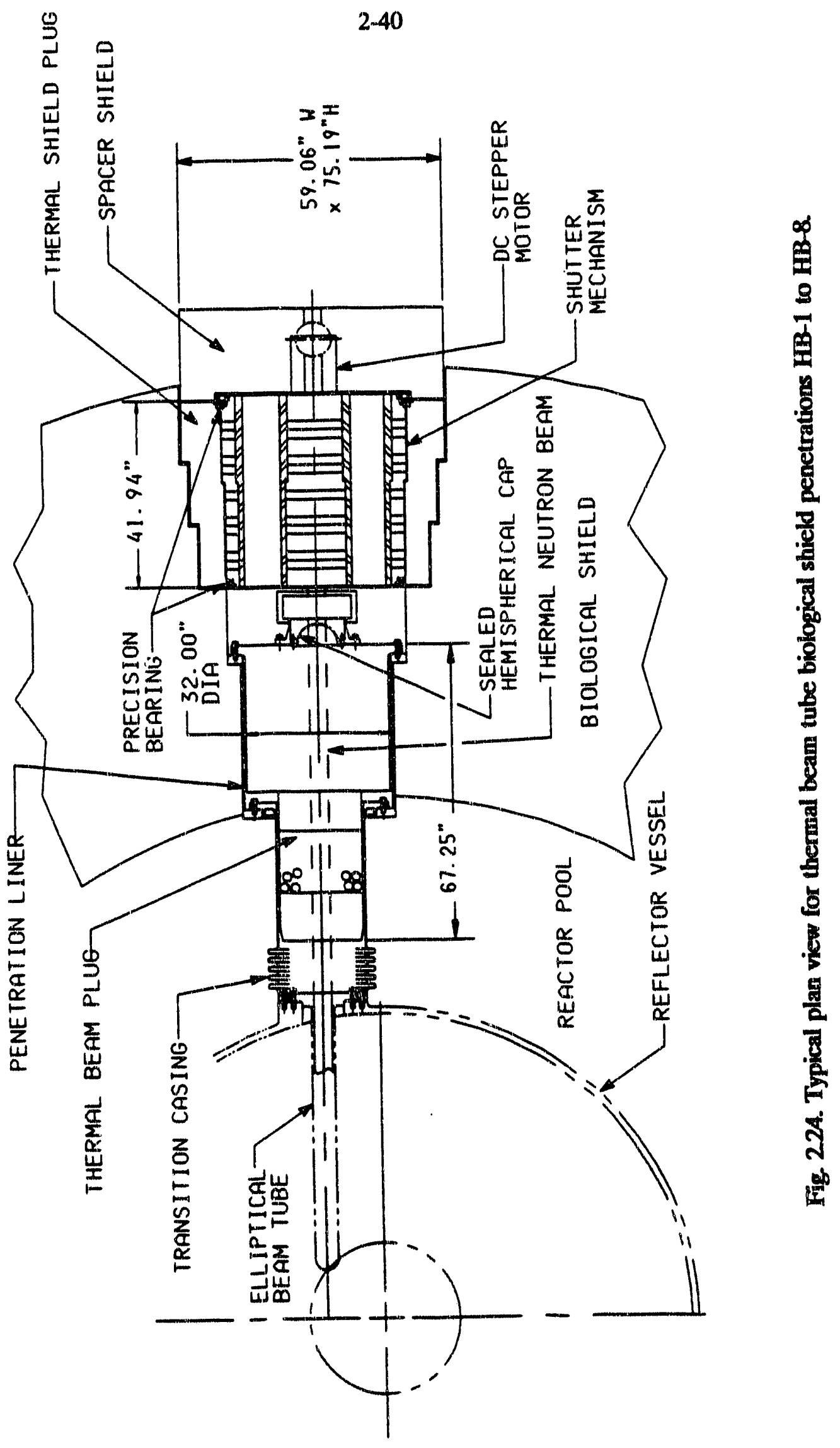


The through-tube system is designed to allow samples to be loaded at one end and viewed from the other end without the background gamma radiation normally associated with a window at the end of a beam tube. The penetration at the viewing end is identical to the thermal beam tube penetrations, while the penetration at the loading end is of a specialized design.

The horizontal cold neutron guide array is shown in Fig. 2.25. Seven guides are illuminated by each cold source. Each guide is aligned to view the center of the cavity in the cold source. Adjacent guides are $2^{\circ}$ apart so that neutrons that are just past the $1^{\circ}$ critical angle for one guide can be collected by the next guide. To provide adequate spacing in the guide hall for instruments, the guides are in three groups with a $6^{\circ}$ angle between the center lines of the closest guides in the adjacent groups. To minimize the gamma flux down the guides, the cold source location and guide layout also have been arranged so that no straight guide has a direct view of the reactor core assembly. The outermost guide from one cold source is split within containment to provide two beams for the D-16 analytical chemistry instruments. In a similar manner, the cutermost guide from the other cold source is split within containment; one polarization is sent to the neutron spin echo instrument, and the other polarization is sent to the L-12 parity violation experiment station.

Three major types of guide mirror materials are used. Normal mirrors are coated with natural nickel; these provide a reflectivity greater than 0.994 and a critical angle of $1^{\circ}$ at a wavelength of $1 \mathrm{~nm}$. Extended mirrors are coated with isotopically pure ${ }^{58} \mathrm{Ni}$; these provide a reflectivity greater than 0.994 and a critical angle of $1.15^{\circ}$ at $1 \mathrm{~nm}$. Supermirrors are coated with a multilayer structure; these provide a reflectivity of greater than 0.98 and a critical angle of $3^{\circ}$ at $1 \mathrm{~nm}$. Not all instruments can take advantage of the greater divergences of the extended performance guides. Thus ${ }^{58} \mathrm{Ni}$ and supermirror guides are used only in situations where real gains are obtained by their use. Most of the horizontal guides have an inside cross section of $200 \mathrm{~mm}$ vertically by $50 \mathrm{~mm}$ horizontally.

The portion of the guides outside the biological shield within the reactor building and in a transition area of the guide hall are contained within a concrete enclosure to provide radiation shielding. The roof panels near the biological shield are removable to allow access to the guide system for maintenance. Beginning at a distance of $\sim 50 \mathrm{~m}$ from the reactor in the guide hall, each guide line is provided with separate shielding. The guides penetrate reactor containment as they extend out into the guide hall. Vacuum gate valves are provided at both primary and secondary containment; containment isolation of the guides is not significantly different from isolation of the piping systems that penetrate containment.

A thermal slant beam tube and one slant cold guide from each cold source extend to the second floor experiment area, as shown in Fig. 2.26. The slant thermal beam tube is provided with a shielded facility used to lower small fissile material foils into the neutron flux; the experiment using this beam tube collects the fission products emitted from the foil. Penetration designs for this facility are somewhat different than for other beam tubes. The slant cold guides are used for neutron depth profiling and other general purpose applications. They have an inside cross section of $75 \mathrm{~mm}$ by $75 \mathrm{~mm}$. Penetrations for the slant guides are relatively straightforward. All three of the slant beam facilities are provided with rotating shutter mechanisms.

One very cold guide extends horizontally from each cold source and is curved to reach a research location on top of the shielding roof over the horizontal cold guides. One of the very cold guides supplies neutrons to an optical bench facility. The other supplies an ultra cold neutron turbine, as shown in Fig. 2.27.

Three types of casks are planned for servicing the neutron transport systems. The most complex and the largest cask is for replacing beam tube thimbles, light water transition assemblies, and hot source and cold source systems, including their thimbles and light water transition assemblies. This cask is to mate to the biological shield face after the penetration plugs have been 


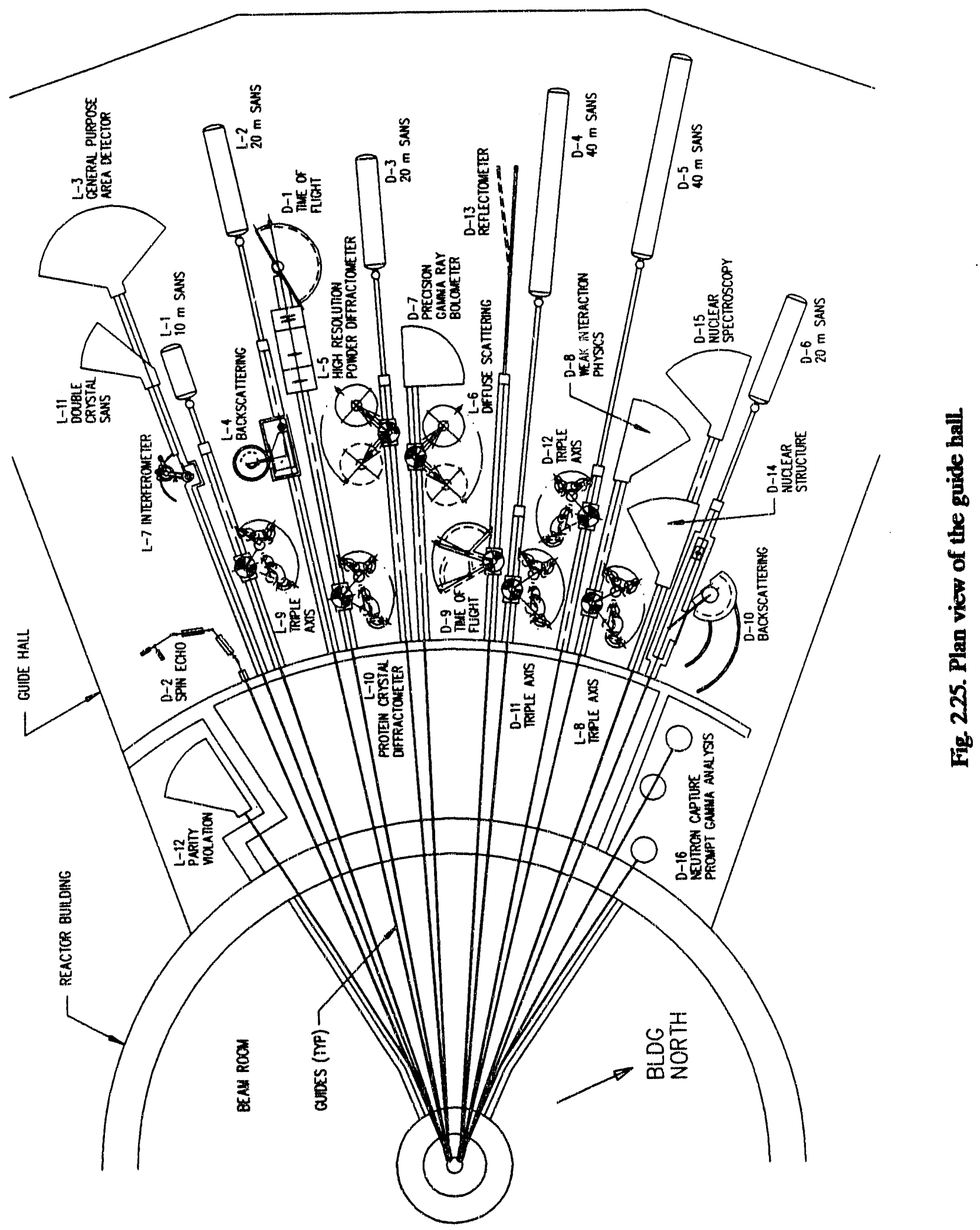




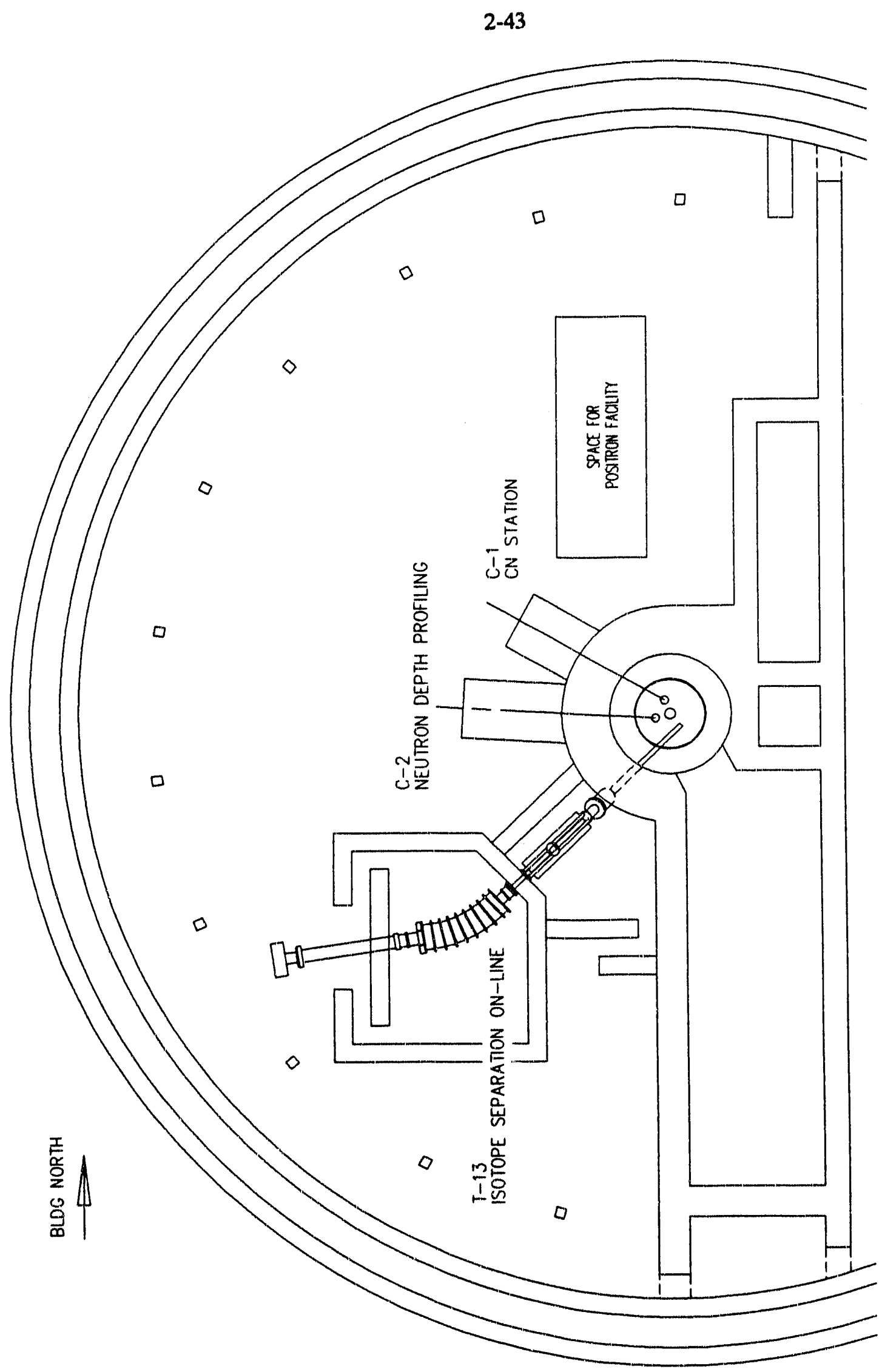

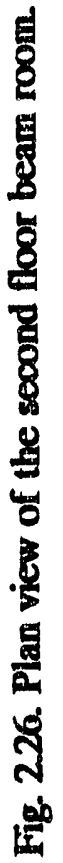




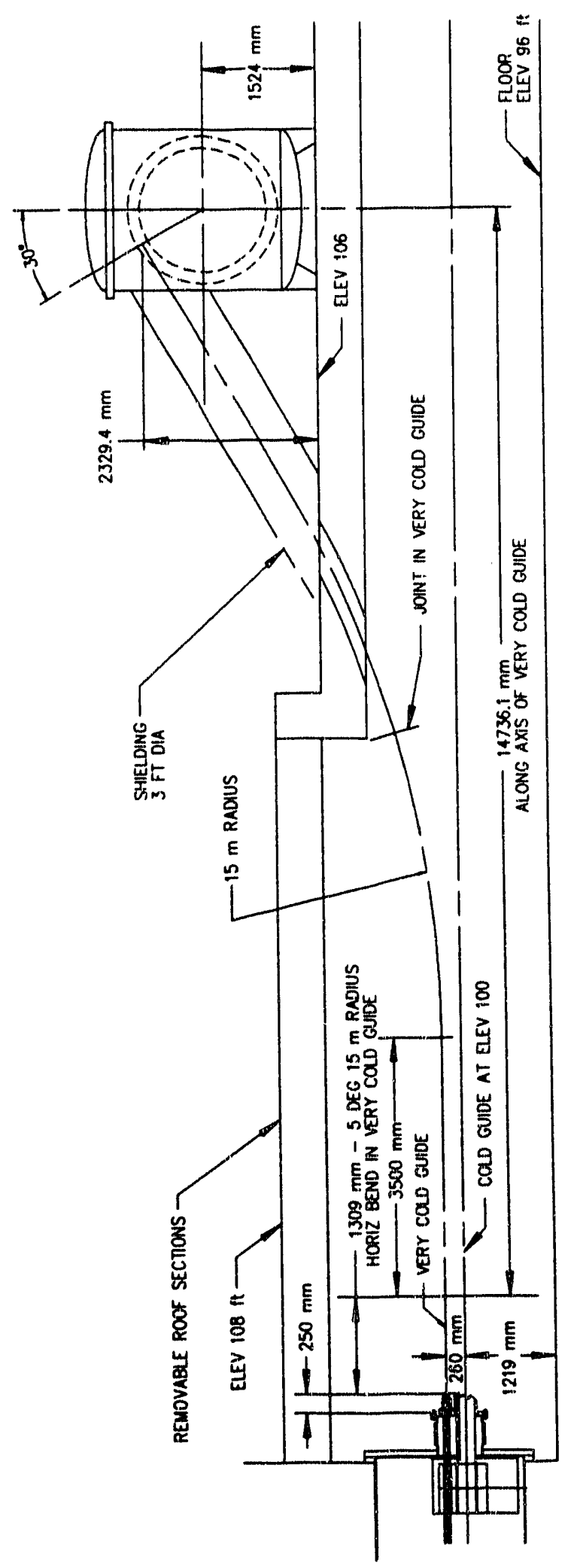

울 
removed. A telescoping arm and end effector will be used to disconnect the component from the reflector vessel and then pull it back into the cask. The shield design is driven by the activation of typical Type 6061 aluminum that produces a significant flux of $1.1 \mathrm{MeV}$ photons by the decay of ${ }^{6} \mathrm{Zn}$, with a 244-day half life. Because of elevation and geometry differences, separate casks will be needed for replacing the through-tube and the slant tubes. These will have similar telescoping and handling systems but can be smaller in diameter.

A list of the 48 beam instruments included in the ANS Project is given in Table 2.3. Of these, 38 instruments are used for neutron scattering. Some of the more versatile scattering instruments are depicted in Figs. 2.28 through 2.31. A single crystal diffractometer is used to measure the atomic or molecular structure of a sample that can be produced as a single crystal. A powder diffractometer is used to measure the atomic or molecular structure of a sample that cannot be produced as a single crystal or that will lose its crystalline form during the experiment, for example by being subjected to a phase transition. A triple axis spectrometer is used to measure the dynamic properties of a sample that can be produced as a single crystal; specific functions include the ability to measure phonons, magnons, and spin or charge density waves as a function of the direction in the crystal. A small-angle neutron scattering camera is used to measure the pattern of intensity scattered in the forward direction by the sample. Many other capabilities are provided by the other instruments listed in Table 2.3.

Most of the neutron scattering instruments share five basic subsystems. The beam preparation system includes the monochromator, polarizer, and collimators that define the beam, and the associated biological shielding that reduces the level of radiation at the first external surface to levels that are as low as reasonably achievable and in any case no more than $25 \mu \mathrm{Sv} / \mathrm{hr}$. The sample handling and environmental control system includes mechanical supports for the sample, automated support movement devices, beam definition diaphragms, and devices such as cryostats or magnets to provide and control the sample environment, together with interfaces to associated services such as helium gas recovery. The beam detection and analysis system includes the postsample collimators, the energy and polarization analysis subsystem, the neutron detectors and motorized detector supports, and anti-back-end encoders. The instrument data collection and control system includes the electronic control interfaces, the local computer and data storage and display system, and networking interfaces to other data handling systems.

Many of the scattering instruments require precise angular adjustments of samples, analyzers, and detectors. These instruments are constructed of standard modules and are floated on precision air pads. Polished, level floors are provided under them to ensure precise alignment of the instrument components. Some instruments, such as the L-7 interferometer, require highly specialized stable foundations. Instrument stations are provided with standard service kiosks, computer and control stations, and other support modules. Instruments are encircled with shielding as appropriate; interlocks close beam shutters when the shield doors are opened. Instrument monitoring and control data are transmitted on an experiment systems network, allowing monitoring and control of an instrument from a remote location such as the office building. 'This reduces the time a user must be at the instrument, reducing dose exposures and the average number of occupants in the containment.

Eight of the beam instruments listed in Table 2.3 are used for nuclear and fundamental physics research. Whereas the scattering instruments tend to be general research tools, some of the nuclear and fundamental physics instruments are designed specifically for a given experiment. Many of the highly specialized instruments may be provided by participating research teams; only the termination of the beam and a set of standard support facilities would be provided by the ANS Project. 
Table 23. Beam instruments at the ANS

\begin{tabular}{|c|c|c|}
\hline Number & Instrument & Beam \\
\hline
\end{tabular}

Single crystal instruments:

T-1 Single crystal diffractometer $\quad$ HB-4

$\begin{array}{lll}\text { T-2 } & \text { Single crystal diffractometer HB-6 }\end{array}$

T-3 Polarized single crystal diffroactometer HB-6

$\begin{array}{ll}\text { H-1 Single crystal diffractometer } & \text { HB-10 }\end{array}$

$\begin{array}{ll}\text { L-10 Protein crystal diffractometer } & \text { CS-23 }\end{array}$

Powder diffractometers:

T-4 High resolution powder diffractometer

T.5 High intensity powder diffractometer HB-2

L-5 High resolution powder diffractometer CS-22

Time-of-llight spectrometers:

T-6 Diffuse scattering time-of-flight spectrometer HB-2

T-7 Diffuse scattering time-of-flight spectrometer HB-2

T-8 Time-of-light spectrometer HB-1

D-1 Multi-chopper time-of-flight spectrometer CS-23

D-9 Time-focussing time-of-flight spectrometer CS-11

L-6 Diffuse scattering time-of-flight spectrometer CS-21

Triple axis spectrometers:

$\begin{array}{lll}\text { T-11 Triple axis spectrometer } & \text { HB-7 }\end{array}$

T-12 Triple axis spectrometer HB-8

H-4 Triple axis spectrometer HB-9

D-11 Triple axis spectrometer $\quad$ CS-12

D-12 Triple axis spectrometer CS-13

L.8 Triple axis spectrometer $\quad$ CS-14

$\begin{array}{ll}\text { L-9 Triple axis spectrometer CS-25 } & \end{array}$

Small angle nevtron scattering cameras:

L-1 $10 \mathrm{~m}$ small angle neutron scattering camera CS-25

D-3 $20 \mathrm{~m}$ small angle neutron scattering camera (biology) CS-22

D-4 $40 \mathrm{~m}$ small angle neutron scattering camera $\quad$ CS-12

L-11 Double crystal small angle neutron scattering camera CS-26

D.5 $40 \mathrm{~m}$ small angle neutron scattering camera $\quad$ CS-13

L-2 $20 \mathrm{~m}$ small angle neutron scattering camera CS-24

D-6 $20 \mathrm{~m}$ small angle neutron scattering camera CS-16

Liquids and amorphows scatteringe

H-2 General purpose liquids diffractometer

HB-10 
Table 23. (continued)

\begin{tabular}{lll}
\hline Number & Instrument & Beam \\
\hline High resolution spectroscopy: & \\
D-2 & Neutron spin echo spectrometer & CS-27a \\
D-10 & Backscattering spectrometer & CS-16 \\
L-4 & Backscattering spectrometer & CS-24 \\
Neutron & optical instruments: & \\
L-7 & Interferometer & CS-26 \\
D-13 & Reflectometer & CD-11 \\
V-1 & Very cold neutron optical bench & VCG-1 \\
Ultra-cold neutron facilities: & \\
V-2 & Ultra cold neutron turbine converter & \\
Stations running off V-2: & VCG-2 \\
U-1 & Gravity-fall spectrometer & \\
U-2 & Neutron storage bottle & \\
U-3 & Neutron microscope & \\
U-4 & Electric dipole moment & \\
U-5 & Ultra cold neutron station & \\
Developmental scattering instruments: & \\
L-3 & General purpose area detector & \\
C-1 & Slant cold neutron station &
\end{tabular}

(There are a total of 38 neutron scattering instruments, counting the turbine but not the ultra cold neutron stations around the turbine)

Nuclear and fundamental physics instruments

Thermal nuclear physics:

T-9 Through-tube loading station

HB-11

T-10 Ultra-high resolution gamma-spectroscopy

HB-5

Polarized nuclear physics:

D-7 Precision gamma ray bolometer

CS-21

D-8 Weak interaction physics

CS-14

L-12 Parity violation

CS-27b 
Table 23. (continued)

\begin{tabular}{lll}
\hline Number & \multicolumn{1}{c}{ Instrument } & Beam \\
\hline General nuclear physics: & \\
D-14 & Nuclear structure & CS-15 \\
D-15 & Nuclear spectroscopy & CS-15 \\
T-13 & Isotope separation on-line & Large \\
& & slant \\
& & beam \\
& & tube \\
(There are a total of 8 nuclear and fundamental physics instruments, not including \\
the ultra cold neutron stations around the turbine) \\
\multicolumn{1}{c}{ Materials analysis facilities: } \\
D-16 & Prompt $\gamma$ activation analysis multibeam & \\
C-2 & Neutron depth profiling & CS-17a, \\
GIF & $\gamma$-irradiation facility & CS-17b \\
& & SGG-2 \\
& & Spent \\
& & fuel \\
& & pool \\
\hline
\end{tabular}




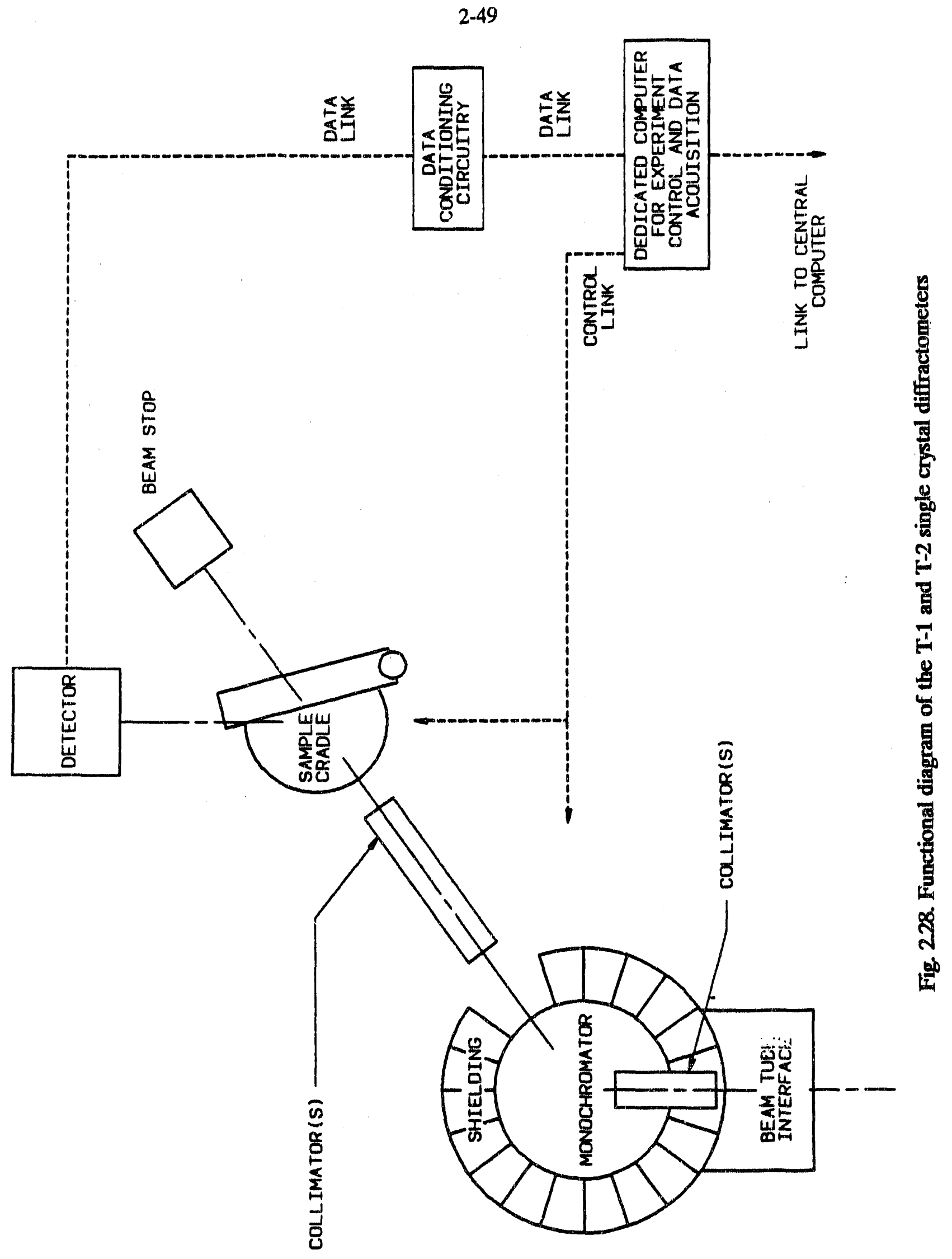




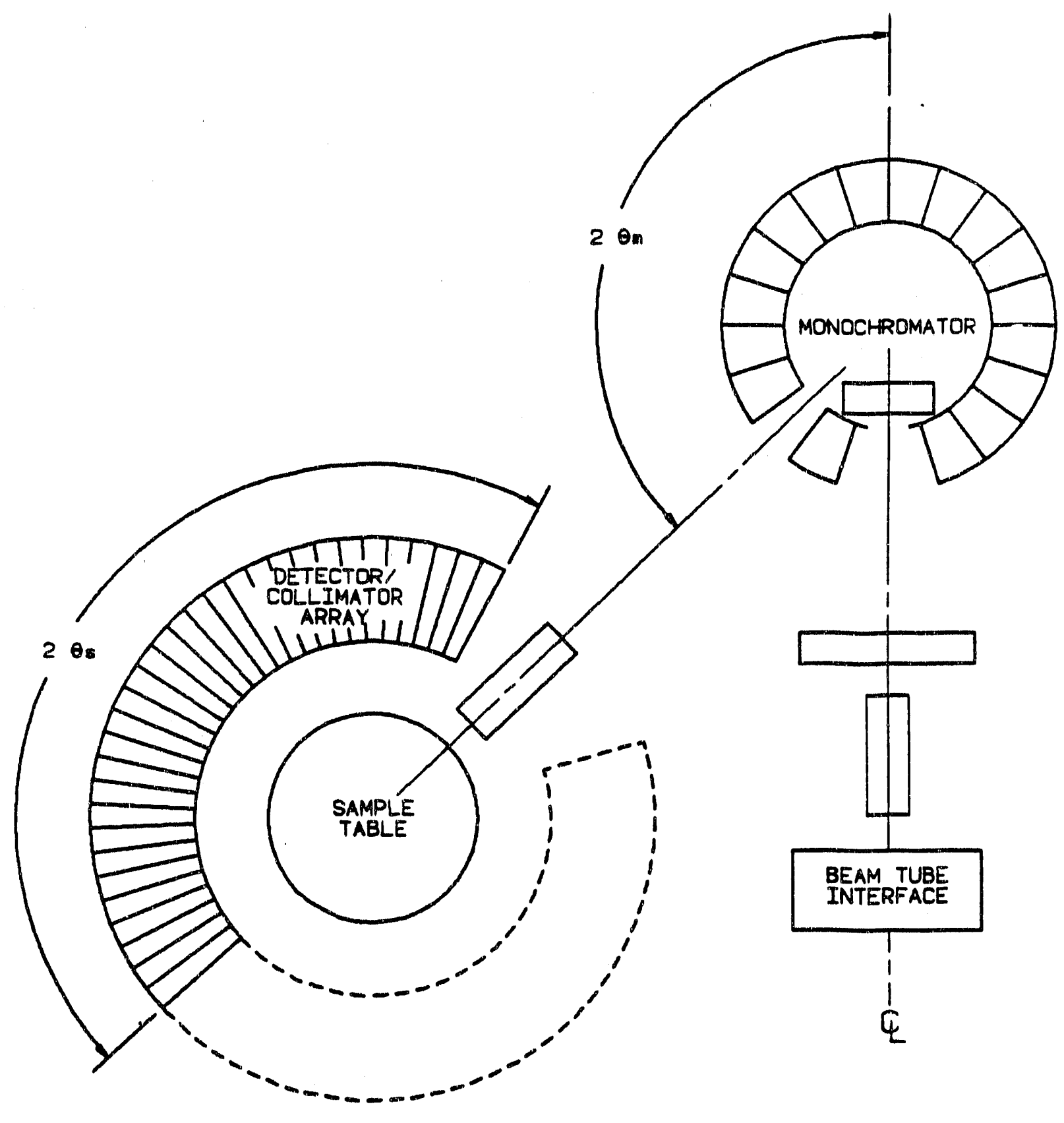

Fig. 229. Functional diagram and assembly of the $T-4$ powder diffractometer 


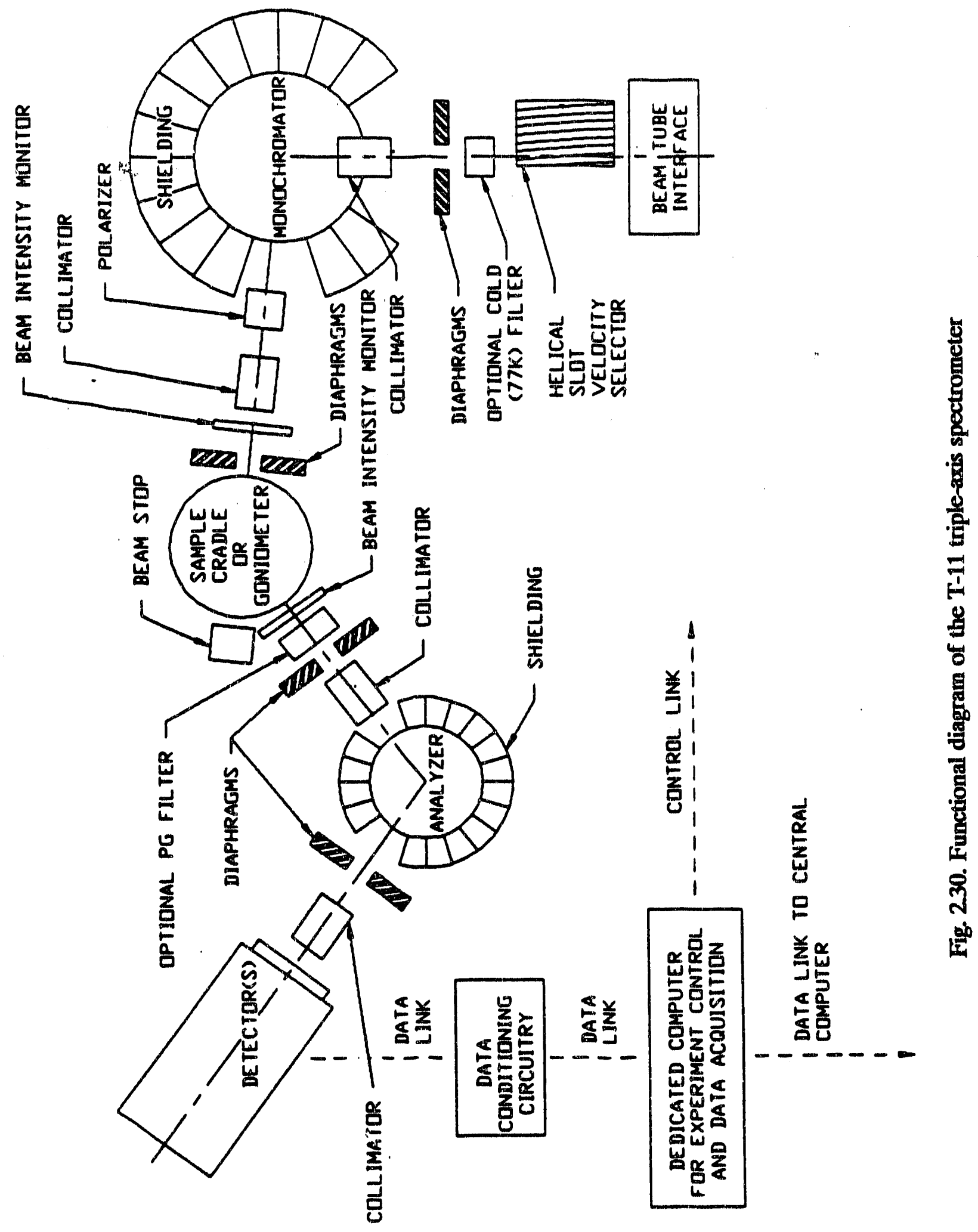




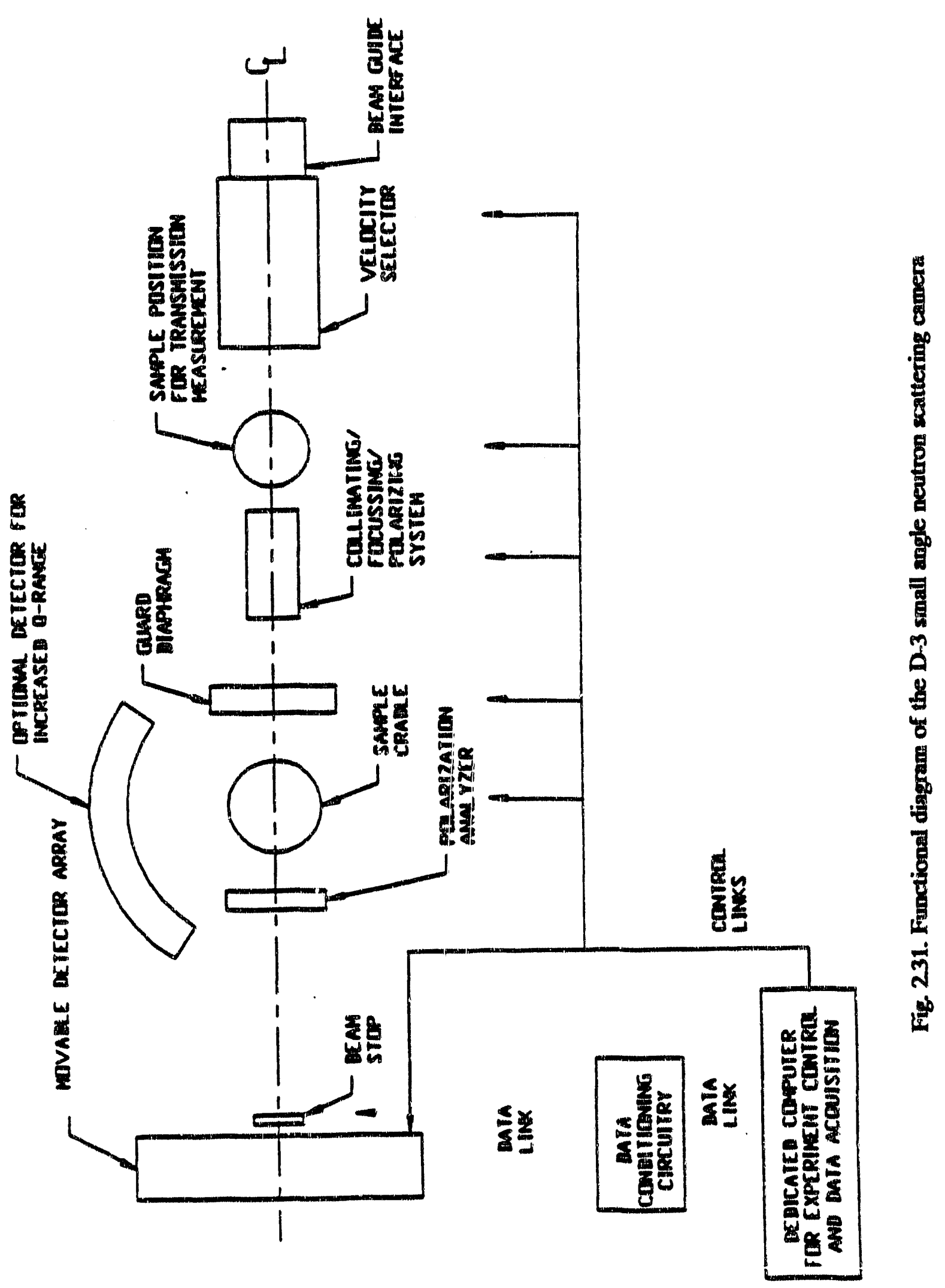


Two of the physics instruments involve the irradiation of target material in a beam. These include the through-tube facility and the isotope separation on-line (ISOL) facility served by the slant thermal beam tube. Neutron-rich, ionized fission fragments are collected and studied at the ISOL facility. An accelerator may be added to this facility, creating unique research opportunities with this type of charged particle.

The parity violation station ( $L-12)$ provides an intense polarized cold neutron beam and a location suitable for safely performing experiments involving multi-litre quantities of liquid hydrogen. The beam is used to investigate weak interactions by creating polarized, excited nuclei through the capture of spin-polarized neutrons and then studying the asymmetry of the radiation emitted by the excited nucleus. This instrument is located in a separate blockhouse at the edge of the guide hall in such a way that hydrogen safety issues do not affect the rest of the reactor and guide hall complex.

Most of the other physics instruments envisioned at this time consist of relatively standard components.

Two classes of beam facilities are provided for materials analysis. The prompt $\gamma$ activation analysis multibeam facility (D-16) is located in the guide hall. Because these instruments measure gamma rays from neutron capture within a specimen, it is essential that the local gamma ray and ambient neutron background be as low as possible. To achieve this result, these instruments will be located on a bent neutron guide tube at one side of the guide hall where gamma rays and fast neutrons from other experiments are likely to be low. The beam will be split at the end of the bent guide, and separate beams will be sent to the instruments along straight sections.

The neutron depth profiling facility is located in the second floor of the reactor building on one of the slant cold guides. Two sample stations will be provided. Having a very low gamma ray background is not as critical for this instrument, as charged particles are being measured in this facility.

\section{In-core Irradiation Facilities}

Irradiation facilities included in the ANS are summarized in Table 2.4. Of these, the transuranium production and materials irradiation programs use irradiation positions inside the primary coolant boundary.

The transuranium production facilities are designed to produce up to $1.5 \mathrm{~g}$ of ${ }^{252} \mathrm{Cf}$ and up to $40 \mu \mathrm{g}$ of ${ }^{254} \mathrm{Es}$ annually. Up to 30 transuranium production targets, similar to those currently produced and processed at the REDC and irradiated at the HFIR, are arranged outside the lower fuel element as seen in the plan view of the core in Fig. 2.11. A sketch of the target currently in use at the HFIR is shown in Fig. 2.32. These targets initially are filled with curium and are irradiated in an epithermal flux, which promotes absorption of neutrons without fissioning. The targets are held in a target cage assembly that attaches to the lower fuel support structure. The target array is installed and removed using the reactor refueling system. Target arrays can be left in the reactor for multicycle irradiations or can be removed during refueling. The target array is lifted out of the heavy water tunnel in the refueling transfer cell and lowered into the light water pool. From there, it is moved to a handling station in a pool, where the cage is dismantled and a new array is assembled. Targets move in and out of the reactor building through the spent fuel pools and transfer tunnels. They are loaded into casks in the fuel handling area of the reactor support building for slipment back to the REDC.

Five instrumented and five noninstrumented materials irradiation targets are located inside the upper fuel element, as seen in the upper element plan view in Fig. 2.10. Again, the capsule design is similar to designs uced gt the HFIR. Instrumented capsules are $48 \mathrm{~mm}$ in diameter; 
Table 24. Irradiation facilities at the ANS

\begin{tabular}{lll}
\hline Number & Facility & Location \\
\hline & Transuranium production facilities
\end{tabular}

In-core irradintion facilities:

In-core irradiation targets (up to 30)

Outside lower fuel element

Reflector irmdintion focilities:

HT-2 Epithermal hydraulic rabbit tube

Reflector

Support facilities:

Target handling area

Cask loading area

Hydraulic tube unloading area

Materials inadiation facilities

In-core irradintion facilities:

Instrumented irradiation facilities (5)

Noninstrumented irradiation facilities (5)

Reflector irrodiation facilities:

SH-1 Slant irradiation facility

SH-2 Slant irradiation facility

Experiment pool

Fuel handling area pool

Reactor building

Support facilities:

Upper slant hole facility

Storage pool experiment handling facility

Shielded valve box

Materials irradiation monitoring and control facility

Capsule segmentation and loading cells

Inside upper fuel element

Inside upper fuel element

Reflector

Reflector

Reactor poil

Experiment pool

Third floor of reactor building

Adjacent to main control room

Third floor of reactor building

Isatope production facilities

\section{Reflector Irradintion Facilitics:}

HT-1 Hydraulic rabbit tube

HT-3 Hydraulic rabbit tube

HT-4 Hydraulic rabbit tube

VH-1 Vertical irradiation facility

VH-2 Vertical irradiation facility

VH-3 Vertical irradiation facility

VH-4 Vertical irradiation facility

Reflector

Reflector

Reflector

Reflector

Reflector

Reflector

Support malities:

Refiector

Rabbit loading and handling facilities

Target handling facilities 


\section{2-55}

Table 24. (continued)

\begin{tabular}{lll}
\hline Number & \multicolumn{1}{c}{ Facility } & \multicolumn{1}{c}{ Location } \\
\hline \multicolumn{3}{c}{ Analytical chemistry facilities } \\
Activation analysis facilities: & \\
PT-1 Pneumatic rabbit tube $(2 \mathrm{cc})$ & Reflector \\
PT-2 $\quad$ Pneumatic rabbit tube $(40 \mathrm{cc})$ & Reflector \\
PT-3 $\quad$ Pneumatic rabbit tube $(40 \mathrm{cc})$ & Reflector \\
PT-4 $\quad$ Pneumatic rabbit tube $(40 \mathrm{cc})$ & Reflector \\
PT-5 $\quad$ Pneumatic rabbit tube $(40 \mathrm{cc})$ & Reflector \\
PF-1 $\quad$ Pneumatic rabbit tube $(120 \mathrm{cc})$ & Light water pool \\
PF-1 $\quad$ Pneumatic rabbit tube $(120 \mathrm{cc})$ & Light water pool \\
Positron facilities: & \\
& Krypton irradiation facility & Reflector (TBD) \\
& Positron beam facilities & Second floor, reactor building \\
Materials analysis facilities: & \\
GIF & $\gamma$-irradiation facility & Spent fuel pool \\
Support frcilities: & \\
& NAAF-1 facility & Reactor building \\
& NAAF-2 facility & Research support building \\
\hline
\end{tabular}




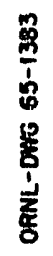

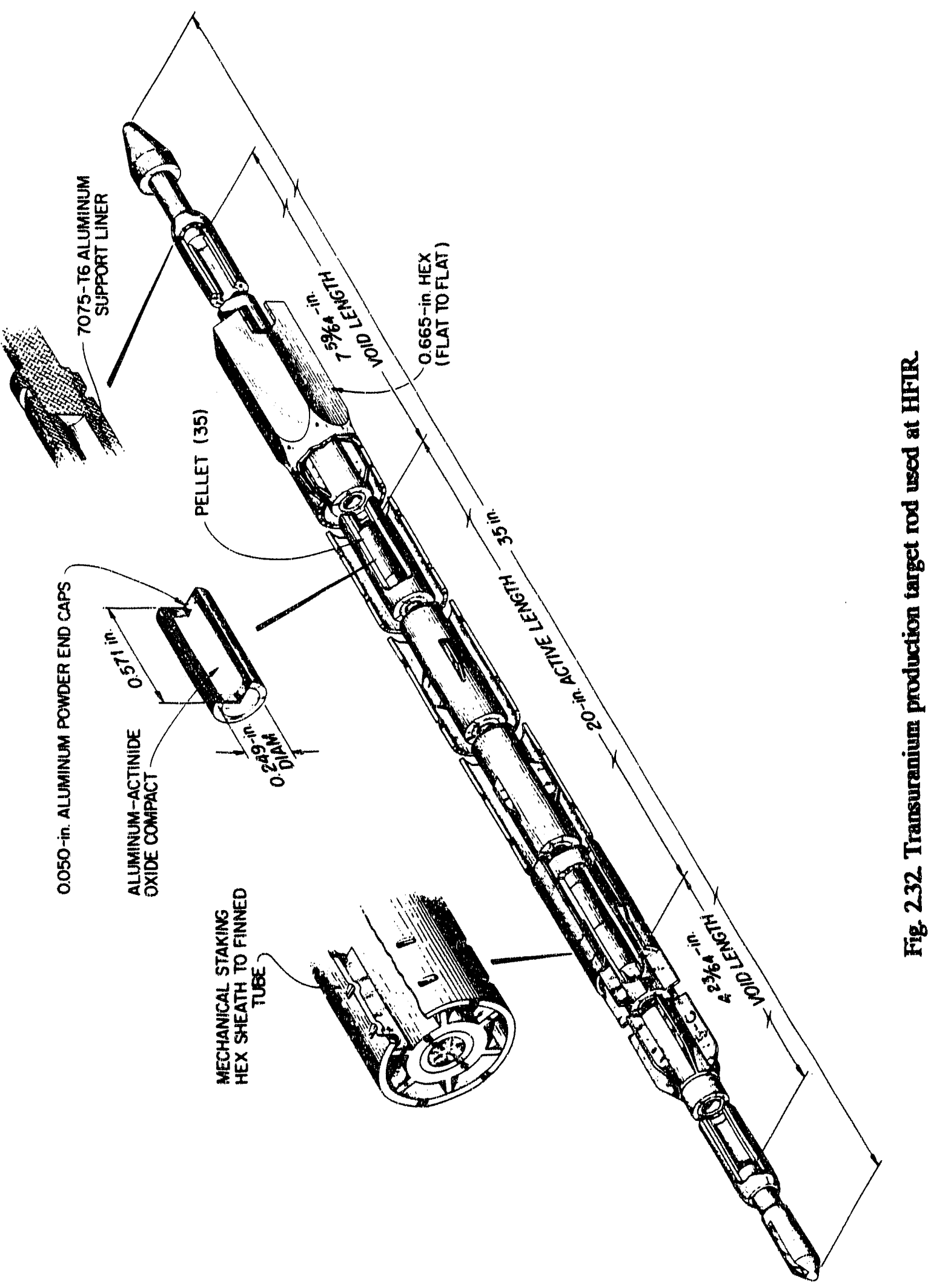


noninstrumented capsules are $16 \mathrm{~mm}$ in diameter. Both are $500 \mathrm{~mm}$ long. The capsules are attached to the materials irradiation target support assembly and are cooled by water exiting the lower fuel element. Heat is removed from specimens inside the instrumented capsules by conduction through a gas mixture and through the capsule tube wall to the primary coolant. The temperature of the samples is controlled by changing the mixture of gases to vary the thermal conductivity of the gas. A continuous flow is provided to ensure mixing of the gases. Noninstrumented positions can be shifted radially for spectral tailoring.

The materials irradiation targets are removed as one assembly by the refueling system and are Iransferred in the controlled atmosphere of the refueling cell to the light water pool. From there, they are moved to the storage pool experiment handling facility, where they are disassembled using long-handled tools. Thermocouple wiring and capillary gas lines will be routed from the experiment array flange assembly, through the refueling tunnel, to thermocouple and capillary gas line junction boxes in or adjacent to the light water pool. From the junction boxes, the lines will go to the shielded valve box assembly. Overtemperature protection and/or monitoring for loss of experiment pressure will be provided through the reactor control system to avoid irradiated capsule conditions that could result in reactor component damage.

Capsule segmentation and loading cells are located on the third floor of the reactor building. One of the cells extends over the light water canal, allowing experiments to be brought into the cells directly from the pools. One hot cell is equipped to cut off the sample end of a material irradiation capsule and to transfer the sample to a second hot cell for shipping in a cask or through the canal system. Facilities are provided for disposing of activated scrap. A laydown area is provided on the third floor of the reactor building for delivery of new capsules. Capsules are moved from the laydown area into the storage pool esperiment handling facility for final assembly and loading into the irradiation facilities.

A shielded valve box is located on the third floor of the reactor building. Remote valves operate the gas systems; the gas supply cylinders are located adjacent to the shielded enclosure. The materials irradiation monitoring and control facility is located adjacent to the main control room. This allows direct communication between the reactor operators and the materials irradiation control room.

\subsection{Reflector and Pool Irradiation Facilities}

Irradiation facilities in the reflector include static facilities; both hydraulic and pneumatic rabbit tubes; and support programs for transuranic isotopes production, production of other industrial and medical isotopes, materials irradiation, and analytical chemistry.

Two irradiation facilities are provided adjacent to the core pressure boundary tube for irradiating materials in a relatively hard spectrum. These are slanted to clear hardware at the top of the reactor assembly. Each facility holds an instrumented capsule $46 \mathrm{~mm}$ in diameter by $300 \mathrm{~mm}$ long. The facility tubes terminate in the light water reactor pool. They are designed for the replacement of capsules after the reactor is shut down and the facility has been drained of heavy water, blown dry, and reflooded with light water. The therrnocouple wires, capillary gas lines, and a strain relief line form a cable from the capsule to a connector assembly held in a support bracket near the top of the enclosure. The cable is routed around a weighted sheave that prevents crimping of the gas lines. After the connector is pulled apart, the cable attached to the capsule is reeled up around the drum until the capsule clears the facility. The entire assembly, with the capsule remaining under pool water for shielding, is then moved to the experiment handling area in the storage pool. The new capsule is inserted by reversing the previous steps. 
The gas and instrument leads are coupled to the shielded valve box used by the in-core facilities. Capsule conditions are controlled from the materials irradiation monitoring and control facility.

Figure 2.33 depicts the array of hydraulic and pneumatic tube facilities included in the ANS. Three of the hydraulic tubes are used for production of industrial and medical isotopes; HT-2, which terminates in a relatively hard spectral region near the core pressure boundary tube, is used for special transuranium isotope production activities. The hydraulic tubes terminate in a hot cell in the high bay of the reactor building; manipulators are used to insert and remove the targets. Targets can be loaded into shielded containers directly from the hot cell bank or can be moved through the pools to any of the other handling facilities.

The pneumatic tubes are used for activation analysis. Five pneumatic tubes enter the outer regions of the reflector, where the thermal neutron flux is still relatively high but heating rates have fallen significantly. Two of the pneumatic tubes extend into the light water pool outside the reflector vessel. These are used with samples that cannot be exposed to the heating rates encountered inside the reflector. The pneumatic tubes terminate in facilities located in the high bay of the reactor building. These facilities include a counting station for very short-lived isotopes and a transfer station to pneumatic tubes that communicate with counting facilities located in the research support building in an area of low radiation background. This approach ensures that pneumatic tubes outside containment do not communicate directly with the reactor assembly.

Four vertical irradiation facilities are located in the outer volume of the reflector vessel. These are used for irradiating larger targets for the industrial and medical isotopes programs. Hydraulic pressure is used to insert the targets in the irradiation position or to return targets to a holding position above the reactor assembly. The holding position is valved off, purged of heavy water, dried, and reflooded with light water. The top of the facility is then opened, and the target is removed through the light water pool.

A facility is provided in the reflector vessel for irradiating krypton gas in support of a positron facility, which is not included in the initial scope of the ANS. Positrons are produced by the decay of ${ }^{79} \mathrm{Kr}$, which has a half life of $35 \mathrm{~h}$. Krypton gas is introduced into an irradiation facility in the reflector vessel for irradiation periods of approximately $100 \mathrm{~h}$. After irradiation, the gas is pumped to a cryogenic condensation station located in space reserved on the second floor of the reactor building. Neon gas then will be condensed on the krypton layer as a moderator. Slow positrons will be directed through beam lines to experiment stations in the second floor experiment area.

A gamma irradiation facility will be located in the fuel storage area. It will use the gamma radiation emitted from one or more spent fuel elements to irradiate paints, plastics, and other materials to allow an evaluation of the damage that high doses of gamma radiation cause to these materials.

\subsubsection{Experiment Support}

Experiment support facilities include a number of laboratories and work areas, many of which are located in the research support building. Cryogenic, high temperature, high pressure, and magnet laboratories are provided for developing and maintaining specialized sample environment systems. Chemistry, biochemistry, and polymer laboratories are provided for sample preparation activities. A support laboratory is provided for calibrating and testing hardware for nuclear and fundamental physics experiments. A crystal growth laboratory is provided for making monochromator and analyzer crystals. 


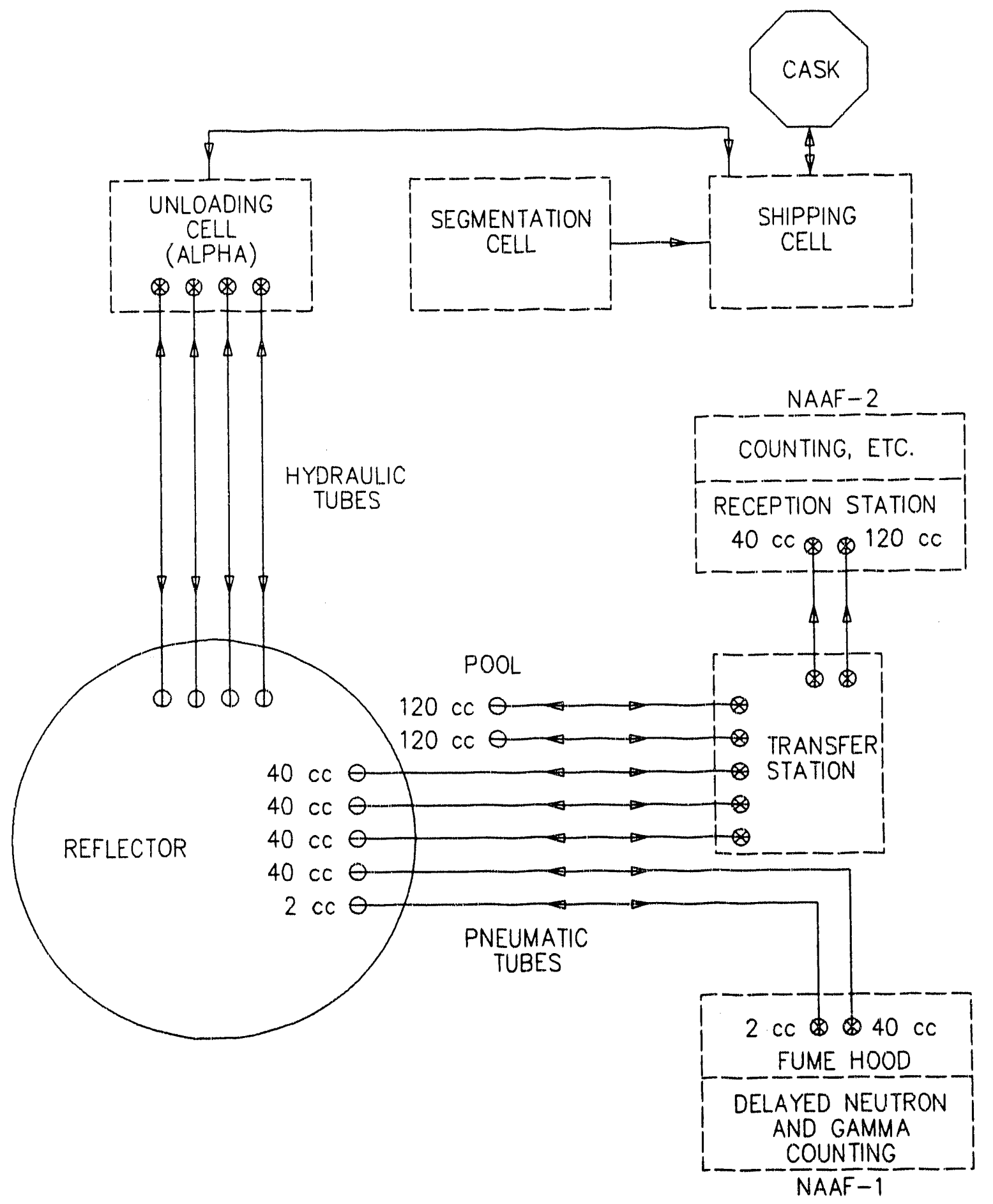

Fig. 233. Schematic diagram of the pneumatic and hydraulic tube systems. 
A work area is provided in the immediate vicinity of each instrument for final sample preparation before mounting the experiment so that new samples can be ready for immediate use when a sample (or user) change takes place. This area will be provided with a standard set of utilities including electric power, plant process cooling water, vacuum pump exhaust, and gas services.

Machine and instrument shops and storage areas are provided for experiment support. A small machine shop is provided for use by experimentalists needing to make small modifications to their experiment as it progresses. An off-line assembly facility with an area equal to the largest experiment station is provided. This facility is readily accessible to truck delivery and serves as a staging area for moving equipment to or from any experiment station in the beam room or guide hall.

An experiment systems computer networls is provided. All of the individual, dedicated computers at the instruments are tied to this network. The network allows communication to remote locations, including office areas, ORNL computing facilities, and national networks. The network also provides access to mass data storage devices on the ANS site and backup storage at ORNL.

\subsection{BUILDINGS}

\subsubsection{Architectural Concepts}

The ANS includes a central building complex and a number of service structures (and possibly guest facilities) on the site surrounding the main complex. The facility is arranged so that functional groupings (e.g., staff groups, plant systems, radioactivity containment, and security) are maintained in designated areas, and so that the most common transit is between areas adjacent to each other. The entire complex is segregated into research and operations zones, which aids programs for security and contamination control and provides fundamental separation of the research and operations environments. The activity and security zones in the main complex are depicted in Fig. 2.34. The central structure is the reactor building; the beam room and half of the second floor are classified as a research zone, and the high bay and the other half of the second floor are in the operations zone. The main entry to the facility is at the front of the office building. As seen in Fig. 2.34, an access control zone extends from this entry to various control points allowing entry to the offices, the laboratories and guide hall, the beam room, or the operations zones. A reception area is located in an entry atrium immediately inside the main entrance. Security badging, visitor training, and health physics functions are located in the interface area. Identification provided by the receptionist is adequate for access to the office building and designated visitor areas. Badging is required for access to the laboratories, the guide hall, or the beam room. Additional controls are placed on beam room access to ensure personnel accountability, although the beam room is readily accessed by outside users. The operations areas outside the reactor building are divided into (1) a large reactor support building that houses the plant systems and the main control complex and (2) an operations support building that houses offices, shops, change rooms, and training facilities for the operations staff but contains no major equipment or radioactive materials.

Zoning outside the main building complex is seen in Fig. 2.3. An overpass over Melton Valley Road provides normal access to the candidate site from the north. This allows transfer of casks containing radioactive material on a closed road (Melton Valley Road) while keeping access to the site open for users. The main parking area is at the northwest corner of the site; a guest 


\section{ENTRY}

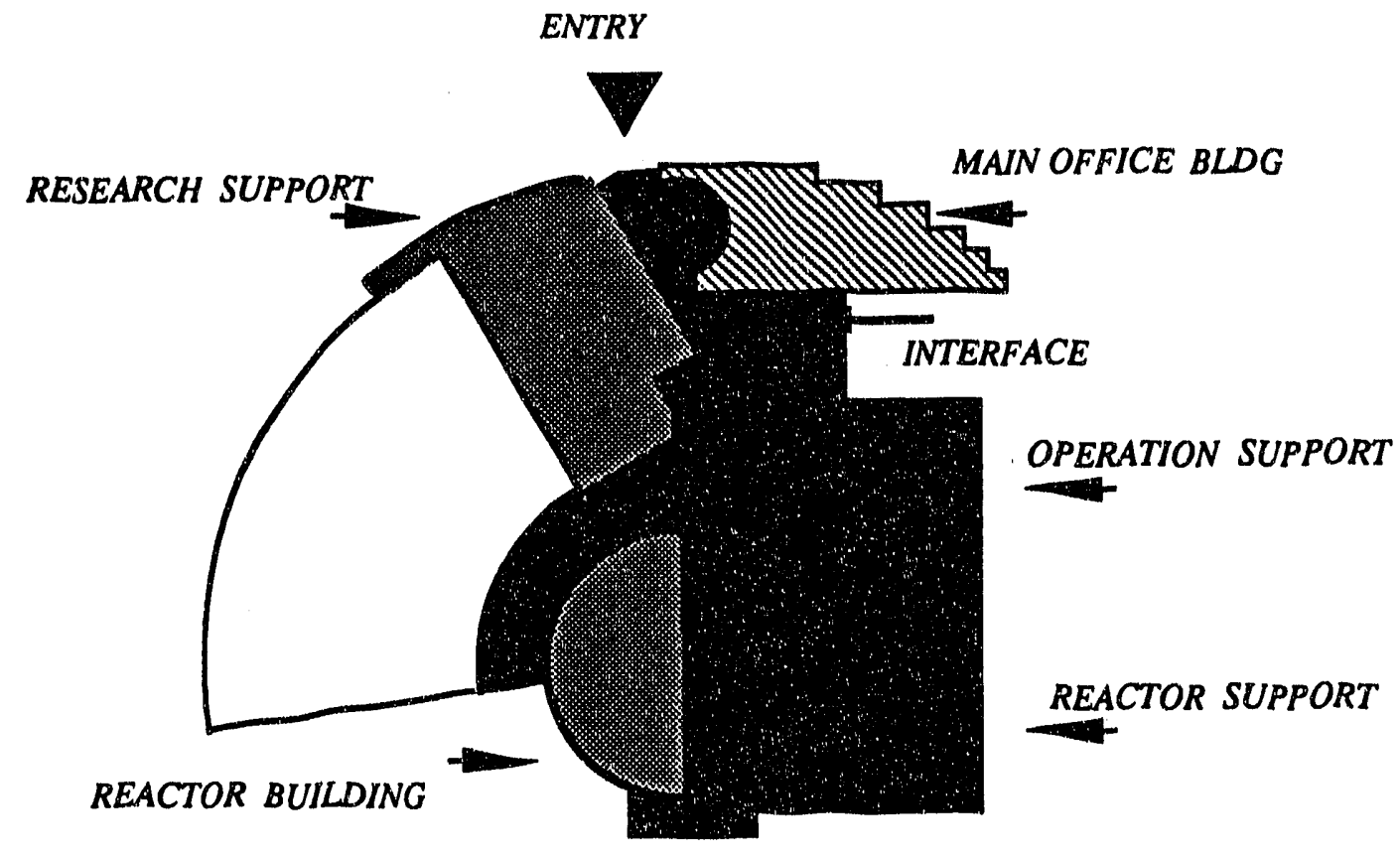

\section{SECOND ELOOR}

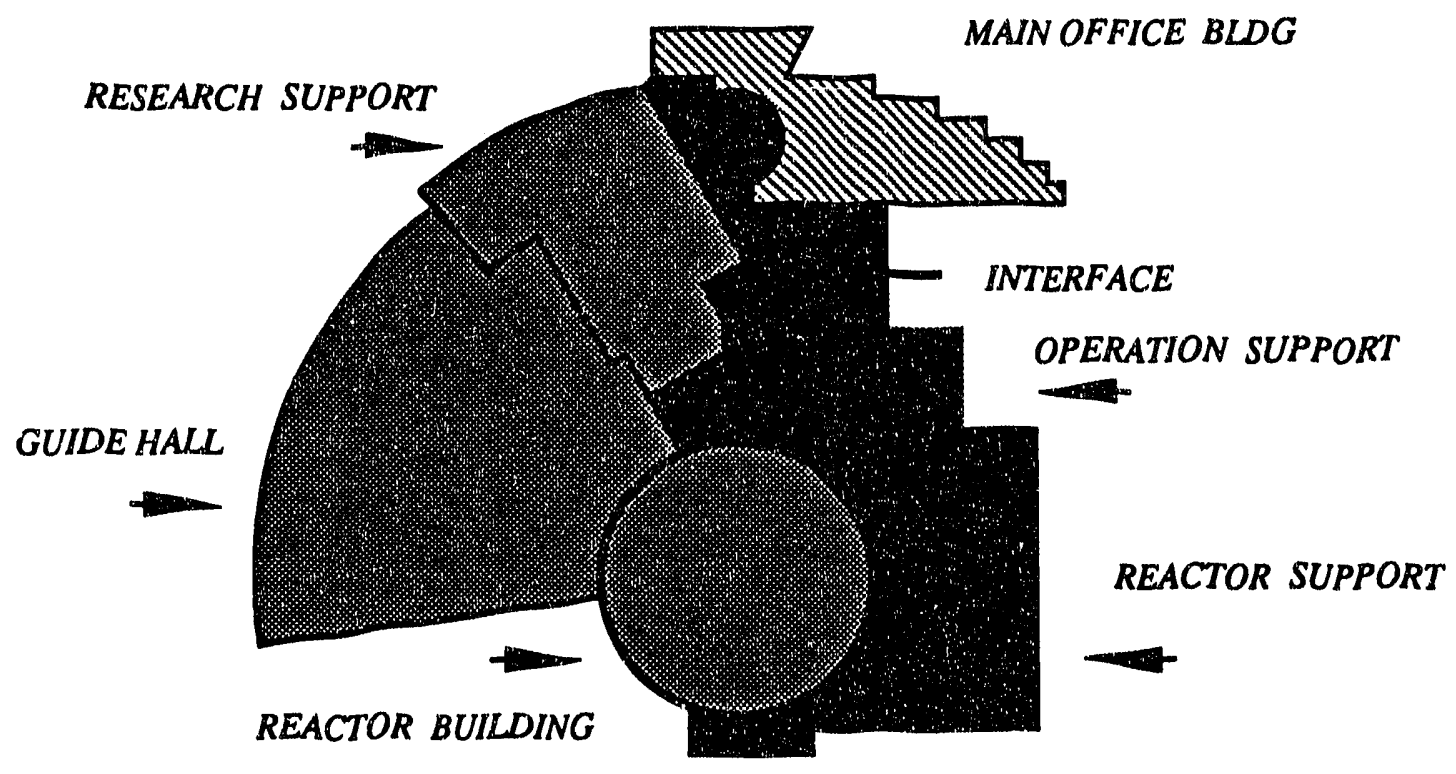

EIRST ELOOR

ACCESS CONTROL

SCIENTISTS/VISITORS

EXPERIMENTS

OPERATIONS

Fig. 234. Activity/security zones in the ANS complex. 
housing facility also may be constructed at the far corner of this area. Traffic to facilities south of the ANS has been rerouted to the west of the complex. A portal is located at the entrance to the parking areas; personnel are screened at this point to determine whether they require access to the site. The entire site is encircled with a standard fence to delineate the site boundary and establish site control.

Facilities within the secure operations zone are encircled by a double fence provided with an intrusion detection system. Facilities inside this fence include the detritiation buildings, the electrical substation, the diesel generators, and the operations zone of the main complex. The secure boundary passes through the interior of the main complex between the research and operations zones. Normal access to the secure area is through the portals in the interface area of the main complex; an alternate entry leads directly to the detritiation facility. The cooling towers and remote stack do not need to be inside the instrumented security fence and are encircled by standard fencing.

\subsubsection{Candidate Site}

The candidate site for the ANS was selected uing a methodology developed by the Atomic Industrial Forum and using the Oak Ridge Reservation as the region of interest. The process is documented in a site selection report. The issue of whether alternate sites off the reservation must be considered is still being debated. Until the NEPA process is complete and a record of decision is issued, no site is selected.

The buildings have been located on the candidate site in a manner that best uses the existing slope, that places the foundations of the reactor and reactor support buildings on sound bedrock, and that provides for a stable foundation for the large guide hall. Cut and fill studies were used to optimize building elevations and orientations on the site. Systems that remove decay heat from the reactor-including the cooling towers, the tower basin pools, and the structures housing the primary and secondary cooling system equipment-are arranged with the appropriate elevation changes to make natural circulation cooling modes possible and to allow water to drain from the towers to the basin pools. This arrangement leads to the location of the towers and a water storage tank on a hill in the eastern part of the site. The detritiation facility is located away from the main complex, to the south, so that hydrogen safety concerns do not affect the main complex.

Grading plans for the candidate site are shown in Fig. 2.35. Criteria for the grading plan include providing stable slopes throughout the site, providing appropriate fill for structures not set on bedrock, maintaining acceptable grades on roadways, providing appropriate access to buildings, and allowing stormwater drainage and control.

The candidate site drains in two directions. About $20 \%$ of the site drains to the east along the northern site boundary. A stormwater retention pond is located north of the main complex. This pond is designed so that a constant water level is maintained, providing a visual feature along the front of the office building. The remainder of the site drains south and west. A retention pond is located at the far southwest corner of the site to prevent flooding and erosion as a result of stormwater runoff.

\section{Reactor Complex}

The main structures of the ANS complex are shown in Figs. 2.36 through 2.43. Fig. 2.36 shows a section across the guide hall, reactor, reactor support, and compressor buildings. Figure 2.4 presents a plan view of the ground floor at the elevation of the reactor centerline. Figure 2.37 shows the plan view across the ground floor of the reactor and reactor support 


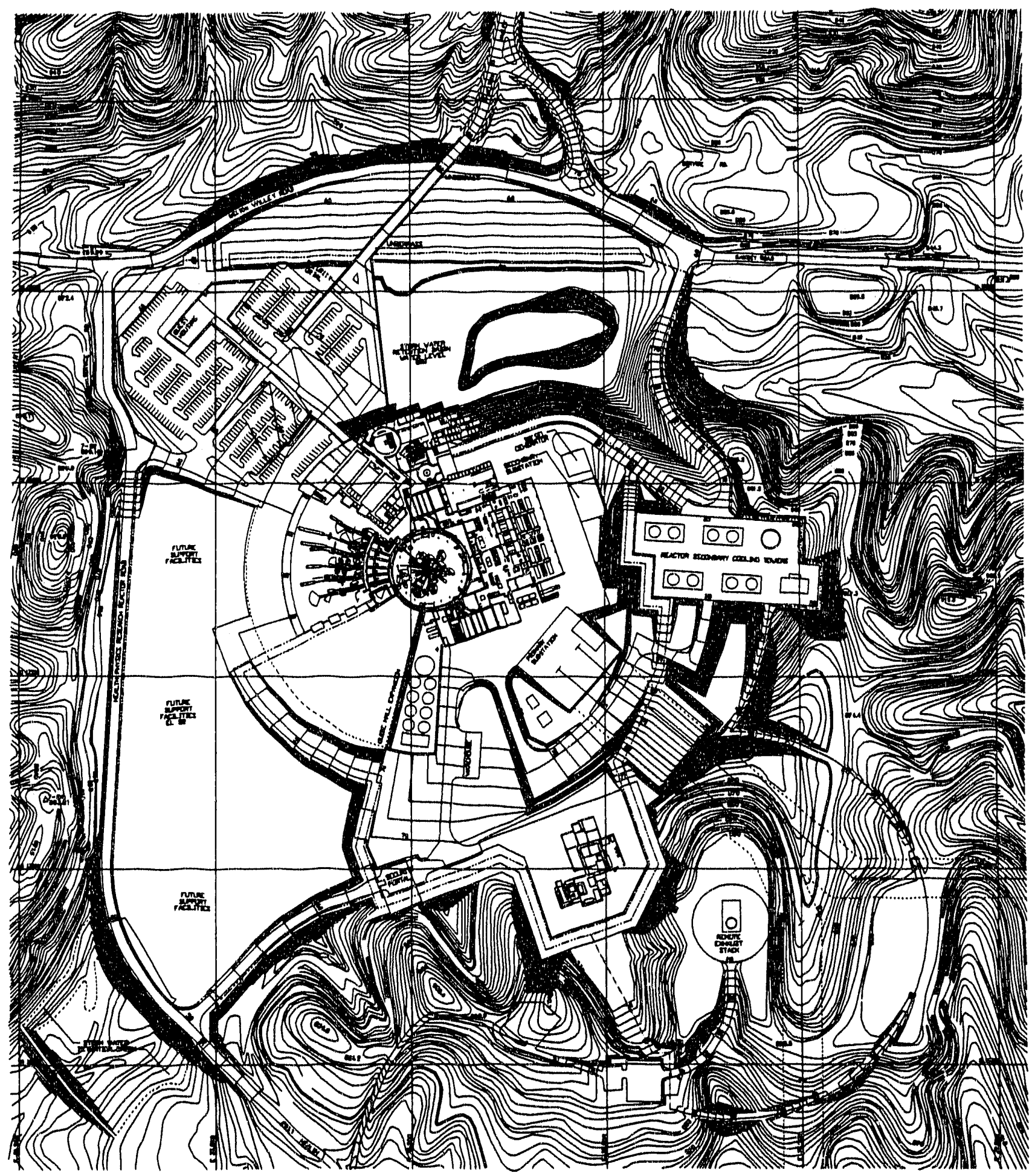

Fig. 235. Grading plan for the candidate site. 


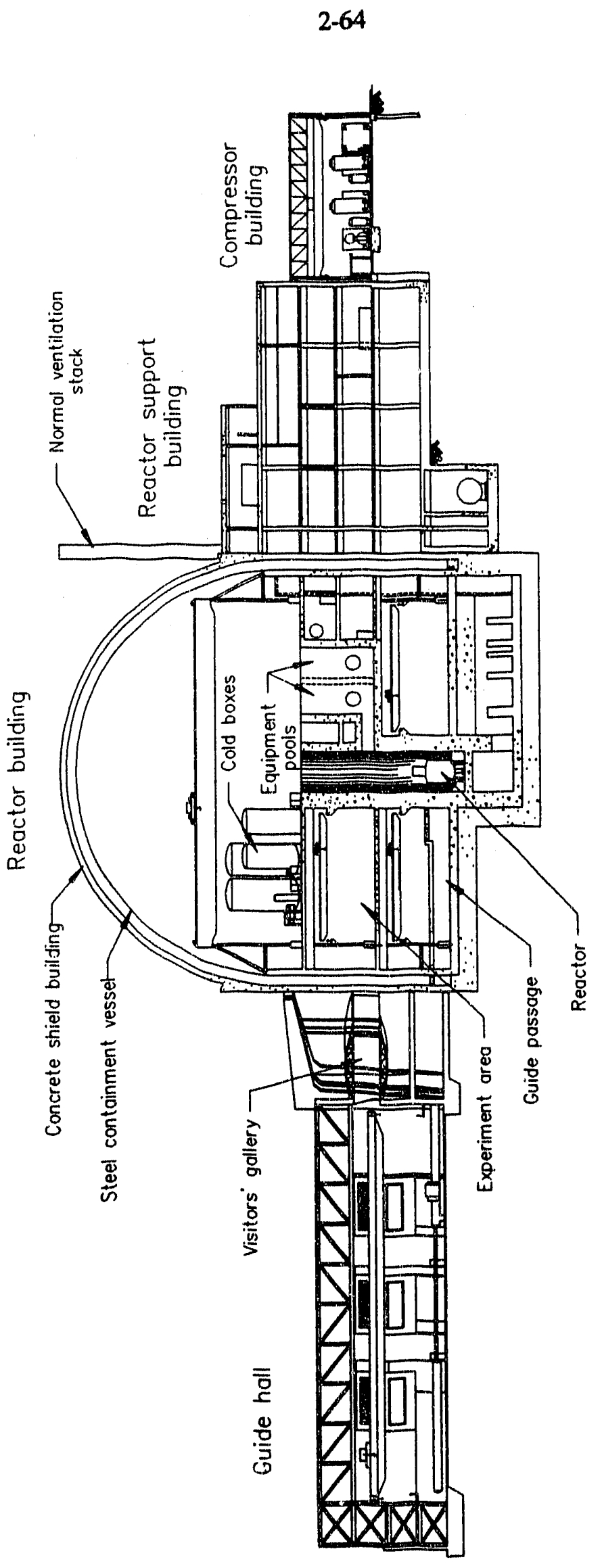

웅 


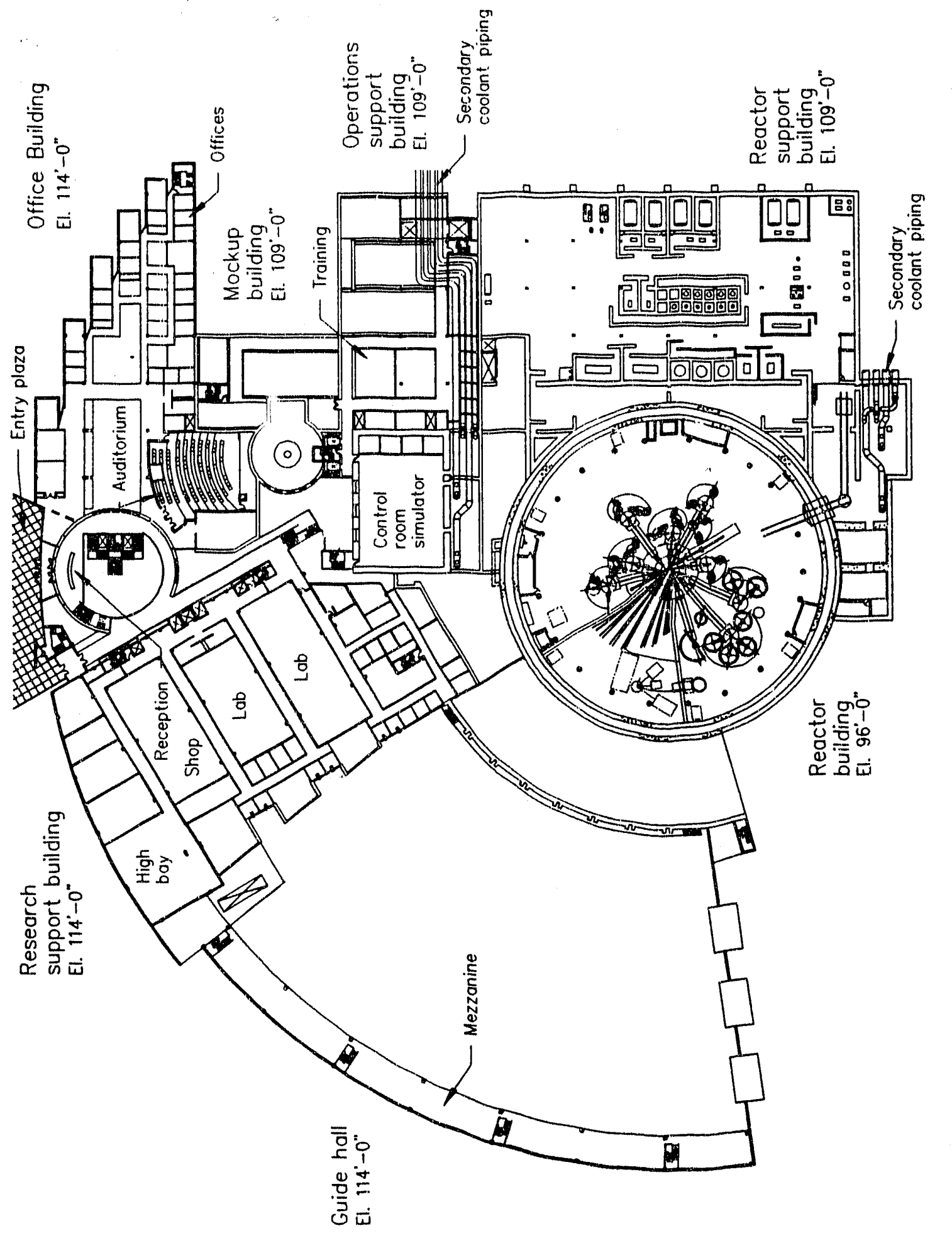

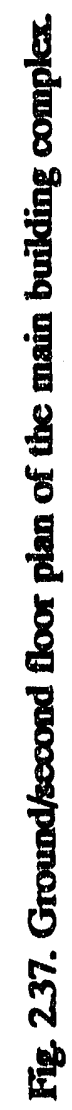


buildings and the second floor of the other buildings. Because the ground floor of the reactor and reactor support buildings have a higher floor to ceiling clearance than the other buildings, both the ground and second floors of the other building areas communicate with this floor. The floor level of the rest of the structures is similarly staggered. The second and third floor plan is shown in Fig. 2.38; the third and fourth floor plan (the second floor of the reactor building again extends an extra floor) is shown in Fig. 2.39; the reactor high bay, fourth floor of the reactor support b Iding, and fifth floor of the other structures are shown in Fig. 2.40; and the reactor high bay, reactor support building roof plan, and sixth floor of the other structures are shown in Fig. 2.41. Plan views of the top floor of the office building and of the basement structures are not given here. Figure 2.42 depicts a section across the office, operations support, reactor support, and reactor buildings, looking south. Figure 2.43 is a section showing the foundations of the reactor, reactor support, guide hall, and compressor buildings. The building drawings listed in Chapter 9 provide a wide range of information on the plans and sections given in the figures and cover additional plan and section views.

The reactor building is constructed on a thick, reinforced concrete basemat set directly on bedrock. The steel containment vessel extends from the basemat to the steel inner dome; a liner embedded in the basemat structure completes the steel containment. Concrete walls inside the containment and the central biological shield structure support the floor structures inside the reactor building. A row of columns near the outer wall of the internal structure extends through each floor from the basemat to the high bay. These columns reduce the free span over the beam rooms and support the polar crane in the high bay. Concrete columns spanning from the biological shield structure to the outer concrete wall support the second floor. The walls of the heat exchanger cell banks are arranged so that they also act as structural members providing additional support and seismic restraint to both the second floor and the high bay floor.

The ground floor of the reactor building is dedicated to beam research. The reactor is at the center of this floor, and the beams and instruments fan out in all directions. A shielded enclosure covers the horizontal cold guides that pass across to the guide hall. Very cold and ultracold instruments are located on top of this structure. Personnel and equipment airlocks providing normal access to the experiment areas in the reactor building are located on the ground floor. The second floor of the reactor building is divided into an experiment area and an operations area. A thick concrete wall divides the two areas. The experiment area contains the large ISOL facility, the depth profiling and general purpose cold guide facilities, and space for the future addition of a positron facili ,. A stairwell or elevator from the beam room provide normal access to experiment area; an emergency airlock is located on the south end of the area. The operations side of the second floor is occupied by the spent fuel and transfer pools and by the flooded cells and the limited-volume dry cells containing the reactor and reflector cooling systems. The high bay of the reactor building is entirely within the operations zone. It contains the refueling equipment, the experiment "ot cells and irtadiation support facilities, a itional cooling system equipment, and the cold boxes for the cold source refrigerators. The normal airlocks for access to the operations zone are located in the high bay.

The reactor support and operations support buildings are actually a single reinforced concrete and structural steel framed structure, dirided by function. The reactor mockup building is a separate structure added on to these buildings. A basement area in the reactor support building houses the drain taniss for the heavy water inventory, a process waste sump tank, and leak detection systems. The ground floor contains the demineralizers, filters, and waste tanks. This floor is arranged for access to and maintenance of systems containing radioactive materials. The second floor proviciss overhead access to the filter and demineralizer systems and the means to transport materials to a waste stabilization and packaoing area. It also houser secondary cooling 


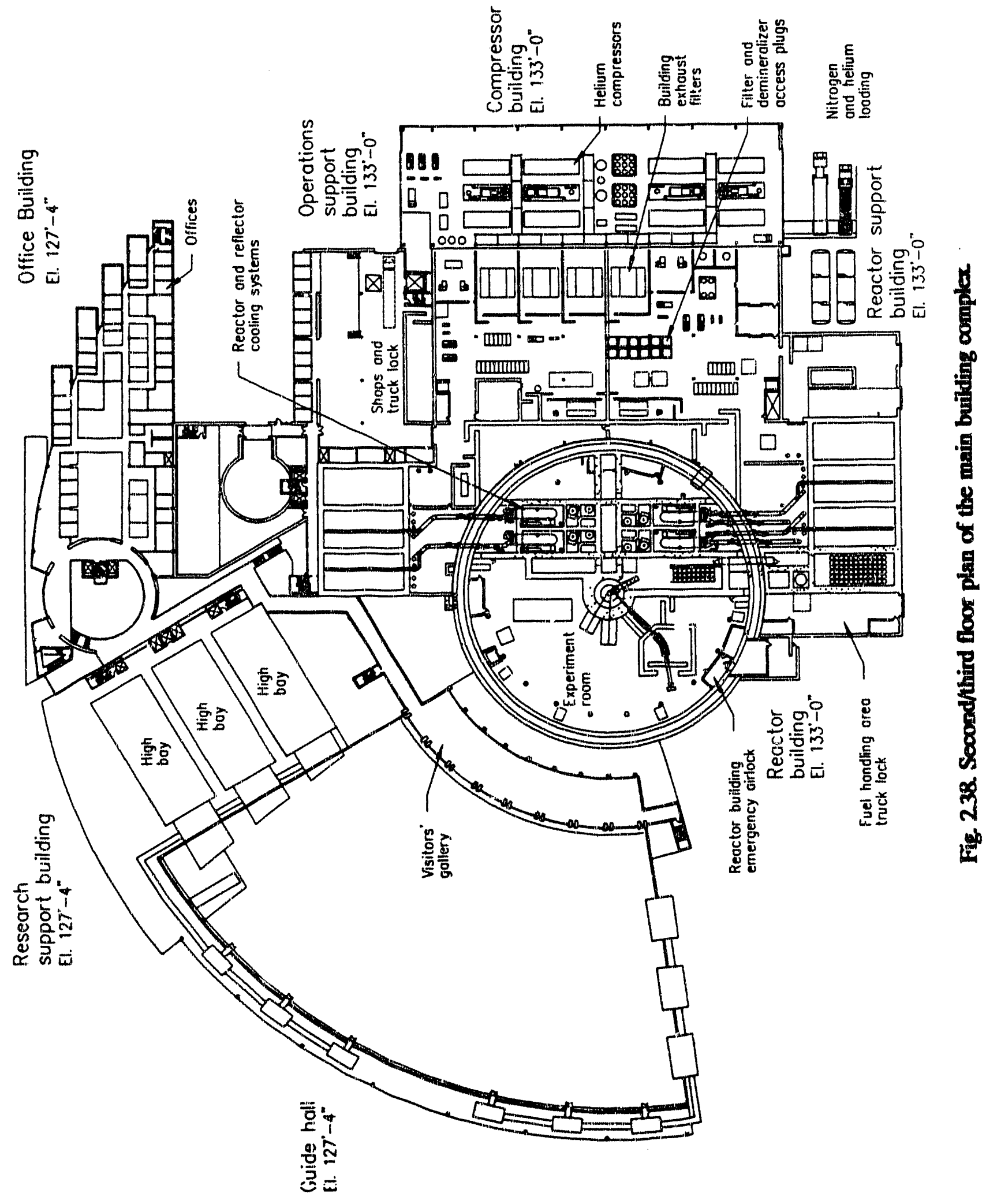




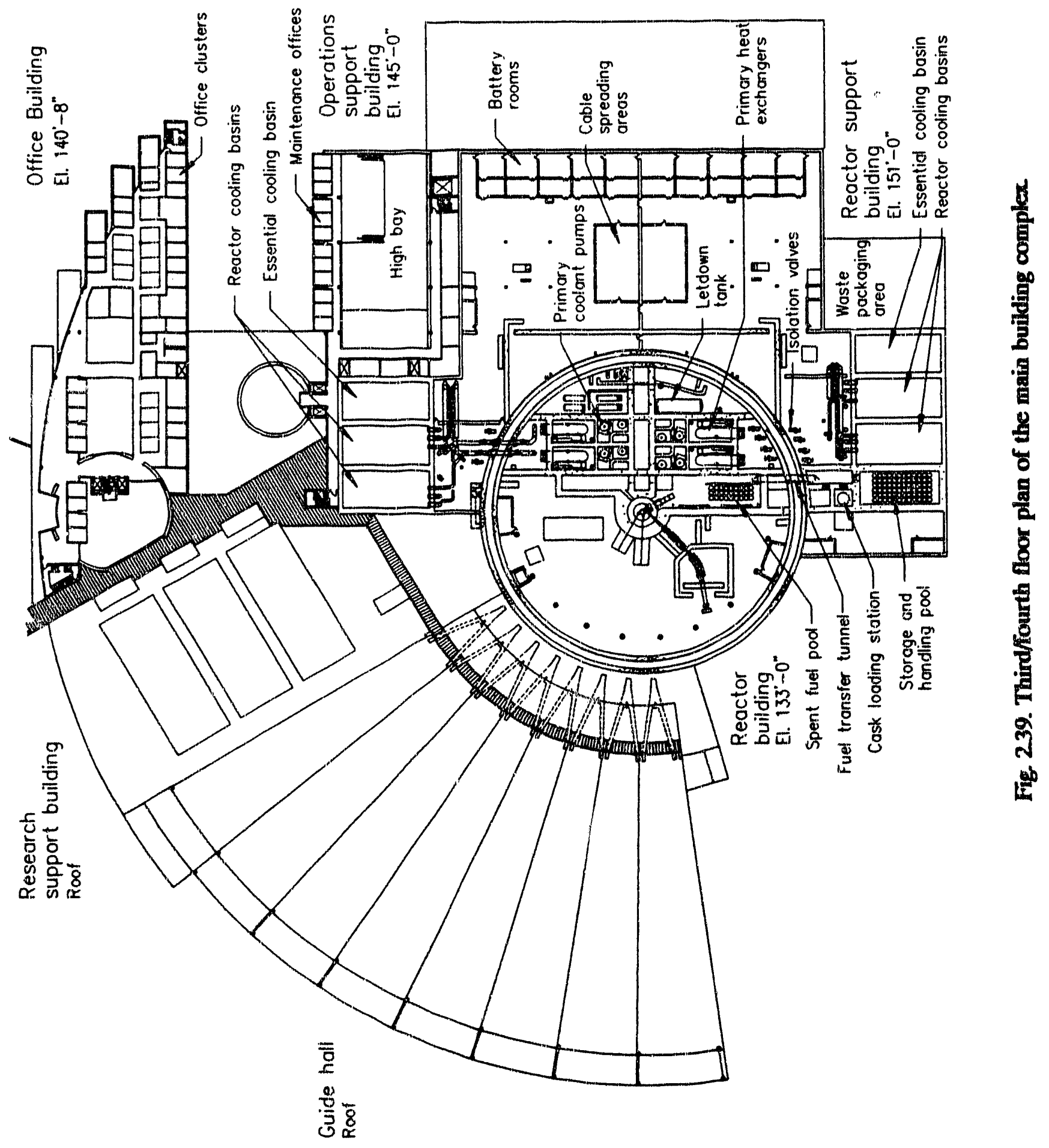




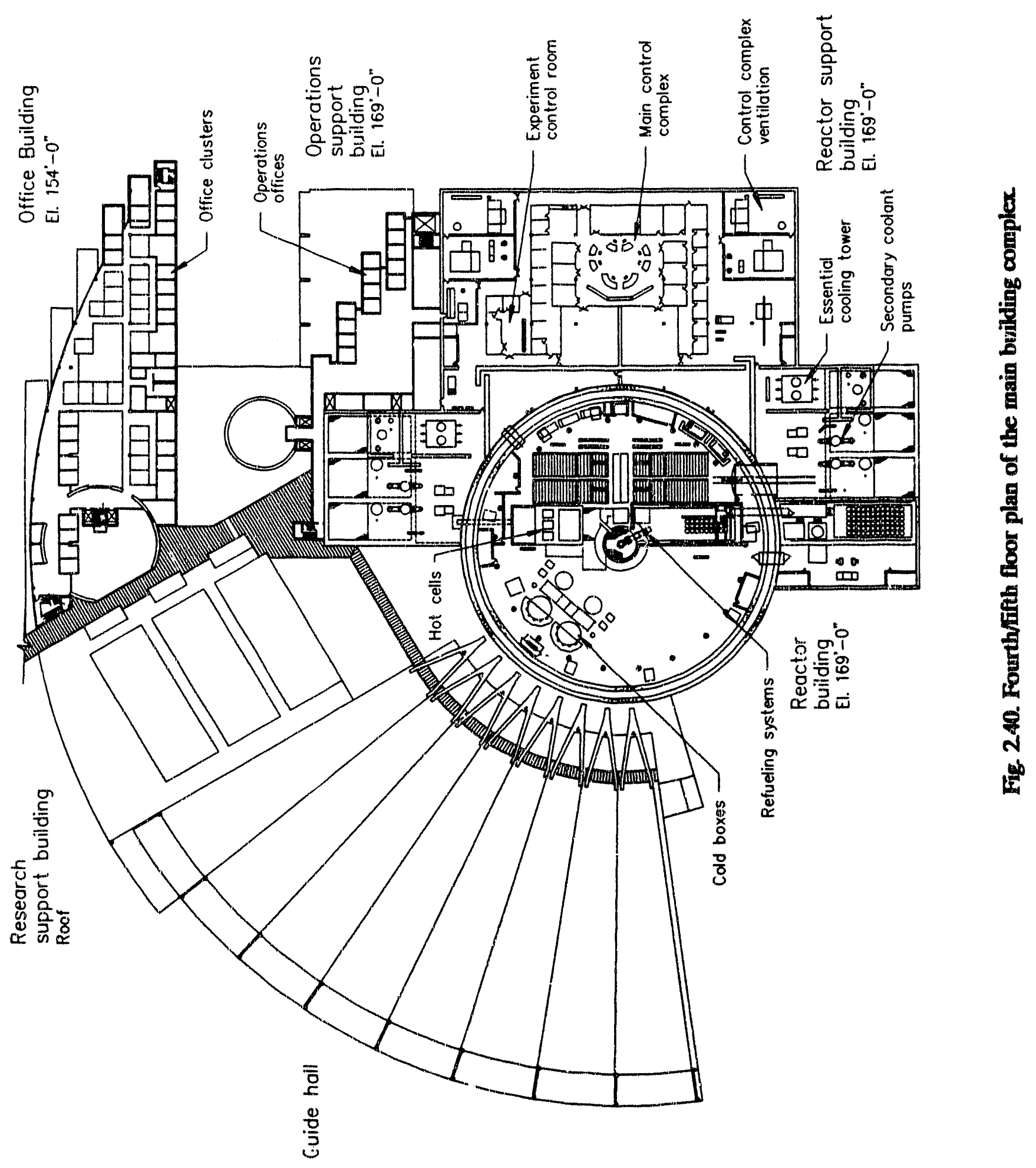




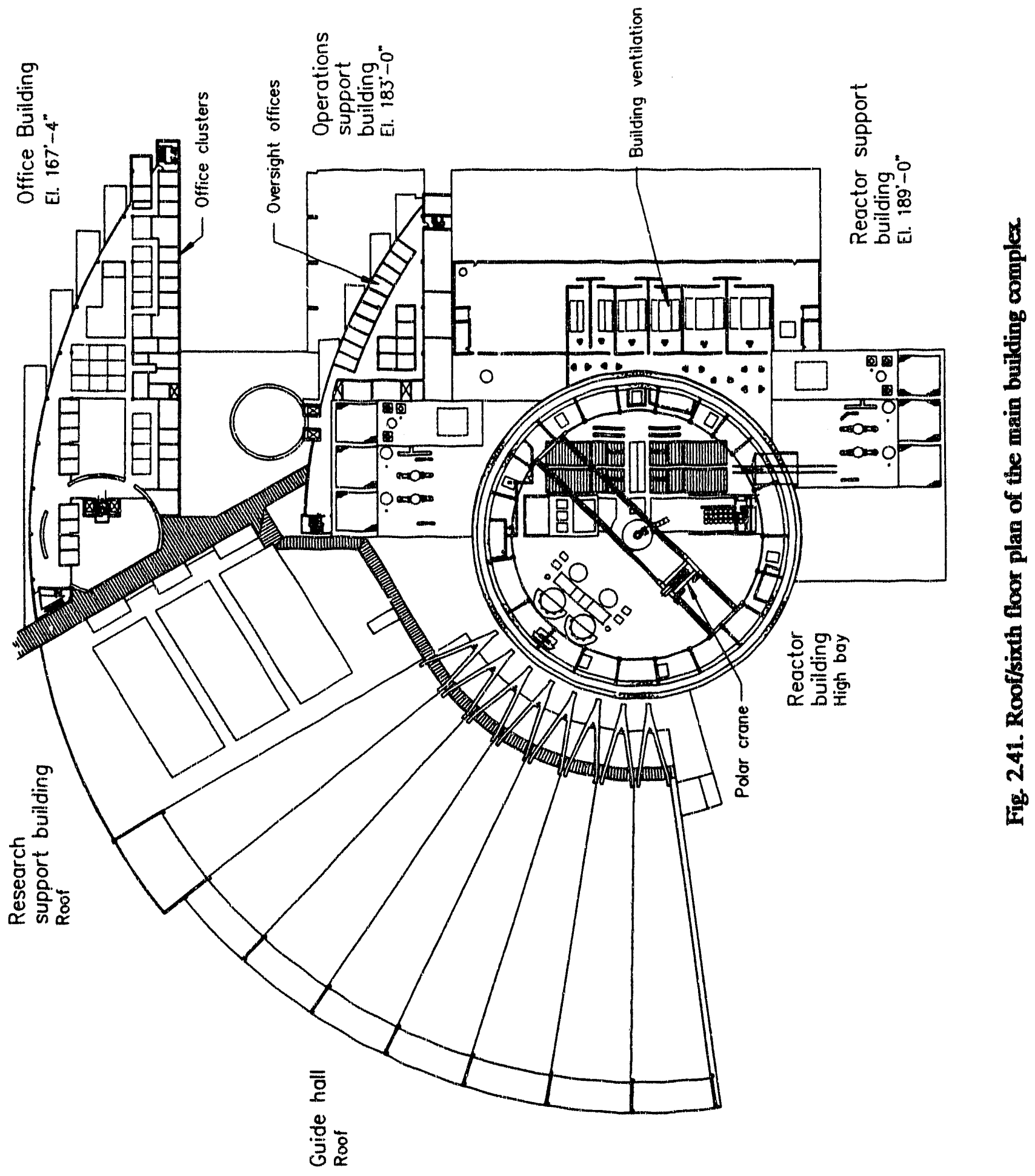




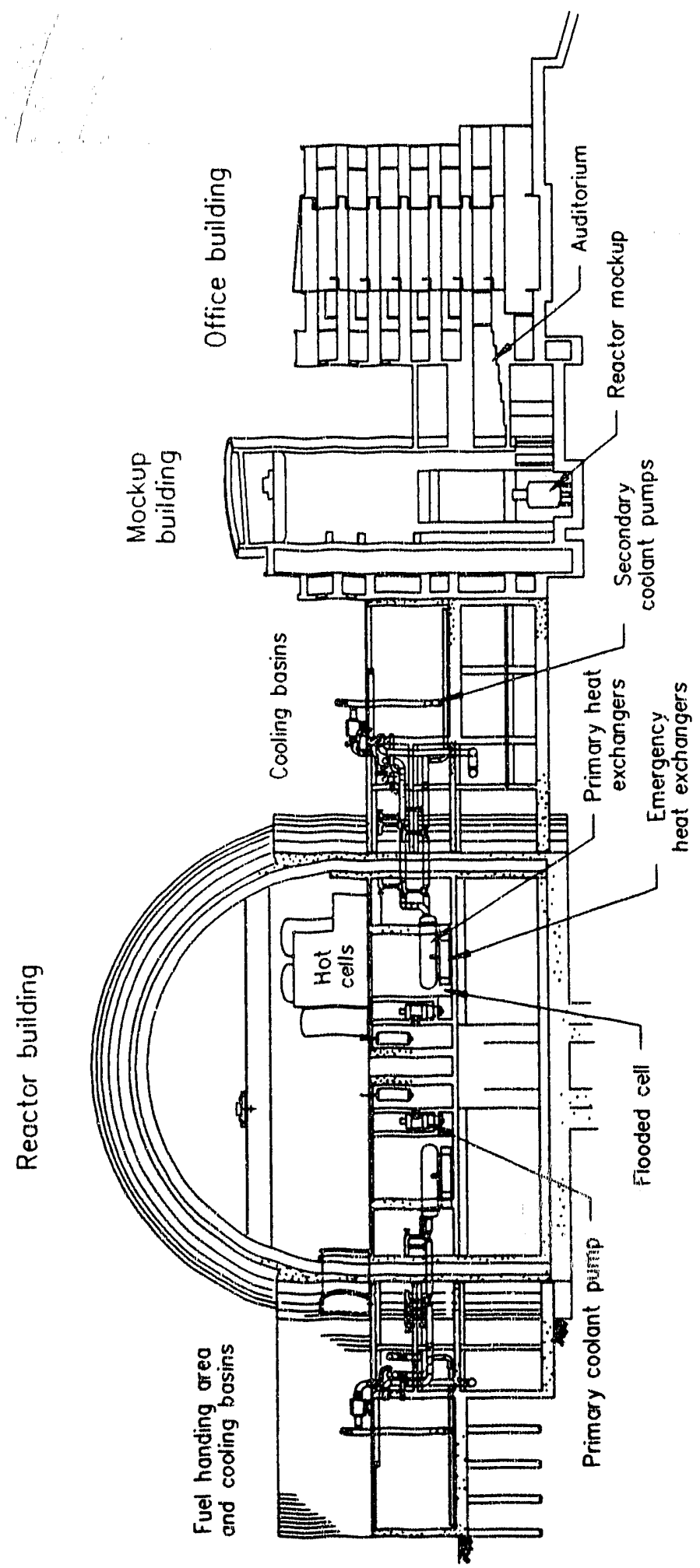


$2-72$

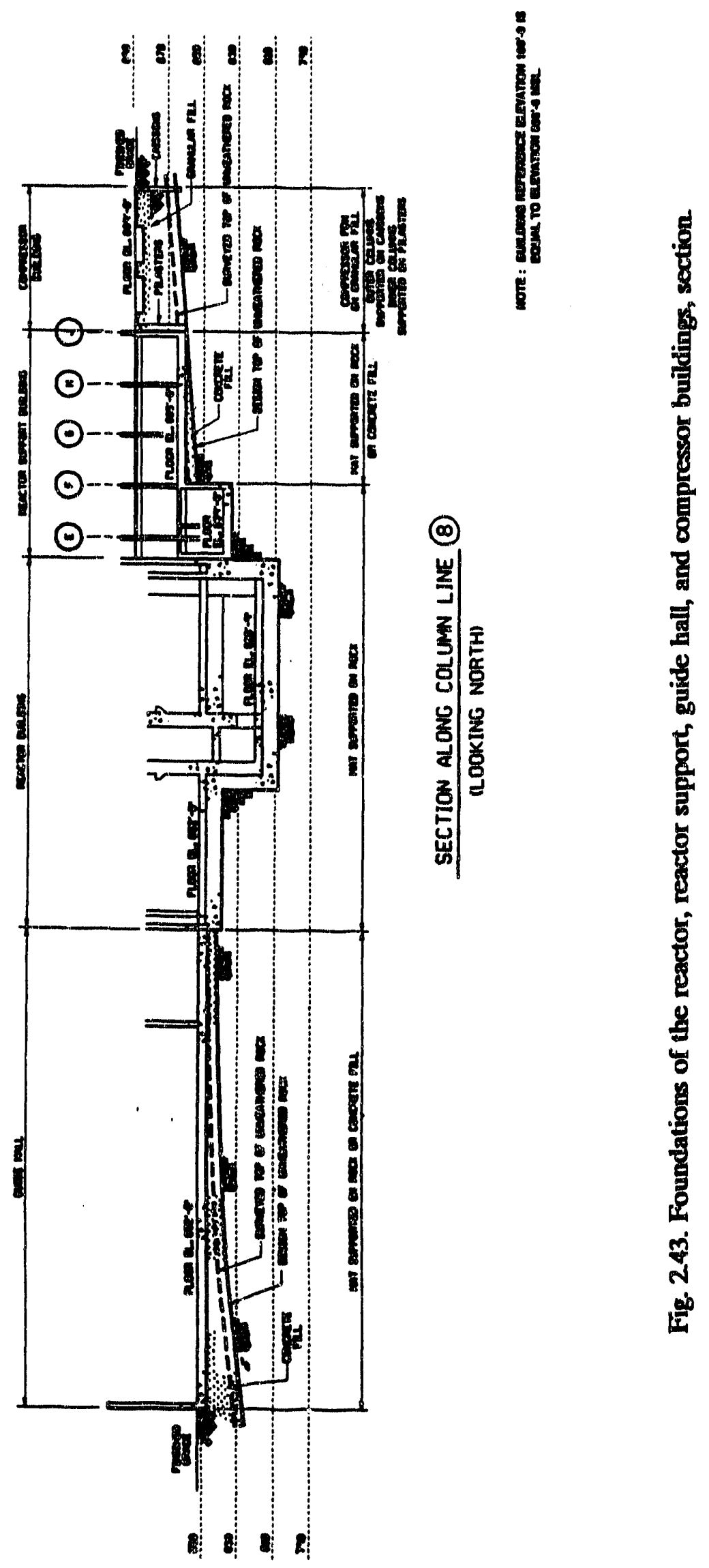


system piping and pools and the lower floor of a fuel handling area. Exhaust filters that might become contaminated are located on this floor. Nearly all of the systems that contain radioactive material are located on the lower floors of the reactor support building. The compressor building, housing the compressors for the cold source refrigeration system and the plant air systems, is east of the reactor support building. The third and fourth floors of the reactor support building contain electrical power distribution systems, battery rooms, cable spreading areas, and the main control complex. This complex, located on the fourth floor, includes the main control room, the technical support center, and key offices and support areas for the operations staff. Control room habitability ventilation systems are located adjacent to the control complex. Additional ventilation systems are located on the roof of the reactor support building.

The ground floor of the operations support building includes the portals that provide access to the beam room and the operations areas, the main change house for the operations staff, and an equipment room. The second floor includes the control room simulator, training facilities, and shops. The remote shutdown control room is located in the third floor of the operations support building, as are additional shop facilities, a truck lock, and offices for shop personnel. The upper floors contain additional offices, computer-assisted drafting rooms, document centers, and other operations support functions. The reactor mockup is located on the ground floor of the mockup building. This structure includes a tall, open central area capable of accommodating systems that mock up reactor assembly, refueling, and maintenance operations, including removal of the central control rod assembly. The lower floors of this structure also include other training facilities, and an elevator and stairwells are provided for access to the upper areas.

The guide hall is a large, open single-story structure enclosed by steel truss structures. A bridge crane provides coverage over all guides and instruments. The section of the guide hall adjacent to the reactor building is separate from the main hall. This structure includes a concrete protective and shielding enclosure around the guide array coming out of the reactor building, including the guide penetrations. An observation gallery is suspended from concrete supports that angle toward the reactor building, providing views of the research activities underway in the guide hall. The roof of the guide hall consists of vertical segments alternating with diagonally sloping panels, creating a sawtooth roof profile. The outer shell of the guide hall is provided with windows, and windows are provided in the vertical section of the roof segments. The result is a large, open environment with ample natural lighting.

The remaining buildings are structural steel beam and column structures topped with reinforced concrete floor slabs. The basement of the research support building contains the NAAF-2 facility, including counting rooms and sample receiving and handling areas. Numerous laboratories and shops are located on the ground floor. A truck lock located at the outer perimeter of the complex between the guide hall and research support buildings provides a means of bringing large research equipment into and out of the facility. Off-line setup areas for instrument assemblies also are provided in the ground floor of the research support building. The upper floors contain high bays over key shop facilities, support facilities for irradiation programs, and building ventilation equipment.

The office building provides space for office clusters for the ANS director, the ANS facility and reactor operations manager, the visitors' secretariat, the scientific coordinator, personnel from ORNL research divisions supporting user programs at the ANS, and other scientific support staff including both permanent staff and visiting users. The office building also provides space for a reception and orientation area, an atrium, meeting and lounge areas, an auditorium for 150 people, conference rooms, a library and media center, a computer room and communications center, food services and dining areas, and space for other support functions. 
The office building encompasses an entry plaza and entrance atrium, a central atrium, and offices and other rooms aligned around the building perimeter or an atrium. The arrangement is such that all closed offices or open work areas have some exposure either to the outdoors or to an atrium. The entrance atrium serves as a reference point upon entry to the complex and serves to conduct traffic to the other floors of the office and interface areas. The basement area of the entrance atrium leads personnel to the NAAF-2 facilities and other areas in the basement of the research support building. The ground floor corresponds to the lower service entrance into the office building. It provides passage to the research support building and ultimately to the guide hall. This floor of the office building includes food services, the library/media center, and other support and general areas that encourage interchange among members i research community.

The next level is the normal level of entry into the complex. An entry plaza leads into the entry atrium, while a direct corridor is established between parking areas and the major internal passageway into the buildings. Reception and security check-in facilities are provided just inside the entry plaza. The auditorium is located on this floor of the office building, and a series of offices and conference rooms for use by the research staff begin on this floor.

The next level of the office building includes a stairwell in the entry atrium that leads to the observation corridors and ultimately to the observation area overlooking the guide hall. This is the normal path by which members of the general public view the activities taking place in the ANS, and the public is allowed routine access to these areas during the daytime working hours. This floor and all higher floors of the seven-story structure continue with closed offices and open work areas serving the groups identified at the beginning of this section.

The interface area is not a building as such, but rather a functional area at the intersection of several of the major structures. The interface area provides the main corridor from the facility entrance into the center of the complex and carries personnel down to the level of the reactor building beam room and the entry into the operations support building (and from there into the reactor support building). Portions of the interface area are covered with a translucent material, creating a sense of openness.

\subsubsection{Other Structures}

The detritiation buildings shown in Fig. 2.44 house process, control, and support equipment for the heavy water detritiation and upgrade systems. The detritiation process building contains the actual detritiation process equipment, including all molecular hydrogen and all significant tritium inventories. This structure has a seven-story tower that encloses the catalytic exchange column and the cold boxes that surround the distillation process columns. Low roof portions of the process building house the tritium withdrawal and packaging systems (and the associated gloveboxes), off-gas recombiners, a deuterium gas makeup cell, and an expansion tank. The service building is physically separate from the process building; covered walkways are provided between the two. This pret ents releases in the process building from accumulating in the service building. The service building contains the local control room, the helium refrigeration system, ventilation and electrical systems, analytical laboratories, and offices and other personnel areas.

The cooling tower structures provide concrete basins and tower superstructures for the four reactor secondary towers and one nonessential cooling tower. The diesel generator building is a reinforced concrete structure supported by a 5 -ft-thick reinforced concrete mat on compacted structural fill. The roof and wall slabs are designed for tornado-generated missile protection. A missile-protected air intake structure is located on the roof; removable concrete missile shields are provided in front of the two primary access doors and the exhaust louvers. Interior concrete fire 


\section{2-75}

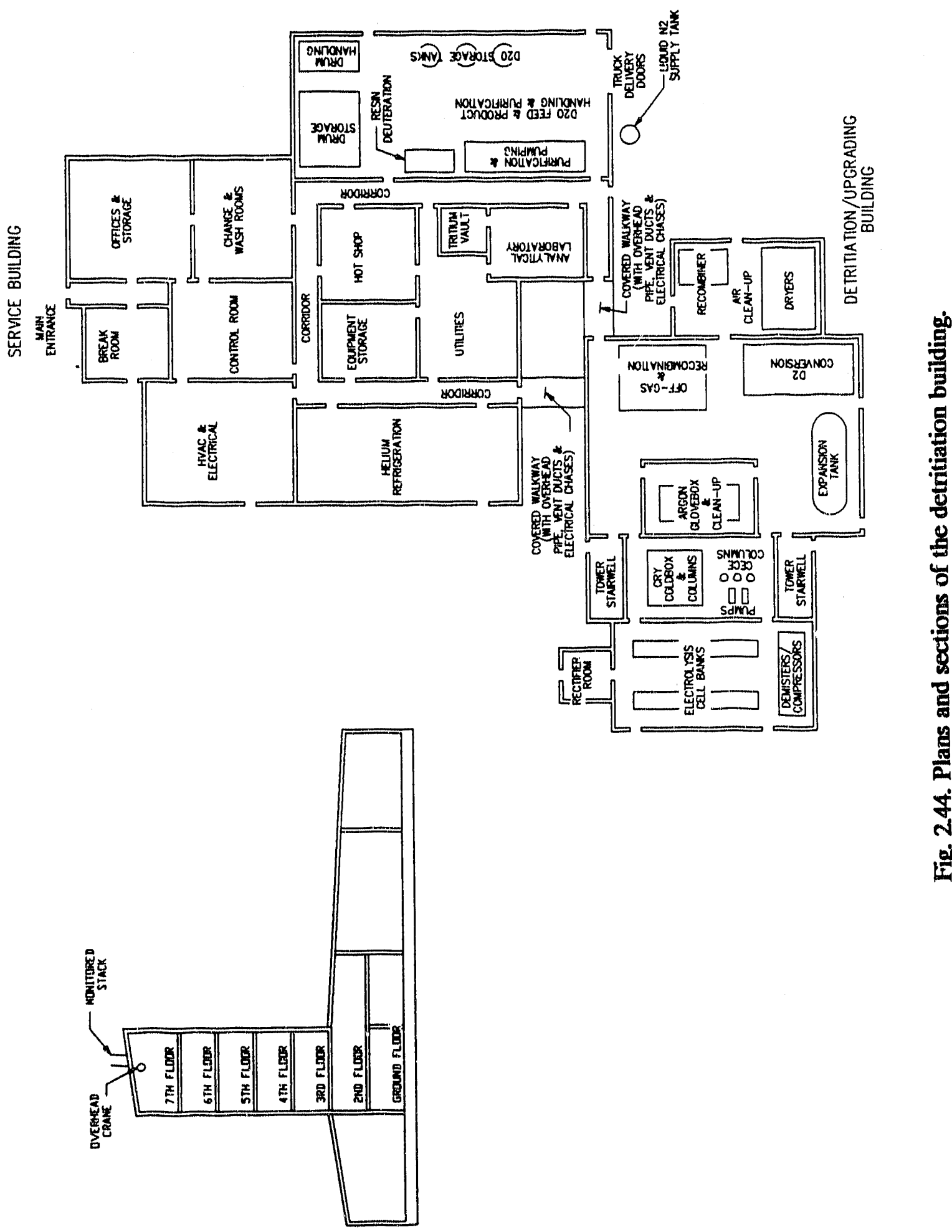


barrier walls are provided between the two diesel generators to meet separation requirements. The two fuel oil tanks are located in a below-grade reinforced concrete vault.

The transformer foundations consist of reinforced concrete piers that support the transformers on concrete mat foundations. A catch basin integrated into the mat is sized to contain the inventory of oil in each transformer. Reinforced concrete walls will be provided between the transformers and the relay house to protect the relay house from the blast or fire in the event of a transformer explosion. The switchyard relay house is a one-story, conventional steel frame structure with columns supported on spread footings. It is covered with a standard built-up roof, and insulated metal siding encloses the structural frame.

The remote exhaust stack consists of a freestanding, reinforced concrete structure extending to treetop height with about a 1-m inside diameter. The stack has suitably thick walls to protect the structure from design basis events. A building at the base of the stack will house instrumentation and other equipment. Other yard foundations provide support for service tanks and service systems located outside the buildings. The warehouse, providing storage for materials and components essential to maintaining plant availability, is a single-story, conventional steel frame structure.

Construction support facilities that must be built to support construction of the ANS also are included in the project. These facilities include temporary access roads and parking areas; sanitary facilities; temporary site utilities; material and equipment storage, staging areas, and warehouses; fabrication shops; office space and records storage facilities; spoil areas; site drainage and waste treatment facilities, including a construction debris landfill; petroleum and fuel storage and distribution facilities; water storage and distribution facilities; fire protection facilities; heavy equipment maintenance shops and motor pools; and electric power distribution facilities.

\section{RLANT SYSTEMS}

\subsubsection{Heavy Water Systems}

The heavy water reactor systems are grouped into eight major subsystems. The overall arrangement and interfaces between these systems are depicted in Fig. 2.45.

The reactor primary cooling system consists of four independent loops, three of which are normally in operation and the fourth of which is an isolated spare. Primary coolant flows up through the core through a single hot leg, and flow branches out to the four primary heat exchangers. Heavy water primary coolant flows through the shell side of the heat exchangers; light water secondary coolant flows through the tube side. After flowing through the primary heat exchangers, coolant flows into the shell side of the emergency heat exchangers. Both heat exchangers are immersed in a light water pool. The emergency heat exchangers function in the event of a loss of normal secondary heat sink and transfer heat directly to the pool by natural circulation of pool water through the heat exchanger. In normal operation, the coolant entering the emergency exchanger is already cool, and only a small amount of heat is transferred to the pool. From the emergency heat exchanger, coolant flows into the primary circulating pumps and is returned to the reactor assembly where flow from the three operating loops is recombined. The primary pumps have dc pony motors capable of providing $10 \%$ flow in each loop. Strainers are located just past the primary pumps. The entire primary coolant system is arranged in a simple, elevated configuration so that natural circulation will occur upon the loss of both normal and dc pony motor pumps. Manually activated loop isolation valses, primany circulating pumps, and key 


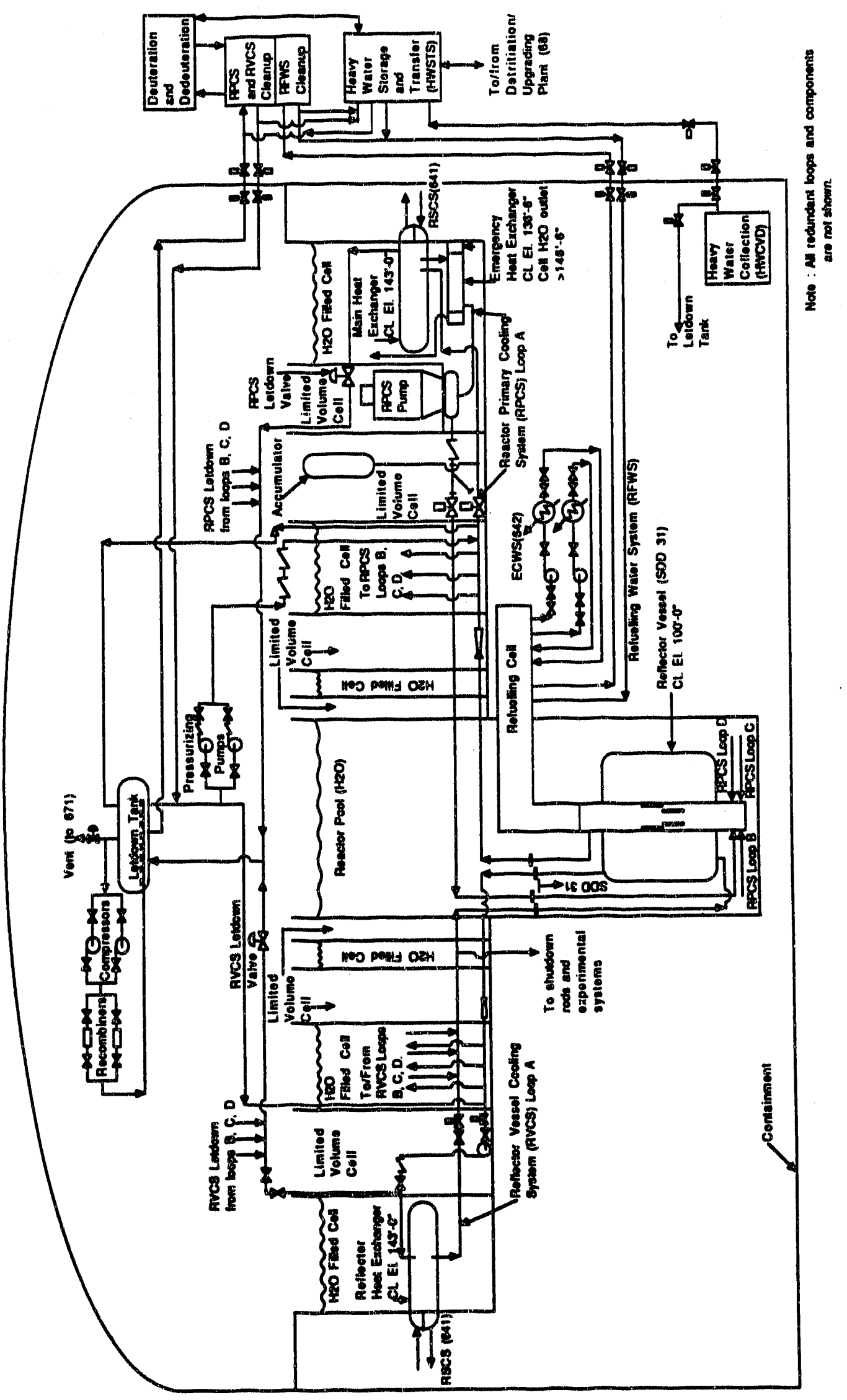

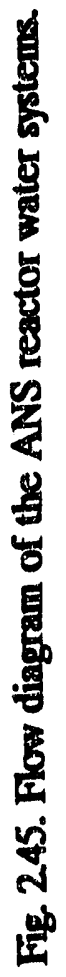


instrumentation are located in limited volume dry cells; the rest of the system is located either in the flooded heat exchanger cells or in a flooded pipe tunnel connected to the reactor pool.

The main components of the reactor pressure and inventory control system are the let-down control valves on the reactor primary cooling system, the let-down tank, the makeup pressurizing pumps, and the accumulators. The let-down control valves on each of the three operating loops maintain the flow through the reactor pressure and inventory control system pressurizer pumps and maintain the pressure in the reactor primary cooling system. A gas-charged accumulator is connected to each of the four primary cooling loops. The accumulators slow depressurization of the reactor primary cooling system following loss of pressure in the system and provide a sufficient volume of heavy water to fill any limited-volume cell. The oxygen content of the reactor heavy water systems is maintained by providing an oxygen-rich environment in the let-down tank. A gas recombination system converts radiolytic deuterium released into the let-down tank to $\mathrm{D}_{2} \mathrm{O}$.

The reflector vessel cooling system consists of four identical heat transfer loops, three of which are in service at any time. Each loop contains one pump with a main and dc pony motor, one heat exchanger, isolation valves, connecting piping, and instrumentation. The let-down tank in the reactor pressure and inventory control system pressurizes the reflector system by its elevation, and the connection to the pressure and inventory control system provides overpressure protection for the reflector vessel and the vessel cooling loops. Components of the reflector vessel cooling system are located in the heat exchanger pools, the flooded pipe chase, and the limited volume cells. Thus, inventory control is maintained in the reflector loops using a similar approach to that used in the primary coolant loops.

The refueling water system provides cooling and cleanup flow to the heavy water refueling cell using two redundant and physically separated cooling loops. Each loop consists of a pump/motor assembly, one heat exchanger, and associated piping and isolating valves, and is cooled by the essential cooling water system.

The heavy water collection, vents, and drains system collects heavy water by gravity from a number of sources to a collection tank located in the basement of the reactor building. When this tank is full, the heavy water normally is pumped back to the let-down tank. Heavy water in the collection tank also can be pumped to the appropriate tank in the heavy water storage and transfer system.

The heavy water storage and transfer system consists of heavy water storage tanks, transfer pumps, and associated valves. It is located in the basement of the reactor support building. The storage and transfer system interfaces with the detritiation and upgrade facility located outside the main reactor complex. A cleanup loop consists of an oil coalescer, a charcoal filter, evaporators, and a blender-dryer. The heavy water leak detection system is capable of detecting leaks of $0.06 \mathrm{~L} / \mathrm{s}(1 \mathrm{gal} / \mathrm{min})$ or less during normal operations and $0.06 \mathrm{~L} / \mathrm{s}(1 \mathrm{gal} / \mathrm{min})$ leakages to air and water following an accident. It consists of four major subsystems: (1) a system to collect leaks from specifically designated flanges by providing tubing connections that drain to one of two tanks; (2) a system to detect and measure heavy water and tritium in the atmosphere surrounding heavy water systems; (3) a system to detect and monitor unidentified $\mathrm{H}_{2} \mathrm{O}$ ingress into $\mathrm{D}_{2} \mathrm{O}$ systems by continuously measuring the isotopic level of the primary, reflector, and refueling water systems; and (4) a system to detect and monitor unidentified $\mathrm{D}_{2} \mathrm{O}$ leakages to light water cooling systems by monitoring the isotopic content in light water systems and pools and by measuring the tritium content in light water.

The resin deuteration and de-deuteration system exchanges heavy water for light water and vice versa in the incoming and outgoing ion-exchange resins used in the heavy water cleanup systems. The system consists of the deuteration/de-deuteration tank, the $\mathrm{D}_{2} \mathrm{O}$ head tank, and 
associated piping and valves, along with the transfer pump used to transfer resin to and from the ion-exchange columns.

\subsection{Electrical Power and Communications}

The off-site power supply system comprises two substations: the primary and the reserve substation. The primary substation is fed by $161 \mathrm{kV}$ transmission lines from two separate, independent sources of electrical power: the TVA Ft. Loudoun dam and the TVA Elza substation, which is fed directly by the Bull Run Steam Plant. The reserve substation has a dedicated $13.8 \mathrm{kV}$ feed from the ORNL 0901 substation.

The primary substation is a standard four breaker ring bus arrangement. Four $\mathrm{SF}_{6}$ power circuit breakers allow power to be fed to one or both of the substation buses. Each of the buses is a full capacity bus both for ANS power and for Elza to Ft. Loudoun through power. Each of two primary plant service transformers is capable of carrying the entire ANS load.

The reserve substation consists of a single reserve plant transformer with a primary breaker. The secondary of the transformer breaker feeds into a $480 \mathrm{~V}$ switchgear and from there is fed to the Class $1 \mathrm{E} 480 \mathrm{~V}$ switchgear. To maintain independence between the two Class $1 \mathrm{E}$ power divisions, the reserve substation can connect to only one Class $1 \mathrm{E}$ power division at any time.

The general outlines of the Class $1 \mathrm{E}$ and non-Class $1 \mathrm{E}$ power distribution systems are shown in Figs. 2.46 and 2.47, respectively. The Class 1E power distribution system draws power from two independent $480 \mathrm{~V}$ buses (Division 1 and Division 2), each of which may be powered from the preferred or reserve off-site power sources or by a Class $1 \mathrm{E}$ diesel generator set. Power is further subdivided into $1 \mathrm{~A}, 1 \mathrm{~B}, 2 \mathrm{~A}$, and $2 \mathrm{~B}$ independent subdivisions, and then into electrically independent primary and secondary load groups, for a total of eight load groups. Non-Class $1 \mathrm{E}$ power is distributed through Divisions $A$ and $B$. Class $1 E$ power distribution system subdivisions are kept physically separated, with no electrical cross-connections, and with appropriate fire barriers (spacing or physical barriers or both) between equipment and raceways. In general, the plant is laid out so that reactor power and support systems are arranged in symmetric layouts around a centerline, with separate power divisions on each side of the centerline. The Class $1 \mathrm{E}$ dc power distribution system includes eight independent battery systems corresponding to the eight load groups of the Class $1 E$ distribution system. Inverters (connected to the Class $1 E$ dc power distribution system) supply the Class $1 E$ uninterruptable power distribution system for loads that require uninterruptable ac power. The plant communications and alarm systems are depicted in Fig. 2.48. The system comprises a series of host computers tied to a plant backbone. Dedicated hardwired systems are used for key safety-related equipment, and a separate system is provided for telephone communications.

\subsection{Environmental Control Systems}

The containment ventilation and gas treatment system provides filters, conditioners, and-for research areas-silencers for reactor building ventilation supply air. It provides both filtered and non-filtered paths for exhaust air (the filtration system is activated upon detection of activity in the air). Cooling of incoming air in the reactor building is provided by the nonessential chilled water system; heating is provided by hot water from the nonessential building heating system. Ventilation systems for operations and research arcas are kept independent of each other. Similar systems serve the reactor support building, including the fuel handling area. Independent, internally recirculating air handling units are used to air condition the reactor and reactor support buildings. These are cooled with nonessentiai chilled water. 


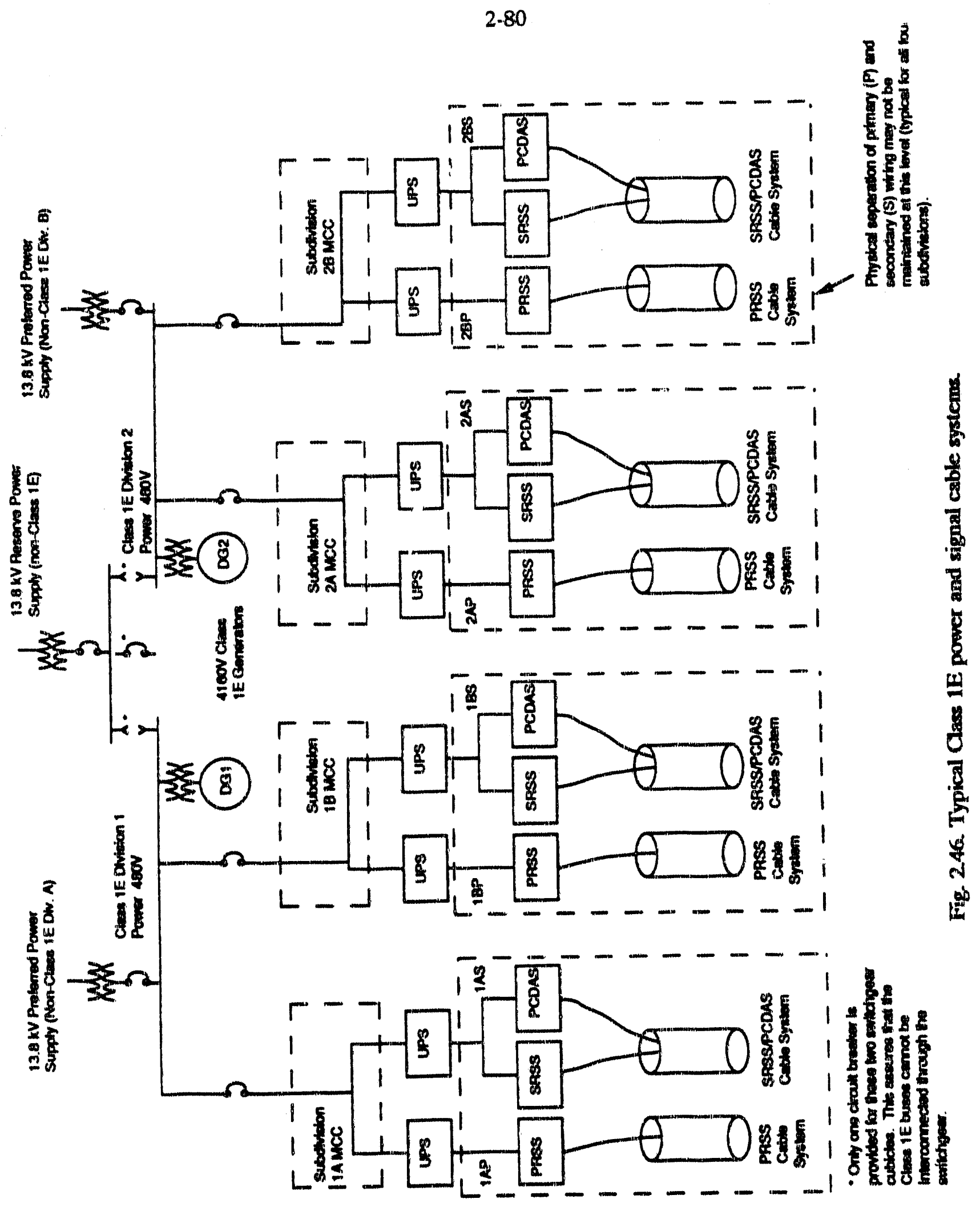




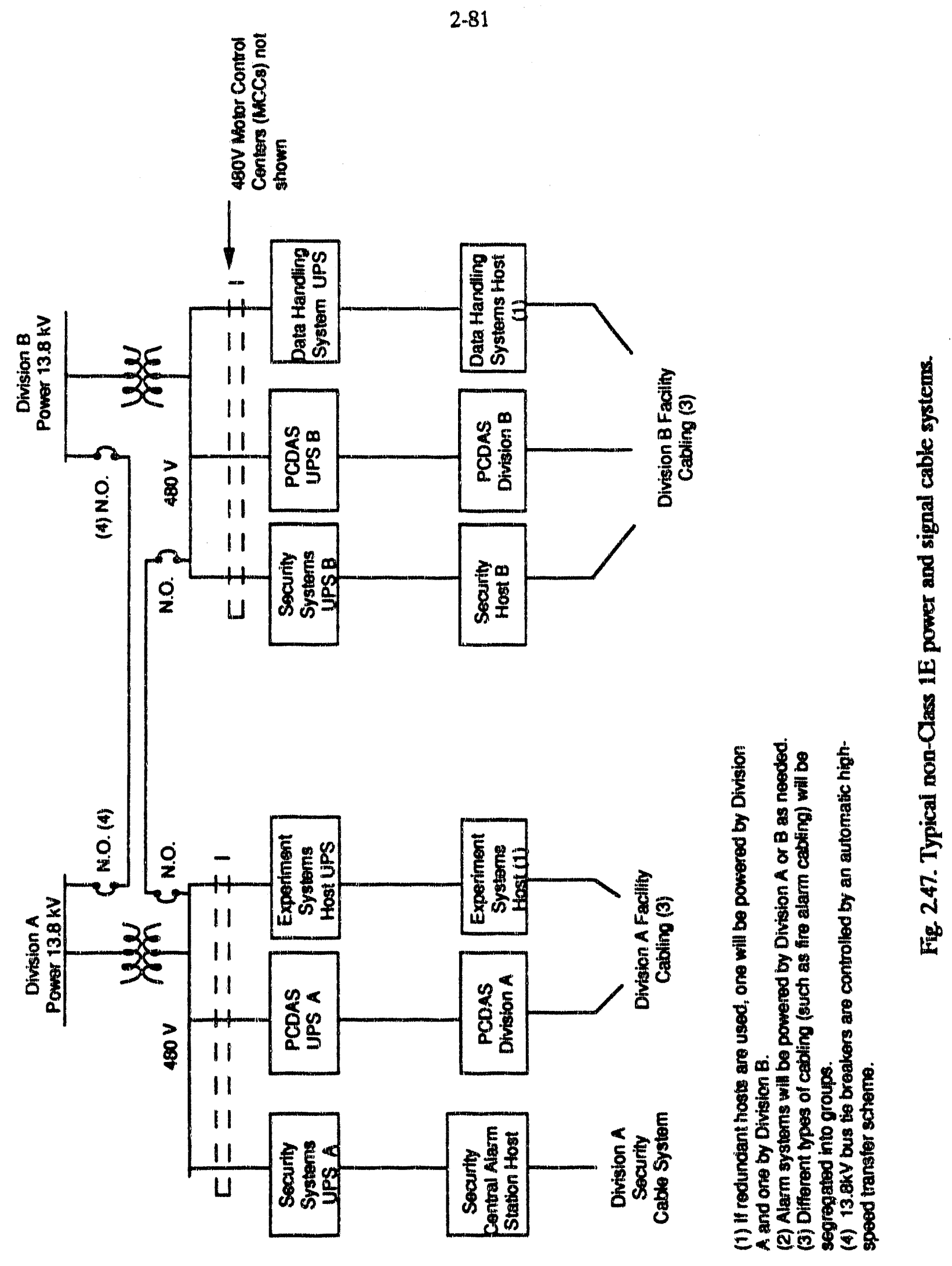




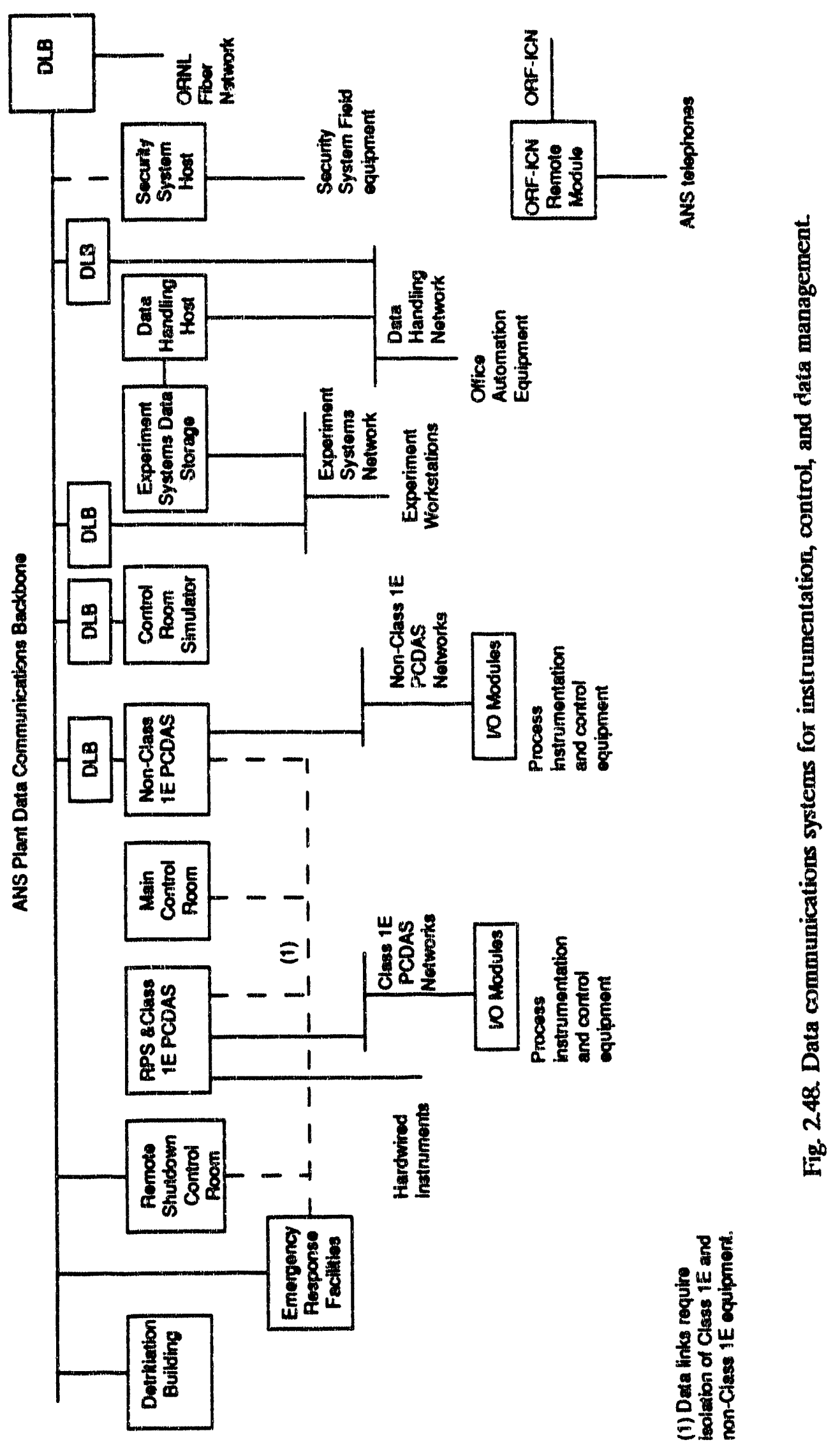


The confinement ventilation and off-gas treatment system provides confinement, off-gas control, and air cleanup from contaminated processes and areas within the reactor and reactor support buildings. These systems create a lower pressure in the confinement areas than in their surroundings.

Rotary dehumidifiers are provided in areas where airborne heavy water releases are likely. The rotary dehumidifiers remove water from the cell atmosphere, and the vapor is condensed for recovery on the regenerative side. Driers are provided for inlet air to these areas so that clean light water vapor is collected separately from heavy water vapor.

The control room habitability system includes air handling units to heat or cool the control room habitability zone atmosphere. These systems are cooled by the essential chilled water system and heated by hot water from the essential building hot water system. Radiation and toxic gas monitors cover the air intake systems for the control room habitability zone. The technical support center habitability subsystem has similar features, except that it is heated and cooled by the nonessential hot and chilled water systems.

The reactor building annulus exhaust system directs outleakage from primary containment into a filter bank, provides filtration for iodine and particulates, and directs the discharge through a remote stack located on a hilltop on the southeast edge of the ANS complex so that the impact of the plume on site evacuation is minimized. The system consists of fans and ductwork, charcoal and HEPA filters, mist eliminators and preheaters, and the remote stack. In normal operation, the standby filters are bypassed so that the charcoal beds do not lose their efficiency. Upon detection of activity in the containment annulus, a set of dampers routes the annulus exhaust through the standby filter system. The standby filter system is designed to provide a decontamination factor of 800 for elemental iodine and particulates and is provided with a water deluge system to extinguish any fire that could occur within the charcoal beds.

The remaining areas of the main reactor complex are provided with standard ventilation and air conditioning systems. Building heat is provided by a circulating hot water system, heated by steam from the central ORNL steam plant, and cooling is provided by the nonessential chilled water system.

The conceptual design basis for the detritiation building ventilation systems incorporates a relatively standard confinement ventilation system for the control of radioactive material. Airflow is directed from areas of lesser contamination potential to areas of higher contamination potential. Exhaust is discharged from a stack at the top of the detritiation building. Recombiners and driers are used selectively for control of airborne tritium. Refinements to the operating modes of the detritiation building ventilation systems, including purge ventilation in the event of potentially flammable hydrogen isotope concentrations, will await detailed fire safety studies in the advanced conceptual and detailed design stages. The heating and air conditioning systems for occupied areas in the detritiation building are standard systems.

\subsubsection{Water and Service Systems}

The reactor secondary cooling system removes heat from the primary reactor cooling circuit (including pump heat), from the reflector cooling system, and from the heat exchanger pools. It consists of four independent heat transport loops. Three are required for full power operation but only one is required to remove decay heat from the reactor. When the reactor is at power, heat is rejected to the atmosphere through forced draft cooling towers. During decay heat removal, natural circulation is used to exchange heat with the water inventory in the secondary cooling system basins. The four secondary cooling towers are located on a hill east of the reactor support building, and the basin structures are integrated into the reactor support building structure. Three 
loops of the reactor secondary cooling system are in operation, and one loop (corresponding to the reactor primary cooling system loop that is out of service at that time) is shut down as a spare. Each loop of the reactor secondary cooling system is dedicated to one corresponding loop of the reactor primary cooling system and the reflector vessel cooling system, with no cross connections. This feature aids in the detection of a primary or reflector to secondary leak by de tecting deuterium or tritium in the secondary basin inventory.

The essential cooling water system removes heat from the refueling systems and spent fuel pools (ihrough the pool cooling system), the chillers serving the control complex, and other systems that must be cooled to accomplish their safety mission. It consists of two independent loops, each capable of servicing all loads allocated to the system. Each loop uses a separate circulating pump, a forced draft cooling tower, and a seismically qualified basin. The towers are located on the roof of the reactor support building and are provided with a seismically and tornado qualified protective structure so that operation of the essential cooling water system is not lost in the event of a design basis natural phenomenon.

The light water pool cooling systems transfer heat from the reactor cavity and spent fuel pools by circulating the pool water to heat exchangers cooled by the essential cooling water system. The light water pool cleanup systems circulate pool water through a demineralizer system to remove contamination from the pools and to maintain the clarity of the pool water.

The nonessential cooling water system is a relatively large, standard forced draft cooling tower system. Tower water is distributed to major equipment in the compressor building and the detritiation building and to many smaller users throughout the facility. The cooling tower blowdown and makeup system provides significant quantities of process water to all cooling tower systems and collects, monitors, treats, and releases blowdown from all towers.

Two separate independent helium refrigeration systems will be provided so that each cold source is served by a dedicated refrigeration system. Figure 2.49 showe the overall flowsheet for one of these refrigerators. The refrigeration system is divided into two main locations: The compressors, oil absorbers, and helium cleanup systems are located in the compressor building just east of the reactor support building; and the cold boxes containing the turbine expanders are located in the high bay of the reactor building. Warm helium gas passes through the reactor containment boundary. Skid-mounted assemblies for two stages of compressors are located in the compressor building. Two compressor trains are normally operating for each system; a third train is maintained as a spare. Seven stages of turbine expanders are located along with a series of regenerative heat exchangers in the cold boxes in the high bay of the reactor building. Cold ( $5 \mathrm{~K}$ ) helium gas is routed to the cold sources on the first flnor of the reactor building in a pipe chase along the outer wall of the reactor building.

Instrument and service air is supplied by rotary-screw compressors located in the compressor building. Breathing air is drawn into a receiver tank from the instrument air system and is filtered to meet breathing air quality requirements. A factory-assembled, skid-mounted vacuum tank and duplex vacuum pumps will serve the central rough vacuum system. Piping networks will be supplied to provide vacuum services to research areas and other systems served by plant vacuurn. Helium will be stored in a tube trailer parked outside the reactor support building. Liquid nitrogen will be supplied from a trailer and distributed throughout the facility. A staging dewar will be included in the reactor building, allowing transfer through the containment on a batch basis. Nitrogen gas will be produced by evaporation of liquid nitrogen. Other gases generally will be distributed from gas bottle stations.

Steam will be supplied to the ANS facility through two new lines tied into the existing ORNL steam distribution system. High-pressure steam will be routed directly to select process equipment, and low-pressure steam will be distributed throughout the facility. The main use for steam is to 


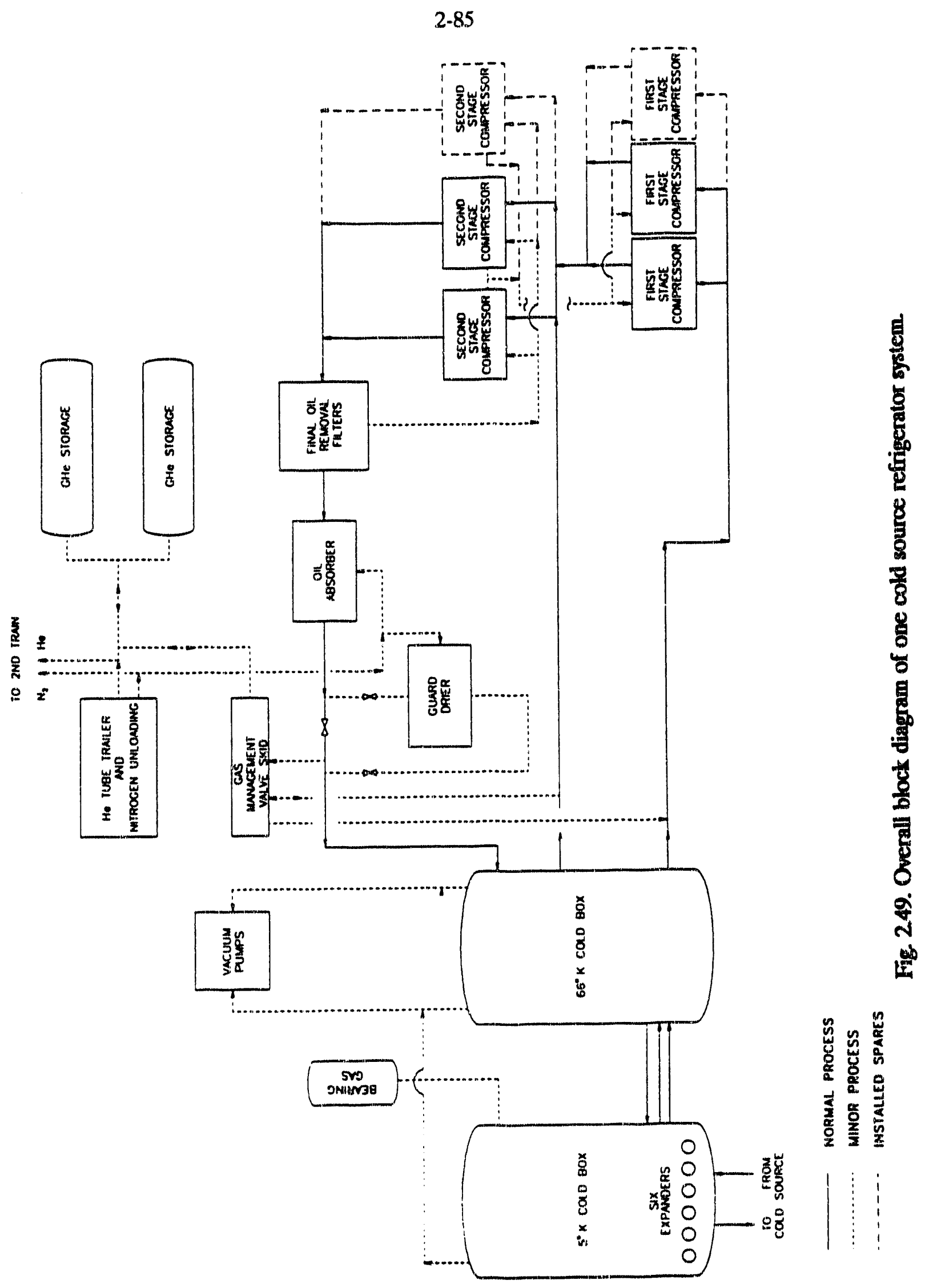


heat the building hot water heating system, and to heat a number of evaporators in the facility. Clean condensate will be collected and pumped to the reactor support building for use as makeup to the plant demineralizer.

Chilled water systems are provided to serve the air conditioning systems and for a number of process applications. The essential chilled water system serves the control room complex. The nonessential chilled water system is divided into two subsystems: One serves those areas that could be contaminated with tritium, and the other serves the remainder of the complex. $A$ demineralizer system is provided to serve the pools, light water cooling and service systems, and various laboratories and shops. Potable water and sewage systems link the ANS with the existing site infrastructure.

\section{Fire Protection}

The fire protection program develops procedures, responsibilities, and hardware to ensure an appropriate level of fire protection at the ANS. The fire protection program establishes the following features of defense-in-depth: preventing fires from starting; rapidly detecting, controlling, and extinguishing fires that do occur; providing protection for personnel, structures, systems, and components important to safety so that a fire that is not promptly extinguished will not prevent the safe shutdown of the plant; and ensuring that personnel onsite are warned of fires and are provided a means of egress. A fire hazards analysis will be performed to demonstrate that the plant can maintain its ability to perform safe shutdown and minimize releases of radioactive materials in the event of a fire. It will also determine special fire prevention and protection features that are deemed appropriate to achieve a level of improved fire protection that limits damage to an acceptable level.

The existing ORNL potable water system will serve as one source of water for fire suppression. A grade-level, welded steel tank located on a hill east of the reactor buildings will serve as an independent water source. Two fire pumps, one electric and one diesel-driven, will supply water to the fire protection distribution system. Automatic wet pipe sprinkler systems will be provided in all structures except where unusual circumstances warrant the use of gaseous fire suppression systems. Hydrants and standpipes will be located at appropriate intervais throughout the site. Fire detection and alarm systems are provided throughout the facility.

The conceptual design combustible gas control system is based on a network of igniters in areas where hydrogen might accumulate. Because of the unique hydrogen safety issues posed by the cold sources, a more detailed review of the hydrogen fire safety program will be conducted during advanced conceptual design.

\subsection{Waste Systems}

The ANS plant waste systems are designed to provide flexibility and allow the facility to respond to changes in waste management strategies throughout its lifetime, especially for radioactive and hazardous wastes. Provisions for the use of contracted mobile waste treatment facilities are made in the design, and a high bay confinement area is included along the south grade-level edge of the reactor support building. Waste collection and treatment facilities are located near, and if possible below, the sources of waste generation to minimize the handling of wastes and to reduce the potential for the spread of contamination. The same path used to transfer spent fuel from the reactor building to the fuel handling area is used to transfer irradiated reactor components, and a segmenting and packaging cell is incorporated into the design of the fuel handling area. The overall waste management program relies as much on 
identifying and reducing waste sources as it does on the facilities for effectively disposing of those wastes that must be generated. A listing of the sources, volumes, and classifications of wastes that are expected to be generated at the ANS is provided in Appendix Q of SDD 67.

The gaseous waste system receives off-gas from the reactor heavy water coolant system and from a variety of other process equipment. Gas streams from the heavy water systems are passed through recombiners and driers to remove heavy water and tritium before the exhaust is transferred to the gaseous waste system. The gaseous waste system provides charcoal, HEPA, and specialty filters as needed to allow release of the gas stream. The gaseous treatment system also includes two sets of compressors and gas hold-up tanks for holding short-lived gaseous isotopes, such as noble gases, for decay.

The liquid low-level radioactive waste system includes a set of collection tanks at the low point of the buildings served by this system. These tanks allow the collection and monitoring of wastes before they are processed or transferred to the ORNL liquid low-level waste (LLLW) system. The ORNL liquid waste systems, as presently operated, do not remove tritium from the treated water that ultimately is released. Therefore, ANS wastes containing significant tritium levels will be solidified for disposal using contract equipment. Wastes not containing significant tritium levels can be solidified, treated by ion exchange, or transferred to the ORNL LLLW system. Because ANS use of the ORNL LLLW system is not extensive, a truck transfer system is provided for these wastes instead of a pipeline. The design of the ANS liquid low-level radioactive waste system allows the plant operators to tailor ANS waste treatment and packaging to interface with the overall ORNL waste handling system that is in place during facility operation.

Both radiological and non-radiological process wastewater drains by gravity into sumps at the low points of each building. It is monitored and transferred from there to the appropriate ORNL collection, treatment, and disposal system. A storage tank farm is provided for the process waste system so that in the event of an unusual event (such as a failure of one of the reactor or plant water systems or a discharge from the fire sprinkler systems), the large quantities of water that could be released in the buildings can be held for monitoring before release.

Solid low-level radioactive waste systems provide the space and physical handling facilities to collect and sort wastes and to process wet wastes for disposal. Sorting categories include compactable, non-compactable, salvageable, and combustible wastes and possibly other special categories. Contact-handled wastes are bagged at the source and transferred manually to sorting, monitoring, and collection stations. Shielded transfer containers are provided for remotely handled wastes. Special facilities are provided to transport wet wastes, such as ion exchange resins, to contractors' equipment for dewatering, drying, packaging, and stabilization. A cell located in the fuel handling area will be used for higher activity waste streams, including reactor components that may be classified as Greater-Than-Class-C.

Hazardous and mixed wastes are collected at the source using portable barrel pumps or other means. Not only is a central collection system not consideref practical for the small, diverse streams involved, but also collection at the source encourages close monitoring and volume reduction practices. These wastes are packaged and held at a designated collection area as regulated by Environmental Protection Agency hazardous waste rules. They then are transferred to the designated ORNL storage centers.

The radwaste sampling and analysis system consists of typical sampling, transport, and analysis equipment. 


\subsection{Heavy Water Detritiation and Upgrade}

Detritiation and upgrade of the ANS heavy water inventory is accomplished with the combined electrolysis-catalytic exchange (CECE) process. CECE produces detritiated and deprotiated deuterium gas, which is reconverted to heavy water. It also produces a concentrated tritium gas, which is packaged as a metal tritide. It produces a virtually tritium-free protium gas stream, which can be released through a stack. This process is similar to the processes used at existing facilities in Canada and France. Figure 2.50 is a block diagram of the key elements of the CECE process.

The $\mathrm{D}_{2} \mathrm{O}$ feed and product purification system receives and stores all heavy water entering or leaving the detritiation and upgrade facility, including fresh heavy water arriving at the site. Feed waters are pumped through carbon and ion exchange purifiers before entering the process columns.

The incoming heavy water is brought into contact with a stream of deuterium gas, over a wetproofed catalyst, in the CECE column. Within the exchange columns, equilibrium moves the lighter protium isotope to the gas phase and leaves the heavier tritium and deuterium isotopes in the liquid phase, where they enter the electrolysis cells. All of the liquid entering the cells is converted to gas by electrolysis; the larger fraction of this stream is sent to the hydrogen distillation columns, and a smaller stream reenters the exchange columns to provide countercurrent exchange with the liquid. The gas passing up the exchange columns gradually is stripped of all but the protium isotope. At the top of the column, the gas contacts a clean, demineralized light water stream, which strips the remaining deuterium and tritium from the gas stream and leaves a gas effluent suitable for release to the atmosphere.

The deuterium entering the cryogenic distillation columns is first passed through catalyst beds and driers to remove water vapor and other impurities. In the first column of the cryogenic distillation system, gas and liquid hydrogen (mostly deuterium) are brought into countercurrent contact over a packed bed at temperatures near $25 \mathrm{~K}$. The lighter protium and deuterium isotopes migrate to the gas phase, and tritium passes to the liquid phase. A side stream of the deuterium gas overhead is converted to oxide in a recombiner with oxygen produced by the electrolysis cells. This stream, deprotiated in the CECE columns and detritiated in the cryogenic distillation column, is returned to the reactor. Tritium is concentrated further in the liquid bottoms of the second and third stages of cryogenic distillation. A catalyst is used to promote the formation of $T_{2}$ from DT. The relatively pure liquid in the bottom of the final distillation column is withdrawn periodically to the tritium handling and storage system, where the tritium is immobilized as a metal tritide in an argon-filled glovebox.

A vacuum coldbox and helium refrigeration systems provide a vacuum environment for the cryogenic distillation columns. They provide the cold helium refrigerant to produce from hydrogen gas the liquid hydrogen used in the distillation columns. A refrigerant system includes compressors in a side portion of the detritiation building and a turbo-expander located in the cold box. The cold box also provides secondary containment for the cryogenic distillation process. An argon glovebox and cleanup system provides a controlled, inert atmosphere for the tritium withdrawal and packaging process and provides secondary containment for the packaging activities. A process off-gas and catalytic recombination system is provided for tritium and deuterium recovery during equipment venting and purging operations and during maintenance shutdowns. An air cleanup system uses a gas-phase recombiner and molecular sieve driers to recover tritium and deuterium that may have leaked into the building air. Auxiliary services are provided to the detritiation and upgrade facility by the plant water and services systems. 


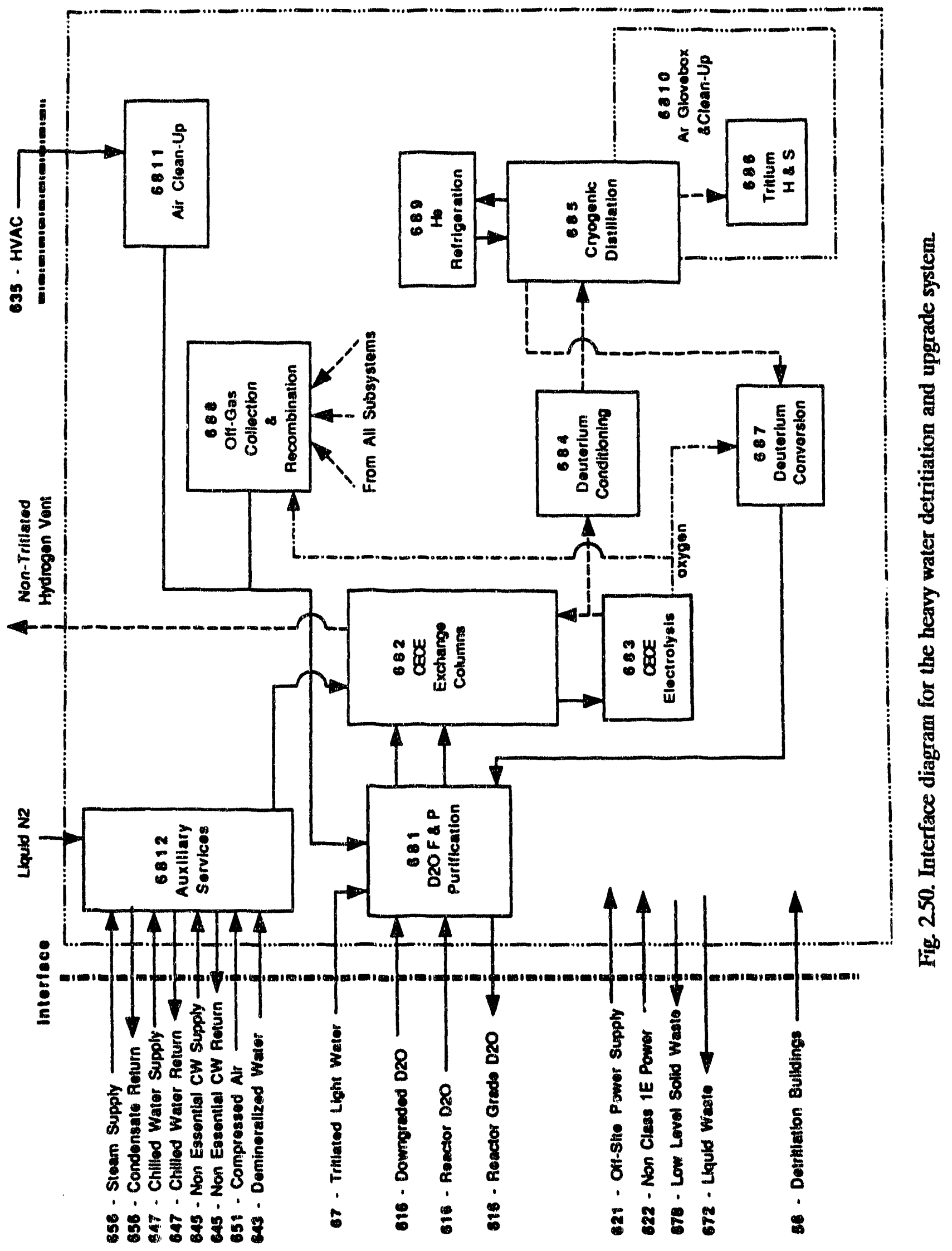




\subsection{Plant Instrumentation, Control, and Data Systems}

Together with the plant data communication backbone, the PCDAS provides the heart of the ANS control, data collection, and data analysis systems. The collective PCDAS gather data from all reactor and plant systems, perform the computer analysis and data reduction functions, and translate information into cathode ray tube screen displays and other forms of display in the main control room. The Class IE PCDAS performs all engineered safety feature actuation, postaccident monitoring, and other safety relat functions. The non-Class 1E PCDAS performs all non-safety-related functions and is connected to the plant data communication backbone for communications with ORNL and other ANS computing facilities. The non-Class 1E PCDAS also receives data from the Class $1 E$ PCDAS and the reactor protection system via isolated (one-way) communication links. Reactor protection functions are not performed by either of the PCDAS. The overall architecture of the Class $1 \mathrm{E}$ and the non-Class 1E PCDAS is shown in Figs. 2.51 and 2.52 , respectively.

Both Class 1E and non-Class $1 \mathrm{E}$ displays are arranged in the main control room in a highly integrated manner consistent with effective human factors principles. The overall layout of the main control complex is shown in Fig. 2.53. This figure depicts the area where most of the nonClass 1E PCDAS display, data acquisition, and calculation equipment and all of the Class $1 \mathrm{E}$ PCDAS equipment will be located. Locations of the various operator consoles and the large display panels are shown, depicting the overall layout of the control room. All hosts, file servers, power conditioners, and all of the input/output cabinets for the Class 1E PCDAS will be located in this area. The input/output cabinets for the non-Class 1E PCDAS will be located throughout the plant. Display consoles also will be provided in the technical support center adjacent to the main control room.

The remote shutdown control room is located on the third floor of the operations support building and contains operator consoles with controls and displays driven by the non-Class $1 \mathrm{E}$ and Class 1E PCDAS and hardwired to field instruments. This room will display both Class $1 \mathrm{E}$ and non-Class $1 \mathrm{E}$ information and will have sufficient control capability to shut the plant down and maintain it in a safe shutdown condition.

The plant simulator duplicates the control room layout in a full-scale and fully operational manner, complete with control panels and alarms that duplicate and simulate control room functions and reactor and plant system responses (by computer). The simulator has the look and feel of the plant and has equipment panels, controls, instruments, and displays identical to those used in the control room. The simulator is used for operator training/certification and recertification and for testing of equipment and procedures. The simulator is located on the ground floor of the operations support building near the interface area. Classrooms, files, and other support facilities are located adjacent to the simulator.

The data handling system provides business system computing and data storage and retrieval of plant records, drawings, and other documents. The system consists of networked computer systems that include central processing units and file servers, mass data storage devices, computer networks, and a variety of workstations including computer-aided design workstations

The perimeter intrusion detection system consists of sensors, processing equipment, electronic surveillance equipment (closed circuit television), and data gathering panels that are connected to security management host computers. Sensors are provided to detect vibration in the security fencing and in the soil between the fencing. The region between the inner and outer fencing is provided with bistatic microwave detectors that sound an alarm upon any interruption of the beam. Similar detector systems are provided along the security area perimeter inside the building. The entire system is designed to annunciate at the central alarm station located in the interface 


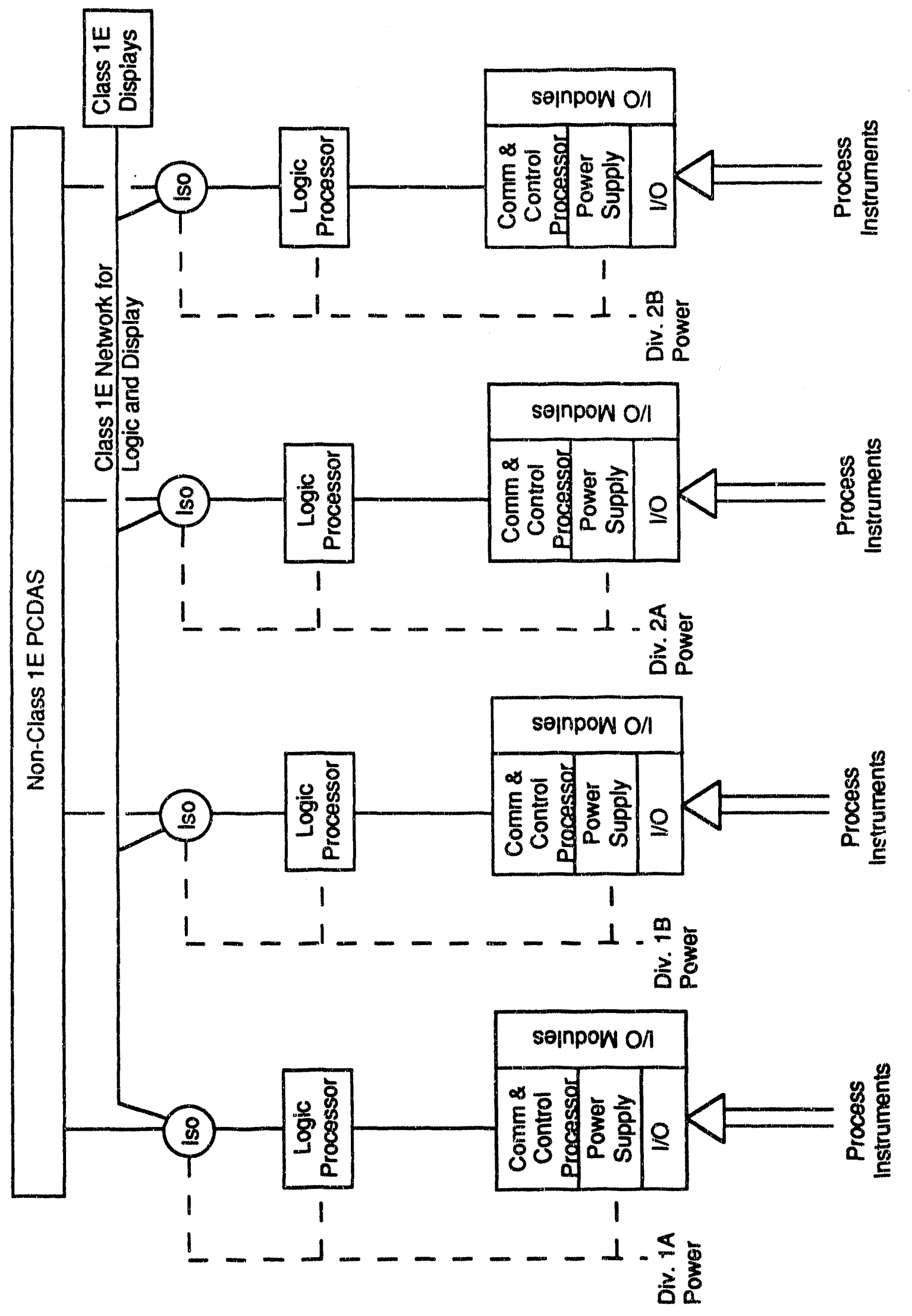




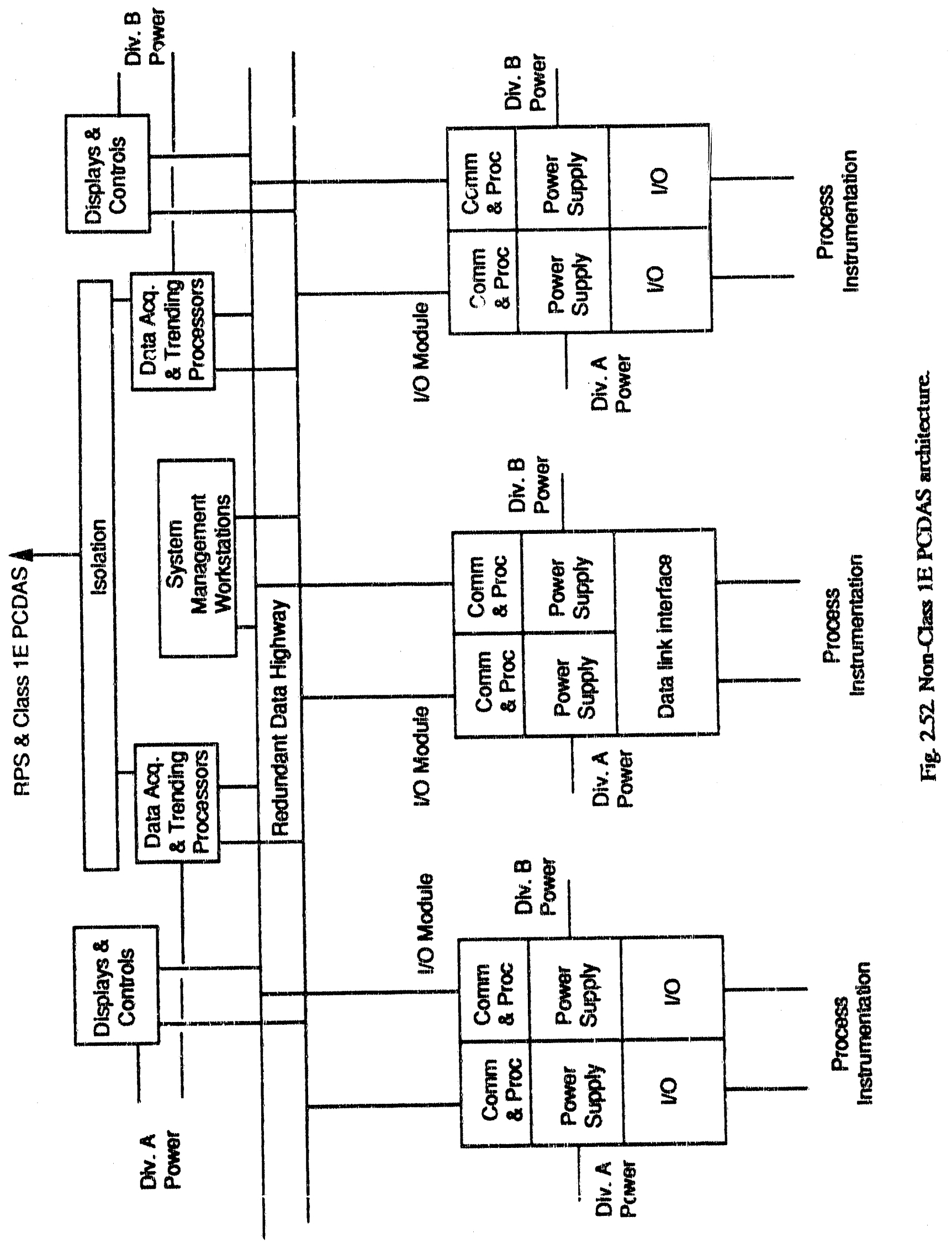




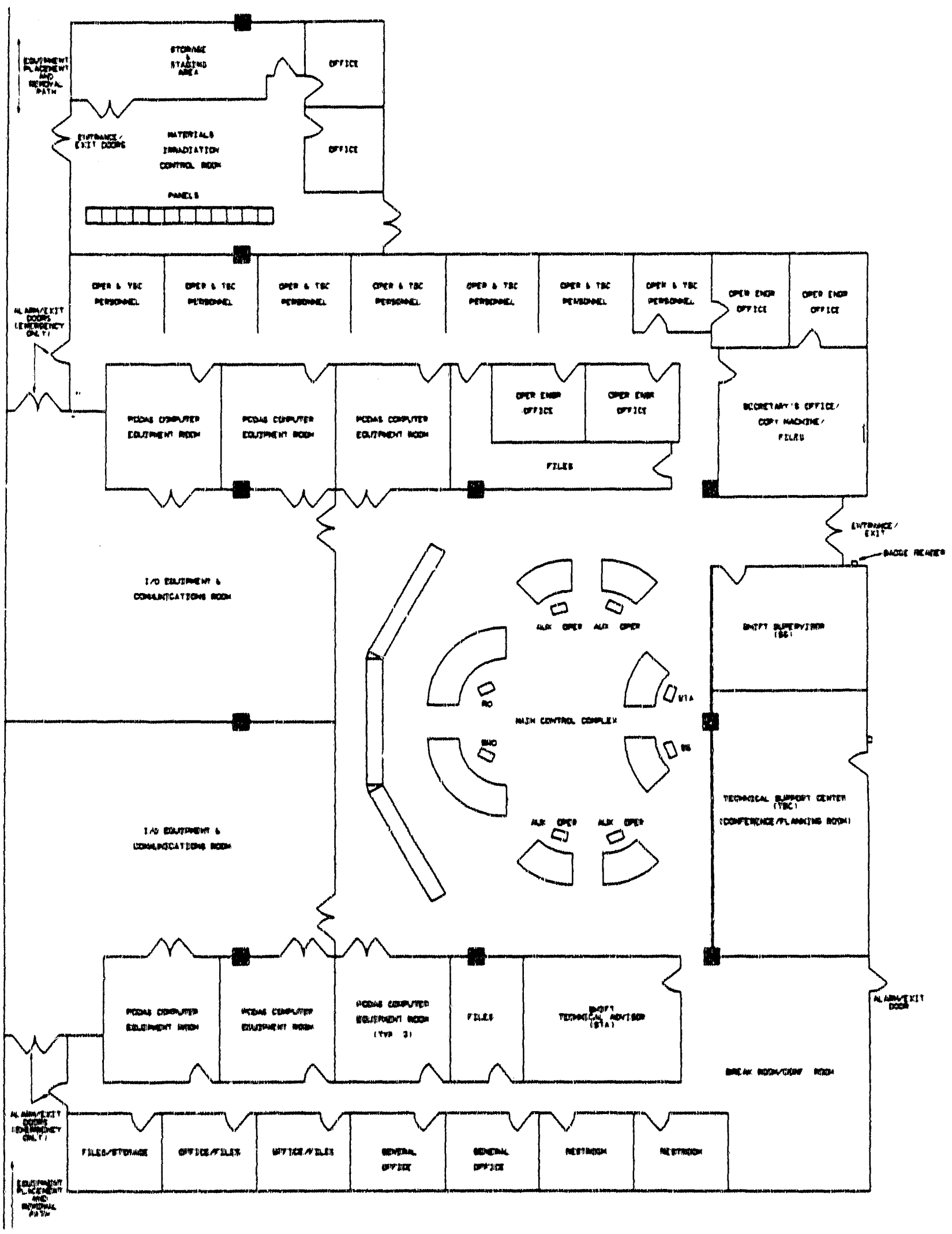

Fig 2.53. Layout of the main control compler 
area and at a secondary alarm station located in Building 2500 at ORNL. The system is provided with an automatic switchover to backup power; this switchover is annunciated at the central alarm stations but does not sound a general alarm.

An automated access control system is provided to control points of personnel and vehicle access. This systen consists of materials detectors, card readers, electronic door locks, magnetic switches, and processing equipment connected to the security management host computers. The security management system provides supervisory control over all components of the plant security systems.

Passive triaxial peak accelerographs, triaxial response spectrum recorders, triaxial time-history accelerographs, and seismic switches provide annunciation and record significant data in the event of an earthquake. Of these, four Class $1 E$ seismic switches provide input to the reactor protection system.

Personnel contamination monitoring is provided to ensure that occupational exposures are kept as low as reasonably achievable and to control radioactive material entering or leaving the facility. Half-body contamination monitors will be located at selected personnel control points at the boundaries of radiological controlled areas. Badge readers are used in conjunction with these portal monitors, and the fixed monitors are supplemented by portable beta-gamma and alpha friskers.

Walk-through portal monitors are provided at the building entrance locations and at the entrances to the guide hall. Although less sensitive than the half-body monitors, these will provide expedient detection of contamination leaving and entering areas that would not be expected to become contaminated. Laboratory instrumentation is provided for the analysis of samples, including various types of samples collected to monitor tritium, and for the analysis of thermoluminescent dosimeters and other personnel monitoring devices.

Process monitoring is provided on those systems that might contain radioactive materials, including waste systems. Process monitoring on systems such as the secondary reactor coolant systems is used to activate containment and other isolation systems. Airborne monitoring is provided in building areas, and the main and remote stacks are monitored for particulates, iodine, noble gases, and other constiturents.

A combustible gas monitoring system is provided. The system consists of remote mounted gas detectors or transmitters located at sources of combustible gases or at locations where gas might accumulate.

The detection of metal debris or loose parts within the reactor primary cooling system is accomplished by the installation of transducers mounted on the exterior of the cooling system components. Signals from these transducers can be monitored manually, through headphones or by sending the signal to an oscilloscope, and by a computerized impact detection system that sends alarm signals to the PCDAS.

The safety parameter display system includes cathode ray tube displays located in the main control room, as well as in the technical support center and the emergency operations facility. The operations support center is located in a training room adjacent to the plant simulator. It serves as an assembly point for support personnel and serves to facilitate the performance of support functions and tasks. The on-site technical support center is a facility adjacent to the main control room where plant management and other personnel will use technical data and displays as necessary to assist control room personnel during emergency conditions.

The emergency operations facility, located in the Laboratory Emergency Response Center at ORNL, provides technical data at a location remote from the ANS facility. The emergency operations facility is provided with the same radinlogical habitability features as the main control room but does not have some of the seismic qualifications, redundancies, and automatic initiation 
features. The capability for a nuclear data link to transmit data and general communications to a DOE facility is provided through a cunnection to the data handling system host.

\section{OPERATIONS}

\subsection{Facility Operations}

A summary of the operating manpower requirements and operating costs for steady state operation is presented in Table 2.5. Profiles for staff buildup and operating costs during the construction project and for the first few years of operation are provided in a basis for operations document. The elements depicted on Table 2.5 are described below; the elements are reordered into similar activities in this discussion.

The reactor operations element covers the actual plant operators and the technical support provided as part of the reactor operations staff. The ANS is operated using a four-shift rotation; an additional training shift must be added for a total of five shifts. The plant operator staff is outlined in Fig. 2.6. The plant is staffed continually by three reactor operators, a senior reactor operator, a shift supervisor, two auxiliary operators, and a shift technical advisor. The auxiliary operators staff the cryogenics plant, oversee the detritiation plant when it is not operated from the local control room, and operate many other auxiliary systems throughout the facility. Additional personnel are included in Table 2.6 to cover for vacations and sick leave and to provide additional manpower during the day shift. 'Technical support and operations engineers also are provided; this staff is normally on the day shift and is aiso on call during any shift to cover unusual circumstances. Three day-shift operators staff the detritiation plant. (Since these operators are not in the main reactor complex, they are not included in the total of 66 reactor operations staff members.)

The research operations category covers the permanent scientific and technical support staff assigned to each instrument. As described further in Sect. 2.6.2, this staff includes two scientists and one technician for each of the 48 beam instruments and additional personnel for the irradiation and analytical chemistry programs.

Maintenance covers all of the craft personnel needed to maintain the facility. It also covers the maintenance engineers, planners, and other support personnel required for an effective maintenance program. Estimates for maintenance needs were developed with the assistance of HFIR maintenance and operations personnel.

Health and safety personnel include 20 health physicists, a bioassay technician, and a wholebody-counter technician. Most of the health physics staff is on a five-shift rotation (including the training shift). Security is staffed by 13 full-time personnel located at the ANS; additional response teams are drawn out of the central ORNL security staff. Eighteen quality assurance and compliance personnel are required, based on current experience at the HFIR. A staff of 25 is included for training. This staff includes trainers for reactor operators, auxiliary system operators, and key maintenance personnel; training personnel to staff the simulator and mockup facilities; instructors for general employee training; and personnel to cover other training functions, including records keeping.

The management and planning category includes the supervisory personnel for all aspects of plant operations. It includes the ANS director, the operations manager, and other plant management; and the management for maintenance, health and safety, training, and the operating groups. Administrative support provides secretarial and other support functions for all of the operations groups at the ANS. 
Table 25. Manpower and operating cost for steady state operation (costs in thousands of FY 1992 dollars)

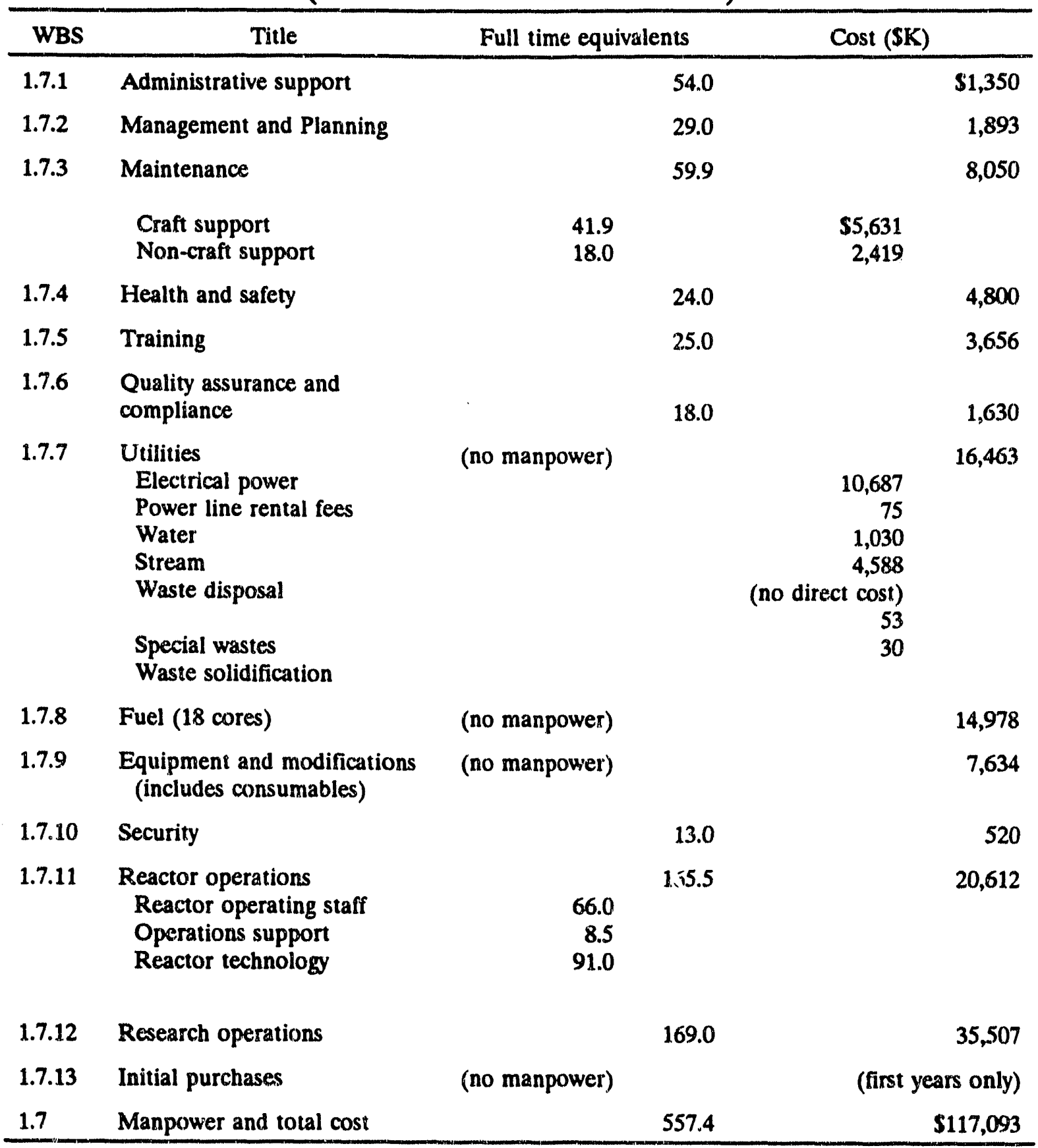


Table 26. Summary of operators at ANS

\begin{tabular}{lcccc}
\hline \multicolumn{1}{c}{ Classification } & $\begin{array}{c}\text { Personnel } \\
\text { per shift }\end{array}$ & $\begin{array}{c}\text { Personnel per } \\
\text { five shifts }\end{array}$ & $\begin{array}{c}\text { Day shift and } \\
\text { relief personnel }\end{array}$ & $\begin{array}{c}\text { Total } \\
\text { personne! }\end{array}$ \\
\hline Reactor operators & 3 & 15 & 4 & 19 \\
Senior reactor operators & 1 & 5 & 1 & 6 \\
Shift supervisors & 1 & 5 & 2 & 7 \\
Auxiliary operators & 2 & 10 & 4 & 14 \\
Shift technical advisors & 1 & 5 & 2 & 7 \\
Technical support & & & 8 & 8 \\
Operating engineers & & & 5 & 5 \\
Detritiation plant operators & & & 3 & 3 \\
$\quad$ Total operators & & & & 69 \\
\hline
\end{tabular}

(Note: Detritiation operators are not located in the main control room.)

All of the operations categories discussed in the previous paragraphs cover manpower only. Other operating costs are covered in the WBS elements for utilities, fuel, and equipment replacement and modification. Utilities categories and costs are listed in Table 2.5 . Of these, electrical power is the most significant. Other significant cost elements are steam, used primarily for building heating but also for some process applications, and water (especially cooling tower makeup water). About $40 \%$ of the electrical power used at the ANS is for the cold source cryogenics plants. About $20 \%$ of the electrical power goes to the primary cooling system pumps, 9\% to the secondary cooling system pumps and cooling tower fans, and $8 \%$ to the electrolytic cells and other components in the detritiation and upgrade plant. The fuel cost represents the cost of 18 sets of fuel elements per year under steady state conditions. The largest fraction of the costs for equipment replacement and modification is associated with the reactor components (such as the core pressure boundary tube or control rods) that must be replaced on a regular basis because of radiation damage. A smaller fraction of this cost covers consumables, such as liquid nitrogen, filter media, and demineralizer resins.

The initial purchases element covers such items as the spent fuel cask. These purchases are made at the beginning of the project, as discussed in Sect. 2.6.3.2, and do not appear during steady state operation.

The assessment of operating staff and cost serves a number of purposes. Estimates of staff size are used to support the design basis for staff support requirements (e.g., the office building, change houses, portal sizing, and control complex design). This task began originally as part of the development of an ANS Buildings and Site Planning Requirements Data Base. The information is uied to estimate operating costs, both for comparisons to the cost of operating existing facilities and for development of the total project cost and life cycle costs. The information developed under the basis for operations will serve as a baseline for future human factors studies and as a baseline for life-cycle cost studies of design alternatives, such as energy efficiency studies. 


\subsubsection{Research Program Operations}

The permanent research staff at each beam instrument includes two scientists and one technician; an additional two outside users are assumed to be at each instrument at all times (these are overall averages; the mix at individual instruments will vary considerably). Thus an average staff of five will be at each instrument; this is typical in the United States, although European facilities average almost seven per instrument. An operating plan lists estimates of the existing user base in the United States, based on data from the HFIR, the High Flux Beam Reactor, the National Institute of Standards and Technology reactor, the Missouri University Research Reactor, and two spallation sources. These estimates show that a user base of 1000 at the completion of the ANS construction project is conservative.

Most of the users of the ANS will be provided free access under DOE's policy for nonproprietary experiments. Other users, such as indus rial users conducting proprietary research, will be subject to cost recovery rules established by DOE. The arrangements for conducting such research will be negotiated on an individual basis.

A system of proposal submission and review will be set up, using procedures similar to those in place at other user facilities in the United States. The potential user will establish contact with a member of the permanent scientific staff, who aids the user in assessing the practicality of a proposed experiment and the type of instrument best suited to its performance. The user then submits a short written proposal in standard format detailing the scientific case for the experiment and containing sufficient technical information to permit feasibility and safety assessments. The proposals received are treated confidentially and reviewed by subcommittees of the ANS Program Advisory Committee composed of scientists mostly external to the ANS. If the proposal is accepted, beam time is scheduled in consultation with the local contact and with all external groups involved. Repeat users must have submitted a written report on the previous use of beam time before any continuation proposal will be considered.

To ensure user participation in the design of instruments at the ANS, some of the instruments may be provided by participating research teams. These teams enter into an agreement with the ANS to develop and operate one or more stations on ANS beam lines. In the early phases of ANS construction, proposals usually will concern the instrumentation of an unused beam station. As the scientific program evolves during routine operation, proposals to replace or modify an existing instrument also will be considered. Each participating research team will allocate at least $25 \%$ of its bean time to other users who request time through the normal proposal process.

\subsection{Transition to Operations}

\subsubsection{Definition of Project Completion}

Project completion has been defined in terms of the completion of standard tests of source brightness and of the delivered neutron flux to an instrument in the guide hall. It is anticipated that these tests can be accomplished during the low power testing phase and scaled to full power operation. Initial criticality is planned for the first quarter of FY 2002; completion of the tests described below is expected by the end of FY 2002.

Neutron source intensity verification. The technical objectives are to be met by construction of a neutron research laboratory based on a high flux reactor that has a peak thermal flux in the reflector exceeding that available at similar, existing facilities by at least a factor of five. The flux 
currently available has been established at $1 \times 10^{19} \mathrm{~m}^{-2} \cdot \mathrm{s}^{-1}$. Verification of achieving this requirement will be accomplished by an incident-source-brightness measurement performed at an appropriate thermal-neutron station of the ANS, such as the T-4 station on the HB-3 thermal guide. The measurement will be on a standard sample approved by the Neutron Diffraction Commission of the International Union of Crystallography.

Neutron guide transport systems verification. Neutron flux measurements will be accomplished at the beginning and end of each installed guide to provide veritication that the neutron guide transport system's acceptance and transmission characteristics will exceed an effective reflectivity per bounce value of 0.95 . These measurements will employ a standard, internationally accepted technique, such as foil activation. The beginning position is defined as an appropriate guide access point near the penetrations through the reactor biological shield, or if applicable, through the reactor building containment wall. The end position is defined as an appropriate guide access point planned for installation of a scientific research instrument.

\subsubsection{Buildup of Operations Activities}

Because of the need for trained operating personnel during the testing and startup phase and at the transition from the construction project to the operating phase, hiring and training of staff must occur during the construction phase. Profiles of operating staff buildup throughout the construction project have been developed. Some level of management, health and safety, security, and administrative support is maintained throughout the construction project, providing ANS operations a role in the design of the facility. Major staff hiring begins in FY 1999, and essentially a full complement will be in place by FY 2002. Costs for utilities and fuel also begin under the operations WBS in FYs 2001 and 2002. A profile for purchases of fuel elements has been developed: two cores are ordered in 2000, twelve in 2001, and twenty in the following 5 years (two more than the annual use of eighteen cores, to build up an inventory). The heavy water inventory is needed in FY 2001, and the spent fuel cask and the initial spare parts inventory are obtained in FY 2002. Tooling for the fabrication of ANS fuel elements is costed in FY 1994. A dummy core for use in the mockup is obtained from the fuel manufacturer in FY 2000.

The research program must also be in place before completion of the facility so that initial proposals for use of the facilities (including proposals for the design and installation of instruments provided by participating research teams) can be evaluated before facility startup.

\subsubsection{First Year of Operations}

Operating costs for the first year of ANS operations (FY 2003) also have been estimated. The inajor differences between operations in 2003 and steady state conditions is that only 12 cores are burned in 2003, and the power consumption is lower than steady state while the testing program and ascension to full power are completed. The estimated operating cost for FY 2003 is $\$ 74$ million in FY 1992 dollars. The research program is expected to cost approximately $\$ 35$ million. 


\section{SUMMARY OF ALTERNATTVES}

\subsection{Overall Concept Alternatives}

The Major Mr erials Facilities Committee of the National Research Council, co-chaired by Frederick Seitz and Dean Eastman, recommended design and construction of an advanced steady state neutron facility in a report issued in August 1984. The report states that the goal is to achieve about ten times the flux of existing machines, with a minimum requirement of five times the flux. These goals and requirements were strongly endorsed in the Review of the National Research Council Report "Major Facilities for Materials Research and Related Disciplines" issued in June $1985^{4}$ by the Materials Ad Hoc Review Panel of the DOE Energy Research Advisory Board. Those documents establish the basic requirements for the ANS Project and establish the features that credible design concepts must include. In particular, the requirement for a steady state neutron source means that pulsed neutron sources (which do not deliver a steady state flux) were not considered as a design alternative for the ANS.

A comprehensive evaluation of concepts for the ANS, which were developed at research centers throughout the world, is documented in the Proceedings of the Workshop on An Advanced Steady-State Neutron Facility. ${ }^{5}$ This was published in a widely read international journal [Nucl. Instr. Methods, A249, 1-132 (1986)] to give it the widest exposure in the scientific community. The workshop was held in Gaithersburg, Maryland, on December 16-18, 1985. Proposals and evaluations covered the extension of HFIR and Advanced Test Reactor technology, pin-fueled liquid metal reactors, cermet-fueled liquid metal reactors, very compact cores cooled and moderated with light water (such as the proposed Munich reactor), and novel reactor concepts including particle bed reactors and a rotating ring concept (in which fuel moves into the high flux region of the reactor and then cycles to a region of lower flux to allow time for cooling). A proposal also was discussed for a steady state neutron spallation source driven by a continuouswave proton or deuteron accelerator. In the course of developing the evaluations, it was noted that some of the concepts, including the pin-fueled liquid metal cooled concepts and the very compact light water cooled concepts, were not realistically capable of achieving the project objectives. A summary session of the Gaithersburg workshop evaluated the merits of those proposals that might achieve the objectives and developed a set of conclusions that has served as a basis for selecting the ANS reactor concept.

Since the 1985 Gaithersburg workshop, additional definition of the features, capabilities, and difficulties associated with high-current, accelerator-driven spallation sources has become available. The SINQ spallation source is now under construction. Because of the radionuclide inventories that would accumulate in a $\mathrm{Pb}-\mathrm{Bi}$ target (and the attendant containment requirements), a Zircaloy target is being used instead. This modification has reduced the performance to about $45 \%$ of earlier expectations. At an Expert Meeting on Accelerators held in September 1991, the features of a plausible next-generation spallation source were defined. Notes distributed at a European Spallation Source Expert Meeting held in February 1992 define the potential neutronic performance in terms of current sources. The source specifications note that the European Spallation Source will have a fast/primary neutron flux some 30 times more intense than the existing ISIS spallation source and will be capable of providing a time average flux equivalent only to that of ILL (but with a sharp pulse structure): These performance levels fall an order of magnitude short of the goals and minimum requirements set forth for the ANS.

Of the reactor concepts considered for the ANS, the extension of existing reactor technology used in the HFIR and Advanced Test Reactor (and the ILL and all the MTR-type reactors) provides the lowest risk to the timely completion of project objectives. None of the alternatives 
offered prospects of lower costs or shorter schedules. Thus the ANS design is based on a compact core reactor using a uranium-aluminum fuel and with heavy water as the coolant, moderator, and reflector.

The Major Materials Facilities Committee (Seitz-Eastman) recommendations state that instead of upgrading an existing reactor, a new facility should be built. Before the publication of the Major Materials Facilities Committee conclusions and the subsequent Energy Research Advisory Board report, Energy Systems initiated two feasibility studies. Comparisons of cost projections and schedules for the two showed that little saving was achieved by upgrading the existing HFIR, and that the scientific capabilities of the new facility were superior to those of the upgrade. Further, demonstration of compliance with current licensing guidelines added additional project risk in the case of the upgrade. Existing programs at the HFIR would be interrupted during the construction phase of an upgrade, and the application of new passive safety concepts would be difficult to implement. Thus the new facility alternative was selected. The Energy Research Advisory Board agreed with this assessment in its review of the Major Materials Facilities Committee recommendations, noting that cost/benefit studies have confirmed the wisdom of building a new facility rather than modifying the existing HFIR.

\subsubsection{Reactor Concept Alternatives}

Selection of the reactor concept was based on an initial series of reviews of the available technology and on a series of workshops used to present credible design alternatives and select the recommended concept.

A compact configuration is required to limit the surface area of the core. Power increases the neutron source strength, and a small core volume (high power density) increases the number of neutrons passing across a surface just outside the core (the location of the peak thermal neutron flux). Curved plates were found to be stronger than pins for the thin fuel structures necessary for heat dissipation in a high power density reactor. Aluminum has a low neutron absorption cross section and a high thermal conductivity and is a proven clad and structural material in many research reactors. Heavy water provides an effective reflector for a beam reactor. It has a low absorption cross section and is an effective moderator. Heavy water reactors tend to have a long neutron mean free path and lifetime. These lead to relatively slow kinetics and tend to create a large volume of useable flux. Comparative calculations were performed using light and heavy water as the coolant. The results showed that even with the addition of beryllium, the use of light water coolant led to reductions in performance, with the heavy water system giving $40 \%$ to $50 \%$ more flux. Thus heavy water was selected as the coolant for the ANS. Comparative calculations were also performed to identify the performance that could be achieved through using low enrichment uranium (20\% or less) as opposed to highly enriched uranium. As discussed in ORNL/M-550 6 and in later calculations, it was found that the ANS could not meet the project objectives without the use of fully enriched uraniurn. Silicide fuel, in the form of $\mathrm{U}_{3} \mathrm{Si}_{2}$, offers the highest thermal conductivity and uranium density of the fuels used to date in uranium-aluminum cores. R\&D conducted on this fuel under ANS conditions has demonstrated its excellent stability, thermal conductivity, and fission product retention properties.

Three workshops and task groups were used to establish the core configuration. The first of those was the ORNL/INEL core comparison workshop held in February 1988. At this workshop, it was decided to adopt the involute fuel geometry but the axially split core configuration. Late in 1988, another set of core configurations was considered and evaluated. This evaluation systematically varied the diameter, height, offset, and other dimensional parameters of the core. A new core configuration was established, termed the PS-2 core, as documented in 
ORNL/TM-11234. ${ }^{7}$ As analytical techniques evolved, the systematic evaluations of the PS-2 core were revisited. The volume was increased slightly, and the span of the fuel plates was decreased to improve plate stability. The resuiting core, termed the conceptual core design, is the one presented in this report.

\subsubsection{Neutron Source, Transport, and Utilization Alternatives}

The Major Materials Facilities Committee (Seitz-Eastman) recommended the construction of a facility that includes at least one large guide hall; a reactor hall containing thermal and hot beams; a variety of spectrometers; and improved national facilities for isotope production, irradiation of materials, neutron activation analysis, and research in nuclear physics. NSCANS, made up of representatives of all the fields of science that are expected to use the facility, meets periodically to assess the evolving design of the ANS in terms of meeting the user community requirements. The recommendations of this and other committees define the overall structure of the research program at the ANS.

The selection of the array of neutron scattering and physics instruments has been the subject of a number of workshops and of ongoing review by NSCANS. Early workshops to identify priorities and recommend specific instruments for the ANS were held at ORNL in May 1984 (CONF-8405192) ${ }^{8}$ and at Shelter Island in October 1984 (CONF-8410256). ${ }^{9}$ A more recent workshop, sponsored jointly by Brookhaven National Laboratory and ORNL, was held in June 1989 (CONF-8906311). ${ }^{10}$

The scope of the materials irradiation facilities also is reviewed by NSCANS on an ongoing basis. The initial scope of the facilities was set by the goal of replacing HFIR capabilities at a minimum. This goal has been modified somewhat to take advantage of the unique opportunities and adjust to the unique limitations of the ANS reactor design. A major workshop on priorities and facilities for materials irradiation at the ANS was held at ORNL in December 1990 (CONF-901276). ${ }^{11}$

Likewise, the scope of transuranum production facilities in the ANS receives regular NSCANS review. A workshop that included discussions of the needs and the size of the ${ }^{252} \mathrm{Cf}$ user base was held at Oak Ridge on April 13 and 14, 1988.

\subsection{Plant System Alternatives}

Many of the ANS plant features were influenced strongly by a safety workshop held in October 1988 (CONF-8810193). ${ }^{12}$ Included in discussions at that workshop were passive safety features of the reactor cooling system and reactor containment and the general approach to regulatory processes, waste management, and environmental compliance. Design features have also been strongly influenced by early probabilistic risk evaluations, many of which were based either on a more developed probabilistic risk assessment for the HFIR or on more qualitative reviews of early design concepts.

A formal evaluation of all realistic possibilities for heavy water primary cooling systems and light water secondary cooling systems was conducted throughout 1989. An exhaustive review of options covering the equipment sequence and geometrical layout for an individual loop, the number of loops, the role of emergency cooling equipment, and heat sink possibilities resulted in the presentation of three candidate systems at a workshop held in February 1990

(CONF-9002142). ${ }^{13}$ The options are described in a workshop notebook. The cooling system described in the Conceptual Design Report was selected shortly after the workshop. 
A similar study was undertaken to evaluate the performance goals and the physical implementation of the reactor containment system. Again, all credible alternatives were described and a set of representative options was presented at a workshop held in August 1990 (draft CONF-9008150). ${ }^{14}$ A notebook describing the key options was distributed at the workshop. The goals and concept selected are described in the Conceptual Design Report.

The general layout and zoning concepts used for the ANS candidate site and main building complex evolved over time. Requirements were established by conducting a series of interviews with representatives of all user groups, reartor operations groups, security and safeguards representatives, and maintenance representatives. A workshop held in October 1989 was a key step in identifying the set of groups to be interviewed and in initiating the formal process. A workbook compiled over the course of preparations for and discussions at the workshop documents the activities used to initiate the process. The interview process has continued throughout the conceptual design phase with the participation of the architectural firm. It has resulted in the development of the Buildings and Site Planning Requirements Data Base.

A formal process for the selection of a candidate site was conducted, using the DOE Oak Ridge Reservation as the region of interest. The study is documented in ORNL/TM-11419. ${ }^{15}$ That candidate site has been used to develop the conceptual design of the facility. Alternative candidate areas were defined in Melton Valley, Bear Creek Valley, and near the Highway 58/95 interchange. Three candidate sites were identified for final evaluation, all located in Melton Valley near ORNL. Extensive interviews of site planning, emergency planning, environmental protection, and geology personnel were conducted during the course of the selection process. 


\section{JUSTIFICATION}

\subsection{STRATEGIC NEEDS}

Much of the research data that form the basis for U.S. materials technology is gathered by probing matter with three types of radiation: electromagnetic (e.g., light or $\mathrm{X}$ rays); charged particle (e.g., electrons), or neutral particle (neutrons). Although the three types of information thus obtained are complementary, certain research areas may be weighted more heavily towards one or the other. In the past few decades, the equipment required to obtain information about materials has become increasingly complex, and the cost of providing research facilities has exceeded the reach of most industries. In response to this need, the federal government has provided access to the necessary equipment through the DOE and other national laboratories. Neutron research at DOE laboratories provides unique information needed to maintain hightechnology R\&D endeavors in several important fields. The proposed ANS facility is needed to help the United States stay competitive in those R\&D fields. There are several indicators that industrial neutron research is cost effective; for example, industry often has preferred to pay full cost recovery for neutron scattering experiments at the HFIR at ORNL even for basic research rather than operate under the policy of free access in return for publishing the results. Another indicator is that industries that began to use neutron data many years ago are still doing so (e.g., Exxon and Rolls Royce Aerospace).

Although many U.S. corporations have found neutron research necessary to their operations, some have had to use overseas facilities to gain access to the best equipment. This situation is complicated by the fact that overseas facilities currently are heavily over-subscribed (typically by a factor of two to five), and priority is given to researchers from member nations. Furthermore, proprietary research by U.S. companies is generally not possible at such facilities.

Neutron scattering research has developed into an important tool for understanding the structure and behavior of solid and liquid structures. Neutrons thermalized to room temperature or below have properties that make them uniquely valuable for probing the structure of condensed matter. Many of the properties of materials are determined by structures that are 100 to 1000 times the size of atoms. Thermalized neutrons have wavelengths in a range suitable for probing these structures. Because they have no electric charge, neutrons can penetrate materials that charged particles cannot; consequently, neutrons can be used to determine the bulk properties of materials. The ability of neutrons to penetrate large items makes it possible to examine large manufactured articles for defects and to study the details of operations.

The ANS neutron scattering capabilities will have multidisciplinary appli zations in physics, astrophysics, nuclear physics, condensed matter (solid and liquid state) physics, surfaces and interfaces, biochemistry, structural biology, materials science and engineering, archaeology, materials irradiation and analysis, and isotope research. For example, neutron scattering has been used to study fluid-flow properties in operating jet engines and can be used to study fluid flow in other situations. Neutron scattering also can be used to measure stress patterns in manufactured objects, and, because it yields important information about the microscopic structure of polymers, it can be used in the design of new polymers. Cold neutron scattering has been used to measure magnetic flux lattices in high-temperature superconductors and is expected to play a critical role in the development of materials that are superconducting at higher temperatures.

ANS also would provide defense-related capabilities. Defense uses of ANS would include production of isotopes for aircraft and other radiography and detection of explosives in counterterrorism; testing of materials under irradiation bombardment; and nondestructive testing 
of critical engineering components. In this context, the most important task for ANS probably would be to take over from HFIR the production of ${ }^{252} \mathrm{Cf}$, a portable neutron source, and thus to enable neutron radiographic inspection to take place in the field.

Although the primary purpose of the ANS facility would be basic research, a secondary function would be the produciion of isotopes with commercial applications. There are more than 300 radioactive isotopes with half-lives varying from about 1 day to 10,000 years or more. The widely varying physical, chemical, and biochemical properties of these radioisotopes have numerous applications in food technology, agriculture, energy supply, aerospace, public health, medicine, industrial technology, and national security. In the United States alone, about 40,000 medical procedures each day make use of radioisotopes, and about $45 \%$ of all single-use medical supplies (e.g., syringes and surgical gloves) are sterilized by radioisotope irradiation.

In assessing the need for ANS as an isotope production facility, it is important to bear in mind that it would be the only source in the United States for the transplutonium isotopes, as HFIR is now. These isotopes have a variety of uses, including medical diagnosis, cancer therapy, and radiography of aircraft wings. A strong case also can be made for the continued production of these isotopes as research materials for basic studies in nuclear physics, chemistry, and solid state physics. The large volume of very high thermal flux in the ANS reflector would also allow the production of high specific activity isotopes of lower mass number as programmatic needs arise. ANS would operate isotope loan agreements and sales in line with DOE policies.

Commercial production accounts for most radioisotopes in general use. The role of DOE has been to fill gaps where no commercial source exists or to supplement inadequate commercial production (for example, of ${ }^{192} \mathrm{I}$ ). Often, this requires facilities unique to DOE. The HFIR in particular is the only source in the United States of transuranic isotopes such as ${ }^{252} \mathrm{Cf}$, which undergoes spontaneous fission with a half-life of 2.64 years. One gram of ${ }^{252} \mathrm{Cf}$ will produce $2.3 \times 10^{12}$ neutrons/s. It is a strong, portable source of neutrons, and this property has led to many applications. At present, DOE has 109 loan agreements with 82 institutiors for HFIRproduced ${ }^{252} \mathrm{Cf}$.

Therapy based on neutron bombardment from ${ }^{252} \mathrm{Cf}$ has been shown to be effective in the treatment of cervical cancer. Sources are also being developed for in vivo neutron activation analysis to be used in clinical diagnosis and monitoring of medical conditions involving abnormal amounts of lithium, aluminum, or nitrogen. In addition, the U.S. Food and Drug Administration has ordered $200 \mathrm{mg}$ of ${ }^{252} \mathrm{Cf}$ (a large fraction of the current national supply) to be used in neutron activation analysis of certain foods. The commercial power industry uses ${ }^{252} \mathrm{Cf}$ as the industry standard method for startup of pressurized water reactors and as a source for neutron radiography of power reactor fuel rods. There are also growing commercial uses of ${ }^{252} \mathrm{Cf}$ as a source for neutron activation analysis and as a standard source for dosimeter calibration. One of the newest applications of ${ }^{252} \mathrm{Cf}$ is detecting hidden explosives in airline passenger luggage. Monitors already have been installed at airports in New York, San Francisco, Los Angeles, and Miami; and the installation of similar devices is planned for London, Atlanta, Frankfurt, and Rome.

The Naval Ocean Systems Center uses neutrons from ${ }^{252} \mathrm{Cf}$ to test infrared devices for resistance to neutron darnage, and the Mound Laboratory uses ${ }^{252} \mathrm{Cf}$ neutron radiography for nondestructive inspection of explosive fill in detonators. Production reactors at the Savannah River Site would require ${ }^{252} \mathrm{Cf}$ for startup, and there are some classified uses.

In addition to producing transplutonium isotopes, ANS would be used to prepare the many other neutron-produced radioisotopes that are used in industry and medicine. For example, certain isotopes such as very high specific activity ${ }^{60} \mathrm{Co}$ that is used in medical therapy, sterilization, and radiography, can be produced only in facilities that provide a very intense neutron flux, such as HFIR or the proposed ANS. 


\subsection{ECONOMIC CONSIDERATIONS}

Table 3.1 was constructed as a basis for comparing the operating cost of ANS with the combined operating cost of the HFIR and the HFBR (the two facilities that the ANS is expected to replace). This table covers reactor operating costs only; research operations costs are not included. Since the ANS is designed to operate at $80 \%$ availability (and operating costs are estimated on that basis), the costs for the HFIR and the HFBR were sciled to what they would be at $80 \%$ availability.

As can be seen from the table, ANS operating costs are roughly comparable to those of the HFIR and HFBR added together, with the research support staff not included. Two measures can be used to compare the performance of the ANS to that of the HFIR and HFBR combined. The first is thermal neutron flux, either in terms of the unperturbed neutron flux in the reflector or in terms of the useful flux delivered to the sample. The number of beam stations, as determined by counting instruments, provides another measure of the relative capabilities of the facilities.

The thermal flux of the HFIR actually peaks in the central flux trap (since the basis for construction of the HFIR was production of transuranium isotopes). The average therrnal flux at the end of the beam tubes, at a power of $85 \mathrm{MW}$, is about $1 \times 10^{19} \mathrm{~m}^{-2} \cdot \mathrm{s}^{-1}$. The peak thermal flux at the HFBR, when operated at $60 \mathrm{MW}$, is also about $1 \times 10^{19} \mathrm{~m}^{-2} \cdot \mathrm{s}^{-1}$. However, the beam tubes at the HFBR are located at a radial distance beyond that of the peak thermal flux, and the reactor is now operating at $30 \mathrm{MW}$. Thus the average thermal flux at the end of the HFBR beam tubes is about $0.5 \times 10^{19} \mathrm{~m}^{-2} \cdot \mathrm{s}^{-1}$. The estimated peak thermal flux in the ANS is from 7 to 7.5 $\times 10^{19} \mathrm{~m}^{-2} \cdot \mathrm{s}^{-1}$, and the beam tubes are located at the location of the peak thermal flux. Thus on the average, the ANS provides a peak thermal flux at the beam tubes that is 10 times that currently available at the HFIR and the HFBR.

Several factors affect the transport of neutrons to the instruments, including the use of neutron guides (including supermirror guides on thermal insiruments) and the dimensions of the beams. The ANS beams are taller than they are wide. Since many experiments require a low angular divergence in the horizontal plane but are less affected by angular divergence in the vertical plane, this configuration increases the useable flux at the sample. The result can be a thermal flux gain of an additional factor of two. More significant is the effect of the ANS cold sources. The HFIR has no cold source; the HIFBR has a cold source that feeds three instruments. All of the ANS instruments that would benefit from the cold flux gain factors are given positions on the cold guides in the guide hall. This can lead to an increase in the flux, at the desired wavelengths, of factors of ten or more. Thus for any given type of beam instrument, the ANS provides an increase in flux from about 10 to 200 over existing U.S. facilities. Since these experiments are flux-limited, this translates to a corresponding increase in the scientific capability of the instrument.

The ANS has 9 thermal beam tubes, 2 hot beam tubes, 14 horizontal cold guides, 1 slant thermal tube, 2 slant cold guides, 2 very cold guides, and a total of 48 bieam instrument stations. The HFIR has a total of 4 beam tubes; through clever design, 9 instruments can be operated at one time. The HFBR has 6 thermal beam tubes and a single penetration with a cold source and 3 beams. A total of 15 instruments are operated at one time at the HFBR. This provides a total of 24 instruments at the HFIR and HFBR combined: half the total complement at the ANS.

Thus at essentially the same operating cost, the ANS provides at least twice as many instruments as the HFIR and HFBR combined, and from 10 to 200 times the flux at each instrument. 
Table 3.1. Annual operating costs for the ANS, the HIFIR, and the HFBR (FY 1992 dollars, assuming $80 \%$ availability)

\begin{tabular}{lcccc}
\hline & $\begin{array}{c}\text { ANS } \\
(\text { SM) }\end{array}$ & $\begin{array}{c}\text { HFIR }^{b} \\
(\text { SM) }\end{array}$ & $\begin{array}{c}\text { HFBR }^{b} \\
(\text { SM })\end{array}$ & $\begin{array}{c}\text { HFIR + HFBR } \\
(\text { SM })\end{array}$ \\
\hline Operating staff & 37.2 & 24.3 & 13.7 & 38.0 \\
Consumables & 3.9 & 0.9 & $9.0^{d}$ & 9.9 \\
Nonrecurring items & $3.7^{*}$ & $2.1^{f}$ & 2.05 & 4.1 \\
Utilities & & & & \\
$\quad$ Steam & 4.6 & 0.2 & Unknown $^{d}$ & 0.2 \\
$\quad$ Water & 1.0 & 0.4 & Unknown $^{d}$ & 0.4 \\
$\quad$ Reactor electric power & 5.6 & 1.8 & 0.8 & 2.6 \\
$\quad$ Cryogenic electric power & 4.3 & $\mathrm{NA}$ & 0.1 & 0.1 \\
Detritiation & $0.8^{h}$ & $\mathrm{NA}$ & $0.2^{i}$ & 0.2 \\
Cores & $15.0^{\circ}$ & $4.8^{k}$ & $0.5^{l}$ & 5.3 \\
Other & $5.5^{\mathrm{m}}$ & $3.0^{n}$ & $0.1^{\circ}$ & 3.1 \\
Total & 81.6 & 37.5 & 26.4 & 63.9 \\
\hline
\end{tabular}

The ANS costs do not include those of the research support staff, since the other facilities do not have such a group.

${ }^{b}$ Currently, HFIR is actually running at a maximum of only $60 \%$ availability and HFBR at $70 \%$, so the actual utility and core costs are lower than these figures.

This does not include research operations, security, or health physics, which are costed separately at HFBR (see fnotnote d).

This is made up of BNL overhead and includes steam, security, water, health physics, maintenance, telephones, etc.

These are major equipment items that must be replaced periodically.

This is for Tiger Team coriective actions.

This number includes a special training development project and a contract for testing and analysis of the reactor power capacity.

This is the electric power for the Detritiation Facility.

'Although this is not the actual cost of operating detritiation facility, it is one-fourth of the cose incurred every 4 years to hav $\mathrm{D}_{2} \mathrm{O}$ shipped, upgraded, and detritiated in Canada.

This assumes 18 cores per year, which is the expected number of whole cores during full, normal operations. While the inventory is being established, two additional cores per year may be needed. Furl burnup costs are not included.

This is a revised fuel cost based on FY 1992 rates from the fabricator combined with our $80 \%$ availability.

'HFBR has produced no new fuel elements since FY 1990; its elements are currently taken out of existing inventory. If new elements are purchased, this cost might double.

"This includes costs for health physics staffing, security staffing, and other utilities.

"This number includes costs for other utllities, fuel burnup, health physics and security staffing, and the critical experiment facility.

This cost represents the charge for Y-12 fuel element storage. 
Other factors are not accounted for in this discussion, including the quality of the beams (with respect to gamma and fast neutron contamination), which is highly optimized at the ANS; and the extent to which experiments can be conducted on the ANS that cannot be conducted at either the HFIR or the HFBR (because the signal at those reactors is simply not strong enough to be discerned from the background).

\subsection{IMPACT IF NOT FUNDED}

The neutron scattering capability of facilities in the United States is being eroded by the aging of current research reactors. This capability will be essentially eliminated by their eventual shutdown. With more instruments than exist cumulatively on all U.S. reactors, ILL is the world leader in neutron research; however, thermal flux at the proposed ANS at a fission power level of $330 \mathrm{MW}$ would be five to ten times greater than any current research reactor's capability and would exceed the capabilities of facilities in any other country. If the proposed ANS is not operational before the HFIR and HFBR are shut down (they are already more than 25 years old), U.S. neutron researchers will be totally dependent on foreign research facilities for high flux beams. As a result, delaying the ANS project could have scientific and technological consequences in the United States. In many fields of research, the HFIR and the HFBR are no longer competitive with Japanese and European facilities. ANS could help restore the United States to a position of leadership in the field of neutron research.

Retiring the HFIR facility and delaying ANS construction and operation also would have economic implications. The immediate impact could be a loss of direct scientific and technical jobs at ORNL because of the HFIR shutdown, followed quickly by a loss of corollary jobs that have been created as the result of off-site support of the HFIR (e.g., the industrial, medical, and research use of the production capability of the HFIR). With the loss of domestic production capability for medical and industrial isotopes, the R\&D and some production work in those fields would be lost to foreign reactor facilities. Critical issues of quality control would arise because programs that evaluate the effects of radiation on components in varying radiation fields would not continue. The result of losing this safeguard could be unanticipated failure of expensive components in, for example, space hardware, reactors, and fusion applications.

Finally, if ANS were delayed, the loss of HFIR capabilities would lead to the simple logistical problem of access. There would be a severe reduction in the time experimenters could spend on a reactor because the available time on the remaining reactors would be in much greater demand and thus more difficult to schedule. 


\section{SIGNIFICANT FACTORS}

\subsection{PROJECT REQUIREMENTS}

The ANS is a large, complex project. It requires nine years to design and construct; it involves three major design organizations, Energy Systems, an integrating contractor, a construction management firm, a host of procurement and construction contracts, and many other subcontractors; and it is subject to a complex set of regulatory requirements. There are many opportunities for schedule slippage and cost overruns. Successful accomplishment of the project requires effective control of schedule and cost. Control of schedule is particularly crucial; schedule slippages inevitably lead to cosł overruns because of escalation, contract extensions, additional administrative overhead, and inefficient use of staff. Aggressive schedules offer significant cost advantages. Effective project management is essential to timely completion of the facility within budget. In addition to the general need for attentive and responsive management, a number of factors discussed in the following sections could lead to schedule and cost overruns and add risk to the successful completion of the project.

The DOE has not constructed a major research reactor for many years. The last major reactor projects by DOE were part of the breeder reactor development program and thus were subjected to NRC licensing procedures to ensure the development of licensable design concepts, and to a licensing process for subsequent commercial breeder reactors. The regulatory environment for the ANS is not clear, especially from a procedural standpoint. In many cases, DOE orders implement standards that are equivalent to those applied to NRC-licensed facilities. Such standards have been applied to the design basis described in this report. However, the procedural aspects of design documentation and review and the nature of a permit to operate a major DOE reactor are not clearly established. Commercial reactor experience has demonstrated that delays associated with licensing procedures can be extremely costly in terms of schedule and cost overruns.

Delays in the environmental analysis and review process, especially with respect to completing the requirements of the NEPA process, also can lead to schedule and cost overruns. Timely completion of the NEPA process and promulgation of a record of decision are necessary for completing the alternatives evaluation (including site selection) and before beginning Title II design.

Procuring nuclear-qualified components has become difficult compared with a few years ago, because the lack of new commercial reactor construction has led many equipment vendors to decide that it is not economical to maintain qualifications. The ANS has unique qualification requirements, including aluminum components qualified to ASME Section III, Class 1 standards, and environmental qualification requirements that may differ from those encountered in commercial reactors (although they are generally less severe). These factors in turn may limit the extent to which normal specification and procurement procedures can be used to obtain reactor components. Other procurement concerns exist with respect to the detritiation facility. Few such plants have been constructed; one firm holds a license on the technology and has supplied proprietary equipment for all such plants currently in existence. 


\subsection{TECHNICAL AND OPERATIONAL UNCERTAINTIES}

\subsection{Issues Addressed by the ANS Research and Development Program}

A number of technical issues exist because of the advanced reactor and experiment facilities in the ANS Project design. In some cases, specific unknowns have been identified (such as the growth rate of oxide on the ANS fuel plates). In other cases, technical data are required to ensure that the design and safety calculations model the performance of ANS systems effectively. In still other areas, it is known that improvements in specific technology areas (such as neutron beam transmission) have the potential to improve greatly the use of the ANS.

An R\&D program has been established to address key uncertainties associated with the design and analysis of the ANS reactor, experiment, and plant systems. This program has been divided into 14 tasks, which are summarized below. This R\&D program has been under way through the preconceptual and conceptual design phases and will continue through detailed design and construction. Some of the activities listed are under way, and some are even complete, in the conceptual design phase. Others will not begin until much later. Part of the R\&D program is appropriately funded under operating funds, part is funded under the line item, and still other parts are funded using capital equipment funds.

\subsubsection{Reactor Core Development}

The ANS reactor core is based on known and proven technology, but it operates with higher heat flux and temperatures than previous research reactors. In some cases, technologies are used in ways not used before (e.g., two-dimensional fuel grading to provide power shaping). In other cases, operating conditions are at or somewhat beyond existing experimental data limits (e.g., power density and coolant velocities). These factors require a program of development or confirmatory tests for the design of the core, including the development and validation of the calculational techniques being used. The reactor core development task addresses the uncertainties posed by an advanced reactor design and develops both the design itself and the design and analysis techniques for the ANS reactor core.

\subsection{Fuel Development}

In comparing the proposed ANS fuel and the HFIR fuel, three issues have been identified: (1) the use of silicide fuel and grading in both axial and radial directions represent changes to the existing fabrication process; (2) the high fuel burnup rates encountered in the ANS represent a fuel performance regime where only a few data points are available; and (3) improvements in the quality control process used during fuel fabrication can be translated into additional safety margin.

\subsubsection{Corrocion Tests and Anałysis}

An oxide layer accumulates on the surface of aluminum cladding in water-cooled research reactors. The oxide layer phenomenon was explored at the time of the design of the HFIR, and the rate of oxide formation was found to increase as heat flux and other parameters increased. The ANS fuel operates at heat fluxes beyond those of the HFIR and beyond the range of the correlations developed for the HFIR. The oxide has a much lower thermal conductivity than the aluminum cladding, and thus uncertainties in the oxide formation rate translate into uncertainties in the fuel and cladding temperatures. Likewise, uncertainties exist as to the long term behavior 
of the oxide, including its stability and adhesion. A test loop has been constructed to identify and measure the corrosion product burnup on Type 6061 aluminum under various flow and power conditions that bound the operating parameters of the ANS. The test specimens simulate the cladding of the ANS fuel plates.

\subsubsection{Core Flow Tests}

The ANS reactor core uses coolant velocities and heat fluxes that are at the boundary of existing data for plate-type fuel thermal hydraulic performance. The ANS design also makes use of natural circulation for decay heat removal to a greater extent than in other high-flux research reactors. As a result, there is a need to verify and improve upon existing correlations for heat transfer and for modeling multi-loop natural circulation behavior. The core flow tests task provides the facilities required to characterize the thermal-hydraulic performance of various simulated reactor components at and beyond ANS operating conditions.

\subsubsection{Control Concepts}

The nature of the ANS reactor (e.g., high fuel burnup and low core volume) generates some unique control requirements. The control concepts task provides the nuclear analysis necessary to develop the control concept. Included in this task are the analyses necessary to define poison location, allocate control to burnable poison material, and demonstrate kinetic behavior for normal and accident transients.

\subsubsection{Critical Experiments}

The analysis of the neutronic performance of a reactor such as the ANS involves many complex computer codes and many simplifying assumptions and modeling techniques. The verification of these calculations is supported by other analyses, but benchmarking against actual experiments is necessary to provide adequate assurance that the neutronic operating and safety parameters are well predicted and understood. The critical experiments tasks include all activities needed to plan, perform, and analyze a set of critical experiments that will be used to benchmark the performance of the ANS core.

\subsubsection{Materials, Structural Tests, and Analyses}

The ANS has many individual reactor components, ranging from the fuel element to components of the coolant pressure boundary and control rods, that will operate in environments different from, and in many cases more severe than, those of other research reactors. Structural tests and analyses are needed to ensure the structural adequacy of components in the ANS reactor. This activity will include the structural analysis of fuel plates, control elements, the core pressure boundary tube, and other important components in the ANS reactor. In addition, it will supply the effort necessary to seed qualification of the core pressure boundary tube material as an ASME Code Pressure Vessel material and will generate required material properties, including irradiation effects. 


\subsubsection{Cold Source Development}

The ANS cold source will operate at neutron flux and heating rates that have not been encountered in existing reactor cold source installations. There are uncertainties associated with establishing the cold moderator environment in the ANS and with the neutronic performance of the ANS cold source design. The overall design of the ANS cold source, while it builds on techniques used at other installations, is itself in large part a developmental task. The cold source development task provides a program of cold source developmental activities and a prototype demonstration.

\subsubsection{Beam Tube, Guide, and Instrument Development}

The ANS reactor is designed to achieve the highest practical neutron flux, with the appropriate spectrum, for all of the applications within the scope of the project. Still further gains can be obtained through more efficient neutron collection and transport systems and by advancing the design of instruments so that more information is obtained from a given number of neutrons. The beam tube, guide, and instrument development activity includes all the tasks necessary to plan, perform, and analyze experimental data required to improve the efficiency of the systems used to deliver the neutrons to the experiments.

\subsection{Hot Source Development}

A hot source developmental effort is necessary to ensure that the design effectively meets the project goals. The hot source R\&D task includes activities necessary to support the design of the hot source and provides for a hot source prototype demonstration.

\subsubsection{Neutron and Gamma Transport and Shielding}

The ANS reactor and reactor shields are compl a systems penetrated by beam tubes, piping systems, instrumentation, irradiation facilities, and orher complex geometries. Specifications for neutron flux, spectra, and gamma contamination have been established for the beam tubes and guides. Radiation background in the experiment area and other areas occupied by personnel or radiation-sensitive equipment must be kept within the requirements established for the design of the ANS and must be kept as low as reasonably achievable. The calculation of neutron and gamma transport into the beam tubes, through the bulk of the shield systems, and through penetrations and potential streaming paths in the shield is a complex task. The neutron and gamma transport and shielding task develops and validates the methods used to calculate transport into the beams and past the elements of the reactor shield.

\subsubsection{Instrumentation and Controls System Development}

The ANS operational objectives place unusual demands on the operating regimes which require unique control and plant protection system capabilities. The instrumentation and controls sycte n development activity is provided to examine the capability of different controls and plant protection systems to meet operational and safeły needs. The extent to which special control and plant protertion system capabilities can be developed will affect the reactor's design concepts and its eventual operational capabilities. 


\subsubsection{Reactor Concepts}

A number of key issues that affect the design of the reactor system have been identified. They are generally associated with unknowns in mechanical system performance and reliability and in the hydraulic performance of the various coolant components that direct flow to all components cooled by the reactor system. Another area of concern is the reliability of the complex remote refueling mechanisms. The reactor concepts development task provides the necessary development activities and tests needed to support the reactor systems design.

\subsubsection{Safety Research and Development}

The safety R\&D task includes all of the additional R\&D activities that are considered necessary to support the ANS Project Safety Program. Experimental testing is proposed to support the analysis of severe accident phenomena in the area of explosive interactions, fission product release, fuel transient tests, fuel/concrete interactions, aerosol chemistry aspects, and containment. Benchmark experiments are being proposed to verify and/or validate the computer models being used in the analyses. Still other tests using existing and new facilities will include experiments to obtain data bases of critical heat flux, flow instability tests, and other tests pertinent to limiting operational criteria for the reactor. It should be noted that some of the activities under this task may be performed under subcontracts that have not been specified.

\subsection{Urcertainties in the Characteristics of the Candidate Site}

A site is not selected until a record of decision is issued at the end of the NEPA process. Thus the entire range of site-specific issues remains an uncertainty until the NEPA process has been completed.

The specific characteristics of the site cannot be fully known until a detailed site characterization has been completed. Until that characterization is carried out, detailed knowledge of the engineering characteristics of rock and soils on the ANS site will not be available. Some risk exists that major nonconformities might be discovered during the characterization that would require adjustments of the location of major structures on the site. An early characterization has not identified any such problems, but it was necessarily limited in scope. Thus early phases of the characterization will take place as soon as possible, within the constraints of the NEPA process and of DOE procedures, so that the potential for redesign is averted.

\subsection{Operational Uncertainties}

Many specific uncertainties exist as to the roles and the number of operators that will be required for the ANS. Two areas where this is particularly significant include the extent of interaction between reactor and auxiliary operators (those operating the refrigeration plant or the detritiation plant) and the extent to which operations are automated and initiated by computer. The human factors program planned for the ANS will address these issues.

Key uncertainties exist with respect to the possible operating modes of the ANS when certain systems are not available. An example of such a situation would be operation with one or both cold sources empty of liquid deuterium. Other uncertainties address runback and startup modes. Situations that must be addressed include reactor runback and restart upon loss of off-site power without being overcome by xenon poisoning; startup of a cold source without reactor shutdown; and startup of a spare cooling system loop accompanied by shutdown of a previously operating 
loop in the event that a failure or degradation of an operating loop appears likely. These uncertainties will be resolved during the advanced conceptual and later design phases.

\subsection{OPERATIONAL CONSIDERATIONS}

One of the major operational considerations associated with the ANS is the ability to operate on a sufficiently predictable basis that the anticipated user program, involving more than 1000 individuals, can be accommodated. It is not enough to meet averaged availability goals; beam time must be provided in accordance with schedules developed many months in advance. Arrangements such as airline tickets and hotel bookings must be made by the users; users cannot remain at the ANS site for many weeks waiting for their station to become available. As a result, predictability goals accompany reliability goals in the Plant Design Requirements, ORNL/TM-11625. ${ }^{16}$

The design of the ANS also must be such that users can be given reasonably unimpeded access to the necessary facilities (including beam instruments in both the guide hall and the beam rooms in the reactor building) while all necessary security, personnel accountability, and contamination control measures are maintained. The graded approach to security and contamination control provided in the overall facility layout has been developed to separate user areas and sensitive operations areas to the greatest extent practical. Procedures for user reception and training must be streamlined to make access for time periods as short as a week an effective use of the visiting scientist's time. Some experiments may require attention $24 \mathrm{~h}$ a day. The conceptual design allows for the construction of an on-site guest house from which a researcher may monitor his or her experiment and may be summoned quickly to respond if necessary. Sufficient support personnel must man the facility throughout all shifts to allow for user access at any time.

The hiring and training of a qualified reactor (and auxiliary system) operator staff also must occur in a timely manner. Hiring profiles have been defined in a basis for operations. Training staff and facilities, including a simulator and a mockup, are also included in the conceptual design. A particular issue is the potential for transferring trained staff from the HFIR to the ANS should the HFIR be shut down as the ANS is commissioned. Discussions have been held with Research Reactors Division management at ORNL on the overall subject of staff hiring and training, including the potential for transition of HFIR staff.

Spare parts and the supply of replacement parts for components that are subject to radiation damage are also key operational issues. The procurement of such components is addressed in a basis for operations. Maintenance activities and facilities at the ANS have been planned in consultation with the HFIR operations and maintenance staff.

\subsection{SPECIAL REQUIREMENIS}

Numerous special requirements are incorporated into the design basis for the ANS, as described in Chap. 2, in response to issues associated with reactor safety. The core design process includes detailed analyses of the neutron kinetics, including reactivity coefficients for power, voiding, light water ingress, and other situations; the rigorous evaluation and incorporation of design margins and uncertainties to ensure that design parameters are not exceeded for any transients within the design basis; and an extensive R\&D program to verify the neutronic and thermal-hydraulic performance of the core and the physical behavior of the fuel, the cladding, and other reactor components. Features of the reactivity control systems (especially the shutdown 
systems) and the reactor and experiment protection systems are provided in response to the special requirements for reactor safety. The design of the reactor cooling systems provides an extremely high level of assurance for the safe removal of decay heat from the core. The design of the containment system and the layout of control zones around the facility ensure that doses to the general public are minimized even under extreme postulated accicient scenarios and ensure ample time for evacuating facilities on the ORNL reservation. The design of the refueling system provides a high level of assurance that nuclear criticality is prevented, that decay heat is removed safely during handling, and that effective physical control is maintained during all fuel transfer activities. An integrated control and communications system is provided to allow the operator access to all needed information within the constraints of human abilities to comprehend the information and without compromising the integrity of the reactor and experiment protection systems.

Because of the use of enriched uranium as a fuel and because of the real or perceived threat to the public that could result if intruders gained control of the facility, detailed safeguards, security, and sabotage assessments are being performed on the design. These in turn result in special design requirements for intrusion-resistant structures and fencing, for intrusion detection systems, and for mobilization of trained response teams.

Because tritium is generated in the heavy water used as the reactor coolant and reflector, special requirements for the monitoring and control of tritium throughout the facility are included in the design basis. The detritiation facility is provided to maintain the tritium concentration in the coolant and reflector sufficiently low that maintenance of the facilities is not impeded, and that small leaks of coolant or reflector water do not lead to unacceptable releases to the environment. Control measures are included to capture leaks, including measures to retain moisture that evaporates and is carried into the ventilation systems.

Criteria for resistance to natural phenomena are included in the design basis. These criteria address not only the safe shutdown of the reactor but also general safety and investment protection concerns.

The presence of hydrogen in the reactor (in the form of deuterium in the cold sources) and in the detritiation facility (where part of the process involves the distillation of elemental hydrogen isotopes) results in specific requirements for implementing a fire safety program. Studies of the hazards posed by the inventories present and of the general hydrogen safety philosophy and its implementation in design will continue into the advanced conceptual design phase.

Environmental protection and regulatory compliance issues affect many individual aspects of the ANS design, including the design of waste, effluent, and monitoring systems. Means have been developed to track those requirements and ensure their implementation in all relevant system designs.

\section{CONSTRAINTS}

One of the major constraints placed on the design is that only proved technology is relied upon to meet the minimum project objectives. Technology need not have been proved in the specific application as long as there is no significant risk connected with its use in the ANS application. Development of new approaches and techniques is not discouraged (especially in terms of enhancements of performance beyond the minimum objectives). However, until such new approaches are considered well proven, the design must not rely on them to meet minimum objectives. 
Constraints also are imposed by the regulatory system for reactor design, construction, and operation. In many cases, DOE or NRC standards prescribe specific design approaches. Compliance with specific regulatory requirements is addressed in the individual SDDs.

A number of constraints are placed on the site selection process. In addition to the obvious requirements that a site offer adequate space, geology, access, and services, the site must allow the development of control zones (e.g., exclusion area and low population zone) with reasonable demographics. The application of these constraints to the selection of the candidate site on the Oak Ridge Reservation is described in the site evaluation report, ORNL/TM-11419. ${ }^{15}$

A number of factors impose constraints on the physical arrangement of the facility. The overall zoning approach for security and contamination control dictates which side of the facility certain operations must be located on. Elevation differences in cooling system components, necessary to create effective natural circulation decay heat removal modes of operation, result in constraints on the location of components and piping in those systems. Neutron be $m$ transport limitations impose constraints on the physical arrangement of the beams, guides, and instruments. The layout-of the beams and instruments defines the basic arrangement of the site, including the diameter of the containment, and the general arrangement of the reactor building and guide hall.

\subsection{INTERFACES}

The ANS will be the major national facility for neutron scattering; users will come from universities and industries across the country. The result is a major interface between the ANS itself and the research community throughout the nation. As is the case with the present neutron scattering facilities, the effective use of the ANS depends on the availability of trained users. This, in turn, establishes key interfaces between the ANS and the universities that train potential future users. In Europe, the success of facilities such as the ILL is greatly influenced by strong programs at universities, including the effective use of university research reactors (such as the Berlin reactor or the new reactor proposed for the Technical University of Munich). With a few exceptions (most notably the Missouri University Research Reactor), many of the U.S. research reactors are not used effectively to train physicists in the applications of neutron research. Promoting the development of scientific resources in the United States is as important to the nation as the actual construction of the ANS.

Many interfaces exist between the ANS and other facilities on the Oak Ridge Reservation. They begin with the site planning considerations taken into account in selecting the candidate site on the Reservation. These considerations include access (including existing and modified roads) and the relationship of the ANS to adjacent facilities or operations. A key physical interface exists between the ANS candidate site and the development of waste storage facilities just west of the ANS. Handled properly, this interface can be a desirable one that minimizes the impact of transportation of waste between the ANS and the storage facilities.

The ANS uses utility services available on the reservation. They include electrical power, potable water, steam, and a central sewage collection and treatment system. The capacities of these systems have been checked to ensure that adequate services are available for operation of the ANS. Similar interfaces exist between the ANS and the Reservation waste collection, packaging, and storage systems. Personnel from waste operations have participated in the design of the ANS waste systems to ensure that the ANS and the other facilities can operate as a coherent unit. The ANS will affect various environmental permits, many of which are written to cover the Reservation as a whole. Again, the personnel responsible for maintaining these permits are participating in the development of permit plans for the ANS to ensure overall compatibility. 
Other interfaces between the ANS and existing ORNL divisions center around support staff and supporting facilities such as maintenance and receiving. The ANS is designed to provide those facilities, and only those facilities (including maintenance shops and staff), that are necessary for effective operation. However, infrequent major maintenance activities can require considerable increases in staff and the use of additional facilities. Decisions on which maintenance facilities to include in the ANS project, and when to rely on existing ORNL facilities, were made together with management of the ORNL maintenance organizations. Similar interfaces exist with respect to security (the ANS has a dedicated security staff for normal operations, but relies on a central response team to support the local staff under major intrusion scenarios); technology support (obtaining additional technical resources from the central Engineering organization and key ORNL Divisions); health physics; instrumentation and controls; and a number of other technical support groups. 


\section{ASSESSMENTS}

\subsection{SAFETY ANALYSIS}

The basis for the safety of the ANS at this stage of design is structured to the outline used by the NRC to evaluate the safety of licensed reactors. Much of this effort covers reactor safety, but auxiliary system safety is also included. The approaches to reactor and auxiliary system safety become part of the design basis and requirements established for each system. Specific systems that are greatly affected by the safety analysis include the reactor system, the reactor instrumentation and control system, the refueling system, and the reactor cooling and containment systems. The systematic classification of all systems and hardware, using the reactor and nonreactor safety classes defined in the Plant Design Requirements, ${ }^{16}$ establishes specific requirements for the design and analysis of systems and components using a graded approach that reflects the importance of that system to safety.

The safety analysis is supported by individual probabilistic risk assessments and severe accident analyses. These also enter the design basis; for example, the design conditions for the containment system were established by performing analyses of a range of severe accident scenarios. Probabilistic analyses in the conceptual design phase were either of a general and often qualitative form or were oriented toward specific issues. Many design features, such as the independence of the primary and secondary shutdown rod assemblies, were influenced by the general risk assessments. Examples of specific, targeted numerical calculations are the reliability evaluations performed to assess whether containment performance goals are being met or calculations used to determine the number of parallel operating cooling system loops needed to meet core damage goals.

\subsection{ENVIRONMENTAL ANALYSIS}

The collection of background data and preliminary evaluations of the environmental impact of the ANS project are documented in ORNL/TM-12069, Phase I Environmental Report for the Advanced Neutron Source at Oak Ridge National Laboratory. ${ }^{17}$ This document will be used by the DOE contractor selected to write the Environmental Impact Statement for the project. The Phase I environmental report is tailored to providing the data and analyses needed to meet the requirements of the NEPA process. Additional data, including detailed design information, must be supplied as part of the license submittal for NRC-licensed reactors. This information will be assembled into a Phase II environmental report to be written later in the detailed design phase.

The results of the environmental report influence the design basis for the ANS in much the same way as the evaluations described in the safety analysis reports. Systems particularly affected include the plant waste systems, land improvements (in terms of site drainage and impact on the

local environment), ventilation systems (in terms of airborne releases), and plant instrumentation (monitoring) systems.

The formal completion of the NEPA process, leading up to the record of decision, also influences the selection of alternatives for the ANS, including the final site selection process. 


\subsection{QUAIITY ASSURANCE}

The overall quality assurance program for the ANS Project is described in the Quality Assurance Plan (ORNL/TM-11446/R1). ${ }^{18}$ The plan describes the general framework for ensuring quality in the design, development, procurement, fabrication, construction, inspection, installation, operation, and maintenance of the ANS facilities and systems. A graded approach to the implementation of the program places special emphasis on those safety-related structures, systems, and components identified in the principal design doruments. An ANS Project Procedures Manual holds the specific procedures that implement the features of the plan.

A system of quality levels is defined in Chap. 7 of the Plant Design Requirements. Those quality levels are correlated to the safety classifications and form the basis for assigning graded levels of quality assurance activities to ANS structures, systems, and components. The highest quality level, including the reactor safety-related systems, implements the basic and supplemental requirements of NQA-1, the nonmandatory appendices of NQA-1, and the requirements of NQA-2. The second level implements the basic requirements of NQA-1 and NQA-2. The lowest quality level implements standard commercial practices, as documented in the industry codes and standards.

\subsection{SELECTION AND CHARACTERIZATION OF THE CANDIDATE SITE}

The process used to identify and evaluate potential sites for the ANS on the Oak Ridge Reservation is described in the Oak Ridge Reservation Site Evaluation Report for the Advanced Neutron Source (ORNL/TM-11419). ${ }^{15}$ This evaluation was limited to sites on the Oak Ridge Reservation. Surveys made of the candidate site during the evaluation process included surveys for wetlands, rare plant and animal species, historical or archeological artifacts, activities that could have resulted in prior contamination of the candidate site, and others documented in the evaluation report. A small area (less than 10 acres) on the perimeter of the candidate site has been classified as wetlands by the U.S. Army Corps of Engineers; indications are that accommodating those wetlands will be relatively straightforward. No significant problems are anticipated at the candidate site.

Once the candidate site was selected, a preliminary geological characterization was undertaken to assess whether any unanticipated subsurface features could adversely affect the use of the site. This characterization was based on five soil and rock cores and four additional soil samples. The results of this survey suggest that the candidate site has appropriate characteristics for the construction of the ANS. Top of rock throughout the candidate site was mapped using seismic refraction techniques, as documented in Seismic Refraction Study of the ANS Preferred Sitc (ORNL/TM-11998). ${ }^{19}$ This mapping, along with the data from the nine preliminary borings, was used to plan the arrangemunt of the buildings on the candidate site in the conceptual design. Additional characterization activities will be conducted during later project phases, as outlined in a draft site characterization plan. A package of all known geological data relevant to Melton Valley was assembled to support the specific characterization results available to date.

Several surveys were undertaken to develop the optimal arrangement of buildings and other structures on the candidate site. These include an analysis of a candidate site on the Oak Ridge Reservation, which identified many of the surface features of the site. More detailed evaluations were performed by the architects during the conceptual design, including the construction of a cork topographical model of the candidate site and the preparation of cut-and-fill diagrams. These types of activities will continue throughout conceptual design. 


\section{METHOD OF ACCOMPLISHMENT, ROLES, AND RESIPONSIBILITIES}

The responsibilities and duties of all project participants are discussed in the following sections. The management organizational structure for all participants, including major subcontractors, is shown in Fig. 6.1.

\subsection{DEPARTMENT OF ENERGY}

DOE will furnish overall project management and review, will approve all documents submitted for DOE appioval, and will administer all prime contracts. DOE. $O R$ will provide the primary interface with DOE/Basic Energy Sciences, DOE/NE, and all other federal agencies. DOE-OR will contract some of the work on ANS (e.g., the preparation of the environmental impact statement) to organizations other than Energy Systems/ORNL.

The DOE/ANS Project Office organization is shown in Fig. 6.2. The DOE/ANS Project Office will serve ar the primary interface with DOE/Headquarters and Energy Systems/ORNL on all matters concerning the ANS.

\subsection{ENERGY SYSTEMS/ORNL}

Energy Systems/ORNL, under prime contract to DOE, has overall responsibility for the planning, execution, and control of all work on the ANS Project except that work specifically excluded by DOE. This responsibility includes work performed by Energy Systems/ORNL and that performed by major subcontractors [the integrating contractor (IC), ANE, reactor manufacturer (RM), and construction manager (CM)] and other subcontractors selected for work on the ANS.

The Energy Systems/ORNL ANS Project organizational structure is shown in Fig. 6.3. This chart depicts the project organization, including the key management assignments and lines of responsibility.

\subsection{ANS PROJECT}

The ANS Project, under the assigned ANS Project director, is responsible for overall project management, quality assurance, and technical oversight; conduct of related research and development; design and implementation of the experiment systems; overall integration of safety analyses and release of safe y analysis reports; support and integration of operation-related activities; direction and nanagement of specialized procurements; and overall direction of the work performed by the project's major subcontractors. The ANS Project direclior also is responsible for the initial release of all baseline documents. Responsibilities fur changes to iaselined documents are delegated in accordance with provisions defined in a configuration management plan.

\subsection{Project Management, Quality Assurance, and Technical Oversight}

The ANS Project will plan, execute, and control the overall project management work assigned to the project. Quality assurance management and control are also directed and 


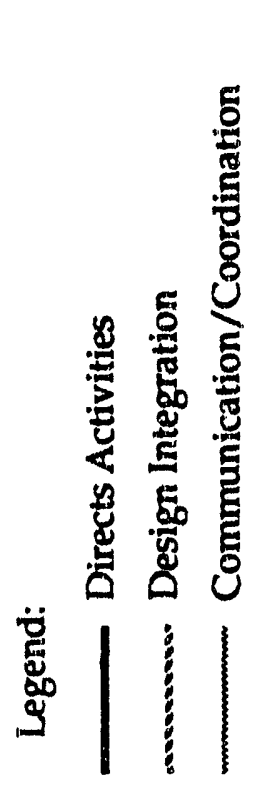

量

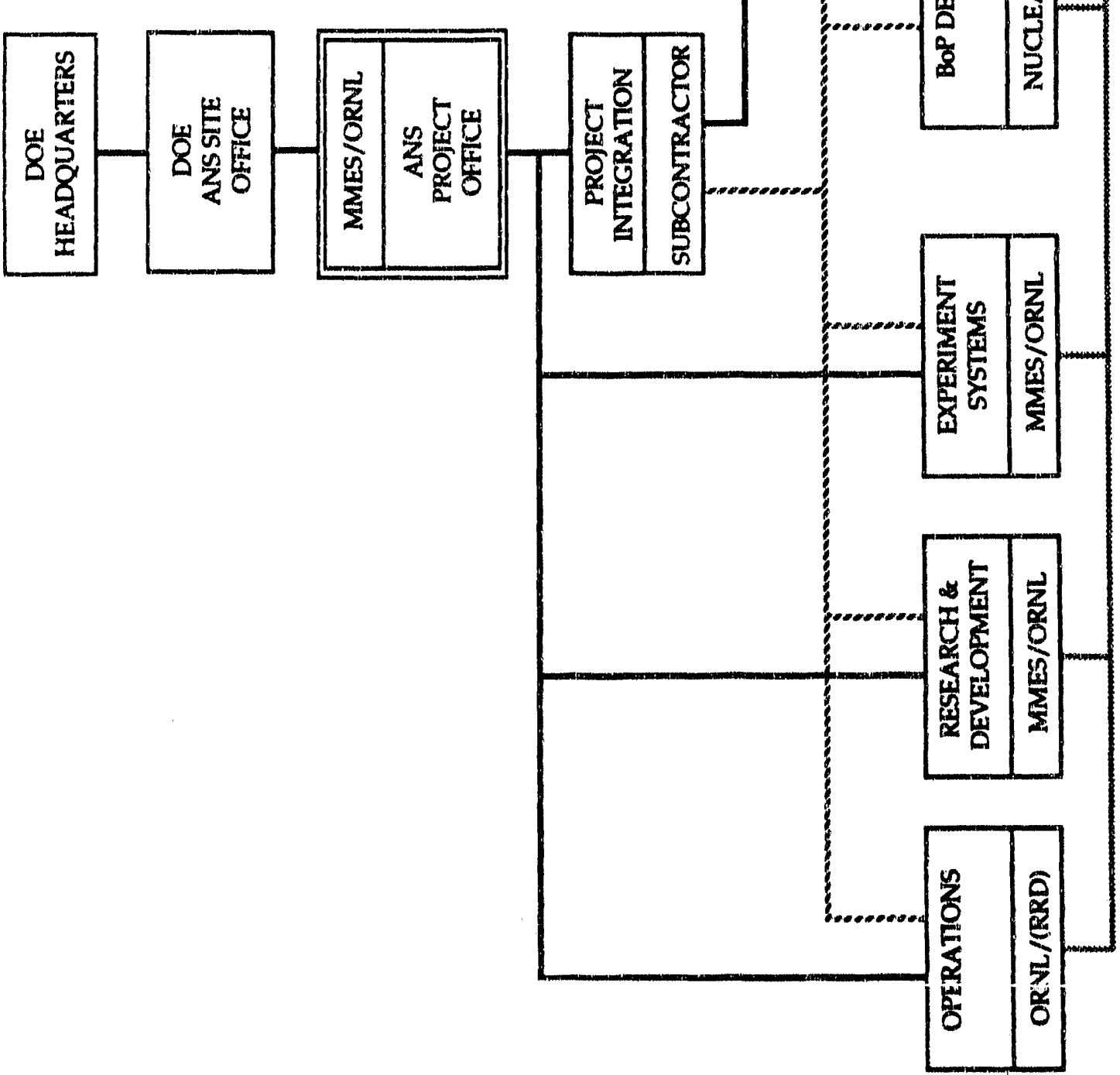




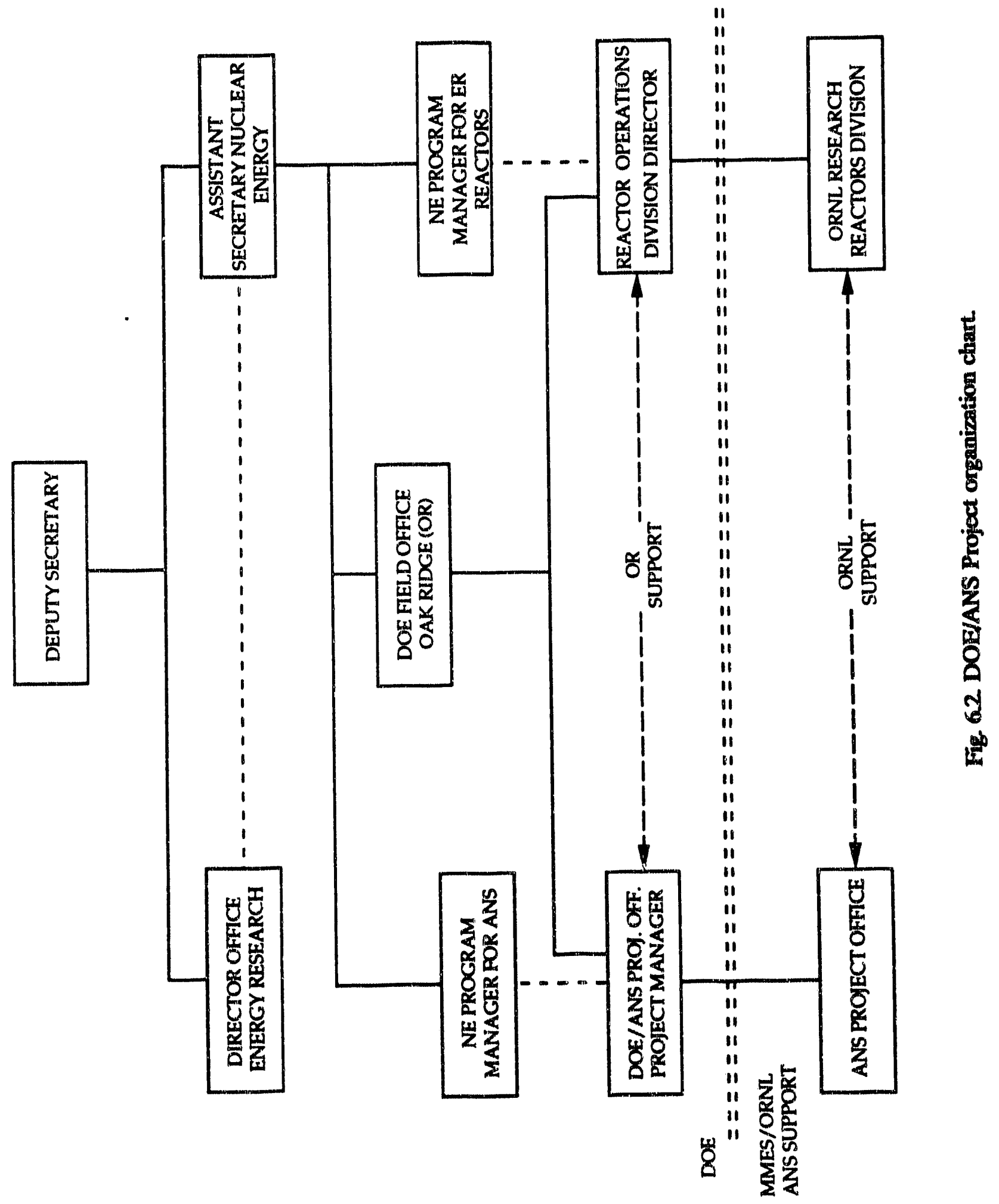




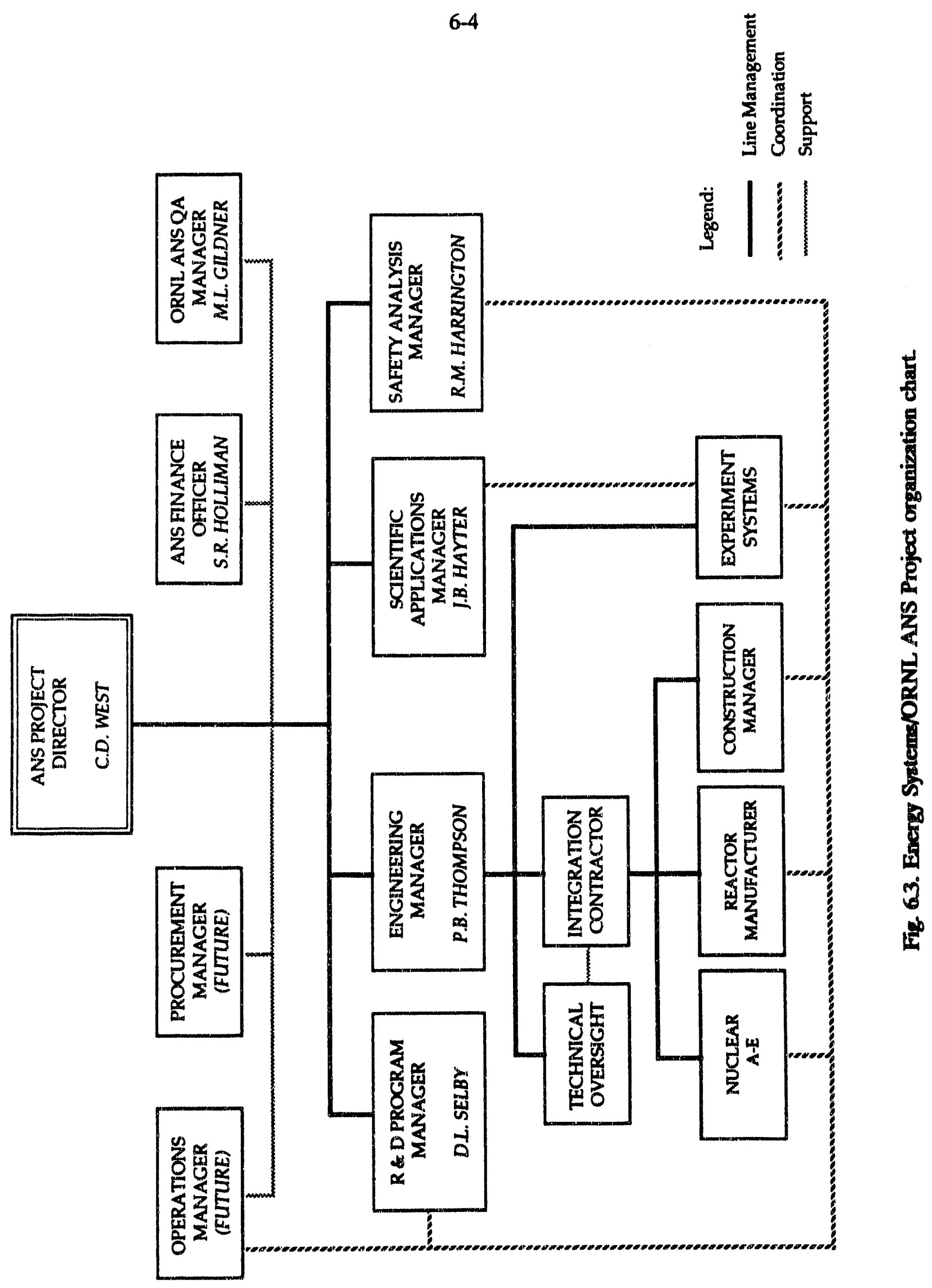


coordinated by the ANS Project, along with technical oversight support at the overall ANS Project level and support for the IC.

\subsection{Research and Development}

The ANS Project, through ORNL, will conduct R\&D programs necessary to support the ANS Project design and safety analyses. Direction for all the activities supporting or requiring interface with the ANS design/construction project will come from the IC.

\subsubsection{Experiment Systems}

The ANS Project will have lead responsibility for the design of the experiment systems and for the procurement of the associated specialized equipment. This will be a coordinated effort between ORNL and Brookhaven National Laboratory, which have significant current technical and scientific expertise in the design of neutron research equipment. Direction for all the activities supporting or requiring interface with the ANS design/construction project will come from the IC.

\subsubsection{Safety Analysis and Reports}

The ANS Project will have lead responsibility for conducting safety analyses and issuing appropriate safety analysis reports. Integrated input from the project design and construction team will come from the IC.

\subsection{Operations}

The ANS Project will have lead responsibility for the elements of the project related to operations. The ORNL Research Reactors Division will provide support and input to this work with a focus on training, operations, maintenance, technical and administrative operations, simulator training, and development of plant operating procedures. Direction of all the activities supporting or requiring interface with the ANS design/construction project will come from the IC.

\subsubsection{Procurement}

The ANS Project will be responsible for procuring all elements associated with the R\&D program, specialized equipment for the reactor and experiment systems, specifically identified long-lead-time items or components with specific early design interfaces, and other specialized elements.

\subsection{MAJOR SUBCONTRACTORS}

The major subcontractors involved in the design and management of the ANS Project will provide specific specialized experience. They are assigned roles and responsibilities as outlined in the following sections. Specific details governing these subcontracts are contained in the statements of work for each selected contractor. Energy Systems is responsible for procuring a design and construction team through a single solicitation for project integration, $A / E$, and $R M$ services and a subsequent solicitation for a construction management firm. 


\subsubsection{Integrating Contractor}

The IC will be a commercial nuclear firm with experience in licensing, managing, and coordinating large, complex nuclear reactor projects. This firm will be responsible for overall design/construction project integration and will provide direction to designated subcontractors and to Energy Systems/ORNL-retained elements supporting design and construction of the facilities. The IC subcontract includes specific technical direction of a qualified nuclear $\mathrm{A} / \mathrm{E}$ and a qualified nuclear RM. The statement of work for the IC also clearly delineates specific responsibilities related to acquiring the services of a qualified $\mathrm{CM}$ at an appropriate time and directing and integrating the $\mathrm{CM}$ activities.

\subsubsection{Architect-Engineer}

The $\mathrm{A} / \mathrm{E}$ will be a commercial nuclear firm with experience in nuclear facility design and with the necessary specialized technical expertise. This firm will be responsible for the design of the site and buildings and all plant systems except the reactor and experiment systems. Technical direction of the A/E will come from the IC.

\subsubsection{Reactor Manufacturer}

The RM will be a commercial nuclear firm with experience in the design and supply of reactor components. Particular emphasis is placed on experience relevant to the ANS mission and reactor systems design needs. This firm has lead responsibility for the design of the reactor systems. However, most of the reactor core and its control systems design will be developed through the efforts of ORNL and Idaho Nuclear Engineering Laboratory, which have expertise in the design of high-flux research reactor cores. The RM will be responsible for finalizing the ORNL and INEL design concepts and the specialized reactor components. Direction of the RM will come from the IC. Energy Systems will have lead responsibility for procuring specialized reactor system components.

\subsubsection{Construction Management Firm}

The CM will be a commercial nuclear firr. with expertise in the construction of nuclear facilities. This firm's initial role will be to perform constructibility reviews of the design as it is developed. Later, the CM will be responsible for all construction and for equipment procurement other than specifically selected safety-related equipment, long-lead items, selected equipment requiring supplier information to complete the design adequately, and specialized items from the experiment and reactor systems. Technical direction for the $\mathrm{CM}$ will come from the IC. 


\section{PROJECT SCHEDULE}

The ANS Project schedule was developed from input from all project participants. The schedule relates in time the start and finish of all essential project components. The schedule comprises about 5200 detailed activities that include research, development, engineering, procurement, construction, testing, startup, and operations. The WBS employed is a comprehensive delineation of all major tasks by system, building, component, and level of effort. The overall project duration is 9 years from the start of Title I design in FY 1994 through completion of low-power reactor tests that conclude in FY 2002.

\subsection{GENERAL}

The project WBS is shown in Fig. 1.1. The project summary schedule at the second level WBS is shown in Fig. 7.1. The major milestone dates reflected in the schedule are as follows:

Start Title I

Start Title II

Start construction

Start reactor building foundation

Start mechanical installation

Mechanical construction complete

Load core

Project complete
October 1993

March 1995

December 1996

June 1997

October 1997

December 2000

November 2001

September 2002

The schedule detail forms the basis for cost distributions. The schedule is based on the assumption that project phases will be contiguous and that sufficient funds will be available to support each phase. The project is planned as an FY 1994 line item project for Title I design only and an FY 1995 line item project for Title II design and construction. That schedule will allow completion of the project by FY 2002.

\subsection{CRITICAL PATH}

The critical path of the project is shown in Fig. 7.2. The critical path begins with the site characterization and the definition of criteria for seismic and severe environmental phenomena in WBS 1.5.1. It progresses through th s design of the interior concrete of the reactor building in WBS 1.5.2, the concrete construction package, construction of interior concrete of the reactor building, installation of the reactor and components, the reactor coolant system cold hydrostatic tests, the hot function testing, and a DOE criticality readiness review, and concludes with the power ascension testing. 


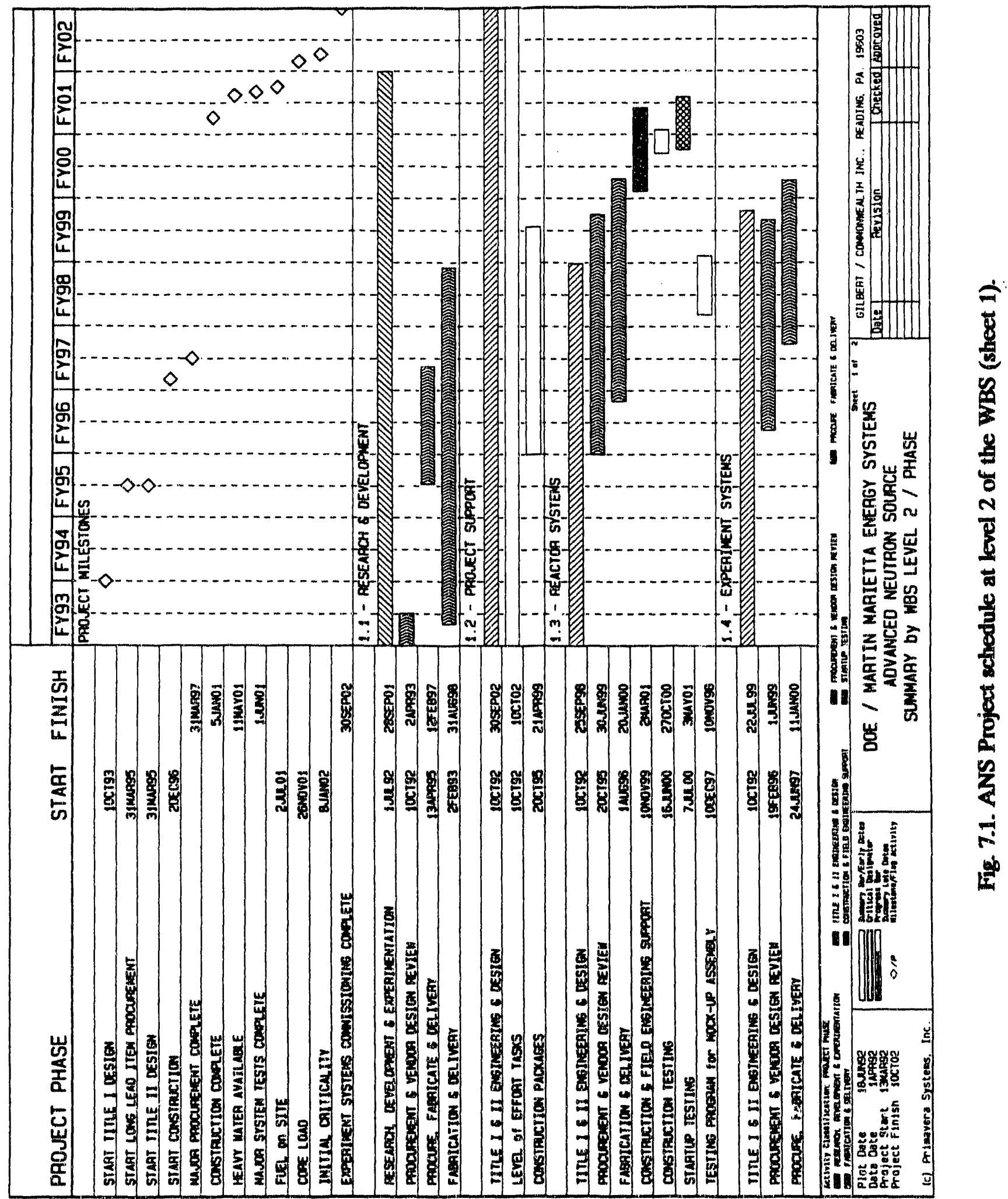




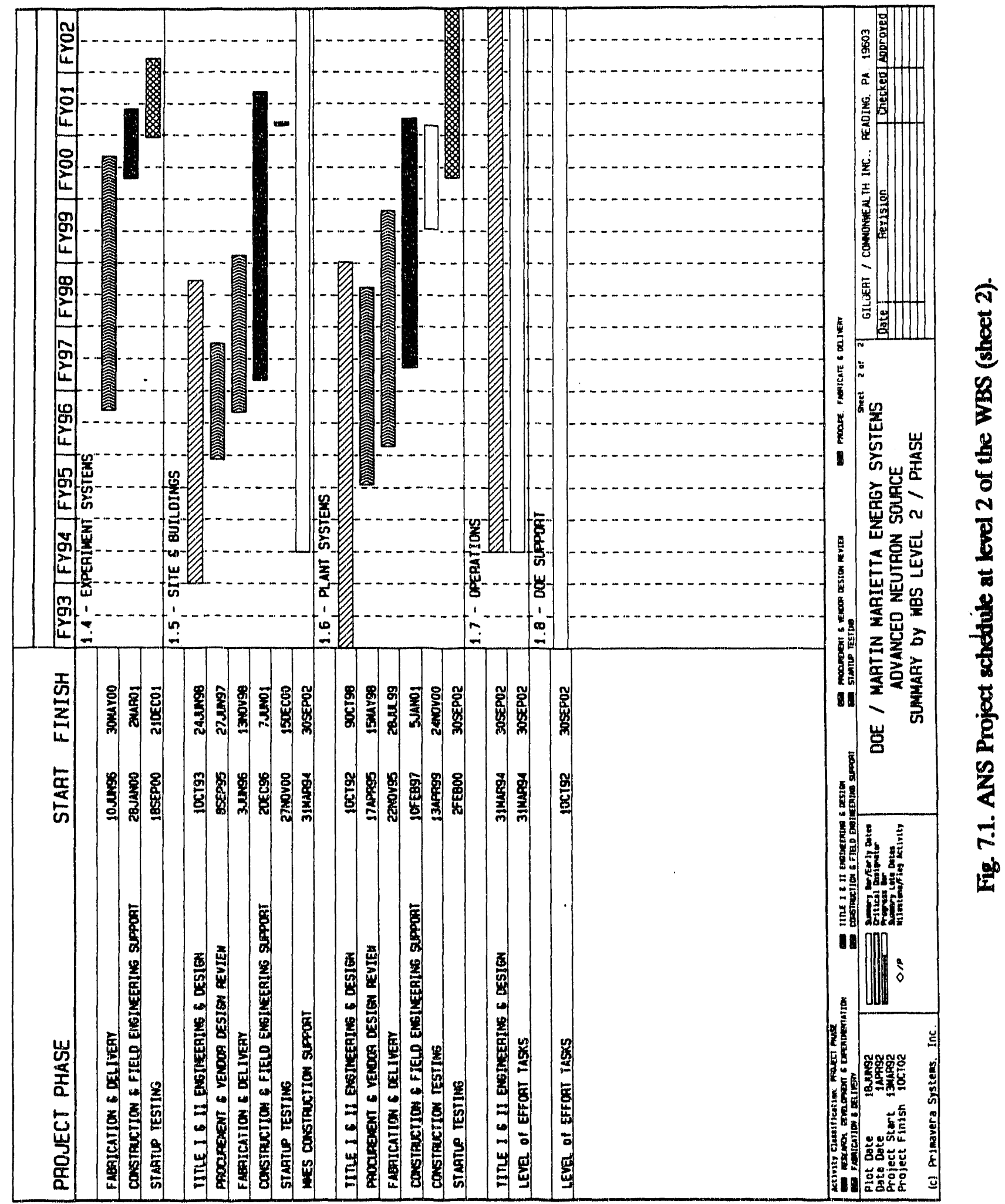




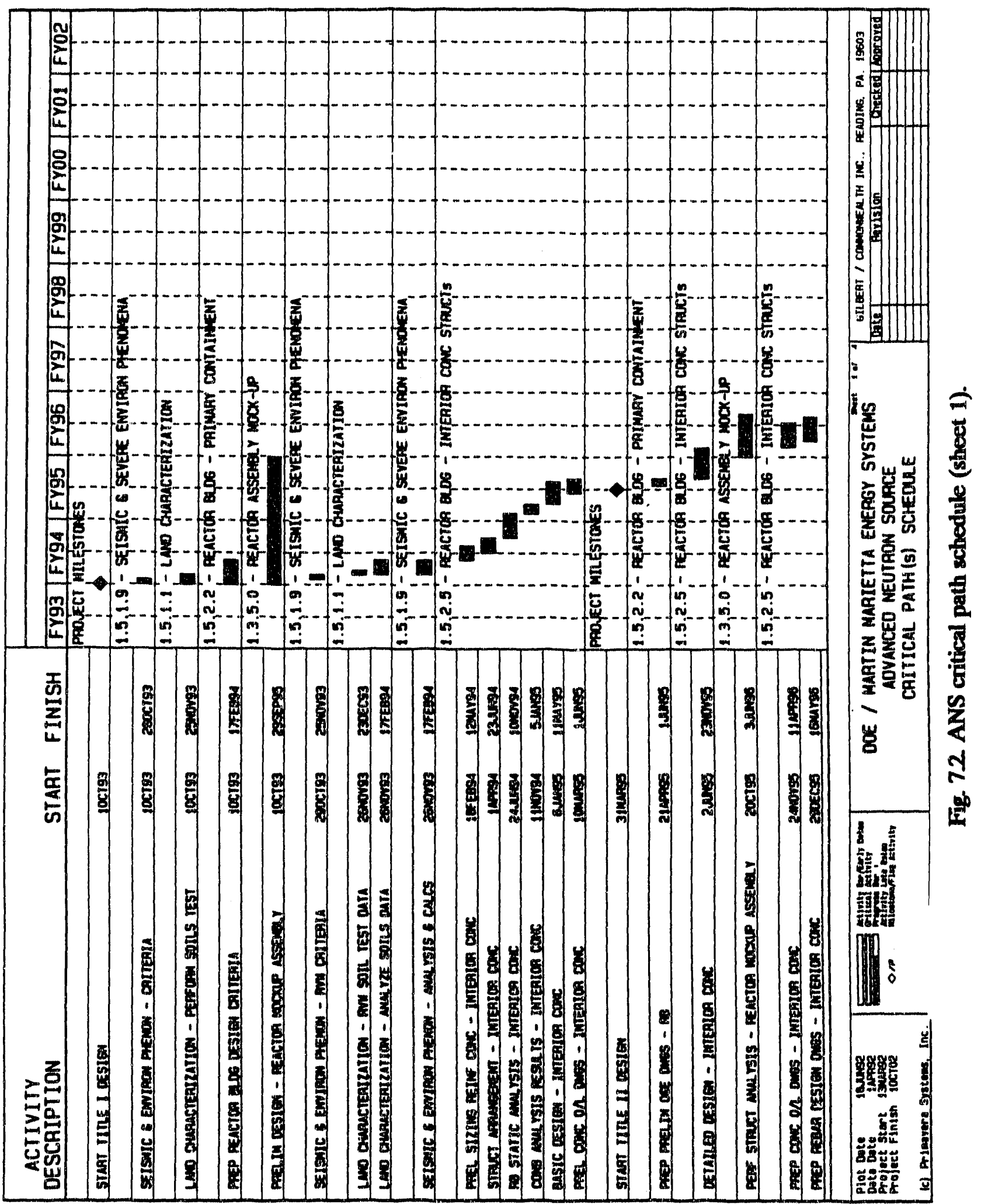




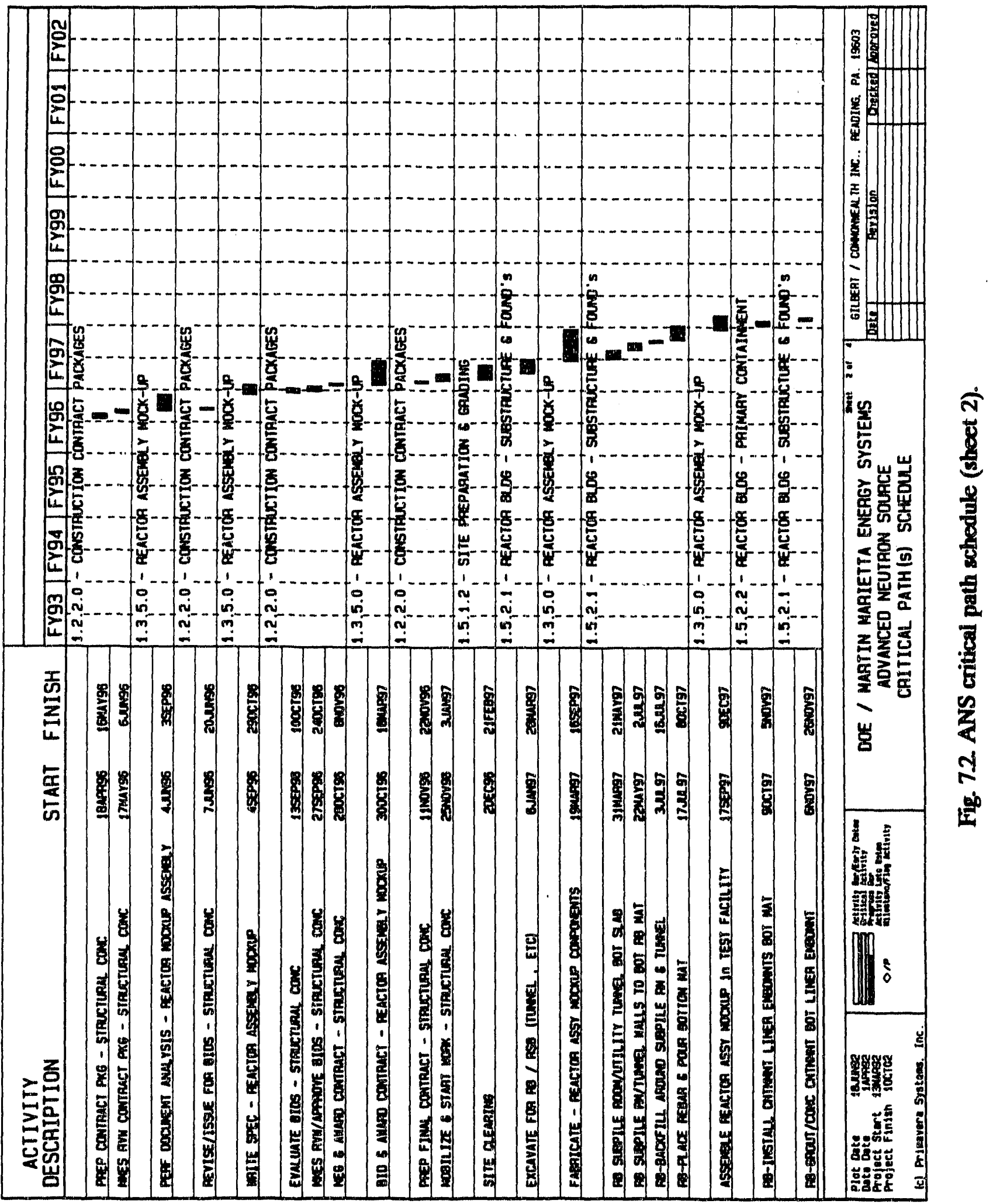




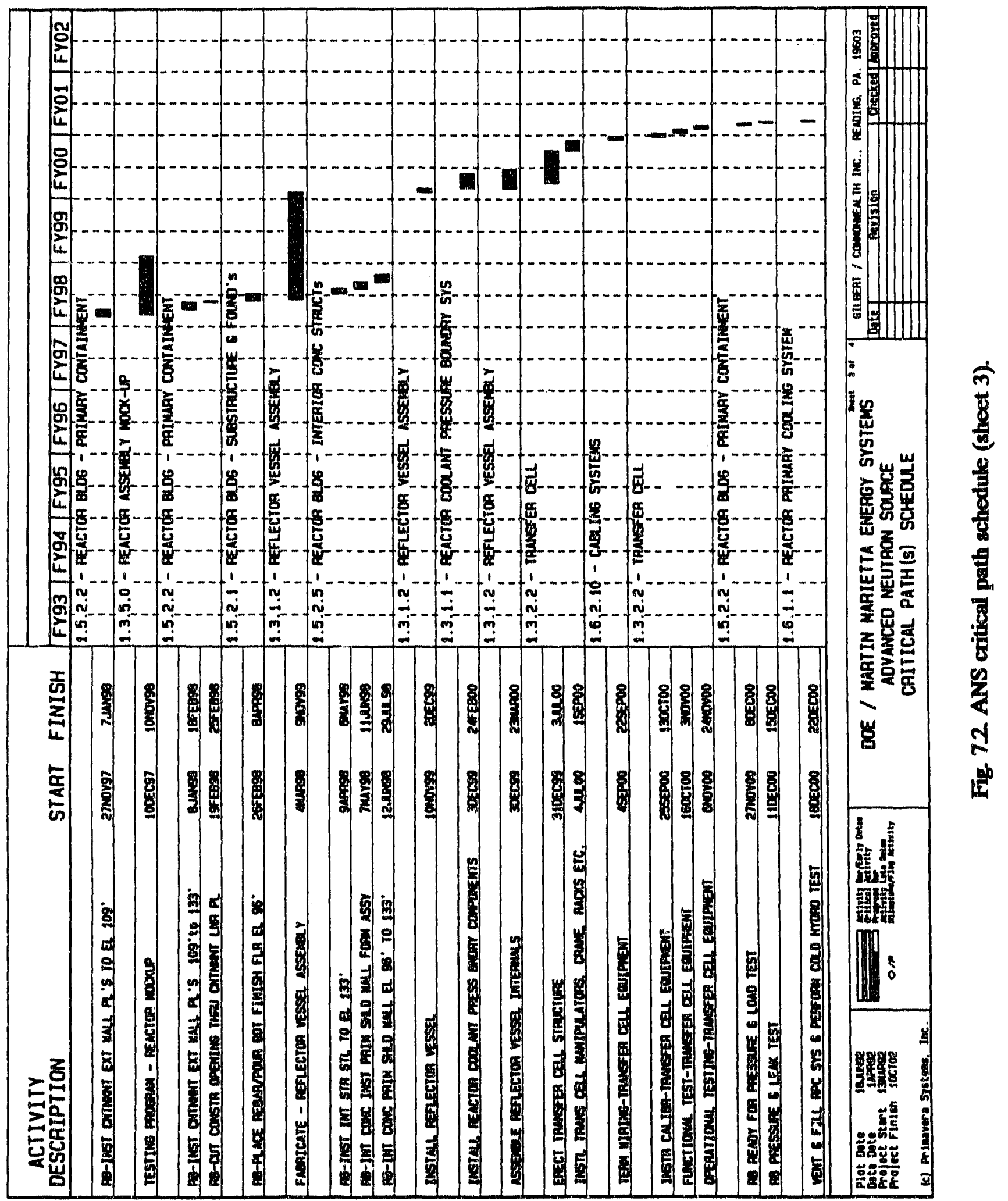




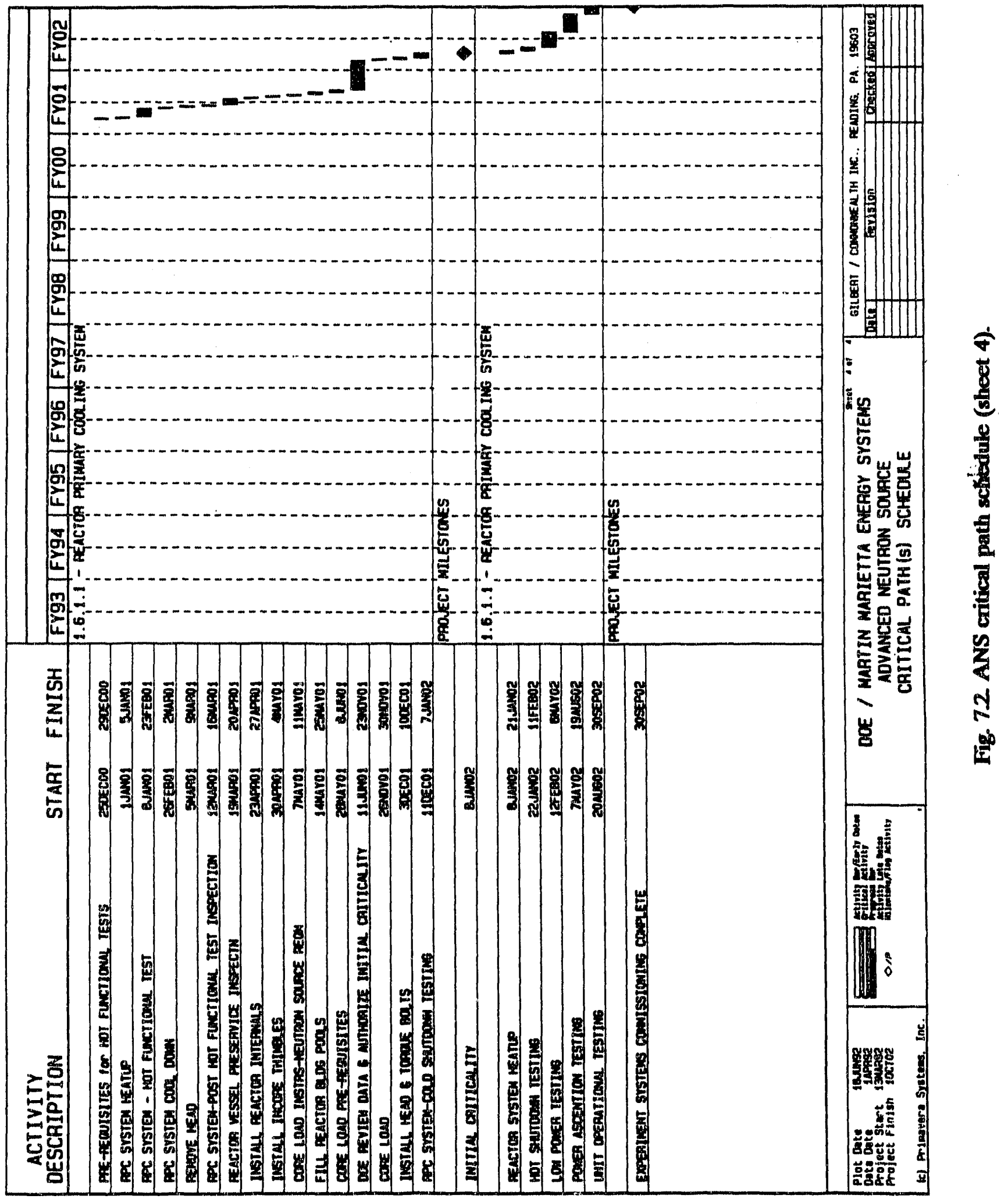




\section{SUMMMARY OF THE COST ESTMMATE}

\subsection{SUMMARY ESTIMATE-TOTAL PROJECT COST}

The total project cost of the ANS Project is made up of three separate estimates. The line item or total-estimated-cost estimate is contained in a cost and schedule document. The operating expense and capital equipment estimates make up the balance of the total project cost. Table 8.1 summarizes the estimate in escalated dollars, rounded to the nearest $\$ 10,000$.

Table 8.1. ANS total project cost in escalated dollars

\begin{tabular}{lr}
\hline \multicolumn{1}{c}{ WBS } & Cost $(\$ K)$ \\
\hline Line Item & \\
WBS 1.1 Research and Development & $\$ 44,210$ \\
WBS 1.2 Project Support & 256,670 \\
WBS 1.3 Reactor Systems & 164,040 \\
WBS 1.4 Experiment Systems & 263,280 \\
WBS 1.5 Site and Building & 563,400 \\
WBS 1.6 Plant Systems & 905,360 \\
WBS 1.7 Operation & 11,980 \\
WBS 1.8 DOE Support & 10,280 \\
Total estimated costs & $2,219,220$ \\
Operating expense & 550,000 \\
Capital equipment & 11,270 \\
Total project cost & $2,780,490$ \\
\hline
\end{tabular}

Table 8.2 contains line item cost information in the data sheet format organized by participant.

\section{COST AND FUNDING PLAN}

The summary financial schedule for the project in thousands of dollars (escalated to year spent and rounded to the nearest $\$ 10,000$ ) is shown in Table 8.3. Detailed funding breakdowns of the capital equipment, line item, and operating expense portion of the total project are provided in a cost and schedule document. The rationale for the obligation profile for line item funding is also contained in that document. Expense and capital equipment dollars are obligated in the year costed. 


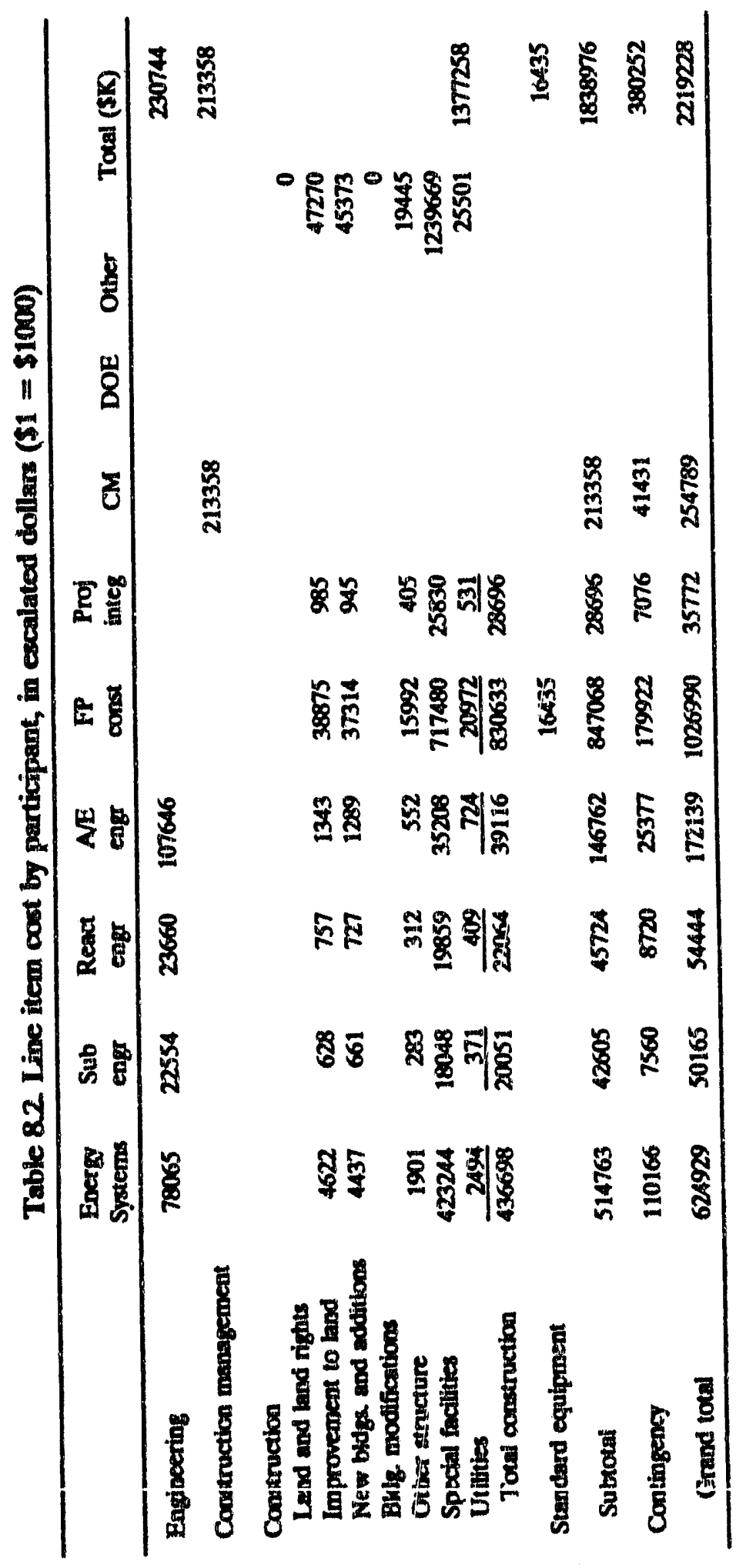


Table 8.3. ANS cost and funding plan in escalated dollars

\begin{tabular}{ccccc}
\hline FY & $\begin{array}{c}\text { Obligation } \\
(\$ K)\end{array}$ & $\begin{array}{c}\text { Annual cost } \\
(\$ K)\end{array}$ & $\begin{array}{c}\text { Expense } \\
(\$ K)\end{array}$ & $\begin{array}{c}\text { Capital eqpt. } \\
(\$ K)\end{array}$ \\
\hline FY 1994 & $\$ 43,170$ & $\$ 43,170$ & $\$ 13,760$ & $\$ 2,180$ \\
FY 1995 & 88,610 & 61,030 & 24,221 & 3,850 \\
FY 1996 & 168,530 & 112,670 & 31,637 & 2,150 \\
FY 1997 & 359,470 & 245,890 & 42,320 & 2,300 \\
FY 1998 & 600,240 & 516,480 & 66,250 & 790 \\
FY 1999 & 609,050 & 725,220 & 48,800 & 0 \\
FY 2000 & 289,860 & 434,570 & 66,600 & 0 \\
FY 2001 & 48,670 & 62,710 & 103,934 & 0 \\
FY 2002 & 11,520 & 17,470 & 152,471 & 0 \\
Total & $2,219,220$ & $2,219,220$ & 549,990 & 11,270 \\
\hline
\end{tabular}

\section{BASIS FOR THE ESTIMATE}

The following assumptions define the methodology used to develop the cost for this project. The ANS will use the same codes, equipment types, manufacturers, design, and construction skills as the commercial nuclear power industry. The techniques and information used for the production of this estimate draw upon the experience and background of the cost engineers and of estimators knowledgeable about the construction of large nuclear construction projects.

The estimate is based on the following assumptions:

1. The overall ANS Project schedule and sequence is as described in this document, and DOE will prowide the nesessary funding to support this schedule.

2. Base costs are in third-quarter FY 1992 dollars.

3. Escalation is based on February 1992 updated rates furnished by DOE.

4. An adequate supply of skilled and unskilled labor exists in the Oak Ridge area.

5. A standard 40-hour work week with occasional overtime only is assumed for the duration of the project.

6. Construction contracts will be fixed price and will be based on a competitive bid.

7. Engineered equipment procured by Energy Systems or the $\mathrm{CM}$ will be competitively bid.

8. Bulk construction materials will be furnished by the installing contractors.

9. The state and local sales tares of $8.25 \%$ bave been applied to all construction materials.

10. These costs are consistent with the plan for the application of SI units in the ANS project.

11. The initial heavy water inventory will be supplied by DOE. The $\$ 127.7$ million approximate cost for this inventory is considered to be government-furnished material and is not included in the estimaic. 


\subsubsection{Engineering Estimate}

The project cost estimate includes costs for Energy Systems, the IC, the A/E, and the RM for Title I, II, and III oversight activities. Estimates were provided by each participant and are based on the following assumptions:

1. Construction drawings will provide the amount of detail customary for nuclear power facilities, which has proved to be adequate when used by competent construction contractors. For example, detailed dimensioning and routing of small pipe, tubing, conduit, or cable will be the responsibility of the installing contractor; general guidelines will be provided by the AVE.

2. Specifications for procuring equipment and materials will be based on standard commercial specifications in the nuclear power industry. Quality requirements will use recognized nuclear industry standards. The intent is to acquire proven commercial equipment and avoid custom designs wherever possible.

3. Drawings, specifications, reports, and other deliverables submitted for review and approval will be reviewed and approved within the time specified in the project schedule. Secondary reviews of already approved deliverables are not included in this estimate.

4. Planning, scheduling, and budgeting of activities in support of the design are the responsibility of and under the control of the IC and Energy Systems.

The labor estimates for each project participant were developed based on the estimated numbers of drawings, specifications, construction packages, and studies and the anticipated staffing requirements for management and supervisory personnel. Base labor rates were developed for the A/E, the RM, and the IC which included other expenses such as travel, computer-assisted drafting machines, reproduction services, computers, subsistence, relocation, and similar costs. These costs were estimated based on past project experience. Base labor rates for Energy Systems participants and subcontractors are based on approved labor rates and other expenses issued by Engineering Resource Management.

\section{Construction Estimate}

The construction estimate is based on the drawings, data files, system designs, equipment supplier budget estimates, physical quantity takeoffs, engineering judgement, estimator's judgement, past project history, industry averages, Energy Systems input, HFIR experience, and similar sources. Physical quantities were developed by detailed takeoffs from the approximately 170 facility and system drawings produced during the conceptual design. These include equipment drawings, architectural and structural drawings, facility layout and arrangement drawings, piping drawings, fluid system diagrams, raceway drawings, landscaping and grading drawings, and engineering sketches. In addition, Energy Systems has produced approximately 230 drawings of the reactor, experiments, refueling equipment, beam tubes, thimbles, instrumentation and control architecture, and similar data for the facility and systems. For systems or structures where no drawings or sketches were available, quantities were developed using a variety of methods. These included referencing the system design descriptions and engineering calculations, square foot estimating techniques, rough design development in conjunction with design engineering, application of historical standards, and comparison with similar systems or structures from previously designed projects. 


\section{$8-5$}

Quantities were summarized on bills of material to which estimators specializing in the various disciplines applied material costs and unit installation rates. Material costs are based on current vendor quotations and consultations, cost data established for similar items on recent projects, and nationally recognized publications such as R.S. Means Construction Cost Data ${ }^{20}$ and Richardson's Construction Estimating Standards. ${ }^{21}$ Unit installation rates are based on vendor data, in-house data, industry standards for similar work, estimator experience, and nationally recognized publications.

Completed bills of material were reviewed with the responsible design engineers to ensure that the estimator had considered the proper materials, sizes, and other variables during the bill of material development process. Adjustments were made for unknowns based on the judgement of the engineer and the estimator.

Workhour estimates were prepared for the major participants, including the CM and Energy Systems shops and field support. The cost associated with DOE participation in the ANS was provided by DOE.

\subsubsection{Contingency}

Contingency has been included in this project to cover costs that may result from incomplete design, unforeseen and unpredictable conditions, or uncertainties within the defined scope. A contingency analysis was conducted in accordance with DOE's Cost Estimating Guide for Application of Contingency ${ }^{2}$ dated June 1985. An evaluation was performed to determine the upper and lower deviations from a midrange contingency of $20 \%$. Using this range, a statistical program was run to establish confidence limits for the range. The percent contingency was selected for each system given a $50 \%$ probability that the actual cost would not exceed the estimate. Table 8.4 identifies the average contingency by level 2 WBS.

\subsubsection{Escalation}

Published DOE escalation rates were updated to provide information on construction projects beyond FY 1993 and were used for ANS. The ANS estimate is based on FY 1992 thirdquarter costs and then escalated over the duration of the activity based on the project schedule. The approved escalation rates are 2.1\% for FY 1992; 3.4\% for FY 1993; $4.3 \%$ for FY 1994; $4.5 \%$ for FY 1995; 4.7\% for FY 1996; 4.8\% for FY 1998; 4.9\% for FY 1999; and 5.0\% for FY 2000 and beyond. 
Table 8.4. Average contingency for ANS by WBS and fund source

\begin{tabular}{lr}
\hline WBS & $\%$ Contingency \\
\hline Line item & $\% 19.8$ \\
WBS 1.1 Research and Development & 20.6 \\
WBS 1.2 Project Support & 24.6 \\
WBS 1.3 Reactor Systems & 22.1 \\
WBS 1.4 Experiment Systems & 19.5 \\
WBS 1.5 Site and Building & 20.4 \\
WBS 1.6 Plant Systems & 20.0 \\
WBS 1.7 Operation & 5.0 \\
WBS 1.8 DOE Support & $\% 20.6$ \\
Average contingency & \\
Expense & $\% 14.5$ \\
Average contingency & \\
Capital equipment & \\
Average contingency & \\
\hline
\end{tabular}




\section{REFERENCES}

1. F. Seitz and D. Eastman (Chairs), Major Facilities for Materials Research and Related Disciplines, National Research Council Major Materials Committee, National Academy Press, Washington, 1984.

2. U.S. Nuclear Regulatory Commission, "Safety Goals for the Operation of Nuclear Power Plants," Fed. Regist. 51, 162, Aug. 21, 1986.

3. U.S. Department of Energy, DOE Nuclear Safety Objectives Policy, draft, Oct. 27, 1988.

4. Major Facilities for Materials Research and Related Disciplines, Review of the National Research Council Report, National Academy Press, Washington, 1984.

5. J. A. Lake and C. D. West, "Report on the Working Group on Critique of Source Concepts," Proceedings of the Workshop on an Advanced Steady-State Neutron Facility, Dec. 16-18, 1985; Nucl. Instr. Methods A249, 1, 125-131, August/September 1986.

6. C. D. West and D. K. Wilfert, Reduced Enrichment Fuel-Performance Penalties, Costs, and Benefits for the ANS Reactor, ORNL/M-550, Martin Marietta Energy Systems, Inc., Oak Ridge Natl. Lab., July 1988.

7. C. D. West et al., Advanced Neutron Source Final Preconceptual Reference Core Design, ORNL/TM-11234, Martin Marietta Energy Systems, Inc., Oak Ridge Natl. Lab., August 1989.

8. R. M. Moon, ed., Proceedings of the Workshop on Instrumentation for the Advanced High Flux Reactor, May 30, 1984, CONF-8405192, Martin Marietta Energy Systems, Inc., Oak Ridge Natl. Lab., 1984.

9. G. H. Lander and V. J. Emery, eds., Proceedings of a Workshop on Scientific Opportunities with Advanced Facilities for Neutron Scattering, Oct. 23-26, 1984, CONF-8410256, Argonne Natl. Lab., 1984; Nucl. Instr. Methods B12, 525 (1985).

10. J. D. Axe and J. B. Hayter, eds., Proceedings of the Workshop on Neutron Scattering Instrumentation, June 5-7, 1989, CONF-8906311, Martin Marietta Energy Systems, Inc., Oak Ridge Natl. Lab., June 1989.

11. A. N. Goland, Brookhaven Natl. Lab., Review of the Advanced Neutron Source Materials Irradiation Facilities, A Workshop Report, Dec. 5-6, 1990, CONF-901276, Martin Marietta Energy Systems, Inc., Oak Ridge Natl. Lab., March 1991.

12. J. R. Buchanan et al., Report of the Advanced Neutron Source (ANS) Safety Workshop, October 25-26, 1988, CONF-8810193, Martin Marietta Energy Systems, Inc., Oak Ridge Natl. Lab., December 1988. 
13. F. J. Peretz, Summary Report of the ANS Reactor Cooling Systems Workshop, February 15-16, 1990, CONF-9002142, Martin Marietta Energy Systems, Inc., Oak Ridge Natl. Lab., December 1991.

14. F. J. Peretz, Summary Report of the ANS Containment Workshop, CONF.9008150, August 23-24, 1990, Martin Marietta Energy Systems, Inc., Oak Ridge Natl. Lab., to be published.

15. B. Sigmon, A. C. Heitzman, Jr., and J. Morrissey, Science Applications International Corp., Oak Ridge Reservation Site-Evaluation Report for the Advanced Neutron Source,

ORNL/TM-11419, Martin Marietta Energy Systems, Inc., Oak Ridge Natl. Lab., March 1990.

16. R. S. Booth, Advanced Neutron Sounce Plant Design Requirements, ORNL/TM-11625/R4, Martin Marietta Energy Systems, Inc., Oak Ridge Natl. Lab., May 1992.

17. T. A. Blasing et al., Phase I Environmental Report for the Advanced Neutron Source at Oak Ridge National Laboratory, ORNL/TM-12069, Martin Marietta Energy Systems, Inc., Oak Ridge Natl. Lab., February 1992.

18. M. L. Gildner, Advanced Neutron Source Quality Assurance Plan, ORNL/TM-11446/R1, Martin Marietta Energy Systems, Inc., Oak Ridge Natl. Lab., May 1991.

19. A. K. Davis, Automated Sciences Group, Inc.; R. A Hopkins, Marrich, Inc., and W. E. Doll, Oak Ridge Natl. Lab., Seismic Refraction Survey of the ANS Preferred Site, ORNLTM-11998, Martin Marietta Energy Systems, Inc., Oak Ridge Natl. Lab., February 1992.

20. A. B. Cleveland and P. R. Waier, eds., Means Building Construction Cost Data, R. S. Means Company, Inc., Kingston, Maine, 1991.

21. Richardson's Process Plant Construction Estimating Standards, 1-4, Richardson Engineering Services, Inc., Mesa, Arizona, 1992.

22. Cost Estimating Guide for Application of Contingency, Martin Marietta Energy Systems, Inc., Oak Ridge Natl. Lab., June 15, 1985. 

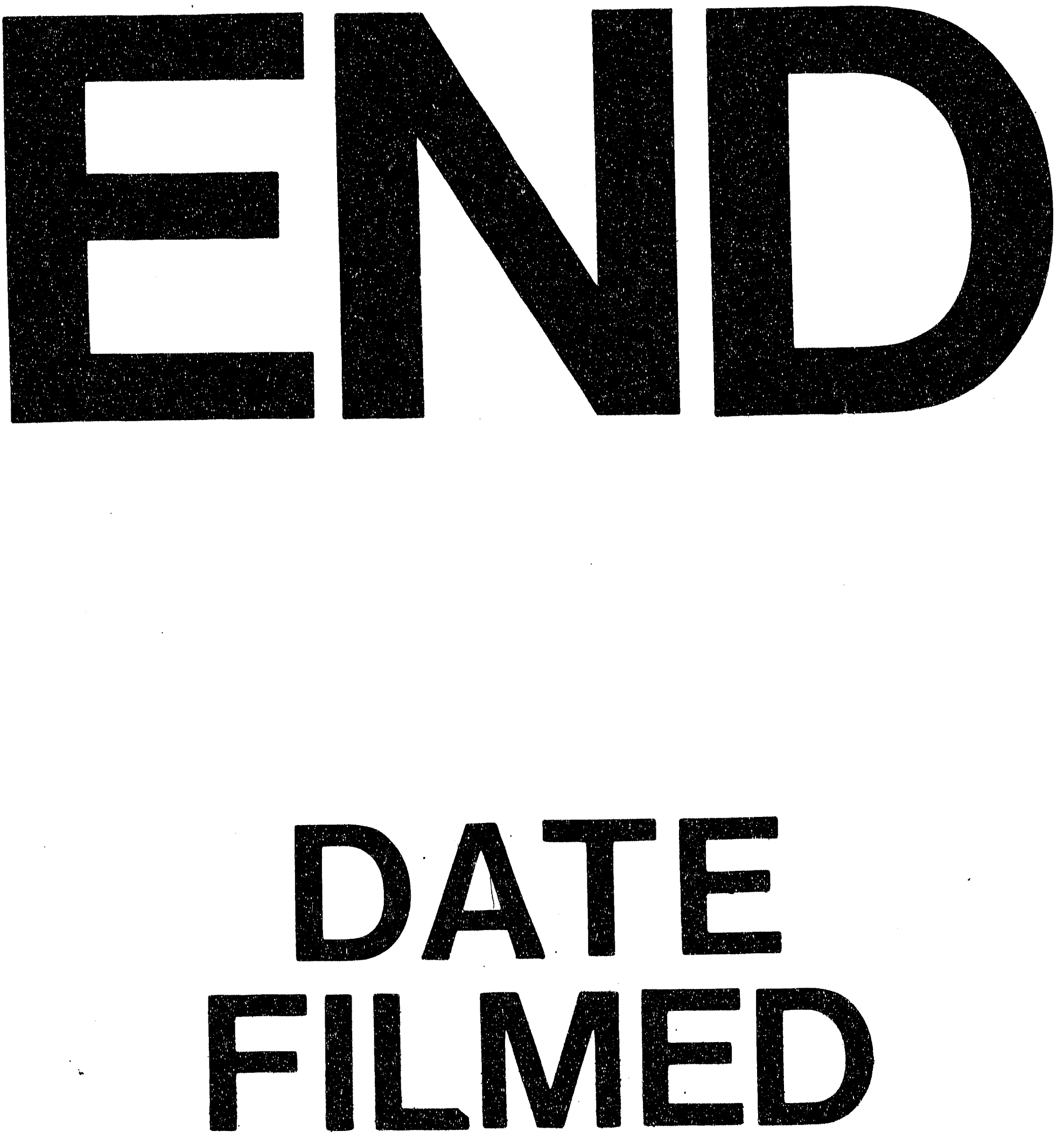

3

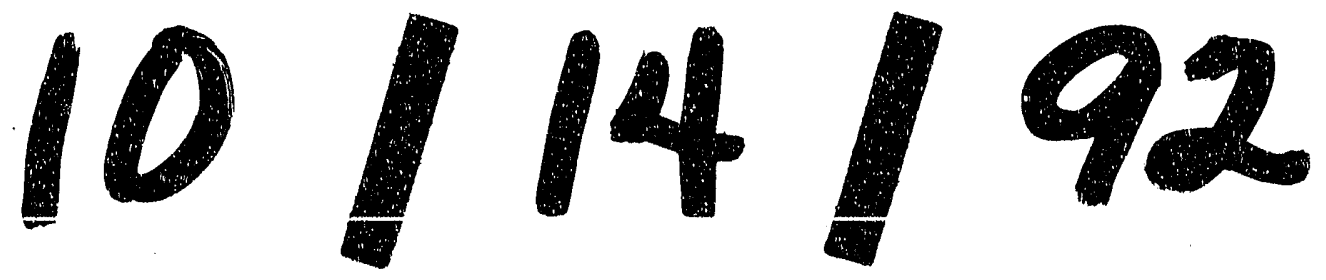


